\title{
MEASURING AND MODELING STREAM AND AIR TEMPERATURE \\ RELATIONSHIPS IN A MULTI-LAND USE WATERSHED OF THE CENTRAL UNITED STATES
}

A Thesis Presented to the

Faculty of the Graduate

School at the University of

Missouri

In Partial Fulfillment of the

Requirements for the Degree

Master of Science

by

SEAN J. ZEIGER

Dr. Jason A. Hubbart, Thesis Supervisor

JULY 2014 
(C) Copyright by Sean J. Zeiger 2014

All Rights Reserved 
The undersigned, appointed by the dean of the Graduate School, have examined the thesis entitled

MEASURING AND MODELING STREAM AND AIR TEMPERATURE RELATIONSHIPS IN A MULTI-LAND USE WATERSHED OF THE CENTRAL UNITED STATES

presented by Sean J. Zeiger,

a candidate for the degree of Master of Science,

and hereby certify that, in their opinion, it is worthy of acceptance.

Dr. Jason A. Hubbart

Dr. Stephen H. Anderson

Dr. Michael C. Stambaugh 


\section{DEDICATION}

I dedicate this thesis to my wife, Bonnie S. Zeiger, and my son, Asher J. Zeiger.

You are the most special people in my life and I appreciate all that you have sacrificed so that I could complete this work. 


\section{ACKNOWLEDGMENTS}

First and foremost, I would like to thank my advisor, Dr. Jason A. Hubbart, for being an outstanding mentor during my M.S. graduate program. His valuable comments regarding this research helped me develop the skills I need to achieve my goals as a research scientist. I am grateful for all the time and effort he has put into guiding me through this project.

I would also like to thank my committee members, Dr. Stephen Anderson and Dr. Michael Stambaugh. They have both taken time to read my writing and provide advice. Their thoughtful comments regarding this research were appreciated. I would also like to thank Dr. Jack Jones for providing me with scientific writing resources.

I would like to thank the federal and state agencies that provided funding for this project including the Environmental Protection Agency, Missouri Department of Conservation, and Missouri Department of Natural Resources. This project would not have been possible without their financial support.

Finally, thanks to all of the former and current members of the Interdisciplinary Hydrology Laboratory who helped with lab and field work. Special thanks to Katy Beaven, Christine Carson, Pennan Chinnasamy, Lynne Hooper, Michael Hullinger, Elliott Kellner, John Nichols, Michael Sunde, and Chris Zell for field assistance and taking time to listen to my thoughts on this research. 


\section{TABLE OF CONTENTS}

ACKNOWLEDGMENTS ................................................................................ ii

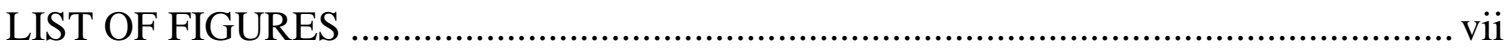

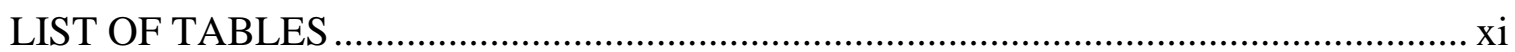

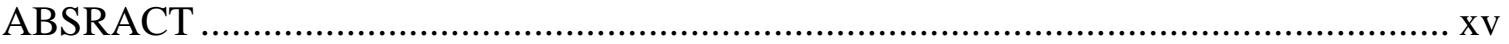

Chapter

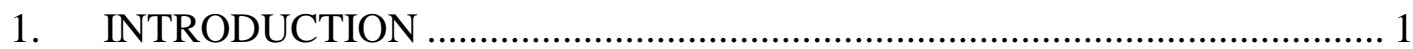

The importance of stream water temperature .......................................... 1

Impacts on stream water temperature regimes....................................... 2

Natural processes that affect $T_{w}$ regimes................................................ 2

Anthropogenic impacts that affect $T_{w}$ regimes............................................ 5

Modeling stream water temperature ….................................................. 8

Stream and air temperature relationships ............................................... 10

The effects of discharge .......................................................................... 14

Modeling stream water temperature with SWAT ...................................... 16

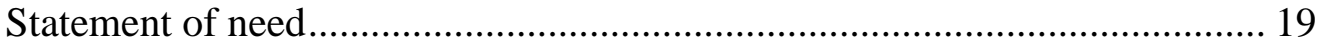

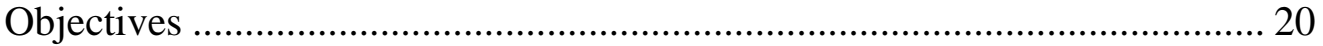

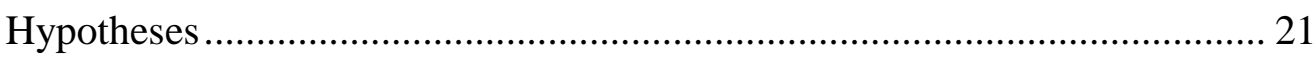

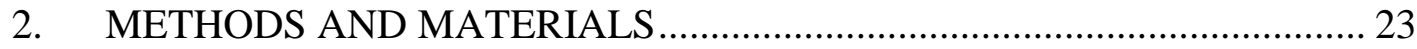

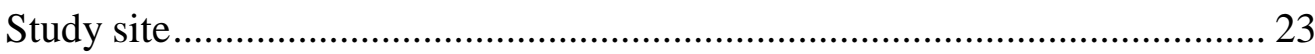

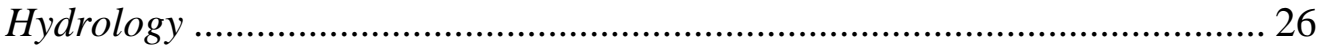

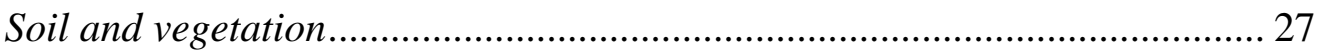


Nested-scale experimental watershed study design ................................... 28

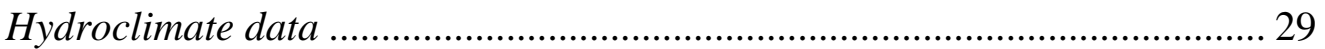

Sudden rises in $T_{w}$ due to summer thunderstorms ...................................... 30

Stage data and rating curves .................................................................... 31

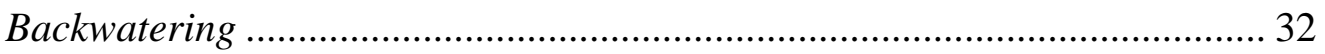

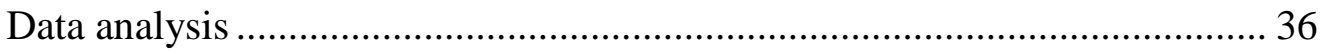

Hydroclimate data analysis ............................................................. 36

Sudden rises in $T_{w}$ due to summer thunderstorms ..................................... 38

The effects of discharge on stream water temperature ............................... 38

Stream and air temperature relationships ............................................... 39

The effects of discharge on $T_{w}$ and $T_{a}$ relationships .................................. 41

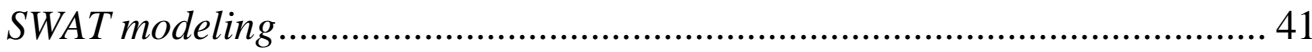

Model evaluation .................................................................................... 44

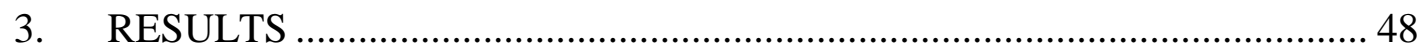

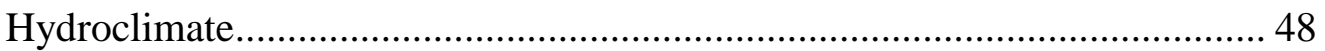

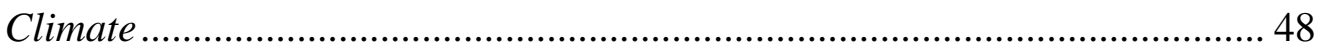

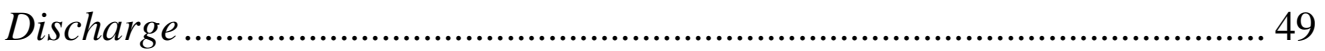

Stream water temperature ................................................................ 50

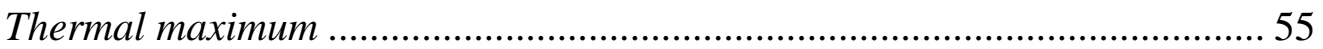

Sudden rises in stream water temperature .............................................. 55

The effects of discharge on stream water temperature ................................. 57

Stream and air temperature relationships ............................................ 60

The effects of discharge on $T_{w}$ and $T_{a}$ relationships .....................................6 66 


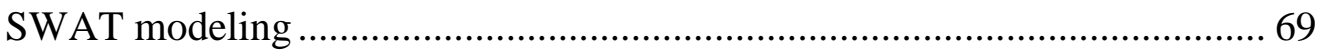

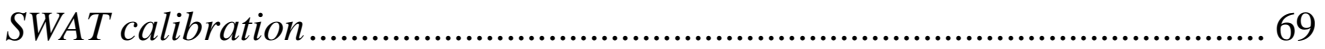

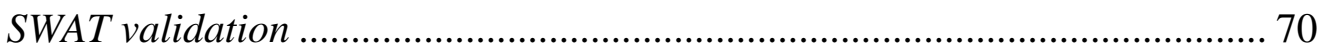

Stream temperature model comparison .................................................... 71

15 minute stream temperature models .................................................... 72

Hourly stream temperature models ..................................................... 74

Daily stream temperature models ...................................................... 76

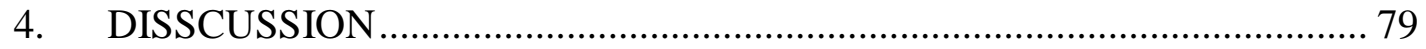

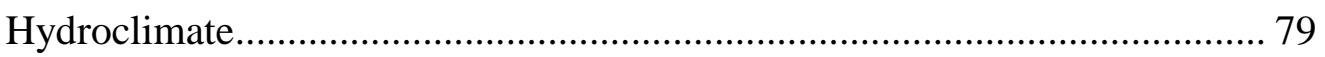

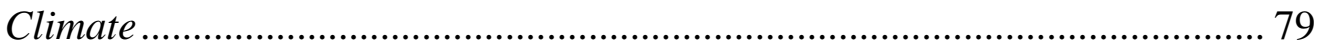

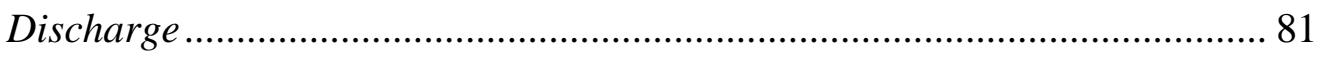

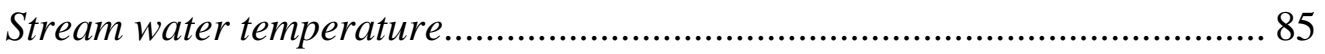

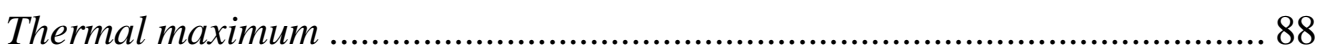

Sudden rises in stream water temperature ................................................ 91

The effects of discharge on stream water temperature ................................. 97

Stream and air temperature relationships ............................................ 104

The effects of discharge on $T_{w}$ and $T_{a}$ relationships ................................ 112

SWAT modeling ....................................................................... 115

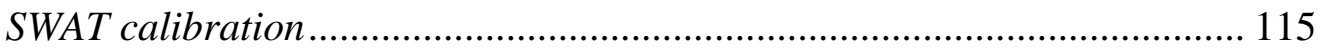

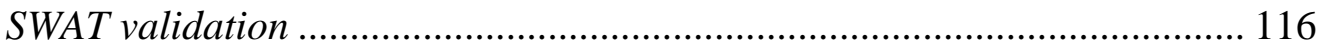

Stream temperature model comparison ............................................... 121

15 minute stream temperature models ................................................. 121

Hourly stream temperature models ...................................................... 124 
Daily stream temperature models.....

Stream water temperature measuring and modeling recommendations ....... 130

5. CONCLUSION AND SYNTHESIS...................................................... 133

Findings on hydroclimate in Hinkson Creek watershed ........................... 134

Findings on high stream water temperature in Hinkson Creek................... 135

Findings on stream and air temperature relationships ........................... 136

Findings on stream water temperatuire model comparrison ..................... 138

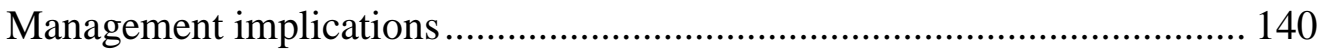

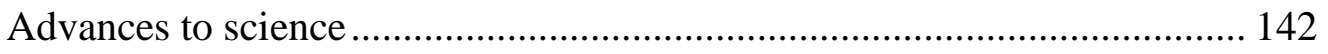

Closing statement ..................................................................... 143

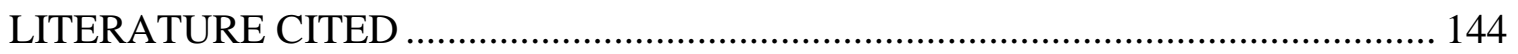

\section{APPENDIX}

A. Climate during the study period ...................................................... 152

B. Stream water temperature model evaluation results ................................ 159

C. Stream water temperature model evaluation results ................................. 170 


\section{LIST OF FIGURES}

Figure

Page

1. Four primary factors that affect stream water temperature regimes recreated after

Caissie, 2006.

2. Representation of nonlinear stream and air temperature equation recreated after

Mohseni et al. (1998).

3. An example of time lag between stream water temperature and air temperature and how the temperature time series can be synchronized is shown. The black points denote peak temperatures. On top, air temperature peaks at 17:00 hours and stream water tempe rature peaks at 21:00 hours. The two time series were synchronized by shifting the air temperature time series forward by 4 hours...13

4. Location of hydroclimate monitoring sites and respective subbasins containing various land use types of the Hinkson Creek Watershed, central Missouri, U.S.A. Sanborn Field meteorological monitoring station is located on the University of Missouri campus.

5. Backwatering phenomenon observed during 111 days of summer 2011 recorded at site \#5 located in Hinkson Creek Watershed, Missouri, U.S.A. Black vertical lines delineate a period of back watering that was modeled out using discharge data from site \#4 (USGS USGS gauging station number 06910230).

6. Tukey-Kramer multiple comparison results showing significant differences in daily mean air temperature in Hinkson Creek Watershed, Missouri, U.S.A. The $\mathrm{x}$-axis shows confidence interval values. The $\mathrm{y}$-axis shows all possible pairs of sample means being compared. The bars show the confidence interval for each pair of sample means being compared. A significant difference is shown when a confidence interval does not contain the value of zero. 
7. Time series precipitation and discharge are shown for the study period (WY 2010 - 2013) recorded at five climate stations (site \#1 on top - site \#5 on bottom) located in Hinkson Creek Watershed, Missouri, U.S.A.

8. Tukey-Kramer multiple comparison results showing significant differences in daily mean discharge in Hinkson Creek Watershed, Missouri, U.S.A. The x-axis shows confidence interval values. The $y$-axis shows all possible pairs of sample means being compared. The bars show the confidence interval for each pair of sample means being compared. A significant difference is shown when a confidence interval does not contain the value of zero.

9. Cumulative land use percent showing percent urban, pasture / crop, forested, and wetland land uses for five subbasins located in Hinkson Creek Watershed, Boone County, Missouri. Site number increases with downstream distance from the headwaters. Site \#1 is located in the headwaters, and site \#5 is located near the watershed outlet.

10. Tukey-Kramer multiple comparison results showing no significant differences in daily mean stream water temperature in Hinkson Creek, Missouri, USA. The xaxis shows confidence interval values. The y-axis shows all possible pairs of sample means being compared. The bars show the confidence interval for each pair of sample means being compared. A significant difference is shown when a confidence interval does not contain the value of zero. 88

11. Time series daily maximum and minimum stream water temperatures are shown for the study period (WY 2010 - 2013) recorded at five climate stations (site \#1 on top - site \#5 on bottom) located in Hinkson Creek Watershed, Missouri, U.S.A. The dotted line signifies the $32{ }^{\circ} \mathrm{C}$ thermal maximum threshold. The dashed line signifies the $35^{\circ} \mathrm{C}$ critical thermal maximum threshold.

12. Stream water temperature surges following a summer thunderstorm sensed at gauging sites \#3, \#4, and \#5 in Hinkson Creek near sunset during summer 2010. The black circles mark the peak $\mathrm{T}_{\mathrm{w}}$ surges and the arrows track the $\mathrm{T}_{\mathrm{w}}$ surges downstream from site \#3 to sites \#4 and \#5. This figure shows how $\mathrm{T}_{\mathrm{w}}$ surges persisted at downstream gauging sites and how $\mathrm{T}_{\mathrm{w}}$ surge duration was longer at sites \#4 and \#5.

13. Plume of heated stormwater after a summer thunderstorm sensed at site \#5 in Hinkson Creek during summer 2011. The black circles mark the peak $\mathrm{T}_{\mathrm{w}}$ after the increase in discharge and the arrows track the event downstream from site \#3 to sites \#4 and \#5 The plume of heated stormwater was observed at site \#5, 
but not upstream at site \#4. Thus, the origin of the heated stormwater was downstream of site \#4 and upstream of site \#5.

14. Two stream water temperature surges following a summer thunderstorm sensed at site \#3 in Hinkson Creek during summer 2012. The black circles mark the peak $\mathrm{T}_{\mathrm{w}}$ following the increase in discharge at site \#3 and the arrows track the event downstream from site \#2 to site \#3. This figure shows how the $T_{w}$ surges were observed at site \#3, but not observed upstream showing the origin of the heated stormwater was downstream of site \#2 and upstream of site \#3.

15. Mean discharge above and below median values are shown for each study site examined during the study period in Hinkson Creek Watershed, U.S.A. Additionally, four other flow classes are shown. A nested plot expands the $>90 \%$ quantile for a total of 15 flow classes.

16. Mean air temperatures above and below median values are shown for each study site examined during the study period in Hinkson Creek Watershed, U.S.A. Additionally, four other flow classes are shown. A nested plot expands the $>90 \%$ quantile for a total of 15 flow classes

17. Mean stream water temperatures above and below median values are shown for each study site examined during the study period in Hinkson Creek Watershed, U.S.A. Additionally, four other flow classes are shown. A nested plot expands the $>90 \%$ quantile for a total of 15 flow classes 103

18. Five site mean coefficients of determination $\left(\mathrm{r}^{2}\right)$ from linear (dashed line) and nonlinear (solid curve) regression analyses are shown for each time step considered (15 minute, hourly, daily, weekly, monthly, and seasonal) and for five gauging sites examined during the study period located in Hinkson Creek Watershed, U.S.A.

19. Coefficients of determination from linear and nonlinear regression analyses are shown for each time step considered (15 minute, hourly, daily, weekly, monthly, and seasonal) and for each study site examined during the study period located in Hinkson Creek Watershed, U.S.A.....

20. Results from linear regression analyses are shown for comparison of each time step considered (15 minute, hourly, daily, weekly, monthly, and seasonal). Linear coefficients $b$ (top) and $a$ (bottom) are displayed for each study site during the study period located in Hinkson Creek Watershed, U.S.A. 
21. Results from nonlinear regression analyses are shown for each time step considered (15 minute, hourly, daily, weekly, monthly, and seasonal). Nonlinear coefficients alpha (top), beta (middle), and gamma (bottom) are displayed for each study site during the study period located in Hinkson Creek Watershed, U.S.A

22. Coefficients of determination from linear regression analyses are shown for 15 different flow classes (quantiles) and for each study site examined during the study period.

23. Time series SWAT simulated and observed discharge data collected during the calibration period (water years 2010 -2012) recorded at five gauging sites located in Hinkson Creek Watershed, U.S.A.

24. Time series SWAT simulated and observed discharge data collected during the validation period (water year 2013) recorded at five gauging sites located in Hinkson Creek Watershed, U.S.A.

25. Validation results showing observed discharge versus SWAT simulated discharge data collected during the validation period (water year 2013) recorded at five gauging sites located in Hinkson Creek Watershed, U.S.A..

26. Results from calibrated linear regression model simulations showing 15 minute time series stream water temperature from five gauging sites in Hinkson Creek for the three year study period. Measured air temperature data are shown as a refrence.

27. Results showing observed stream water temperature versus simulated stream water temperature data for each of the models tested at a daily time step collected during the study period (water years 2011, 2012, 2013) located in Hinkson Creek Watershed, U.S.A. 


\section{LIST OF TABLES}

Table

Page

1. Locations of five nested hydroclimate stations in Hinkson Creek Watershed located in central Missouri, U.S.A............................................................. 23

2. Cumulative contributing area of sub-basins and land use type in the Hinkson Creek Watershed, central Missouri, USA. LULC percent areas are shown in parentheses. All LULC data were obtained from the MSDIS website. The LULC data were collected in 2005.

3. Instrumentation installed at gauging sites along Hinkson Creek, Missouri, U.S.A., and associated variables sensed, necessary for the current work

4. Rating equations for five gauging stations in Hinkson Creek, Missouri, U.S.A. Variables $\alpha_{0}$ are constants, $\alpha_{1}$ to $\alpha_{3}$ are regression coefficients, and $\kappa$ are exponential constants used in regression equations

5. Land use land cover (LULC) data for the current research. All LULC data were obtained from the MSDIS website with the exception of the SSURGO soils data set. The SSURGO soils data set was acquired from online from NRCS.USDA.gov.

6. Ratings used in this research to quantitatively evaluate sub-daily and daily model efficiency.....

7. Summary of daily climate statistics during the study period (WY 2010 - 2013) for six climate stations located in Hinkson Creek Watershed, Missouri, U.S.A. *Precipitation (Precip) data are average annual totals. **Solar radiation data are daily totals. Air Temp = Air Temperature. "St. Dev." is standard deviation.

8. Summary of average daily discharge $\left(\mathrm{m}^{3} / \mathrm{s}\right)$ statistics during the study period (WY 2010 - 2013) for five hydroclimate stations located in Hinkson Creek Watershed, Missouri, U.S.A. "St. Dev." is standard deviation. 50 
9. Summary of average daily stream water temperature $\left({ }^{\circ} \mathrm{C}\right)$ statistics during the study period (WY 2010 - 2013) for five hydroclimate stations located in Hinkson Creek Watershed, Missouri, U.S.A. "St. Dev." is standard deviation.

10. Summary of average 15 minute stream water temperature $\left({ }^{\circ} \mathrm{C}\right)$ statistics during the study period (WY 2010 - 2013) for five hydroclimate stations located in Hinkson Creek Watershed, Missouri, U.S.A. "Study Period" is a three year average for the study period "St. Dev." is standard deviation.

11. Summary of seasonal average stream water temperature $\left({ }^{\circ} \mathrm{C}\right)$ statistics during the study period (WY 2010 - 2013) for five hydroclimate stations located in Hinkson Creek Watershed, Missouri, U.S.A.

12. Days and duration stream water temperature was greater than 32 and $35^{\circ} \mathrm{C}$ during the study period (WY 2010 - 2013) for five hydroclimate stations located in Hinkson Creek Watershed, Missouri, U.S.A.

13. Summary statistics of $T_{w}$ surges detected in stormwater outfalls between gauging sites \#3 and \#5 during summer 2009 ( $\mathrm{N}=40)$ 56

14. Summary statistics of $\mathrm{T}_{\mathrm{w}}$ surges sensed between gauging sites \#3 and \#5 in Hinkson Creek during summers 2010, 2011, and $2012(\mathrm{~N}=15)$.

15. Daily mean stream discharge $\left(\mathrm{m}^{3} / \mathrm{s}\right)$ for fifteen different flow classes and five hydroclimate stations located in Hinkson Creek Watershed, Missouri, U.S.A.

16. Daily mean air temperature $\left({ }^{\circ} \mathrm{C}\right)$ for fifteen different flow classes and five hydroclimate stations located in Hinkson Creek Watershed, Missouri, U.S.A.

17. Daily mean stream water temperature $\left({ }^{\circ} \mathrm{C}\right)$ for fifteen different flow classes and five hydroclimate stations located in Hinkson Creek Watershed, Missouri, U.S.A

18. Coefficients of determination $\left(\mathrm{r}^{2}\right)$ from linear and nonlinear regression analyses are shown for each time step considered (15 minute, hourly, daily, weekly, monthly, and seasonal) for each of five gauging sites in Hinkson Creek Watershed, U.S.A. The term "time lag" denotes analyses that accounted for 
the lagged response of $\mathrm{T}_{\mathrm{a}}$ relative to $\mathrm{T}_{\mathrm{w}}$. Lag was determined using crosscorrelation analysis.

19. Coefficients $a$ (slope) and $b$ (y-intercept) from linear regression analyses are shown for each time step considered (15 minute, hourly, daily, weekly, monthly, and seasonal) for each of five study sites in Hinkson Creek Watershed, U.S.A. The term "time lag" denotes analyses that accounted for the lagged response of $\mathrm{T}_{\mathrm{a}}$ relative to $\mathrm{T}_{\mathrm{w}}$. Lag was determined using crosscorrelation analysis.

20. Coefficients $\alpha$ (estimated maximum $\mathrm{T}_{\mathrm{w}}$ ) and $\beta$ ( $\mathrm{T}_{\mathrm{a}}$ at the inflection point of the function) $\gamma$ (measure of the steepest slope) from nonlinear regression analyses are shown for each time step considered (15 minute, hourly, daily, weekly, monthly, and seasonal) for each of five study sites in Hinkson Creek Watershed, U.S.A. The term "time lag" denotes analyses that accounted for the lagged response of $\mathrm{T}_{\mathrm{a}}$ relative to $\mathrm{T}_{\mathrm{w}}$. Lag was determined using crosscorrelation analysis.

21. Calibration parameters for the calibrated 15 minute linear $\mathrm{T}_{\mathrm{w}}$ model

22. Coefficient of determination $\left(\mathrm{r}^{2}\right)$ values from linear regression results for fifteen different flow classes using daily average stream and air temperature data collected from five hydroclimatic stations located in Hinkson Creek

Watershed, Missouri, U.S.A.

23. Flow empirical analysis $a$ and $b$ coefficients for fifteen different flow classes at a daily time step using data collected from five hydroclimate stations located in Hinkson Creek Watershed, Missouri, U.S.A. 68

24. Simulated and observed stream discharge calibration results showing daily descriptive statistics and six model evaluation criterion for five gauging sites in Hinkson Creek, U.S.A. Observed data are shown in parentheses for comparison with simulated data....

25. SWAT simulated and observed stream discharge validation results showing daily descriptive statistics and six model evaluation criterion for five gauging sites in Hinkson Creek, U.S.A. Observed data are shown in parentheses.

26. Five site mean summary of 15 minute linear, nonlinear, and calibrated linear stream water temperature model evaluation results during calibration and validation periods for five gauging sites in Hinkson Creek Watershed, U.S.A. 
27. Five site mean summary of hourly linear, nonlinear, and calibrated linear stream water temperature model evaluation results during calibration and validation periods for five gauging sites in Hinkson Creek Watershed, U.S.A................ 76

28. Summary of the mean model evaluation results from all five sites for the daily linear, nonlinear, calibrated linear, original SWAT, and Ficklin et al. (2012) stream water temperature model evaluation results during calibration and validation periods for five gauging sites in Hinkson Creek Watershed, U.S.A. 


\title{
MEASURING AND MODELING STREAM AND AIR TEMPERATURE RELATIONSHIPS IN A MULTI-LAND USE WATERSHED OF THE CENTRAL UNITED STATES
}

Sean J. Zeiger

Dr. Jason A. Hubbart, Thesis Supervisor

\begin{abstract}
ABSRACT
A nested-scale experimental watershed study design approach was used in an urban watershed of the central U.S. to investigate stream water temperature $\left(\mathrm{T}_{\mathrm{w}}\right)$ variability during water year's 2011,2012, and 2013. Drought conditions were observed during water year 2012 when total annual precipitation was approximately $340 \mathrm{~mm}$ less than the 30 year record. Sudden increases of $>1{ }^{\circ} \mathrm{C}$ within a 15 minute time interval in $\mathrm{T}_{\mathrm{w}}$ ( $\mathrm{T}_{\mathrm{w}}$ surges) following summer thunderstorms were observed at urban sites. Differences in mean $T_{w}$ between gauging sites were significantly $(p=0.02)$ correlated to urban land use and downstream distance as discharge increased. Linear and nonlinear regression analyses were performed between $\mathrm{T}_{\mathrm{w}}$ and air temperature $\left(\mathrm{T}_{\mathrm{a}}\right)$ data at time scales ranging from 15 minute to seasonal time steps. Additionally, the linear $\mathrm{T}_{\mathrm{w}}$ model used in the Soil and Water Assessment Tool (SWAT), and a new processed based $\mathrm{T}_{\mathrm{w}}$ model that accounts for hydrology were evaluated. Significant $(p>0.05)$ differences in model efficiency were not found between the linear $\mathrm{T}_{\mathrm{w}}$ model used in SWAT and the new process based $\mathrm{T}_{\mathrm{w}}$ model. Results from this study will provide land managers with quantitative information and $\mathrm{T}_{\mathrm{w}}$ models needed to make informed management decisions and improve water quality in urban watersheds.
\end{abstract}




\section{CHAPTER I}

\section{INTRODUCTION}

\section{THE IMPORTANCE OF STREAM WATER TEMPERATURE}

Stream water temperature $\left(\mathrm{T}_{\mathrm{w}}\right)$ is an important water quality variable because of its effects on nearly all aspects of aquatic ecosystems (Subehi et al. 2010). Temperature affects physical and chemical properties of water, and biological processes in aquatic ecosystems (Bogan et al. 2004). For example, temperature affects the physical state, density, pressure, conductivity / resistivity, and solubility of water. Additionally, chemical / biochemical reaction rates (e.g. redox reactions) in aquatic systems are dependent on $\mathrm{T}_{\mathrm{w}}$. Thus, $\mathrm{T}_{\mathrm{w}}$ affects nearly every biological process in aquatic systems including cell growth, reproduction, digestion, photosynthesis, respiration. Stream water temperature also affects the absorption, distribution, metabolism, and excretion of chemicals (including toxins) in aquatic organisms (Subehi et al. 2010).

Many water quality parameters are directly or indirectly influenced by $\mathrm{T}_{\mathrm{w}}$ including, but not limited to, suspended / dissolved solids, nutrient concentrations, dissolved oxygen (DO), and biological oxygen demand (BOD) (Webb et al. 2008, McClain et al. 1998). As an example, the effect of increased $T_{w}$ on dissolved oxygen supply due to decreased solubility of water coupled with increased microbial activity is a classic example of a water quality problem affected by increased $\mathrm{T}_{\mathrm{w}}$.

According to Henry's law, $\mathrm{T}_{\mathrm{w}}$ regulates the amount of DO water can hold.

Dissolved oxygen concentrations decrease with increases in $\mathrm{T}_{\mathrm{w}}$. Microbial activity also increases with increased $\mathrm{T}_{\mathrm{w}}$ (McClain et al. 1998). Too much heat, however, can denature 
proteins in microbial cells leading to disruption of microbial activity or even cell death (McClain et al. 1998). As microbial activity increases, microbial communities require more DO to meet BOD. When increased microbial activity results in DO levels lower than BOD, aquatic communities become stressed for DO. Low DO levels can cause reproductive problems ranging from birth defects to mortality in heterotrophic aquatic species (Cox, 2003). Additionally, heterotrophic aquatic species can asphyxiate without enough DO (Anka-Lufford et al. 2007).

When $\mathrm{T}_{\mathrm{w}}$ reaches 32 to $40{ }^{\circ} \mathrm{C}$ most North American freshwater fish species will perish (Nelson and Palmer, 2007; Beitinger et al. 2000). A Thermal Maximum (TM) water quality $\mathrm{T}_{\mathrm{w}}$ standard of $32{ }^{\circ} \mathrm{C}$ has been used for many states in the U.S.A. (Gu et al. 1999). Dinan (1992) justified a threshold of $35^{\circ} \mathrm{C}$ as a temperature that is closer to Critical Thermal Maximum (CTM) than the $32{ }^{\circ} \mathrm{C}$ standard for many fish species in Platte River, Nebraska (Gu et al. 1999). At CTM ectotherms experience muscular spasms that they cannot escape from leading to the organism's death (Hutchison, 1961). It is important that $\mathrm{T}_{\mathrm{w}}$ does not exceed $\mathrm{TM}$ because of the relationship between aquatic ecosystem health and elevated $\mathrm{T}_{\mathrm{w}}$. It is therefore critical to understand the independent and interacting natural processes and anthropogenic impacts that affect $\mathrm{T}_{\mathrm{w}}$ regimes for effective management and sustainability of aquatic ecosystem health (Caissie, 2006).

\section{IMPACTS ON STREAM WATER TEMPERATURE REGIMES}

Natural processes that affect $T_{w}$ regimes

Stream water temperature $\left(\mathrm{T}_{\mathrm{w}}\right)$ regimes are affected by four primary factors including meteorological conditions (i.e. solar radiation, air temperature, etc.), 
topography, stream discharge, and streambed interactions (e.g. hyporheic exchange) (Figure 1). Meteorological conditions usually account for the majority of heat inputs (Webb et al. 2008; Caissie, 2006). For example, $\mathrm{T}_{\mathrm{w}}$ regimes are governed by seasonal and diel (i.e. 24 hour) cycles in solar radiation input (Erickson and Stefan, 2000). Seasonal cycles of solar radiation input are a result of the tilt of the Earth's axis (Zachos et al. 2001), while diel cycles in solar radiation input are largely a result of the rotation of the Earth (Wahr, 1988). Other factors that affect solar radiation regimes include the Earth's movement and position relative to the Sun (Bennett, 1990).

The relationship between solar radiation regimes and $\mathrm{T}_{\mathrm{w}}$ has been studied to better understand the physical processes that affect $\mathrm{T}_{\mathrm{w}}$ regimes. Studies by Webb and Zhang (1997, 1999) quantified heat fluxes that control $\mathrm{T}_{\mathrm{w}}$ fluctuations. Results showed that solar radiation accounted for more than $70 \%$ of stream water heating. Sensible heat flux between the stream water and the atmosphere was also a significant source of energy that contributed $10.3 \%$ of advected heat inputs and $13.6 \%$ of non-advected heat inputs.

Topography is also important for influencing $\mathrm{T}_{\mathrm{w}}$ primarily because they influence atmospheric conditions. A review by Ward (1985) discussed the importance of topographic factors including longitude and altitude on temperature regimes. Further, a study by Webb et al. (1995) concluded that valley and channel morphology, riparian vegetation, and geology, can influence stream exposure to atmospheric conditions including wind and solar radiation. Topography and atmospheric conditions also affect stream discharge. 


\begin{tabular}{|c|c|}
\hline $\begin{array}{c}\text { Meteorological Conditions } \\
\text { solar radiation } \\
\text { air temperature } \\
\text { wind speed / humidity } \\
\text { precipitation (rain / snow) } \\
\text { evaporation / condensation } \\
\text { phase change (e.g. melting) }\end{array}$ & $\begin{array}{c}\text { Topography } \\
\text { upland shading } \\
\text { riparian vegetation } \\
\text { geology (bedrock) } \\
\text { aspect (stream orientation) } \\
\text { latitude / altitude }\end{array}$ \\
\hline Stream Water Temperature \\
\hline \begin{tabular}{c|c} 
Stream Discharge \\
volume of water \\
slope / water falls \\
turbulence \\
inflow / outflow \\
friction (streambed)
\end{tabular} \\
$\begin{array}{c}\text { Streambed Interactions } \\
\text { conduction (sediment) } \\
\text { longwave radiation (sediment) } \\
\text { hyporheic exchange } \\
\text { goundwater input }\end{array}$ \\
\hline
\end{tabular}

Figure 1. Four primary factors that affect stream water temperature regimes recreated after Caissie, 2006.

Stream water temperature regimes are controlled by meteorological conditions (e.g. solar radiation, and $\mathrm{T}_{\mathrm{a}}$ ), particularly during low flow periods. But, hydrologic factors (e.g. volume of water, source of water) dominate during high flow periods. As discharge increases, streams are more thermally stable and less responsive to changes in meteorological conditions, in part, because of the high specific heat capacity of water $\left(4.184 \mathrm{~J} / \mathrm{g}{ }^{\circ} \mathrm{C}\right)$. Additionally, residence times decrease as flow rates increase. Decreased 
residence times decrease stream interaction with the atmosphere (Erickson and Stefan, 2000).

Heat exchange processes at the stream / streambed interface can be important inputs and outputs of stream heat fluxes. Friction between the stream and the bed / banks can affect $T_{w}$ regimes especially where large amounts of topographic shading and steep channel slopes are present (Webb et al. 2008). Webb and Zhang (2004) showed friction accounted for the majority of stream heat inputs during winter months in four streams located in South-West England. Groundwater inflows affect $\mathrm{T}_{\mathrm{w}}$ regimes, generally increasing $\mathrm{T}_{\mathrm{w}}$ in winter months and decreasing $\mathrm{T}_{\mathrm{w}}$ in summer months (Webb et al. 2008).

\section{Anthropogenic impacts that affect $T_{w}$ regimes}

Anthropogenic impacts on $\mathrm{T}_{\mathrm{w}}$ regimes of aquatic ecosystems include (but are not limited to) deforestation (Doyle and Shields, 2012), flow alteration (Sinokrot and Gulliver, 2000), and thermal pollution (Mohseni et al. 1999, Herb et al. 2008). For example, deforestation of riparian zones has been shown to alter $T_{\mathrm{w}}$ significantly $(\mathrm{P}<0.05)$, particularly during summer months, when $\mathrm{T}_{\mathrm{w}}$ can increase as much as $8.8^{\circ} \mathrm{C}$ (Webb et al. 2008; Gomi et al. 2006). The vegetation canopy in riparian zones attenuates radiation that can lead to stream heating by increasing net radiation at the stream surface (Moore et al. 2005; Webb et al. 2008). For example, a recent study by Bulliner (2011) in a central U.S. hardwood forest concluded that any thinning of forested riparian zones could result in stream water heating by increasing net radiation.

Flow alteration / reduction associated with increased impervious surfaces can alter $\mathrm{T}_{\mathrm{w}}$ regimes. Sinokrot and Gulliver (2000) noted during a four year study (summer 1991 
to summer 1994) in Platte River at Shelton, Nebraska [population 1,074 (USCB, 1012)] that as discharge decreased the number of days $\mathrm{T}_{\mathrm{w}}$ was above $32{ }^{\circ} \mathrm{C}$ increased by approximately 4 days per $5.6 \mathrm{~m}^{3} / \mathrm{s}$ (Sinokrot and Gulliver, 2000). Stream water temperature exceeded the $32{ }^{\circ} \mathrm{C}$ thermal maximum (threshold for potential mortality of North American freshwater fishes) and the $35^{\circ} \mathrm{C}$ "critical thermal maximum" at four hydrometeorological stations for an average of 57 days, and 14 days, respectively. One of four hydroclimate stations in the study recorded a maximum of 101 days during which $\mathrm{T}_{\mathrm{w}}$ was above $32{ }^{\circ} \mathrm{C}$, and 26 days above $35^{\circ} \mathrm{C}$. Stream water temperature was shown to be inversely proportional to stream discharge when heat capacity of water $\left(4.184 \mathrm{~J} / \mathrm{g}{ }^{\circ} \mathrm{C}\right)$ and heat input were held constant (Gu et al. 1999). Stream water temperature can exceed 32 ${ }^{\circ} \mathrm{C}$ particularly during hot dry summer months when incoming solar radiation is high and base flow rates are low (Sinokrot and Gulliver, 2000).

Previous studies showed that independent and interacting physical hydrologic and land use practices impact aquatic ecosystems with thermal pollution (Webb et al. 2003; Nelson and Palmer, 2007; Webb et al. 2008; Kaushal et al. 2010). For example, increases in impervious surfaces were shown to increase $\mathrm{T}_{\mathrm{w}}$ (Webb et al. 2008; Kaushal et al. 2010) in part due to re-emitted heat energy from those surfaces heating stormwater runoff. Additionally, urban heat island effects on local climate can increase surrounding air temperature $\left(\mathrm{T}_{\mathrm{a}}\right)$ by as much as $6{ }^{\circ} \mathrm{C}$ (Lin et al. 2008). A study by Akyuz et al. (2004), showed "a distinct urban influence" on $\mathrm{T}_{\mathrm{a}}$ where the difference in monthly maximum $\mathrm{T}_{\mathrm{a}}$ ranged from 1.5 to $3.5^{\circ} \mathrm{C}$ between urban and rural sites in Columbia, Missouri, U.S.A. Another study in Columbia, Missouri, U.S.A., by Hubbart et al. (2014) showed an urban heat island effect on local climate during 1995 to 2013 where significant differences 
$(\mathrm{p}<0.001)$ in mean air temperature and relative humidity ranged from $13.47{ }^{\circ} \mathrm{C}$ and 12.89 ${ }^{\circ} \mathrm{C}$, and $69.11 \%$ and $72.51 \%$ in urban and rural sites, respectively.

Studies showed heated stormwater runoff from impervious surfaces following summer thunderstorms cause sudden increases (surges) in $\mathrm{T}_{\mathrm{w}}$ (Hester and Baumen, 2012; Rice et al. 2011; Anderson et al. 2011; Nelson and Palmer, 2007). The surges in $T_{w}$ were, attributed to reduced shading associated with deforestation, and the conduction of heat energy from impervious surfaces to stormwater runoff. Rice et al. (2011) showed during January 2007 to October 2010, in Boone Creek (a headwater stream) in the Town of Boone, North Carolina, U.S.A., that increased impervious surfaces from 13.7 to $24.3 \%$ caused an increase of summer and winter $\mathrm{T}_{\mathrm{w}}$ by 4 to $5{ }^{\circ} \mathrm{C}$ and 3 to $4{ }^{\circ} \mathrm{C}$, respectively. There were 44 sudden rises (surges) in $\mathrm{T}_{\mathrm{w}}$ from heated stormwater runoff $\left(>1{ }^{\circ} \mathrm{C}\right.$ increase within 15 minutes) recorded showing mean $\mathrm{T}_{\mathrm{w}}$ surges that ranged from 1.9 to $3.7^{\circ} \mathrm{C}$ with a mean surge duration of more than 3 hours. Another study in Boone Creek, North Carolina, USA, by Anderson et al. (2011) showed 71 temperature surges with a mean $\mathrm{T}_{\mathrm{w}}$ surge of $2.39{ }^{\circ} \mathrm{C}$ and a maximum increase of $6.36{ }^{\circ} \mathrm{C}$ during four summers of years 2006 , 2007, 2008, and 2010. Nelson and Palmer (2007) used multiple regression techniques to model the effects of $T_{w}$ increases due to summer thunder storms in urbanizing watersheds in a three year study (summers of 2002, 2003, and 2004) within the Piedmont region of Maryland north of Washington DC. Thirty-seven sudden rises in $\mathrm{T}_{\mathrm{w}}$ were detected subsequent to summer thunder storm generated stormwater runoff $\left(>2^{\circ} \mathrm{C}\right.$ increase in 30 minutes) with an average $\mathrm{T}_{\mathrm{w}}$ surge and surge duration of $3.7^{\circ} \mathrm{C}$ and 2.8 hours, respectively. Maximum $\mathrm{T}_{\mathrm{w}}$ surge and surge duration was $7.4{ }^{\circ} \mathrm{C}$ and 7.6 hours respectively. Hester and Baumen (2012) measured $\mathrm{T}_{\mathrm{w}}$ surges at a stormwater outfall at 
Stroubles Creek located in Blacksburg, Virginia U.S.A. during June to August 2009. A total of $15 \mathrm{~T}_{\mathrm{w}}$ surges showed a mean $\mathrm{T}_{\mathrm{w}}$ surge of $2.8{ }^{\circ} \mathrm{C}$, a maximum $\mathrm{T}_{\mathrm{w}}$ surge of $8.1^{\circ} \mathrm{C}$, and a peak surge temperature of $25.2^{\circ} \mathrm{C}$. Mean surge duration was approximately 2 hours.

\section{MODELING STREAM WATER TEMPERATURE}

A considerable amount of research has been conducted to develop predictive models to foretell future effects of natural and anthropogenic impacts (including urbanization and global warming) on $\mathrm{T}_{\mathrm{w}}$ regimes. Caissie (2006) and Benyahya et al. (2007) reviewed three main groups of models used for $T_{w}$ predictions, including: 1) deterministic models; 2) stochastic models; and 3) regression models.

Deterministic $\mathrm{T}_{\mathrm{w}}$ models include physical models that use an energy balance approach to quantify heat transfer between a stream and its surrounding environment. Deterministic models, while robust and highly transferable, require measurements of all physical hydroclimate parameters making model development expensive because of costs associated with instruments (sensors, data loggers, etc.) and labor (installation, maintenance, etc.) (Caissie, 2006; Benyahya et al. 2007).

Stochastic models have been used to analyze long term (annual) and short term (diel) $\mathrm{T}_{\mathrm{w}}$ fluctuations (Webb and Walling, 1993; Caissie, 2006). Stochastic models have been shown to predict $\mathrm{T}_{\mathrm{w}}$ reliably at daily intervals, generally within $2{ }^{\circ} \mathrm{C}$, but are computationally demanding (Caissie, 2006). Regression models (e.g. simple linear regression or nonlinear regression) are stochastic models that can be created using the least squares method (Dong et al. 1998). The least squares method minimizes the sum of 
squared deviations for each individual observed y value from a best fit line or curve. Stream water temperature linear regression models, developed using the least squares method generally follow a format as follows (Caissie, 2006; Caissie et al. 2007):

$$
T_{w}=b_{0}+b_{1} * x
$$

where $T_{w}$ is stream water temperature, $b_{1}$ is the independent variable (e.g. $\mathrm{T}_{\mathrm{a}}$ ), $b_{0}$ is $T_{w}$ at the $y$-intercept, and $x$ is the slope of the linear relationship between the dependent variable and the independent variable.

Nonlinear regression models are more arithmetically complex than simple linear regression models making them potentially more difficult for land managers to create and utilize. Nonlinear regression models can be used to model nonlinear $\mathrm{T}_{\mathrm{w}} / \mathrm{T}_{\mathrm{a}}$ relationships with the following equation (Mohseni et al. 1998; Webb et al. 2003):

$$
T_{w}=\mu+\frac{\alpha+\mu}{1+e^{\gamma\left(\beta-T_{a}\right)}}
$$

where $T_{w}$ is stream water temperature, $T_{a}$ is air temperature, $\alpha$ is maximum $\mathrm{T}_{\mathrm{w}}, \mu$ is minimum $\mathrm{T}_{\mathrm{w}}, \beta$ is $\mathrm{T}_{\mathrm{a}}$ at the inflection point of the function, $\gamma$ is the steepest slope of the function, and $e$ (Euler's number) is 2.71828 . The nonlinear equation shown in Figure 2 is an s-curve function characterized by two curves. The inflection point separates the two curves in the function. Below the inflection point, the curve is positive increasing from left to right. Above the inflection point, the curve is negative decreasing from left to right. The steepest slope of the function $\gamma$ is a function of the slope $\tan \theta$ at the point of inflection:

$$
\gamma=\frac{4 \tan \theta}{\alpha-\mu}
$$

where $\gamma$ is the steepest slope of the function, $\alpha$ is maximum $\mathrm{T}_{\mathrm{w}}$, and $\mu$ is minimum $\mathrm{T}_{\mathrm{w}}$. 


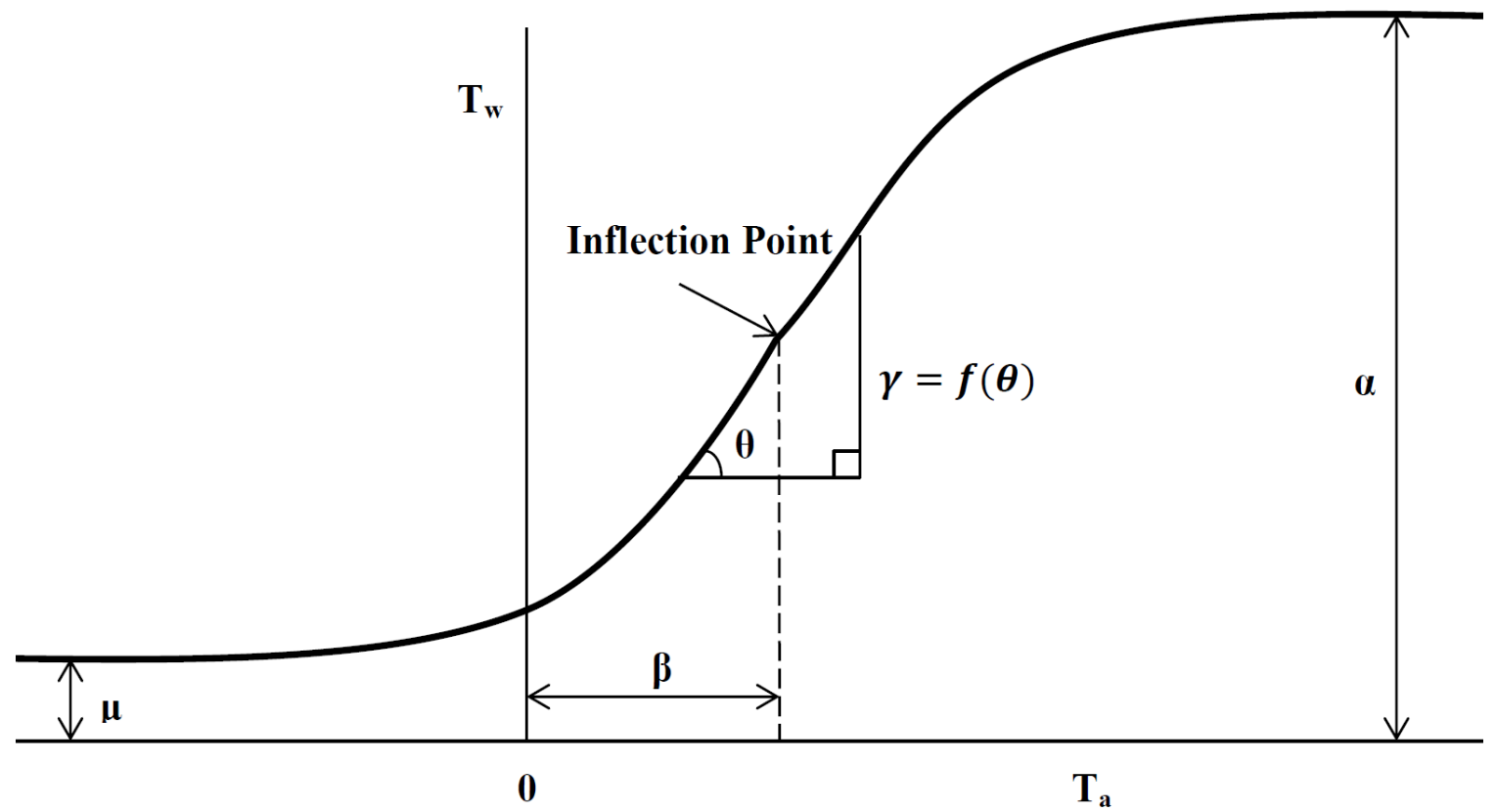

Figure 2. Representation of nonlinear stream and air temperature equation recreated after Mohseni et al. (1998).

\section{Stream and air temperature relationships}

After a $T_{w}$ regression model is created, the model can be used to predict $T_{w}$ by imputing the appropriate independent variable (e.g. $\mathrm{T}_{\mathrm{a}}$ ) into the model and then solving the model equation. Observed stream water temperature data are rare and more difficult to obtain compared to air temperature (Stefan and Preud'homme, 1993). Given its availability, and significant correlation with $\mathrm{T}_{\mathrm{w}}, \mathrm{T}_{\mathrm{a}}$ is commonly used as an independent variable to predict $T_{w}$ with regression modeling techniques (Caissie, 2006). Mohseni (1999) made the following statement that supports the use of $T_{a}$ data to predict $T_{w}$ :

"Regressions between water temperatures at individual stream gauging stations and air temperatures at nearby weather stations provide the easiest practical method to estimate stream temperatures for the entire United States." 
While linear and nonlinear $T_{w}$ regression models dependent on only $T_{a}$ are attractive because of ease of use and availability of data, there are limitations. For example, $\mathrm{T}_{\mathrm{w}}$ regression models do not work as well at sub-daily time steps, or when air temperature is $>25^{\circ} \mathrm{C}$. Stream and air temperature relationships are affected by time scale (Erickson and Stefan, 2001).

Stream water temperature regression models have been used to predict $\mathrm{T}_{\mathrm{w}}$ at hourly, daily, weekly, monthly, and seasonal time steps (Stefan and Preud'homme, 1993; Erickson and Stefan, 2000; Webb et al. 2003). Erickson and Stefan (2000) showed time scale affected stream and air temperature relationships. The range of the data sets decreased when averaged. Meaning, the maximums decreased and the minimums increased. Air temperature had a greater diel and seasonal range than $T_{w}$ mainly because of the specific heat capacity of water. Thus, $\mathrm{T}_{\mathrm{a}}$ is affected more by averaging causing a slight counter clockwise rotation of the best fit line in linear regression analyses (Erickson and Stefan, 2000). Therefore, the slope of the best fit lines (linear coefficient $a$ ) increased and the y-intercept (linear coefficient $b$ ) decreased as time step increased.

Time lag has also been shown to affect stream and air temperature relationships. "Time lag" is a term used to describe the lagged response of $T_{w}$ relative to $T_{a}$. Stream water temperature lags behind fluctuations in $\mathrm{T}_{\mathrm{a}}$ (Figure 3 ) due to the time it takes water to absorb thermal energy from its surroundings (i.e. thermal inertia) (Stefan and Preud'homme, 1993). Webb et al. (2003) showed that accounting for time lag improved $\mathrm{r}^{2}$ values by 3.6 to $8.5 \%$ in regression analysis. Time lag was shown to increase with watershed scale by a range of 2 hours (h) to $6 \mathrm{~h}$, because as volume of water increases so does stream thermal capacity, thereby affecting the response time of $T_{w}$ to changes in 
surrounding $T_{a}$ (Webb et al. 2003). Stefan and Preud'homme (1993) used regression analysis techniques for 11 streams in the Mississippi River Basin to predict $T_{w}$ with $T_{a}$ data at daily and weekly time intervals. Time lag increased with stream depth from hours to days in length. Accounting for time lag slightly increased $r^{2}$ values by 0.03 to 0.07 , and decreased the mean standard deviation of predicted $\mathrm{T}_{\mathrm{w}}$ by 0.04 degrees at daily intervals. There was not a time lag effect for weekly intervals. Stefan and Preud'homme (1993) concluded that time lag was directly proportional to average stream depth. Ultimately, accounting for time lag has been shown to improve model accuracy when investigating $\mathrm{T}_{\mathrm{w}} / \mathrm{T}_{\mathrm{a}}$ relationships at timescales less than weekly intervals. 


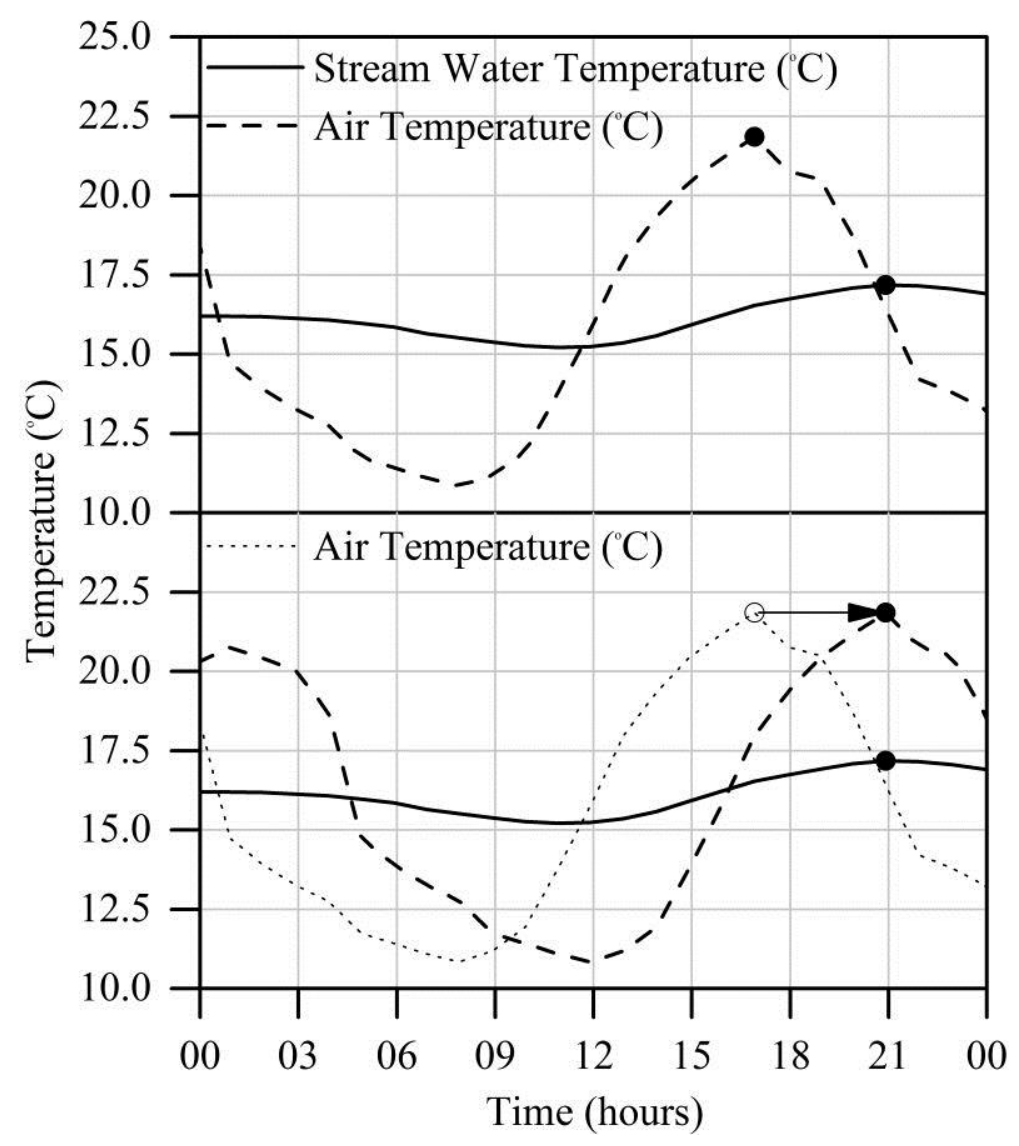

Figure 3. An example of time lag between stream water temperature and air temperature and how the temperature time series can be synchronized is shown. The black points denote peak temperatures. On top, air temperature peaks at 17:00 hours and stream water temperature peaks at 21:00 hours. The two time series were synchronized by shifting the air temperature time series forward by 4 hours.

Accounting for latent heat exchange has also been shown to improve model accuracy. The relationship between $\mathrm{T}_{\mathrm{w}} / \mathrm{T}_{\mathrm{a}}$ is linear between 5 and $20{ }^{\circ} \mathrm{C}$, but energy required for phase change of water causes departure from linearity (Mohseni et al. 1998; Mohseni et al. 1999; Webb et al. 2003). For example, nonlinear relationships in $T_{w} / T_{a}$ regressions are, in part, attributable to latent heat exchange at the stream surface at temperatures above $20^{\circ} \mathrm{C}$, (latent heat of vaporization), and below $5^{\circ} \mathrm{C}$ (latent heat of fusion). 
Previous studies showed that using nonlinear $\mathrm{T}_{\mathrm{w}} / \mathrm{T}_{\mathrm{a}}$ regressions to account for the effects of latent heat exchange result in slightly greater level of explained variance than simple linear relationships (Mohseni et al. 1998; Webb et al. 2003). Mohseni et al. (1998) fitted nonlinear regression models to weekly $\mathrm{T}_{\mathrm{w}} / \mathrm{T}_{\mathrm{a}}$ data collected from 584 USGS stream gauging stations and nearby weather stations located in the contiguous United States. Results showed an average coefficient of determination of $0.93 \pm 0.01$ for $89 \%$ of the stream gauging stations. Webb et al. (2003) showed nonlinear $\mathrm{T}_{w} / \mathrm{T}_{\mathrm{a}}$ regressions at hourly time steps with increased $r^{2}$ values of 1.3 to $0.8 \%$. At daily and weekly time steps, however, there was not significant evidence to support a nonlinear $\mathrm{T}_{\mathrm{w}}$ / $\mathrm{T}_{\mathrm{a}}$ relationship.

\section{The effects of discharge}

Discharge can affect $\mathrm{T}_{\mathrm{w}}$ (as previously presented) and $\mathrm{T}_{\mathrm{w}} / \mathrm{T}_{\mathrm{a}}$ regression analyses. Webb et al. (2003) used regression modeling techniques to study the $\mathrm{T}_{\mathrm{w}} / \mathrm{T}_{\mathrm{a}}$ relationship and modulation by discharge in the United Kingdom. Reduced flow was usually found to increase levels of explained variance in $\mathrm{T}_{\mathrm{w}} / \mathrm{T}_{\mathrm{a}}$ regression analyses at hourly, daily, and weekly time steps for all study catchments considered by an average of 1.7, 7.7, and $4.7 \%$, respectively. While reduced flow greatly affected levels of explained variance for $\mathrm{T}_{\mathrm{w}} / \mathrm{T}_{\mathrm{a}}$ regression analyses in smaller catchments, larger catchments were only slightly affected by reduced flow. For example, $\mathrm{r}^{2}$ values decreased by $0.8 \%$ in $\mathrm{T}_{\mathrm{w}} / \mathrm{T}_{\mathrm{a}}$ regression analyses at hourly time steps for the River Barle catchment $\left(128 \mathrm{~km}^{2}\right)$ and only slightly increased by $0.6 \%$ the River Exe catchment $\left(601 \mathrm{~km}^{2}\right)$. Webb et al. (2003) explained that reduced discharge decreases stream thermal capacity (i.e. specific heat capacity), which 
in turn increases stream response to temperature changes of the surrounding environment (Stefan and Preud'homme, 1993; Webb et al. 2003). Heat exchange rates at both the stream water-atmosphere and stream water-streambed interfaces are influenced by stream width to depth ratios, which affect surface area (i.e. stream / air surface interface) to volume ratios (Brown et al. 2005; Poole and Berman, 2001). Other previous studies investigated the effects of stream boundaries and inflows (e.g. reservoirs and groundwater inflows) on the relationship between $\mathrm{T}_{\mathrm{w}}$ and $\mathrm{T}_{\mathrm{a}}$.

Erickson and Stefan (2000) showed that $\mathrm{T}_{\mathrm{w}} / \mathrm{T}_{\mathrm{a}}$ relationships are affected by various factors including, but not limited to, impoundments and reservoirs, groundwater interaction, and thermal effluent (e.g. hydroelectric dams, and wastewater). The $\mathrm{T}_{\mathrm{w}} / \mathrm{T}_{\mathrm{a}}$ relationship is lost when the temperature and volume of inflows from impoundments and reservoirs, groundwater sources, and thermal effluent are drastically different from stream conditions. Impoundments and reservoirs have stratified water temperature. Water at the surface in the epilimnion (i.e. the upper layer of water in a thermally stratified lake) is affected by meteorological conditions, but not water below the surface in the hypolimnion (the denser bottom layer of water in a thermally stratified lake). Therefore, the $\mathrm{T}_{\mathrm{w}} / \mathrm{T}_{\mathrm{a}}$ relationship downstream can be weakened when impoundments and reservoirs release large volumes of water from the hypolimnion. Residence times can also affect $T_{w}$ / $\mathrm{T}_{\mathrm{a}}$ relationships because stream interaction with the atmosphere decreases as residence time decreases (Erickson and Stefan, 2000). Stream water temperature regression models need to account for hydrology. 


\section{MODELING STREAM WATER TEMPERATURE WITH SWAT}

The Soil and Water Assessment Tool (SWAT) is a physically based, daily time step, deterministic model that uses commonly available input data (i.e. topography, soils, land use, and meteorological data) and regression modeling techniques (e.g. linear regression) to predict long term impacts of land management practices on water yield, sediment yield, and chemical agriculture yields (Neitsch et al. 2005). SWAT simulates components of watershed hydrology including snowmelt, groundwater flow, soil water lateral flow, discharge, and surface water runoff. SWAT was designed to simulate management strategies in large ungauged basins thereby saving time and money making the model an economical choice for land managers (Arnold et al. 2012). To test the SWAT models capability of simulating streamflow in ungauged basins, Srinivasan et al. (2010) used SWAT to simulate streamflow in the Upper Mississippi River Basin (UMRB) without calibration. Results showed $\mathrm{r}^{2}$ ranged from 0.78 to 0.99 on an annual scale and 0.29 to 0.81 on a monthly scale.

To model in-stream water quality and biological processes, SWAT requires daily estimates of $\mathrm{T}_{\mathrm{w}}$. The currently available 2012 version of SWAT (SWAT 2012) uses a linear regression $T_{w}$ model, developed by Stefan and Preud'homme (1993), to predict $T_{w}$ :

$$
T_{w}(t)=5.0+0.75 T_{a}
$$

where $T_{w}$ is stream water temperature $\left({ }^{\circ} \mathrm{C}\right), T_{a}$ is air temperature $\left({ }^{\circ} \mathrm{C}\right)$, and $t$ is time (daily).

Equation 4 was generated using average coefficients from linear regression analyses that were performed by Stefan and Preud'homme (1993) using stream water temperature data collected from 11 streams in the Mississippi River basin and 
corresponding $T_{a}$ data collected from weather stations ranging in distances of 0 to 144 miles from the rivers.

Stefan and Preud'homme (1993) showed the average standard deviation between observed and simulated $\mathrm{T}_{\mathrm{w}}$ was $2.7^{\circ} \mathrm{C}$ using equation 4 . The average standard deviation was $2.1^{\circ} \mathrm{C}$ using equations derived for each stream individually. Thus, it was reported advantageous to develop an equation for each stream individually, or to use a relationship calculated for a stream of similar size and climate.

Stefan and Prud'homme (1993) showed lower standard deviations between observed and simulated $\mathrm{T}_{\mathrm{w}}$ were obtained from smaller rivers (rivers with lower discharge). For example, average discharge of Straight River was $1.3 \mathrm{~m}^{3} / \mathrm{s}$ and the standard deviation between observed and simulated $\mathrm{T}_{\mathrm{w}}$ was $1.8^{\circ} \mathrm{C}$, while average discharge at Mississippi River was $317 \mathrm{~m}^{3} / \mathrm{s}$ and standard deviation between observed and simulated $\mathrm{T}_{\mathrm{w}}$ was $4.4^{\circ} \mathrm{C}$.

A major limitation associated with Equation 4, the original SWAT $\mathrm{T}_{\mathrm{w}}$ regression model, was linear regression models do not account for the damping temperature amplitudes caused by thermal inertia of water as discharge increases. Another limitation reported by Ficklin et al. (2012) was that the original SWAT $\mathrm{T}_{\mathrm{w}}$ model does not consider the effects of watershed hydrology (e.g. snowmelt, groundwater flow, soil water lateral flow, discharge, and surface water runoff) on $\mathrm{T}_{\mathrm{w}}$.

Ficklin et al. (2012) proposed a new process based SWAT $\mathrm{T}_{\mathrm{w}}$ model that accounts for $\mathrm{T}_{\mathrm{a}}$, snowmelt, groundwater flow, soil water lateral flow, discharge, and surface water runoff. All of the input data required to run the Ficklin et al. (2012) $T_{w}$ model is generated by SWAT 2012. Three components are considered including $\mathrm{T}_{\mathrm{w}}$ and amount of 
the local water contribution within the subbasin, the temperature and volume of inflows from upstream subbasin(s), and heat transfer at the stream surface during the streamflow travel time in the subbasin. Stream water temperature and the amount of local water contribution within the subbasin are derived with the following equation:

$$
T w_{\text {local }}=\frac{\left(T_{\text {snow }} \text { sub_snow }\right)+\left(T_{g w} \text { sub_gw }\right)+\left(\lambda T_{\text {air.lag }}\right)\left(s u b_{-} s u r q+s u b_{-} l a t q\right)}{\text { sub_wyld }}
$$

where $s u b \_s n o w$ is snowmelt volume $\left(\mathrm{m}^{3} \mathrm{~d}^{-1}\right), s u b \_g w$ is groundwater flow $\left(\mathrm{m}^{3} \mathrm{~d}^{-1}\right)$, $s u b \_s u r q$ is surface water runoff $\left(\mathrm{m}^{3} \mathrm{~d}^{-1}\right), s u b \_l a t q$ is soil water lateral flow $\left(\mathrm{m}^{3} \mathrm{~d}^{-1}\right)$, and $s u b \_w y l d$ is total water yield within the subbasin. Lambda $(\lambda)$ is a calibration coefficient relating $\mathrm{T}_{\text {air.lag }}$ and sub_latq and sub_surq. $T_{\text {air.lag }}$ is the average daily $\mathrm{T}_{\mathrm{a}}$ with lag $\left({ }^{\circ} \mathrm{C}\right)$. $T_{\text {snow }}$ is the temperature of inflows from snowmelt $\left(0.1^{\circ} \mathrm{C}\right)$, and $T_{g w}$ is groundwater temperature $\left({ }^{\circ} \mathrm{C}\right)($ Ficklin et al. 2012).

The temperature and amount of inflow from upstream subbasin(s) is derived with the following equation:

$$
T w_{\text {initial }}=\frac{\left(T w_{\text {upstream }}\left(Q_{\text {outlet }}-\text { sub_wyld }\right)+T w_{\text {local }}\right. \text { sub_wyld }}{Q_{\text {outlet }}}
$$

where $T w_{\text {upstream }}$ is water temperature of streamflow entering the subbasin $\left({ }^{\circ} \mathrm{C}\right), Q_{\text {outlet }}$ is discharge at the outlet $\left(\mathrm{m}^{3} \mathrm{~d}^{-1}\right)$. For headwater streams $T w_{\text {initial }}$ equals $T w_{\text {local }}$ (Ficklin et al. 2012).

The heat transfer at the stream water surface during the streamflow travel time in the subbasin is derived with the following equations:

$$
\begin{aligned}
& T_{w}=T w_{\text {initial }}+\left(T_{\text {air }}-T w_{\text {initial }}\right) K(T T) \text { if } T_{\text {air }}>0 \\
& T_{w}=T w_{\text {initial }}+\left[\left(T_{\text {air }}+\varepsilon\right)-T w_{\text {initial }}\right] K(T T) \text { if } T_{\text {air }}<0,
\end{aligned}
$$


where $T_{\text {air }}$ is the mean daily temperature $\left({ }^{\circ} \mathrm{C}\right), K(1 / \mathrm{h})$ is a bulk coefficient of heat transfer ranging from 0 to $1, T T$ is travel time (hourly) of water through the subbasin, and $\varepsilon$ is a coefficient that accounts for $\mathrm{T}_{\mathrm{w}}$ pulses when $T_{\text {air }}$ is less than $0{ }^{\circ} \mathrm{C}$ (Ficklin et al. 2012).

The Ficklin et al. (2012) $\mathrm{T}_{\mathrm{w}}$ model and the original SWAT $\mathrm{T}_{\mathrm{w}}$ model were tested on seven streams located in the costal and mountainous regions of western United States (Washington, Oregon, Idaho, and northern California). The Ficklin et al. (2012) $\mathrm{T}_{\mathrm{w}}$ model showed better predictions than the original SWAT $T_{w}$ model. The Ficklin et al. (2012) $T_{w}$ model produced a seven stream average Nash-Sutcliffe efficiency coefficient (NSE) and mean error $(\mathrm{ME})$ of 0.81 and $-0.69^{\circ} \mathrm{C}$, respectively, during the calibration period and 0.82 and $-0.63{ }^{\circ} \mathrm{C}$, respectively, during the validation period. The original SWAT $\mathrm{T}_{\mathrm{w}}$ model (equation 4) produced a seven stream average NSE of -0.27 and ME of $3.21{ }^{\circ} \mathrm{C}$ during the calibration period and a NSE of -0.26 and ME of $3.02{ }^{\circ} \mathrm{C}$ during the validation period. NSE values range from $-\infty$ to 1 where a value of 1 corresponds to a perfect match of modeled output and observed data. The lower the NSE value the less accurate the model. NSE values $>0.50$ are considered sufficient when simulating at a monthly time step (Moriasi et al. 2007). Lower ME values are desirable with a ME value of 0 corresponding to a perfect score.

\section{STATEMENT OF NEED}

Research is needed to improve mechanistic understanding of the relationships between natural and anthropogenic processes that control $\mathrm{T}_{\mathrm{w}}$ (Webb et al. 2008), and ultimately the relationship between $\mathrm{T}_{\mathrm{w}}$ and $\mathrm{T}_{\mathrm{a}}$ (Caissie, 2006). Such an understanding is increasingly important as urban land use continues to alter aquatic ecosystem health 
(Anderson et al. 2011). There is, however, a lack of long term high resolution data in low order urban streams mainly because of the difficulty of maintaining gauging sites in "flashy" urban catchments (Anderson et al. 2011; Nelson and Palmer, 2007). Validated $\mathrm{T}_{\mathrm{w}}$ models that are useful in urban streams are needed to aid in the protection of water quality, thereby providing local land managers with the knowledge to make informed management decisions in the central United States. Practical $\mathrm{T}_{\mathrm{w}}$ regression models dependent on $\mathrm{T}_{\mathrm{a}}$ are an attractive choice, but there is controversy on the accuracy of $\mathrm{T}_{\mathrm{w}}$ regression model output as discharge increases and time scale decreases. Therefore, $\mathrm{T}_{\mathrm{w}}$ regression model outputs need to be evaluated against observed $\mathrm{T}_{\mathrm{w}}$ data and the effect of increased discharge and land use on the $\mathrm{T}_{\mathrm{w}} / \mathrm{T}_{\mathrm{a}}$ relationship needs to be quantitatively characterized. Stefan and Preud'homme (1993) showed the magnitude of error associated with daily and weekly $T_{w}$ regression models dependent on $T_{a}$, but there remains a need to investigate the error associated with $\mathrm{T}_{\mathrm{w}}$ regression models at sub-daily time scales because information showing diel variation of $\mathrm{T}_{\mathrm{w}}$ can be important in ecologic modeling and water quality investigations. Finally, the Ficklin et al. (2012) $\mathrm{T}_{\mathrm{w}}$ model produced better predictions than the original SWAT $\mathrm{T}_{\mathrm{w}}$ model in seven coastal and mountainous regions of the western United States; however, the models have not been tested in the central United States where hydrogeological and land use interactions may be different.

\section{OBJECTIVES}

The overall objective of the following research was to investigate $\mathrm{T}_{\mathrm{w}}$ variability due to land use and validate $\mathrm{T}_{\mathrm{w}}$ models using time series data collected in a multi-land use urbanizing watershed in the central United States. Sub objectives included: 1) test for 
significant differences in $T_{\mathrm{w}}$ between five stream gauging sites each with different land uses, 2) compare $T_{w} / T_{a}$ relationships between five stream gauging sites each with different land uses, 3) compare $T_{w} / T_{a}$ relationships at 15 minute, hourly, daily, weekly, monthly, and seasonal time scales, 4) quantitatively characterize the significance of the effects of discharge in the $T_{w} / T_{a}$ relationship, 5) test the daily $T_{w}$ model utilized in the SWAT 2012, and the new $\mathrm{T}_{\mathrm{w}}$ model developed by Ficklin et al. (2012) with observed hydroclimate data from five stream gauging sites each with different land uses, and 6) test sub-daily $\mathrm{T}_{\mathrm{w}}$ linear and nonlinear regression models with observed hydroclimatic data from five stream gauging sites each with different land uses.

\section{HYPOTHESES}

1.) $\mathrm{H}_{\mathrm{o}}: \mathrm{T}_{\mathrm{w}}$ will not be significantly different $(\mathrm{CI}=95 \%)$ between land use types. $\mathrm{H}_{\mathrm{a}}: \mathrm{T}_{\mathrm{w}}$ will be significantly different $(\mathrm{CI}=95 \%)$ between land use types.

2.) $H_{0}: T_{w} / T_{a}$ relationships will not be significantly different (CI=95\%) between study stream sites.

$\mathrm{H}_{\mathrm{a}}: \mathrm{T}_{\mathrm{w}} / \mathrm{T}_{\mathrm{a}}$ relationships will be significantly different $(\mathrm{CI}=95 \%)$ between study stream sites.

3.) $\mathrm{H}_{\mathrm{o}}: \mathrm{T}_{\mathrm{w}} / \mathrm{T}_{\mathrm{a}}$ relationships will not be significantly different (CI=95\%) as time step increases.

$\mathrm{H}_{\mathrm{a}}: \mathrm{T}_{\mathrm{w}} / \mathrm{T}_{\mathrm{a}}$ relationships will be significantly different $(\mathrm{CI}=95 \%)$ as time step increases.

4.) $\mathrm{H}_{\mathrm{o}}: \mathrm{T}_{\mathrm{w}} / \mathrm{T}_{\mathrm{a}}$ relationships will not be significantly different $(\mathrm{CI}=95 \%)$ as discharge increases. 
$H_{a}: T_{w} / T_{a}$ relationships will be significantly different $(C I=95 \%)$ as discharge increases.

5.) $H_{0}$ : Model evaluation results from the sub-daily linear $T_{w}$ models and the nonlinear $\mathrm{T}_{\mathrm{w}}$ models will not be significantly different $(\mathrm{CI}=95 \%)$.

$H_{a}$ : Model evaluation results from the sub-daily linear and nonlinear $T_{w}$ models will be significantly different $(\mathrm{CI}=95 \%)$.

6.) $\mathrm{H}_{\mathrm{o}}$ : Model evaluation results from the original SWAT $\mathrm{T}_{\mathrm{w}}$ model utilized in SWAT 2012 and the new $T_{w}$ model developed by Ficklin et al. (2012) will not be significantly different $(\mathrm{CI}=95 \%)$.

$\mathrm{H}_{\mathrm{a}}$ : Model evaluation results from the original SWAT T $\mathrm{T}_{\mathrm{w}}$ model utilized in SWAT 2012 and the new $T_{\mathrm{w}}$ model developed by Ficklin et al. (2012) will be significantly different $(\mathrm{CI}=95 \%)$. 


\section{CHAPTER II}

\section{METHODS AND MATERIALS}

\section{STUDY SITE}

The study watershed for the following research was the Hinkson Creek Watershed (HCW), located in the Lower Missouri Moreau River Basin (LMMRB, HUC 10300102) (Figure 4). The HCW is approximately 22,790 ha in size. The headwaters of HCW are primarily rural agricultural lands and forested areas; however, the lower reaches are mostly urbanized. Approximately $60 \%$ of the city of Columbia, Missouri is located in the lower elevations of the HCW (MDNR, 2011). The study period for this research included the 2011, 2012, and 2013 water years. A water year dates from October $1^{\text {st }}$ to September $30^{\text {th }}$ and the year of the water year corresponds to the year at the end of the water year on September $30^{\text {th }}$. The population of Columbia, Missouri was estimated to be 113,225 as per 2012 census results (USCB, 2012). The locations of five hydroclimate monitoring stations that provided data used for this research are provided in Table 1 and shown in Figure 4. The reader is referred to Hubbart et al. (2010) for additional information about the watershed and experimental design. Land use information for the study site is provided in Table 2.

Table 1. Locations of five nested hydroclimate stations in Hinkson Creek Watershed located in central Missouri, U.S.A.

\begin{tabular}{|c|c|}
\hline Gauging site & Location (meters) \\
\hline Site \#1 & $922460 \mathrm{~W} 3902363 \mathrm{~N}$ \\
\hline Site \#2 & 922793W 3898230N \\
\hline Site \#3 & $923053 \mathrm{~W} 3894818 \mathrm{~N}$ \\
\hline Site \#4 & 923398W 3892783N \\
\hline Site \#5 & $924001 \mathrm{~W} 3891411 \mathrm{~N}$ \\
\hline
\end{tabular}


Table 2. Cumulative contributing area of sub-basins and land use type in the Hinkson Creek Watershed, central Missouri, USA. LULC percent areas are shown in parentheses. All LULC data were obtained from the MSDIS website. The LULC data were collected in 2005.

\begin{tabular}{llllllll}
\hline Subbasin & $\begin{array}{l}\text { Total } \\
\text { Area } \\
\left(\mathrm{km}^{2}\right)\end{array}$ & $\begin{array}{l}\text { Stream } \\
\text { Length } \\
(\mathrm{km})\end{array}$ & $\begin{array}{l}\text { Stream } \\
\text { Width } \\
(\mathrm{m})\end{array}$ & $\begin{array}{l}\text { Urban } \\
\left(\mathrm{km}^{2}\right)\end{array}$ & $\begin{array}{l}\text { Pasture / } \\
\text { Crop } \\
\left(\mathrm{km}^{2}\right)\end{array}$ & $\begin{array}{l}\text { Forested } \\
\left(\mathrm{km}^{2}\right)\end{array}$ & $\begin{array}{l}\text { Wetland/ } \\
\text { Water } \\
\left(\mathrm{km}^{2}\right)\end{array}$ \\
\hline Site \#1 & 77 & 20 & 12.2 & $3.9(5)$ & $43.9(57)$ & $27.7(36)$ & $1.5(2)$ \\
Site \#2 & 101 & 27 & 16 & $6.1(6)$ & $56.6(56)$ & $36.4(36)$ & $2.0(2)$ \\
Site \#3 & 114 & 32 & 13.4 & $12.5(11)$ & $58.1(51)$ & $41.0(36)$ & $2.3(2)$ \\
Site \#4 & 180 & 40 & 18.4 & $28.8(16)$ & $82.8(46)$ & $64.8(36)$ & $3.6(2)$ \\
Site \#5 & 206 & 49 & 14.1 & $47.4(23)$ & $84.5(41)$ & $70.0(34)$ & $4.1(2)$ \\
\hline
\end{tabular}




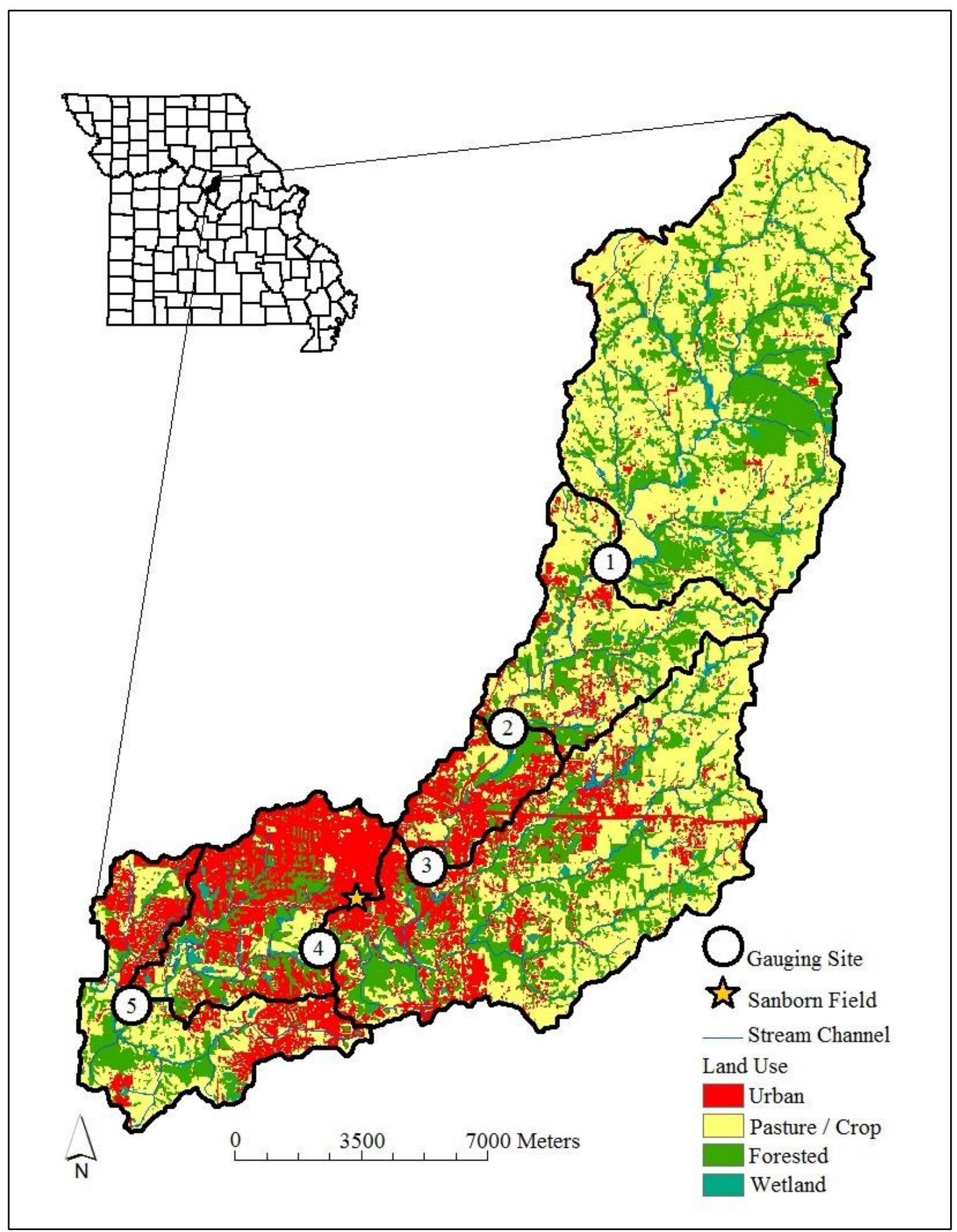

Figure 4. Location of hydroclimate monitoring sites and respective subbasins containing various land use types of the Hinkson Creek Watershed, central Missouri, USA. Sanborn Field meteorological monitoring station is located on the University of Missouri campus. 


\section{Climate}

Climate in Missouri is dominated by maritime and continental tropical air masses in the summer and continental polar air masses in the winter (Nigh and Shroeder, 2002, Hubbart et al. 2010). Average annual total precipitation was $1082 \mathrm{~mm}$ and average annual $\mathrm{T}_{\mathrm{a}}$ was $14{ }^{\circ} \mathrm{C}$ (30 year record) (Hubbart and Zell, 2013). Data from Sanborn Field climate station (located on University of Missouri campus) indicated average annual total precipitation, mean $\mathrm{T}_{\mathrm{a}}$ and total daily solar radiation of $1037 \mathrm{~mm}, 13.4{ }^{\circ} \mathrm{C}$ and 14.5 $\mathrm{MJ} / \mathrm{m}^{2}$, respectively, from 2000 through 2013 in Columbia (14 year record). The wettest months in Missouri are March through June, while the driest months are November to March (Hubbart et al. 2013).

\section{Hydrology}

Hinkson Creek (HC) is approximately 42 linear kilometers in length; flowing southwesterly from the headwaters in Hallsville, Missouri through Columbia, Missouri to its confluence with Perche Creek. After its confluence with Perche Creek, Hinkson Creek flows approximately 18 kilometers (including meandering) through Perche Creek to its confluence with Missouri River. Elevation of Hinkson Creek ranges from $274 \mathrm{~m}$ above mean sea level in headwater to $177 \mathrm{~m}$ above mean sea level at the confluence of Perche Creek (Hubbart et al. 2010; Freeman, 2011). Stage of Hinkson Creek has been intermittently monitored since 1967 at a U.S. Geological Survey gauging station (\#06910230) located $122 \mathrm{~m}$ downstream of Providence Road in the city of Columbia, MO. U.S. Geological Survey gauging station (\#06910230) corresponds to site \#4 (Figure 4). Mean annual discharge from 1967-1981, 1986-1991, and 2007-2013 was $1.73 \mathrm{~m}^{3} / \mathrm{s}$. 
Four other stream gauge stations, co-located with meteorological sites, were installed in winter 2008 (see sub section "Nested Hydroclimate Stations" below for more information.

\section{Soil and vegetation}

Soils in the HCW are comprised of poorly drained to well drained prairie-forest transitional soils (Perkins, 1995). Soils in the headwater portion of HCW are loamy loess with an underlying claypan, while soils in the lower reaches of HCW are composed of silty and sandy clay (Chapman et al. 2002). Floodplain alluvial soils in the lower reaches have infiltration rates that vary dramatically from agricultural sites (porosity $=0.5 \mathrm{~g} / \mathrm{cm}^{3}$, bulk density $=1.33 \mathrm{~g} / \mathrm{cm}^{3}$ ) to bottom land hardwood forest sites (porosity $=0.51 \mathrm{~g} / \mathrm{cm}^{3}$, bulk density $=1.31 \mathrm{~g} / \mathrm{cm}^{3}$ ) ranging from 0.1 to $126.0 \mathrm{~cm} / \mathrm{hr}$, respectively (Hubbart, 2011). Soils outside of the alluvium in the lower reaches are composed of a cherty clay solution residuum corresponding to the Weller-Bardley-Clinkenbeard (CBC) association (Hubbart and Zell, 2013). Upland hardwood forests in the HCW are dominated by oak species. Bottomland hardwood forests in the HCW are dominated by woody species including Acer saccharinum (silver maple), Acer negundo (boxelder), Ulmus americana (American elm), Populus deltoides (eastern cottonwood), and Juglans nigra (black walnut) (Hubbart et al. 2011), Salix spp. (willows), Betula spp. (birches), Platanus occidentalis (sycamores), Tilia spp. (basswoods), and woody shrubs (MDNR 2006). 


\section{Water quality}

Approximately $39 \mathrm{~km}$ of Hinkson Creek was listed as impaired under section 303(d) of the federal Clean Water Act in 1998 (Hubbart et al. 2010). While the pollutant resulting in initial 303(d) listing is listed as unknown, the stream is currently deemed impaired for protection of warm water aquatic life (EPA, 2011). Urban land use is suspected to have caused the majority of impairment (EPA, 2011). In 2011 a TMDL was developed for Hinkson Creek that used "storm water runoff as a surrogate for multiple pollutants and stressors associated with urban storm water" (EPA, 2011). Given the lack of understanding pertaining to impairment, further investigation is greatly needed to validate the assumption that stormwater reduction will remediate the water quality problems in $\mathrm{HCW}$. This research investigated $\mathrm{T}_{\mathrm{w}}$ because of its known importance pertaining to water quality and aquatic ecosystem health.

Nested-scale experimental watershed study design

Hinkson Creek Watershed was instrumented with a nested-scale experimental watershed study design in fall of 2008 that partitioned the HCW into five subbasins (Hubbart et al. 2010). Each subbasin was characterized by different dominant land use types (e.g. site \#1 is mainly agricultural, while site \#5 is mainly urban). Hydroclimate stations monitor solar radiation, $\mathrm{T}_{\mathrm{w}}, \mathrm{T}_{\mathrm{a}}$, and a suite of additional variables in each subbasin (Hubbart et al. 2013). At the time of the current study, site 1, the largest subbasin at $77 \mathrm{~km}^{2}$, and site \#2 were mostly rural subbasins, while sites \#3,\# 4, and \#5 were primarily urbanized subbasins (see Table 2 above) (Hubbart et al. 2010). 


\section{DATA COLLECTION}

Hydroclimate data

Solar powered hydroclimatic stations were installed at the top of the stream bank at each gauging site. Data loggers were housed in an air tight box located $>2 \mathrm{~m}$ above the top of the stream bank. Rechargeable desiccant bags were placed inside the air tight boxes to keep water vapor from damaging the electronic data loggers. Desiccant bags were changed approximately once every two months. Solar panels and sensors that measure meteorological variables (i.e. rain gauge, pyrometer, anemometer, and $\mathrm{T}_{\mathrm{a}} / \mathrm{Rh}$ sensors) were installed on steel (pipe) masts three meters above the ground at all sites. Instream $T_{w}$ and stage sensors were installed inside of conduit to protect the cables from any potential damage. The conduit for the $T_{\mathrm{w}}$ and stage sensors were buried $10 \mathrm{~cm}$ below the soil surface and covered with soil and rip-rap (large rock). The tips of the $\mathrm{T}_{\mathrm{w}}$ and stage sensors were located under and over each other (respectively) low enough to record the lowest expected stage. All the instruments required for the current research are described in Table 3. Hydroclimate data were sensed every 30 seconds, and averaged and logged (i.e. stored in Campbell Scientific CR-1000 data loggers) at each site every five minutes. 
Table 3. Instrumentation installed at gauging sites along Hinkson Creek, Missouri, USA, and associated variables sensed, necessary for the current work.

\begin{tabular}{|c|c|c|}
\hline Instrument & Measurement & Accuracy \\
\hline TE525WS Rain Gauge & Precipitation in $\mathrm{mm}$ & $\begin{array}{l}+1 \% \text { at } 1 \mathrm{in} / \mathrm{hr} \text { rainfall rate } \\
\text { to }-3.5 \% \text { at } 2 \text { to } 3 \mathrm{in} / \mathrm{hr} \\
\text { rainfall rate }\end{array}$ \\
\hline LI200X, LICOR pyrometer & Solar Radiation in $\mathrm{W} / \mathrm{m}^{2}$ & $\pm 5 \%$ \\
\hline MET1 034B & $\begin{array}{l}\text { Wind speed in } \mathrm{m} / \mathrm{s} \text { and } \\
\text { wind direction in degrees }\end{array}$ & $\begin{array}{l} \pm 0.11 \mathrm{~m} / \mathrm{s} \text { at }<10.1 \mathrm{~m} / \mathrm{s} \text { to } \\
\pm 1.1 \% \text { at }>10.1 \mathrm{~m} / \mathrm{s}\end{array}$ \\
\hline $\begin{array}{l}\text { Sutron Accubar® Constant } \\
\text { Flow Bubble } \\
\text { Gauge/Recorder } 560133\end{array}$ & Water stage in $\mathrm{mm}$ & $\begin{array}{l}0.02 \% \text { at } 0-25 \mathrm{ft} \text { to } 0.05 \% \text { at } \\
26-50 \mathrm{ft}\end{array}$ \\
\hline $\begin{array}{l}\text { Campbell Scientific, Inc. } \\
\text { Model HMP45C } \\
\text { Temperature and Relative } \\
\text { Humidity Probe with } \\
\text { radiation shield }\end{array}$ & $\begin{array}{l}\text { Air temperature in }{ }^{\circ} \mathrm{C} \text { and } \\
\text { relative humidity in } \%\end{array}$ & $\begin{array}{l} \pm 0.2^{\circ} \mathrm{C} \text { at } 20^{\circ} \mathrm{C} \text { to } \pm 0.5 \text { at } \\
<-40{ }^{\circ} \mathrm{C} \text { and }>60{ }^{\circ} \mathrm{C}\end{array}$ \\
\hline $\begin{array}{l}\text { Campbell Scientific, Inc. } \\
\text { Model } 107 \text { Temperature } \\
\text { Probe }\end{array}$ & Water temperature in ${ }^{\circ} \mathrm{C}$ & $\pm 0.2^{\circ} \mathrm{C}$ \\
\hline Thermochron iButtons & Water temperature in ${ }^{\circ} \mathrm{C}$ & $\pm 0.1^{\circ} \mathrm{C}$ \\
\hline
\end{tabular}

Sudden rises in $T_{w}$ due to summer thunderstorms

To investigate urban land use effects on stream heating, Thermochron iButtons (temperature sensors) were deployed during summer 2009 (June $1^{\text {st }}$ to August $31^{\text {st }}$ ).

Thermochron iButtons are digital temperature sensors that can log up to 2048 data points from 1 to 255 time intervals (Hubbart et al. 2005). The temperature sensors were small (about the size of a stack of five dimes), durable, and produced accurate $\left( \pm 1.0^{\circ} \mathrm{C}\right)$ temperature results making them well suited for hydrologic and water quality research (Hubbart et al. 2005). The temperature sensors were programmed to $\log \mathrm{T}_{\mathrm{w}}$ data at each location every 15 minute. Each temperature sensor was placed in a 2" by 4" piece of PVC 
pipe that was anchored in stormwater drains so that the pipe was oriented with flow. The PVC pipes served as a radiation shield.

\section{Stage Data and Rating Curves}

Each nested hydroclimate station was equipped with a Sutron Accubar® Constant Flow Bubble Gauge and Recorder designed to measure stage. Stage was measured every second (Sutron, 2008). One second data were averaged and stored every five minutes. Rating curves were used to accurately estimate stream discharge by developing a relationship between stage and equivalent manually measured stream discharge (Dottori et al. 2009). In the development of a rating curve, stage is the independent variable, and stream discharge is the dependent variable. For the current research, the incremental cross section method was used to manually measure stream discharge in order to develop rating curves. In the development of rating curves, a power function is commonly used (Yu, 2000). A power function was fit to the measured stage and stream discharge data. The power function is as follows:

$$
Q=a h^{b}
$$

where $Q$ and $h$ are instantaneous stage and stream discharge values and $a$ and $b$ are constants (Yu, 2000). Polynomial functions are also commonly used when developing a rating curve (Herschy, 1985; Krashnikikov, 1987):

$$
Q^{\prime}=\beta_{0}+\beta_{1} H^{1}+\beta_{2} H^{2}+\cdots+\beta_{m} H^{m}
$$

where $Q^{\prime}$ is discharge, $\beta$ is a fitted parameter, $H$ is stage, and $m$ is the exponent of the polynomial function. A piecewise approximation of stage and flow rate regressions is recommended when the relationship of stage and flow rate become too complex 
(Shiklomanov et al. 2005). In this study, recent rating curves formulated by Freeman (2011), and Scollan (2011), were used to calculate estimates for total stream discharge, and stream discharge statistics (Table 4) (Shiklomanov et al. 2005). Additional cross section data collected in the spring of 2013 were used to update current rating curves.

Table 4. Rating equations for five gauging stations in Hinkson Creek, Missouri, USA. Variables $\alpha_{0}$ are constants, $\alpha_{1}$ to $\alpha_{3}$ are regression coefficients, and $\kappa$ are exponential constants used in regression equations.

\begin{tabular}{llllll}
\hline Equation & HCW \#1 & HCW \#2 & HCW \#3 & HCW \#4 & HCW \#5 \\
\hline Linear & $(0-0.552)$ & $(0-0.464)$ & $(0-0.120)$ & $(0-0.303)$ & -- \\
$\alpha_{1}$ & 0.0472 & 0.4163 & 1.35902 & 0.8286 & -- \\
\hline Polynomial & $(0.552-m a x)$ & $(0.464-m a x)$ & $(0.120-0.363)$ & $(0.303-\max )$ & -- \\
$\alpha_{3}$ & 12.794 & 4.3007 & 17.57 & 0.7788 & -- \\
$\alpha_{2}$ & 17.502 & 21.944 & 7.0615 & 17.908 & -- \\
$\alpha_{1}$ & 10.57 & 20.288 & 3.94 & 9.249 & -- \\
$\alpha_{0}$ & 2.6548 & 4.4526 & 0.238 & 1.1784 & -- \\
\hline Power & -- & -- & $(0.363-\max )$ & -- & $(0-$ max $)$ \\
$\alpha_{1}$ & -- & -- & 15.061 & -- & 5.136 \\
$\kappa$ & -- & -- & 2.5797 & -- & 1.8118 \\
\hline
\end{tabular}

\section{Backwatering}

Backwatering in Hinkson Creek was observed during WY 2011 when stage in Missouri River rose above $8.5 \mathrm{~m}$ at Booneville, Missouri located approximately $30 \mathrm{~km}$ west of Columbia, Missouri. Missouri River discharge was $7363.2 \mathrm{~m}^{3} / \mathrm{s}$ at Booneville, Missouri. Measured discharge at HCW site \#5 was affected for 111 days (Figure 5) during that time period. The affected discharge data at site \#5 were interpolated using measured discharge data from the nearest upstream gauging site, site \#4 (USGS gauging station). First, the affected discharge data at site \#5 were delineated and deleted in Excel. 
Next, a power regression analysis was performed in Excel to calculate the relationship between discharge data at site \#4 and site \#5. Finally, the discharge data at site \#5 were interpolated using the following equation from the power regression analysis $(\mathrm{n}=70)$ $\left(r^{2}=0.92\right)$ :

$$
y=2.1391 x^{0.9014}
$$

where $\mathrm{y}$ is discharge at site $\# 5$ and $\mathrm{x}$ is discharge at site \#4. 


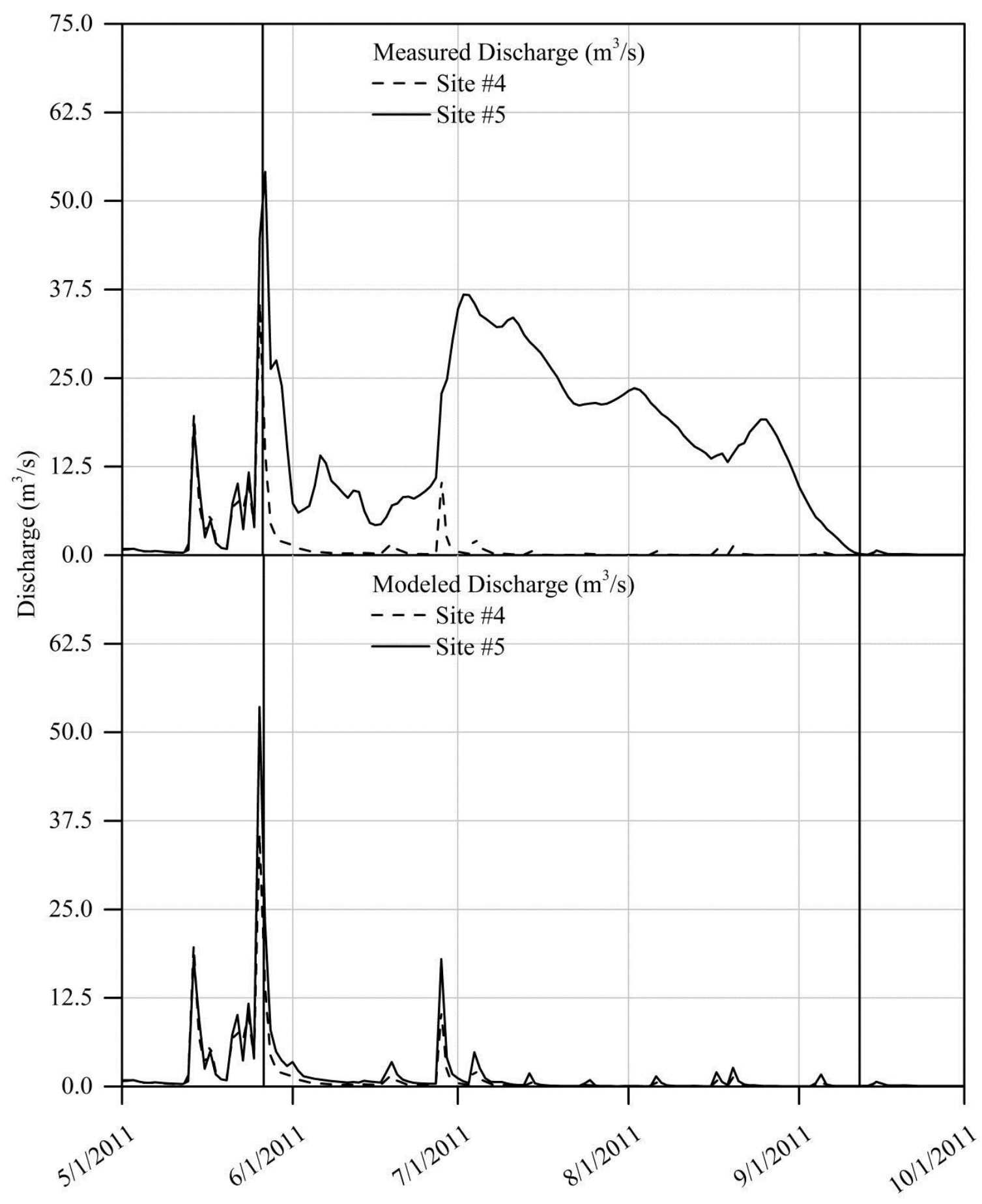

Figure 5. Backwatering phenomenon observed during 111 days of summer 2011 recorded at site \#5 located in Hinkson Creek Watershed, Missouri, USA. Black vertical lines delineate a period of back watering that was modeled out using discharge data from site \#4 (USGS gauging station number 06910230). 


\section{Land use data}

Silva and Williams (2001) used an earlier version of ArcGIS (ArcView) to study land use effects on river quality. For the current study similar analyses methods were performed, using ESRIC ArcGIS10 software, to determine subbasin areas and land use cover classes. The Missouri Spatial Data Information Service (MSDIS) website (http://www.msdis.missouri.edu) contained all necessary LULC data for this project. The most recent available LULC data (LULC data created in 2005) on the MSDIS website were used. LULC data are presented in Table 5.

Table 5. Land use land cover (LULC) data for the current research. All LULC data were obtained from the MSDIS website with the exception of the SSURGO soils data set. The SSURGO soils data set was acquired from online from NRCS.USDA.gov.

\begin{tabular}{|c|c|c|c|c|}
\hline Data & $\begin{array}{l}\text { Projected Coordinate } \\
\text { System }\end{array}$ & Feature Class & Units & Year Created \\
\hline Hydrology & $\begin{array}{l}\text { NAD } 1983 \text { State Plane } \\
\text { Missouri central FIPS } 2402\end{array}$ & Arc & Meter & 2003 \\
\hline LULC & $\begin{array}{l}\text { NAD } 1983 \text { State Plane } \\
\text { Missouri central FIPS } 2402\end{array}$ & Arc & Meter & 2005 \\
\hline County & $\begin{array}{l}\text { NAD } 1983 \text { State Plane } \\
\text { Missouri central FIPS } 2402\end{array}$ & Arc & Meter & 2003 \\
\hline DEM & $\begin{array}{l}\text { NAD } 1983 \text { UTM Zone } \\
15 \mathrm{~N}\end{array}$ & Raster & 30 Meter & 2003 \\
\hline Soils & $\begin{array}{l}\text { NAD } 1983 \text { UTM Zone } \\
15 \mathrm{~N}\end{array}$ & Raster & 30 Meter & 2011 \\
\hline State & $\begin{array}{l}\text { NAD } 1983 \text { UTM Zone } \\
15 N\end{array}$ & Polygon & Meter & 2003 \\
\hline
\end{tabular}

To determine subbasin areas in HCW a point shape file was created from XY coordinates (Table 1) of the gauging sites in HCW. ESRIC ArcGIS10 spatial analyst hydrology tools were used to delineate the HCW and its subbasins. Land use/land cover 
data were extracted by mask to the extent of a polygon representing the delineated subbasins within the HCW. Finally, tables containing the quantity of each LULC type within each subbasin were exported for further analysis.

\section{DATA ANALYSIS}

\section{Hydroclimate data analysis}

Hydroclimate data including $\mathrm{T}_{\mathrm{w}}, \mathrm{T}_{\mathrm{a}}$, and stream discharge from the 2011, 2012, and 2013 water years were reduced (by averaging the time series data into several time steps) and graphed. The time steps considered were 15 minute, hourly, daily, weekly, monthly, seasonal, and water year. The seasonal time step divided the water year into three seasons; October $1^{\text {st }}-$ January $31^{\text {st }}$, February $1^{\text {st }}-$ May $31^{\text {st }}$, and June $1^{\text {st }}-$

September $30^{\text {th }}$. The water year time step began October $1^{\text {st }}$ and ended September $30^{\text {th }}$ of the following year. Post processing of hydroclimate data to replace missing or erroneous data points was performed as needed with mathematical models using data from the Sanborn Field weather station and USGS gauging station (site \#4).

Descriptive statistics were calculated including mean, minimum, maximum, median, and standard deviation of daily hydroclimate data. High resolution (15 minute interval) $T_{w}$ data were also examined with descriptive statistics, and for the days $T_{w}$ was above $32^{\circ} \mathrm{C}$ and $35^{\circ} \mathrm{C}$ [similar to the work of Sinokrot and Gulliver (2000)].

Additionally, the maximum duration $\mathrm{T}_{\mathrm{w}}$ was above $32{ }^{\circ} \mathrm{C}$ and $35^{\circ} \mathrm{C}$ was analyzed.

Monk et al. (2008) used one way Analysis of Variance (p>0.05) and TukeyKramer multiple comparison test to test for significant differences in hydroclimate measurements between multiple gauging stations. In this study, similar methods were 
conducted using statistics software (Origin) at a 95\% CI ( $\alpha=0.05)$. Tukey-Kramer is an effective test for significant difference in means between all sites, like ANOVA, but can elucidate specifically which sites differ. Tukey-Kramer was used for this research because it produces more narrow confidence intervals than other post-hoc multiple comparison tests (Stoline, 1981).

ANOVA is dependent on sample size ( $n$ ) (Bonett, 2002). As $n$ increases, the observed mean of a sampled population is closer to the "true mean". The true mean is the mean of the population if every individual, or in this case every possible temperature sample, were considered in the calculation. If the observed mean were equal to the true mean, then there would be no doubt that any differences in mean would be "significant", meaning free from the error associated with estimating the true mean with only a small part of the population. However, the observed mean will never equal the true mean when sampling a continuum, no matter how many samples are collected, because a continuum, by definition, is infinite and it's impossible to collect an infinite amount of samples. Therefore, statistical tests like ANOVA were created to be less dependent on sample size to quantitatively test for significant differences in means. As sample size increases, there is a less likely chance that differences in means are due to error associated with estimating the true mean using only a small part of the population. Thus, any differences in observed means are more likely to be significant. There are more costs associated with sampling high resolution data for long time periods compared to low resolution data for short time periods; however, one major benefit is increased $n$ provides an increased confidence that any results derived with the use of statistics are error free, or significant (Peck and Devore, 2012). 


\section{Sudden rises in $T_{w}$ due to summer thunderstorms}

As per the work of Nelson and Palmer (2007), temperature time series were examined to quantitatively characterize sudden rises in stormwater temperature $\left(\mathrm{T}_{\mathrm{w}}\right.$ surge) due to summer thunderstorms in stormwater inputs that flow into Hinkson Creek. $\mathrm{T}_{\mathrm{w}}$ surges following summer thunderstorms, defined as sudden rises of $>1{ }^{\circ} \mathrm{C}$ increase in $\mathrm{T}_{\mathrm{w}}$ within a 15 minute time period (Anderson et al. 2011), were verified with a TE525WS Rain Gage located $<50 \mathrm{~m}$ from the $\mathrm{T}_{\mathrm{w}}$ sensor. Results indicating date and time of surge, pre-surge $T_{w}$, peak surge $T_{w}, T_{w}$ surge (calculated as the difference between pre-surge and peak surge $T_{w}$ ), and $T_{w}$ surge duration (defined as the time required for $T_{w}$ to return to pre-surge $T_{w}$ ) for each sensor were calculated in Excel (Nelson and Palmer, 2007; Rice et al. 2010; Anderson et al. 2011). The summer season (June $1^{\text {st }}$ to August $31^{\text {st }}$ ) of stormwater $\mathrm{T}_{\mathrm{w}}$ data were analyzed for the summer of 2009. Additionally, in-stream $\mathrm{T}_{\mathrm{w}}$ data were analyzed for the 2010, 2011, 2012, and 2013 water years.

\section{The effects of discharge on stream water temperature}

The effects of stream discharge on $\mathrm{T}_{\mathrm{w}}$ and the $\mathrm{T}_{\mathrm{w}} / \mathrm{T}_{\mathrm{a}}$ relationship were analyzed by performing statistical analyses above and below median discharge values for each site similar to the work of Webb et al. (2003). Separating mean $\mathrm{T}_{\mathrm{w}}$ into different flow classes similar to the methods used by Webb et al. (2003) elucidated $\mathrm{T}_{\mathrm{w}}$ at each gauging site in Hinkson Creek relative to flow. The $<50 \%$ flow class best represented $\mathrm{T}_{\mathrm{w}}$ during periods of low flow, or base flow. The $>50 \%$ flow class best represented stormflows. To investigate $\mathrm{T}_{\mathrm{w}}$ during stormflow periods in the current work flow classes $>50 \%$ were separated into an additional four flow classes $(>60,>70,>80$, and $>90 \%)$. The $>90 \%$ 
flow class represented peakflows. The $90 \%$ flow class was also separated into an additional nine flow classes. The $>99 \%$ flow class showed $\mathrm{T}_{\mathrm{w}}$ when Hinkson Creek was close to or overbank full. Time series mean discharge, $\mathrm{T}_{\mathrm{a}}$, and $\mathrm{T}_{\mathrm{w}}$ data were first sorted in ascending order according to discharge value. Then, mean discharge, $T_{a}$, and $T_{w}$ were recorded for each flow class and tested for significant differences $(\mathrm{p}>0.5)$.

\section{Stream and air temperature relationships}

As mentioned earlier (see introduction), a common method for analyzing $\mathrm{T}_{\mathrm{w}}$ and $\mathrm{T}_{\mathrm{a}}$ relationships includes development of regression models (Webb et al. 2003; Caissie, 2006; Webb et al. 2008). Therefore, linear regression analyses (equation 1), and nonlinear regression analyses (equation 2) were performed using mean $\mathrm{T}_{\mathrm{w}} \mathrm{vs}$. mean $\mathrm{T}_{\mathrm{a}}$ data for each site at 15 minute, hourly, daily, weekly, monthly, and seasonal time steps using statistics software (Origin). Results from regression analyses were used to create $T_{w}$ models.

Because accounting for time lag (Figure 3) with cross-correlation analysis was previously shown to improve results of $\mathrm{T}_{\mathrm{w}} / \mathrm{T}_{\mathrm{a}}$ regression analysis (Webb et al. 2003), cross-correlation analyses were performed in the current work using the cross correlation function $(\mathrm{CCF})$ :

$$
R_{k}=\frac{\sum_{t=1}^{n-k}\left(x_{t}-\mu_{x}\right)\left(y_{t}+k-\mu_{y}\right)}{s_{x} s_{y}}
$$

where $R_{k}$ is the correlation coefficient at lag $k, n$ is the number of observations, $t$ is time, $k$ is the lag, $\mu_{x}$ is mean $\mathrm{T}_{\mathrm{a}}, \mu_{y}$ is mean $\mathrm{T}_{\mathrm{w}}, s_{x}$ is computed using the following equation:

$$
s_{x}=\sqrt{\sum_{t=1}^{n}\left(x-\mu_{x}\right)^{2}}
$$


$s_{y}$ is calculated with the following equation:

$$
s_{y}=\sqrt{\sum_{t=1}^{n}\left(y-\mu_{y}\right)^{2}}
$$

$R_{k}$ values range from 0 and 1.0. A value of zero is no correlation. A value of 1 is a perfect correlation.

Ultimately, results from the CCF can be used to quantify the optimum amount of time lag between $\mathrm{T}_{\mathrm{a}}$ and $\mathrm{T}_{\mathrm{w}}$ time series. Cross correlation analyses produced a time series of $R_{k}$ values for each time lag $k$. The optimum amount of time lag was the value of $k$ that corresponds with the maximum $R_{k}$ value in the $R_{k}$ time series. Once time lag was known, the $\mathrm{T}_{\mathrm{a}}$ time series was shifted forward the appropriate amount of time lag. For example, if maximum $R_{k}$ value in the $R_{k}$ time series corresponded to $k=1$, then the entire $\mathrm{T}_{\mathrm{a}}$ time series was shifted forward one unit of time. Results from cross-correlation analyses were used to improve $\mathrm{T}_{\mathrm{w}}$ models.

To further improve $\mathrm{T}_{\mathrm{w}}$ models, calibration coefficients were added to the 15 minute linear stream water temperature model. A 15 minute "calibrated linear stream water temperature model" was created in Origin for each gauging site. Sub-daily time series $\mathrm{T}_{\mathrm{w}}$ data resembled a sin curve over the course of a day. By adding calibration coefficients to the 15 minute linear $\mathrm{T}_{\mathrm{w}}$ models, the amplitude of the sin curve was decreased. Simulated 15 minute stream water temperature estimates were weighted to daily mean $\mathrm{T}_{\mathrm{a}}$ for each day of simulation using the following equation:

$$
\begin{aligned}
& T_{w}=\alpha\left(b_{0}+b_{1} * x\right)+\beta\left(\Delta T_{a}\right) \\
& \alpha+\beta=1
\end{aligned}
$$

where $T_{w}$ is stream water temperature, $b_{1}$ is the independent variable (e.g. $\mathrm{T}_{\mathrm{a}}$ ), $b_{0}$ is $T_{w}$ at the $y$-intercept, $x$ is the slope of the linear relationship between the dependent variable 
and the independent variable, $\Delta T_{a}$ is daily mean $\mathrm{T}_{\mathrm{a}}$ for the day of simulation, and $\alpha$ and $\beta$ are calibration coefficients.

The calibrated linear stream water temperature models were forced and calibrated in Excel using observed $\mathrm{T}_{\mathrm{a}}$ data from each Hinkson Creek gauging site and linear regression coefficients derived from linear regression analyses (time lag was accounted for). After the model was calibrated at a 15 minute time step, the model outputs were reduced in Excel by averaging 15 minute data to hourly and daily time steps.

The effects of discharge on $T_{w}$ and $T_{a}$ relationships

The effects of stream discharge on $\mathrm{T}_{\mathrm{w}} / \mathrm{T}_{\mathrm{a}}$ relationships were analyzed by performing statistical analyses above and below median discharge values for each site similar to the work of Webb et al. (2003). First, hydroclimate data were separated into 15 different flow classes by sorting time series data sets in ascending order according to discharge value. Then, regression analyses were performed on time series $T_{w}$ and $T_{a}$ data for each flow class (Webb et al. 2003). Finally, coefficient of determination values $\left(\mathrm{r}^{2}\right.$ values) were compared and contrasted. The $r^{2}$ values quantify the total variation in $y$ values attributed to the model relationship (Moriasi et al. 2007).

\section{SWAT modeling}

The current SWAT T $\mathrm{w}_{\mathrm{w}}$ model (SWAT 2012) (equation 4) was manually configured in Microsoft Excel, and forced with $\mathrm{T}_{\mathrm{a}}$ data collected from five hydroclimate sites in HCW. Next, the new SWAT T ${ }_{\mathrm{w}}$ model, developed by Ficklin et al. (2012) 
(equations 5, 6, 7, and 8) was forced in Microsoft Excel using input data extracted from SWAT 2012.

To acquire the needed forcing data to run the Ficklin et al. (2012) $\mathrm{T}_{\mathrm{w}}$ model, a SWAT 2012 project was created using ArcSWAT 2012. The watershed was delineated using the automatic watershed delineation option in ArcSWAT. The needed input files for watershed delineation, land use, soils, and slope are provided above in Table 5. The SSURGO soils input files were edited using the SWAT editor tool found on the SWAT website. The slope classes were defined as a single slope. Weather input data from the five Hinkson Creek hydroclimatic stations and Sanborn Field weather station. When prompted to change "Manning's n" default values, overland flow Manning's n was set to 0.065, and channel flow Manning's n was set to 0.05. Troubleshooting problems encountered while attempting to "Write Input Tables" were addressed by mining online SWAT forums and via email communications with the SWAT development team members Georgie Mitchell, and Nancy Sammons.

Once the SWAT project was successfully parameterized, SWAT model watershed general input data parameters under the pathway "Edit SWAT Input" > "Watershed Data" were edited as follows:

- Potential ET method was "Penman-Monteith"

- Crack flow was set to "Active"

- Channel routing was set to "Muskingum"

- Channel degradation was set to "Active"

- Pesticide routing was left blank. 
Hydrologic Response Units (HRU's) files (format .hru) were edited to show land use practices realistic for Hinkson Creek Watershed. Agricultural HRU's were set to a corn-soybean rotation with three fertilization operations (anhydrous ammonia, elemental nitrogen, and elemental phosphorus) and tandem disk tillage. Pasture HRU's were set to a grazing operation. Urban HRU's were set to a fescue growing operation by default, but lawn fertilization and street sweeping operations were scheduled by keying in a schedule into SWAT management operations tab.

SWAT was manually calibrated and validated for flow at a daily time step using discharge data from the five Hinkson Creek gauging sites. Water years 2010, 2011, and 2012 were used for calibration and water year 2013 was used for validation. To enhance the reliability of SWAT model calibration and validation results, SWAT was calibrated at site \#5 nearest the watershed outlet as well as the 4 nested subbasins concurrently. Each subbasin was calibrated in order of increasing downstream distance from site \#1 in the headwaters to site \#5 nearest the watershed outlet. During manual calibration of SWAT several parameters were adjusted including curve number $(\mathrm{CN})$, alpha base flow (ALPHA_BF), SURLAG, and ESCO. The parameters were chosen for adjustment during calibration because they were among the most adjusted parameters for streamflow calibration found in the literature as reported by in a review by Arnold et al. (2012). All CN's (CN2 and CNOP) were increased by 3 simultaneously using the SWAT manual calibration helper tool. The pathway to the SWAT manual calibration helper tool is "SWAT Simulation" > "Manual Calibration Helper". ALPHA_BF was increased by 0.4 in the groundwater input files (.gw). The SURLAG value was set to 1.0 in the basin input files (.bsn). And, ESCO was set to 1.0 using the SWAT manual calibration helper tool. 


\section{Model evaluation}

Moriasi et al. (2007) suggested the use of three model evaluation criteria to assess hydrologic model performance including Nash-Sutcliffe efficiency (NSE), ratio of root mean square error to the standard deviation of observed data (RSR), and percent bias (PBIAS). In addition to the three model evaluation criteria suggested by Moriasi et al. (2007), three error indices were used to evaluate model efficiency including mean absolute error (MAE), mean squared error (MSE) and root mean squared error (RMSE). Moriasi et al. (2007) suggested general performance ratings for the three aforementioned model evaluation criteria at a monthly time step (Table 6). To be conservative, the current research used the same ratings for evaluation of sub-daily and daily model efficiency.

Table 6. Ratings used in this research to quantitatively evaluate sub-daily and daily model efficiency.

\begin{tabular}{llll} 
Rating & RSR & NSE & PBIAS \\
\hline Very good & $0.30<\mathrm{RSR} \leq 0.50$ & $0.75<\mathrm{NSE} \leq 0.90$ & $\pm 5 \leq$ PBIAS $< \pm 10$ \\
Good & $0.50<\mathrm{RSR} \leq 0.60$ & $0.65<\mathrm{NSE} \leq 0.75$ & $\pm 10 \leq$ PBIAS $< \pm 15$ \\
Satisfactory & $0.60<\mathrm{RSR} \leq 0.70$ & $0.50<\mathrm{NSE} \leq 0.65$ & $\pm 15 \leq \mathrm{PBIAS}< \pm 25$ \\
Unsatisfactory & RSR $>0.70$ & $\mathrm{NSE} \leq 0.50$ & PBIAS $\geq \pm 25$ \\
\hline
\end{tabular}

Nash-Sutcliffe efficiency tests are used to quantify the variance of observed versus simulated data relative to a 1:1 best fit line NSE values range between $\infty$ and one, where an NSE value of one is a perfect simulation. Any NSE value greater or equal to zero indicates that the simulated value estimated the constituent of concern better than the mean observed value. NSE values can be calculated using the following equation: 


$$
N S E=1-\left[\frac{\sum_{i=1}^{n}\left(Y_{i}^{o b s}-Y_{i}^{\text {sim }}\right)^{2}}{\sum_{i=1}^{n}\left(Y_{i}^{\text {obs }}-Y_{i}^{\text {mean }}\right)^{2}}\right]
$$

where $Y_{i}^{o b s}$ is the $i$ th observed datum for the variable being estimated. $Y_{i}^{\text {sim }}$ is the $i$ th simulated datum for the variable being estimated, $Y_{i}^{\text {mean }}$ is the mean of observed data for the variable being estimated, and $n$ is the total number of observations.

Ratio of root mean square error to the standard deviation is an error index statistic. RSR values of zero equal a perfect simulation. Any RSR value less than 0.50 indicates an acceptable simulation. RSR values can be calculated using the following equation:

$$
R S R=\left[\frac{\sqrt{\sum_{i=1}^{n}\left(Y_{i}^{\text {obs }}-Y_{i}^{\text {sim }}\right)^{2}}}{\sqrt{\sum_{i=1}^{n}\left(Y_{i}^{\text {obs }}-Y_{i}^{\text {mean }}\right)^{2}}}\right]
$$

where $Y_{i}^{o b s}$ is the $i$ th observed datum for the variable being estimated. $Y_{i}^{\text {sim }}$ is the $i$ th simulated datum for the variable being estimated, $Y_{i}^{\text {mean }}$ is the mean of observed data for the variable being estimated, and $n$ is the total number of observations.

Percent bias tests are used to indicate the average tendency of simulated data to be greater than or less than the observed data. Any negative PBIAS value indicates the simulated data were greater than the observed data on average. Conversely, any positive PBIAS value indicates the simulate data were less than the observed data on average. A PBIAS value of zero is a perfect simulation. PBIAS values can be calculated using the following equation:

$$
P B I A S=\left[\frac{\sum_{i=1}^{n}\left(Y_{i}^{o b s}-Y_{i}^{s i m}\right) * 100}{\sum_{i=1}^{n}\left(Y_{i}^{o b s}\right)}\right]
$$

where $Y_{i}^{o b s}$ is the $i$ th observed datum for the variable being estimated. $Y_{i}^{\text {sim }}$ is the $i$ th 
simulated datum for the variable being estimated, and $n$ is the total number of observations.

Mean absolute error (MAE) is estimated to quantify the error in units of observed versus simulated data. MAE values are a measure of the average of the absolute value of the difference between simulated and observed values. MAE values of zero equal a perfect simulation. MAE values can be calculated using the following equation:

$$
M A E=\frac{1}{n} \sum_{i=1}^{n}\left|Y_{i}^{o b s}-Y_{i}^{s i m}\right|
$$

where $Y_{i}^{o b s}$ is the $i$ th observed datum for the variable being estimated. $Y_{i}^{s i m}$ is the $i$ th simulated datum for the variable being estimated, and $n$ is the total number of observations.

Mean square error is calculated to quantify the error in squared units of observed versus simulated data. MSE values are the average of the squared differences between simulated and observed data. MSE values of zero equal a perfect simulation. NSE values can be calculated using the following equation:

$$
M S E=\frac{1}{n} \sum_{i=1}^{n}\left(Y_{i}^{o b s}-Y_{i}^{s i m}\right)^{2}
$$

where $Y_{i}^{o b s}$ is the $i$ th observed datum for the variable being estimated. $Y_{i}^{s i m}$ is the $i$ th simulated datum for the variable being estimated, and $n$ is the total number of observations.

Root mean square error is estimated to quantify the error, in squared units of observed versus simulated data. RMSE is the square-root of the average of the squared differences between simulated and observed data. RMSE values of zero equal a perfect simulation. RMSE values can be calculated using the following equation:

$$
R M S E=\sqrt{M S E}
$$


Finally, graphical representations, and the six aforementioned model evaluation criteria were used to compare the current SWAT $T_{w}$ model, the Ficklin et al. (2012) $T_{w}$ model, Hinkson Creek $\mathrm{T}_{\mathrm{w}}$ models (linear / nonlinear / calibrated linear), and observed data (2011, 2012 and 2013 water years) collected from five hydroclimate sites in Hinkson Creek. 


\section{CHAPTER III}

RESULTS

\section{HYDROCLIMATE}

\section{Climate}

Summary of climate statistics recorded from the five HCW climate stations and the Sanborn Field climate station during the three year study period (WY 2011 - 2013) are shown in Appendix A and descriptive statistics in Table 7. Average annual total precipitation ranged from $803.8 \mathrm{~mm}$ at site $\# 5$ to $872.1 \mathrm{~mm}$ at site $\# 3$ with a six site mean of $837.9 \mathrm{~mm}$. Maximum $\mathrm{T}_{\mathrm{a}}$ during the study period ranged from $40.8^{\circ} \mathrm{C}$ at Sanborn Field to $43.0^{\circ} \mathrm{C}$ at site $\# 3$ with a mean of $41.9^{\circ} \mathrm{C}$. Mean $\mathrm{T}_{\mathrm{a}}$ ranged from $12.3^{\circ} \mathrm{C}$ at site $\# 1$ to 13.9 ${ }^{\circ} \mathrm{C}$ at Sanborn Field with a six site mean of $13.1^{\circ} \mathrm{C}$. Minimum $\mathrm{T}_{\mathrm{a}}$ during the study period ranged from $-30.8^{\circ} \mathrm{C}$ at site $\# 1$ to $-19.8^{\circ} \mathrm{C}$ at Sanborn Field with a six site mean of $-27.2{ }^{\circ} \mathrm{C}$. Mean relative humidity ranged from $65.4 \%$ at Sanborn Field to $71.8 \%$ at site \#1 with a six site mean of $69.3 \%$. Mean wind speed ranged from $0.8 \mathrm{~m} / \mathrm{s}$ at site \#4 to $2.0 \mathrm{~m} / \mathrm{s}$ at Sanborn Field with a six site mean of $1.3 \mathrm{~m} / \mathrm{s}$. Mean daily total solar radiation ranged from $12.9 \mathrm{MJ} / \mathrm{m}^{2}$ at site $\# 4$ to $14.8 \mathrm{MJ} / \mathrm{m}^{2}$ at site $\# 2$ with a six site mean of $13.8 \mathrm{MJ} / \mathrm{m}^{2}$. There were no significant differences found in daily maximum $\mathrm{T}_{\mathrm{a}}$ between sites $(\mathrm{p}=0.66)$. There were, however, significant differences found in daily mean $T_{a}(p=0.01)$ and daily minimum $\mathrm{T}_{\mathrm{a}}(\mathrm{p}<0.01)$. 
Table 7. Summary of daily climate statistics during the study period (WY $2010-2013$ ) for six climate stations located in Hinkson Creek Watershed, Missouri, USA.

*Precipitation (Precip) data are average annual totals. **Solar radiation data are daily totals. Air Temp = Air Temperature. "St. Dev." is standard deviation.

\begin{tabular}{llllllll}
$\begin{array}{l}\text { Climate } \\
\text { Data }\end{array}$ & $\begin{array}{l}\text { Daily } \\
\text { Statistic }\end{array}$ & Site \#1 & Site \#2 & Site \#3 & Site \#4 & Site \#5 & $\begin{array}{l}\text { Sanborn } \\
\text { Field }\end{array}$ \\
\hline *Precip. & Annual & & & & & & \\
$(\mathrm{mm})$ & Total & 838.4 & 826.5 & 872.1 & 866.0 & 803.8 & 820.4 \\
\hline \multirow{2}{*}{ Air Temp } & Max & 31.6 & 32.2 & 33.4 & 32.3 & 32.3 & 33.8 \\
$\left({ }^{\circ}\right.$ C) & Mean & 12.3 & 12.9 & 13.5 & 13.1 & 13.0 & 13.9 \\
& Min & -30.8 & -30.4 & -26.6 & -26.7 & -29.0 & -19.8 \\
& St. Dev. & 10.6 & 10.7 & 10.7 & 10.5 & 10.6 & 10.6 \\
\hline \multirow{2}{*}{ Relative } & Max & 97.7 & 98.0 & 98.0 & 97.1 & 99.4 & 98.0 \\
Humidity & Mean & 71.8 & 70.3 & 67.5 & 70.8 & 70.0 & 65.4 \\
$(\%)$ & Min & 33.6 & 33.0 & 32.3 & 33.5 & 32.5 & 32.7 \\
& St. Dev. & 11.4 & 11.3 & 12.1 & 10.8 & 11.0 & 13.4 \\
\hline \multirow{2}{*}{ Wind } & Max & 5.2 & 3.8 & 4.1 & 3.0 & 4.1 & 5.3 \\
Speed & Mean & 1.3 & 1.1 & 1.2 & 0.8 & 1.3 & 2.0 \\
$(\mathrm{~m} / \mathrm{s})$ & Min & 0.0 & 0.0 & 0.0 & 0.0 & 0.0 & 0.0 \\
& St. Dev. & 0.7 & 0.6 & 0.6 & 0.4 & 0.6 & 0.7 \\
\hline \multirow{2}{*}{ *Solar } & Max & 30.1 & 31.5 & 29.2 & 28.3 & 29.3 & 29.3 \\
Radiation & Mean & 13.8 & 14.8 & 13.4 & 12.9 & 13.9 & 14.1 \\
$\left(\mathrm{MJ} / \mathrm{m}^{2}\right)$ & Min & 0.4 & 0.6 & 0.8 & 0.5 & 0.3 & 0.5 \\
& St. Dev. & 7.8 & 8.3 & 7.8 & 7.3 & 7.6 & 7.8 \\
\hline
\end{tabular}

\section{Discharge}

A summary of average daily discharge statistics recorded from the five Hinkson

Creek (HC) sites during the three year study period (WY 2011 to 2013) is provided in

Table 8 . Mean discharge ranged from $0.7 \mathrm{~m}^{3} / \mathrm{s}$ at site \#1 to $2.5 \mathrm{~m}^{3} / \mathrm{s}$ at site \#5 with a five site mean of $1.3 \mathrm{~m}^{3} / \mathrm{s}$. Maximum discharge ranged from $66.4 \mathrm{~m}^{3} / \mathrm{s}$ at site \#2 to $137.9 \mathrm{~m}^{3} / \mathrm{s}$ at site \#5 with a five site mean of $97.6 \mathrm{~m}^{3} / \mathrm{s}$. Median discharge ranged from $0.0 \mathrm{~m}^{3} / \mathrm{s}$ at site \#1 to $0.4 \mathrm{~m}^{3} / \mathrm{s}$ at site \#5 with a five site mean of $0.2 \mathrm{~m}^{3} / \mathrm{s}$. Minimum discharge ranged from $0.0 \mathrm{~m}^{3} / \mathrm{s}$ at site $\# 1$ to $0.1 \mathrm{~m}^{3} / \mathrm{s}$ at site \#2 with a five site mean of $0.0 \mathrm{~m}^{3} / \mathrm{s}$. There was a significant $(\mathrm{p}<0.01)$ difference found in mean discharge between gauging sites. 
Drainage area and cumulative percent urban land use accounted for $92.6 \%$ of the explained variance.

Table 8 . Summary of average daily discharge $\left(\mathrm{m}^{3} / \mathrm{s}\right)$ statistics during the study period (WY 2010 - 2013) for five hydroclimate stations located in Hinkson Creek Watershed, Missouri, USA. "St. Dev." is standard deviation.

\begin{tabular}{llllll} 
Daily Statistic & Site \#1 & Site \#2 & Site \#3 & Site \#4 & Site \#5 \\
\hline Mean & 0.7 & 0.7 & 1.0 & 1.5 & 2.5 \\
St. Dev. & 4.5 & 4.2 & 5.3 & 6.2 & 10.0 \\
Minimum & 0.0 & 0.1 & 0.0 & 0.0 & 0.0 \\
Median & 0.0 & 0.1 & 0.1 & 0.2 & 0.4 \\
Maximum & 82.1 & 66.4 & 86.7 & 114.9 & 137.9 \\
\hline
\end{tabular}

\section{Stream water temperature}

Summary of average daily $\mathrm{T}_{\mathrm{w}}$ statistics recorded from the five Hinkson Creek climate stations during the three year study period (WY 2011 - 2013) are shown in Table 9. Daily mean $\mathrm{T}_{\mathrm{w}}$ ranged from $13.7^{\circ} \mathrm{C}$ at site $\# 1$ to $14.4{ }^{\circ} \mathrm{C}$ at site $\# 4$ with a five site mean of $14.2{ }^{\circ} \mathrm{C}$. Daily maximum $\mathrm{T}_{\mathrm{w}}$ for the study period ranged from $32.1{ }^{\circ} \mathrm{C}$ at site \#1 to 36.1 ${ }^{\circ} \mathrm{C}$ at site \#3 with a five site mean of $34.4{ }^{\circ} \mathrm{C}$. Daily median $\mathrm{T}_{\mathrm{w}}$ ranged from $13.9{ }^{\circ} \mathrm{C}$ at site \#1 to $14.6{ }^{\circ} \mathrm{C}$ at site \#2 with a five site mean of $14.4{ }^{\circ} \mathrm{C}$. Daily minimum $\mathrm{T}_{\mathrm{w}}$ for the study period ranged from $0.4{ }^{\circ} \mathrm{C}$ at site $\# 2$ to $0.0^{\circ} \mathrm{C}$ at site $\# 1$ with a five site mean of 0.2 ${ }^{\circ} \mathrm{C}$.

Daily mean $\mathrm{T}_{\mathrm{w}}$ at rural site \#1 in the headwaters was lower than all other Hinkson Creek gauging sites by 0.5 to $0.7^{\circ} \mathrm{C}$ (this is within the sensitivity / accuracy of the $\mathrm{T}_{\mathrm{w}}$ sensors). The greatest absolute difference was $0.7{ }^{\circ} \mathrm{C}$ between daily mean $\mathrm{T}_{\mathrm{w}}$ between site $\# 1$ and \#4. Urban site \#4 daily mean $\mathrm{T}_{\mathrm{w}}$ was higher than all other Hinkson Creek gauging 
sites by 0.2 to $0.7^{\circ} \mathrm{C}$. Maximum daily mean $\mathrm{T}_{\mathrm{w}}$ was also lower at rural site \#1 in the headwaters compared to all other Hinkson Creek gauging sites by 1.7 to $2.5^{\circ} \mathrm{C}$. Site \#4 maximum daily mean $T_{w}$ was higher than all other Hinkson Creek gauging sites by 0.4 to $2.5^{\circ} \mathrm{C}$. Despite these differences, there were no significant differences found in daily mean $\mathrm{T}_{\mathrm{w}}(\mathrm{p}=0.51)$.

Table 9. Summary of average daily stream water temperature $\left({ }^{\circ} \mathrm{C}\right)$ statistics during the study period (WY 2010 - 2013) for five hydroclimate stations located in Hinkson Creek Watershed, Missouri, USA. "St. Dev." is standard deviation.

\begin{tabular}{llllll}
\hline Daily Statistic & Site \#1 & Site \#2 & Site \#3 & Site \#4 & Site \#5 \\
\hline Mean & 13.7 & 14.2 & 14.2 & 14.4 & 14.2 \\
St. Dev. & 8.6 & 9.7 & 9.5 & 9.5 & 9.4 \\
Minimum & 0.0 & 0.4 & 0.2 & 0.1 & 0.1 \\
Median & 13.9 & 14.6 & 14.6 & 14.4 & 14.4 \\
Maximum & 32.1 & 34.7 & 36.1 & 33.9 & 32.9 \\
\hline
\end{tabular}

Stream water temperature data were also analyzed at a 15 minute time step. Summary of average 15 minute $T_{w}$ statistics for the entire three year study period, and each water year (WY 2011 - 2013) are shown in Table 10. Fifteen minute mean $\mathrm{T}_{\mathrm{w}}$ ranged from $13.1^{\circ} \mathrm{C}$ at site $\# 1$ during WY2013 to $15.7^{\circ} \mathrm{C}$ at site \#4 during WY 2012 with a five site mean of $14.2^{\circ} \mathrm{C}$ for the study period. Fifteen minute maximum $\mathrm{T}_{\mathrm{w}}$ ranged from $27.9{ }^{\circ} \mathrm{C}$ at site \#1 during WY 2103 to $36.1{ }^{\circ} \mathrm{C}$ at site \#3 during WY 2011 with a five site mean of $34.4{ }^{\circ} \mathrm{C}$ for the entire study period. Fifteen minute median $\mathrm{T}_{\mathrm{w}}$ ranged from $11.9^{\circ} \mathrm{C}$ at site \#1 during WY2011 to $16.7^{\circ} \mathrm{C}$ at site \#4 during WY 2012 with a five site mean of $14.4{ }^{\circ} \mathrm{C}$ during the study period. Fifteen minute minimum $\mathrm{T}_{\mathrm{w}}$ ranged from $1.0{ }^{\circ} \mathrm{C}$ 
at site \#3 during WY 2013 to $1.2{ }^{\circ} \mathrm{C}$ at site \#1 with a five site mean of $0.6{ }^{\circ} \mathrm{C}$ during the study period.

There were significant differences found in 15 minute mean $\mathrm{T}_{\mathrm{w}}$ between gauging sites for the study period $(\mathrm{p}<0.01)$, and for each water year investigated $(\mathrm{p}<0.01)$. For WY2011, $\mathrm{T}_{\mathrm{w}}$ was significantly lower $(\mathrm{p}=0.01)$ at site \#1 compared to all other Hinkson Creek sites by 0.5 (sites \#3 and \#4) to $0.6{ }^{\circ} \mathrm{C}$ (sites \#2 and \#5). During WY 2012 mean $\mathrm{T}_{\mathrm{w}}$ was significantly lowest at site \#1 $\left(14.7^{\circ} \mathrm{C}\right)$ and highest at site $\# 4\left(15.7^{\circ} \mathrm{C}\right)$ compared to all other Hinkson Creek sites by 0.6 to $1.0^{\circ} \mathrm{C}$, and 0.3 to $1.0^{\circ} \mathrm{C}$, respectively. During WY $2013 \mathrm{~T}_{\mathrm{w}}$ was significantly lower at site \#1 compared to all other Hinkson Creek sites (with the exception of site \#2) by 0.3 to $0.6{ }^{\circ} \mathrm{C}$. Also, mean $\mathrm{T}_{\mathrm{w}}$ was significantly higher at urban site \#4 0.3 to $0.6^{\circ} \mathrm{C}$. Fifteen minute maximum $\mathrm{T}_{\mathrm{w}}$ was highest at site \#3 for every WY of the study period compared to all other Hinkson Creek sites by 1.4 to $4.0^{\circ} \mathrm{C}$. The greatest difference in maximum $\mathrm{T}_{\mathrm{w}}$ was between sites \#3 and \#1. Minimum $\mathrm{T}_{\mathrm{w}}$ was higher at site \#1 compared to all other Hinkson Creek sites for every WY in this study by 0.4 to $1.0^{\circ} \mathrm{C}$. 
Table 10. Summary of average 15 minute stream water temperature $\left({ }^{\circ} \mathrm{C}\right)$ statistics during the study period (WY 2010 - 2013) for five hydroclimate stations located in Hinkson Creek Watershed, Missouri, USA. "Study Period" is a three year average for the study period. "St. Dev." is standard deviation.

\begin{tabular}{lllllll}
\hline & Water Year & Site \#1 & Site \#2 & Site \#3 & Site \#4 & Site \#5 \\
\hline Mean & 2011 & 13.4 & 14.0 & 13.9 & 13.9 & 14.0 \\
& 2012 & 14.7 & 15.3 & 15.4 & 15.7 & 15.3 \\
& 2013 & 13.1 & 13.2 & 13.4 & 13.7 & 13.4 \\
& Study Period & 13.7 & 14.2 & 14.2 & 14.4 & 14.2 \\
\hline \multirow{2}{*}{ St. Dev. } & 2011 & 9.5 & 10.2 & 10.1 & 10.0 & 10.1 \\
& 2012 & 8.1 & 9.5 & 9.3 & 9.2 & 9.0 \\
& 2013 & 8.3 & 9.7 & 9.6 & 9.2 & 9.2 \\
& Study Period & 8.7 & 9.8 & 9.7 & 9.5 & 9.4 \\
\hline \multirow{6}{*}{ Minimum } & 2011 & 0.3 & 0.3 & 0.4 & 0.4 & 0.1 \\
& 2012 & 1.2 & 0.2 & 1.0 & 0.6 & 0.1 \\
& 2013 & 0.0 & 1.0 & 1.0 & 0.1 & 0.1 \\
& Study Period & 0.3 & 1.0 & 1.0 & 0.4 & 0.1 \\
\hline Median & 2011 & 13.7 & 14.2 & 14.1 & 14.4 & 14.2 \\
& 2012 & 15.7 & 16.4 & 16.4 & 16.7 & 16.2 \\
& 2013 & 11.9 & 12.6 & 12.8 & 12.6 & 12.5 \\
& Study Period & 13.9 & 14.5 & 14.5 & 14.6 & 14.5 \\
\hline Maximum & 2011 & 30.9 & 33.3 & 36.1 & 33.9 & 32.9 \\
& 2012 & 32.1 & 34.7 & 35.9 & 33.0 & 32.9 \\
& 2013 & 27.9 & 30.0 & 34.2 & 31.5 & 31.6 \\
& Study Period & 32.1 & 34.7 & 36.1 & 33.9 & 32.9
\end{tabular}

15 minute $\mathrm{T}_{\mathrm{w}}$ data were also analyzed at a seasonal (winter / spring / summer) time step (Table 11). Mean $\mathrm{T}_{\mathrm{w}}$ ranged from $6.3^{\circ} \mathrm{C}$ at site $\# 2$ during the winter to $24.8^{\circ} \mathrm{C}$ at site $\# 4$ during the summer. Maximum $\mathrm{T}_{\mathrm{w}}$ ranged from $21.6^{\circ} \mathrm{C}$ at site $\# 1$ during the winter to $36.1{ }^{\circ} \mathrm{C}$ at site \#3 during the summer. Median $\mathrm{T}_{\mathrm{w}}$ ranged from $5.0{ }^{\circ} \mathrm{C}$ at site \#2 during the winter to $25.3{ }^{\circ} \mathrm{C}$ at site $\# 4$ during the summer. Minimum $\mathrm{T}_{\mathrm{w}}$ ranged from 1.0 ${ }^{\circ} \mathrm{C}$ at site \#3 during the winter to $12.3{ }^{\circ} \mathrm{C}$ at site $\# 4$ in the summer. 
There were significant differences $(\mathrm{p}<0.05)$ found in 15 minute mean $\mathrm{T}_{\mathrm{w}}$ between gauging sites for each season investigated. During the winter seasons, $\mathrm{T}_{\mathrm{w}}$ was significantly higher at sites \#1 and \#4 compared to all other Hinkson Creek sites by 0.3 to $0.5^{\circ} \mathrm{C}$, and 0.4 to $0.6^{\circ} \mathrm{C}$, respectively. During the spring seasons, mean $\mathrm{T}_{\mathrm{w}}$ was significantly lower at site \#1 compared to all other Hinkson Creek sites by 0.4 to $0.6^{\circ} \mathrm{C}$. During the summer seasons, mean $\mathrm{T}_{\mathrm{w}}$ was significantly lower at sites \#1 and \#5 compared to all other Hinkson Creek sites by 1.3 to $1.7^{\circ} \mathrm{C}$, and 0.2 to $0.4{ }^{\circ} \mathrm{C}$, respectively. During the summer seasons, $\mathrm{T}_{\mathrm{w}}$ was significantly higher at site $\# 4$ compared to all other Hinkson Creek sites by $0.2^{\circ} \mathrm{C}$ to $1.7^{\circ} \mathrm{C}$.

Table 11. Summary of seasonal average stream water temperature $\left({ }^{\circ} \mathrm{C}\right)$ statistics during the study period (WY 2010 - 2013) for five hydroclimate stations located in Hinkson Creek Watershed, Missouri, USA.

\begin{tabular}{lllllll}
\hline Statistic & Season & Site \#1 & Site \#2 & Site \#3 & Site \#4 & Site \#5 \\
\hline Mean & Winter & 6.8 & 6.3 & 6.5 & 6.9 & 6.5 \\
& Spring & 11.2 & 11.6 & 11.6 & 11.7 & 11.8 \\
& Summer & 23.1 & 24.6 & 24.6 & 24.8 & 24.4 \\
\hline St. Dev. & Winter & 4.8 & 6.1 & 6.1 & 5.5 & 5.6 \\
& Spring & 7 & 7.4 & 7.3 & 7.3 & 7.1 \\
& Summer & 3.5 & 3.9 & 4.2 & 4 & 4 \\
\hline Minimum & Winter & 0 & 1 & 1 & 0.1 & 0.1 \\
& Spring & 0.3 & 0.1 & 0.1 & 0.4 & 0.1 \\
& Summer & 11.8 & 12.0 & 9.8 & 12.3 & 12 \\
\hline Median & Winter & 5.5 & 5 & 5.5 & 5.8 & 5.9 \\
& Spring & 11.9 & 12.2 & 12.2 & 12.4 & 12.4 \\
& Summer & 23.4 & 25.0 & 24.9 & 25.3 & 24.8 \\
\hline Maximum & Winter & 21.6 & 26.8 & 26.5 & 23.2 & 22.3 \\
& Spring & 27.6 & 31.9 & 31 & 28.7 & 28.7 \\
& Summer & 32.1 & 34.7 & 36.1 & 33.9 & 32.9
\end{tabular}




\section{Thermal maximum}

The total number of days $\mathrm{T}_{\mathrm{w}}$ was $>32^{\circ} \mathrm{C}$ (thermal maximum) for each Hinkson Creek gauging site are summarized in Table 12. Results showed that the number of days $\mathrm{T}_{\mathrm{w}}$ was $>32{ }^{\circ} \mathrm{C}$ ranged from 1 day at site \#1 to 55 days at site \#3 with an all site mean of 19 days. The maximum duration $\mathrm{T}_{\mathrm{w}}$ were $>32{ }^{\circ} \mathrm{C}$ ranged from 0.25 hours at site \#1 to 9.75 hours at site \#4 with an all site mean of 6.55 hours. Stream $\mathrm{T}_{\mathrm{w}}$ was $>35^{\circ} \mathrm{C}$ (critical thermal maximum) at site \#3 for 5 days. The maximum duration $\mathrm{T}_{\mathrm{w}}$ was $>35^{\circ} \mathrm{C}$ at site $\# 3$ was 2.5 hours. The days $\mathrm{T}_{\mathrm{w}}$ was $>32^{\circ} \mathrm{C}$ were significantly correlated $(\mathrm{p}=0.04)$ to maximum $\mathrm{T}_{\mathrm{w}}$ for the study period, while the maximum duration $\mathrm{T}_{\mathrm{w}}$ was $>32^{\circ} \mathrm{C}$ was significantly $(\mathrm{p}<0.01)$ correlated to mean $\mathrm{T}_{\mathrm{w}}$ for the study period.

Table 12. Days and duration stream water temperature was greater than 32 and $35{ }^{\circ} \mathrm{C}$ during the study period (WY 2010 - 2013) for five hydroclimate stations located in Hinkson Creek Watershed, Missouri, USA.

\begin{tabular}{llllll} 
Critical Thermal Criteria & Site \#1 & Site \#2 & Site \#3 & Site \#4 & Site \#5 \\
\hline Days $\mathrm{T}_{\mathrm{w}}>32^{\circ} \mathrm{C}$ & 1 & 12 & 55 & 20 & 8 \\
Max duration $\mathrm{T}_{\mathrm{w}}>32^{\circ} \mathrm{C}$ (hours) & 0.25 & 7.25 & 8.25 & 9.75 & 7.25 \\
\hline Days $\mathrm{T}_{\mathrm{w}}>35^{\circ} \mathrm{C}$ & 0 & 0 & 5 & 0 & 0 \\
Max duration $\mathrm{T}_{\mathrm{w}}>35^{\circ} \mathrm{C}$ (hours) & 0 & 0 & 2.5 & 0 & 0 \\
\hline
\end{tabular}

\section{Sudden rises in stream water temperature}

Results showed that 23 iButton temperature sensors detected a total of $40 \mathrm{~T}_{\mathrm{w}}$ surges in stormwater outfalls at 12 general locations in Hinkson Creek subsequent to urban stormwater inputs during summer 2009 (Table 13). All 12 locations where the $\mathrm{T}_{\mathrm{w}}$ surges were detected had $>12.9 \mathrm{~km}^{2}$ urban land use within the drainage subbasins. Mean 
$\mathrm{T}_{\mathrm{w}}$ surge and surge duration was $4.0^{\circ} \mathrm{C}$ and 11.4 hours, respectively. While, maximum $\mathrm{T}_{\mathrm{w}}$ surge and surge duration was $5.6^{\circ} \mathrm{C}$ and 24.75 hours, respectively.

Table 13. Summary statistics of $T_{w}$ surges detected in stormwater outfalls between gauging sites \#3 and \#5 during summer $2009(\mathrm{~N}=40)$.

\begin{tabular}{llllll}
\hline Data & Mean & Stand. Dev. & Minimum & Median & Maximum \\
\hline Peak $\mathrm{T}_{\mathrm{w}}\left({ }^{\circ} \mathrm{C}\right)$ & 25.1 & 2.7 & 20.5 & 24.4 & 33.4 \\
$\mathrm{~T}_{\mathrm{w}}$ Surge $\left({ }^{\circ} \mathrm{C}\right)$ & 4.0 & 2.3 & 2.0 & 3.2 & 5.6 \\
Surge Duration $(\mathrm{h})$ & 11.4 & 6.2 & 2.5 & 11.0 & 24.75 \\
\hline
\end{tabular}

Stream water temperature data from the five Hinkson Creek gauging sites were also analyzed for $\mathrm{T}_{\mathrm{w}}$ surges during summers 2010, 2011, and 2012. When investigated at five minute and 30 minute resolution, five minute data showed more $T_{w}$ surges of greater magnitude in Hinkson Creek. For example, nine $\mathrm{T}_{\mathrm{w}}$ surges were detected at a 30 minute resolution data. Conversely, results showed a total of $15 \mathrm{~T}_{\mathrm{w}}$ surges when using five minute resolution $T_{w}$ data. Furthermore, in one instance, a decrease in $T_{w}$ was shown with the 30 minute data resolution while the five minute resolution detected a $T_{w}$ surge of 1.22 ${ }^{\circ} \mathrm{C}$ and 1.25 hours surge duration during the same time period.

Results from the five minute data set are shown in Table 14. Mean peak $\mathrm{T}_{\mathrm{w}}$ was $26.5^{\circ} \mathrm{C}$. Maximum peak $\mathrm{T}_{\mathrm{w}}$ was $34.2^{\circ} \mathrm{C}$. Mean $\mathrm{T}_{\mathrm{w}}$ surge and surge duration was $1.6^{\circ} \mathrm{C}$ and 1.8 hours, respectively. While, maximum $\mathrm{T}_{\mathrm{w}}$ surge and surge duration was $2.6{ }^{\circ} \mathrm{C}$ and 6.3 hours, respectively. 
Table 14. Summary statistics of $\mathrm{T}_{\mathrm{w}}$ surges sensed between gauging sites \#3 and \#5 in Hinkson Creek during summers 2010, 2011, and $2012(\mathrm{~N}=15)$.

\begin{tabular}{llllll}
\hline Data & Mean & Stand. Dev. & Minimum & Median & Maximum \\
\hline Peak $\mathrm{T}_{\mathrm{w}}\left({ }^{\circ} \mathrm{C}\right)$ & 26.5 & 2.7 & 22.3 & 26.8 & 34.2 \\
$\mathrm{~T}_{\mathrm{w}}$ Surges $\left({ }^{\circ} \mathrm{C}\right)$ & 1.6 & 0.5 & 1.1 & 1.5 & 2.6 \\
Surge Duration $(\mathrm{h})$ & 1.8 & 1.5 & 0.3 & 1.4 & 6.3 \\
\hline
\end{tabular}

\section{The effects of discharge on stream water temperature}

Daily mean discharge, $\mathrm{T}_{\mathrm{a}}$, and $\mathrm{T}_{\mathrm{w}}$ data were sorted into 15 different flow classes to investigate the effects of stream discharge on hydroclimate. Statistical analyses provided information pertaining to mean discharge, $\mathrm{T}_{\mathrm{a}}$, and $\mathrm{T}_{\mathrm{w}}$ for 15 different flow classes at each gauging site. Please see Methods section (page 38) for more information regarding the methods used (including statistical analyses). Results from statistical analyses quantifiably characterize the relationship in mean discharge, $T_{a}$, and $T_{w}$ between gauging sites as flow class increased and are presented in the following sections.

Discharge increased linearly from site \#1 to site \#5 below median flow values ( $<50 \%$ flow class), and exponentially above median flow values ( $>50 \%$ flow class). The rate of exponential growth increased as flow class increased because of the relationship between drainage area, urban land use, and discharge at each site. Discharge in the $<50 \%$ flow class (below median discharge) increased from $0.0 \mathrm{~m}^{3} / \mathrm{s}$ at site \#1 to $0.2 \mathrm{~m}^{3} / \mathrm{s}$ at site \#5 with a five site mean of $0.1 \mathrm{~m}^{3} / \mathrm{s}$ (Table 15). Discharge in the $>50 \%$ flow class (above median discharge) increased from $1.3 \mathrm{~m}^{3} / \mathrm{s}$ at site $\# 1$ to $4.6 \mathrm{~m}^{3} / \mathrm{s}$ at site $\# 5$ with a five site mean of $2.5 \mathrm{~m}^{3} / \mathrm{s}$. Discharge in the $>90 \%$ flow class increased from $6.2 \mathrm{~m}^{3} / \mathrm{s}$ at site \#1 to $19.7 \mathrm{~m}^{3} / \mathrm{s}$ at site \#5 with a five site mean of $10.84 \mathrm{~m}^{3} / \mathrm{s}$. Discharge in the $>99 \%$ flow class increased from $30.1 \mathrm{~m}^{3} / \mathrm{s}$ at site $\# 1$ to $89.9 \mathrm{~m}^{3} / \mathrm{s}$ at site $\# 5$ with a five site mean of 48.64 
$\mathrm{m}^{3} / \mathrm{s}$. For a complete detailed description of mean discharge at each gauging site for each flow class considered in this research see Table 15.

Table 15 . Daily mean stream discharge $\left(\mathrm{m}^{3} / \mathrm{s}\right)$ for fifteen different flow classes and five hydroclimate stations located in Hinkson Creek Watershed, Missouri, USA.

\begin{tabular}{llllll}
\multirow{2}{*}{$\begin{array}{l}\text { Flow Class } \\
(\%)\end{array}$} & \multicolumn{5}{c}{ Stream Discharge $\left(\mathrm{m}^{3} / \mathrm{s}\right)$} \\
\cline { 2 - 6 }$<50$ & Site \#1 & Site \#2 & Site \#3 & Site \#4 & Site \#5 \\
$>50$ & 0.0 & 0.1 & 0.1 & 0.1 & 0.2 \\
\hline$>60$ & 1.3 & 1.5 & 2.0 & 3.1 & 4.6 \\
$>70$ & 1.6 & 1.8 & 2.5 & 3.8 & 5.7 \\
$>80$ & 2.1 & 2.3 & 3.3 & 5.0 & 7.4 \\
$>90$ & 3.2 & 3.4 & 4.8 & 7.2 & 10.7 \\
\hline$>91$ & 6.2 & 6.6 & 9.0 & 12.7 & 19.7 \\
$>92$ & 6.8 & 7.3 & 9.8 & 13.9 & 21.6 \\
$>93$ & 7.5 & 8.1 & 10.9 & 15.2 & 23.9 \\
$>94$ & 8.6 & 9.2 & 12.2 & 16.8 & 26.8 \\
$>95$ & 9.9 & 10.6 & 13.9 & 18.9 & 30.5 \\
$>96$ & 11.7 & 12.3 & 16.0 & 21.7 & 35.4 \\
$>97$ & 14.2 & 14.8 & 19.1 & 25.4 & 42.1 \\
$>98$ & 17.5 & 17.0 & 23.1 & 30.6 & 51.6 \\
$>99$ & 22.4 & 21.6 & 29.4 & 38.6 & 66.3 \\
\hline
\end{tabular}

Results showed there was no significant $(\mathrm{p}>0.05)$ effect of discharge on mean $\mathrm{T}_{\mathrm{a}}$ as flow class increased. Mean $\mathrm{T}_{\mathrm{a}}$ in the $<50 \%$ flow class (below median discharge) ranged from $13.4{ }^{\circ} \mathrm{C}$ at site $\# 1$ to $14.8{ }^{\circ} \mathrm{C}$ at site $\# 3$ with a five site mean of $14.1{ }^{\circ} \mathrm{C}$. Mean $\mathrm{T}_{\mathrm{a}}$ in the $>50 \%$ flow class (above median discharge) increased from $11.1^{\circ} \mathrm{C}$ at site $\# 1$ to $12.3{ }^{\circ} \mathrm{C}$ at site $\# 3$ with a five site mean of $11.8^{\circ} \mathrm{C}$. Mean $\mathrm{T}_{\mathrm{a}}$ in the $>90 \%$ flow class increased from $11.1{ }^{\circ} \mathrm{C}$ at site $\# 1$ to $12.0{ }^{\circ} \mathrm{C}$ at site $\# 3$ with a five site mean of $11.6{ }^{\circ} \mathrm{C}$. Mean $\mathrm{T}_{\mathrm{a}}$ in the $>99 \%$ flow class increased from $12.4{ }^{\circ} \mathrm{C}$ at site $\# 1$ to $13.1{ }^{\circ} \mathrm{C}$ at site $\# 3$ 
with a five site mean of $12.9^{\circ} \mathrm{C}$. For a complete detailed description of mean $\mathrm{T}_{\mathrm{a}}$ at each gauging site for each flow class considered in this research see Table 16.

Table 16. Daily mean air temperature $\left({ }^{\circ} \mathrm{C}\right)$ for fifteen different flow classes and five hydroclimate stations located in Hinkson Creek Watershed, Missouri, USA.

\begin{tabular}{llllll}
\hline \multirow{2}{*}{$\begin{array}{l}\text { Flow Class } \\
(\%)\end{array}$} & \multicolumn{5}{c}{ Air Temperature $\left({ }^{\circ} \mathrm{C}\right)$} \\
\cline { 2 - 6 } & Site \#1 & Site \#2 & Site \#3 & Site \#4 & Site \#5 \\
\hline$<50$ & 13.4 & 14.1 & 14.8 & 14.2 & 14.2 \\
$>50$ & 11.1 & 11.7 & 12.3 & 11.9 & 11.9 \\
\hline$>60$ & 11.3 & 11.9 & 12.4 & 12.1 & 12.2 \\
$>70$ & 11.1 & 11.7 & 12.2 & 11.9 & 11.9 \\
$>80$ & 11.1 & 11.6 & 12.1 & 11.8 & 11.9 \\
$>90$ & 11.1 & 11.6 & 12.0 & 11.7 & 11.8 \\
\hline$>91$ & 11.0 & 11.5 & 11.9 & 11.7 & 11.7 \\
$>92$ & 11.1 & 11.6 & 12.0 & 11.7 & 11.8 \\
$>93$ & 11.2 & 11.7 & 12.1 & 11.9 & 12.0 \\
$>94$ & 11.5 & 12.0 & 12.4 & 12.1 & 12.2 \\
$>95$ & 11.6 & 12.1 & 12.5 & 12.3 & 12.3 \\
$>96$ & 11.6 & 12.2 & 12.5 & 12.3 & 12.4 \\
$>97$ & 11.8 & 12.3 & 12.7 & 12.4 & 12.5 \\
$>98$ & 12.3 & 12.8 & 13.2 & 13.0 & 13.1 \\
$>99$ & 12.4 & 12.9 & 13.1 & 13.0 & 13.1 \\
\hline
\end{tabular}

While there were no apparent trends pertaining to mean $T_{a}$ between sites as flow class increased, stream water temperature increased at the downstream gauging sites \#4 and \#5 relative to the upstream gauging sites as flow class increased. The effect of discharge was not found to be significant $(\mathrm{p}>0.05)$ for any flow class considered, but a significant $(\mathrm{p}=0.04)$ effect of urban land use on $\mathrm{T}_{\mathrm{w}}$ was observed for flow classes $>90 \%$. Results showing mean $T_{w}$ for each gauging site and flow class considered in this research see Table 17. Mean $\mathrm{T}_{\mathrm{w}}$ in the $<50 \%$ flow class (below median discharge) ranged from 
$14.4{ }^{\circ} \mathrm{C}$ at site $\# 1$ to $15.1{ }^{\circ} \mathrm{C}$ at site $\# 4$ with a five site mean of $14.8^{\circ} \mathrm{C}$. Mean $\mathrm{T}_{\mathrm{w}}$ in the $>50 \%$ flow class (above median discharge) increased from $13.0^{\circ} \mathrm{C}$ at site $\# 1$ to $13.7^{\circ} \mathrm{C}$ at site \#4 with a five site mean of $13.4{ }^{\circ} \mathrm{C}$. Mean $\mathrm{T}_{\mathrm{w}}$ in the $>90 \%$ flow class increased from $11.7^{\circ} \mathrm{C}$ at site \#1 to $12.4{ }^{\circ} \mathrm{C}$ at site \#4 with a five site mean of $12.1{ }^{\circ} \mathrm{C}$. Mean $\mathrm{T}_{\mathrm{w}}$ in the $>99 \%$ flow class increased from $13.2{ }^{\circ} \mathrm{C}$ at site \#1 to $14.0{ }^{\circ} \mathrm{C}$ at site $\# 3$ with a five site mean of $13.6^{\circ} \mathrm{C}$.

Table 17. Daily mean stream water temperature $\left({ }^{\circ} \mathrm{C}\right)$ for fifteen different flow classes and five hydroclimate stations located in Hinkson Creek Watershed, Missouri, USA.

\begin{tabular}{llllll} 
Flow Class & \multicolumn{5}{c}{ Stream Temperature $\left({ }^{\circ} \mathrm{C}\right)$} \\
\cline { 2 - 6 }$(\%)$ & Site \#1 & Site \#2 & Site \#3 & Site \#4 & Site \#5 \\
\hline$<50$ & 14.4 & 15.0 & 15.0 & 15.1 & 14.5 \\
$>50$ & 13.0 & 13.5 & 13.5 & 13.7 & 13.5 \\
\hline$>60$ & 12.9 & 13.4 & 13.4 & 13.6 & 13.5 \\
$>70$ & 12.5 & 12.9 & 13.0 & 13.2 & 13.1 \\
$>80$ & 12.1 & 12.5 & 12.5 & 12.8 & 12.7 \\
$>90$ & 11.7 & 12.0 & 12.1 & 12.4 & 12.4 \\
\hline$>91$ & 11.7 & 12.0 & 12.0 & 12.3 & 12.3 \\
$>92$ & 11.6 & 11.9 & 11.9 & 12.2 & 12.2 \\
$>93$ & 11.7 & 11.9 & 12.0 & 12.3 & 12.3 \\
$>94$ & 11.8 & 12.1 & 12.1 & 12.5 & 12.5 \\
$>95$ & 11.9 & 12.2 & 12.2 & 12.6 & 12.6 \\
$>96$ & 11.9 & 12.1 & 12.2 & 12.6 & 12.6 \\
$>97$ & 12.2 & 12.4 & 12.5 & 12.9 & 12.9 \\
$>98$ & 12.6 & 12.8 & 12.9 & 13.3 & 13.3 \\
$>99$ & 13.2 & 13.4 & 13.5 & 14.0 & 14.0 \\
\hline
\end{tabular}

\section{STREAM AND AIR TEMPERATURE RELATIONSHIPS}

Linear and nonlinear regression analyses (performed in Origin) using mean $\mathrm{T}_{\mathrm{w}} \mathrm{vs}$. mean $\mathrm{T}_{\mathrm{a}}$ data from each site (sites \#1 to \#5) and at each time step (15 minute, hourly, 
daily, weekly, monthly, and seasonal) yielded $r^{2}$ values; linear coefficients $a$ (slope), and $b$ (y-intercept) for linear regression $\mathrm{T}_{\mathrm{w}}$ models (equation 1); and nonlinear coefficients $\alpha$ (estimated maximum $\mathrm{T}_{\mathrm{w}}$ ), $\beta$ ( $\mathrm{T}_{\mathrm{a}}$ at the inflection point of the function), and $\gamma$ (measure of the steepest slope) for nonlinear regression models (equation 2). Linear and nonlinear $\mathrm{T}_{\mathrm{w}}$ models were created using the results of the regression analyses. Results from linear and nonlinear regression analyses are shown in Tables 18 to 20 .

Linear and nonlinear $\mathrm{T}_{\mathrm{w}}$ models showed significant $(\mathrm{p}<0.01)$ increased levels of explained variance as time scale increased from 15 minute to seasonal averages. Linear regression analyses resulted in five site mean $r^{2}$ values ranging from 0.80 for a 15 minute time step to 0.99 at a seasonal time step (Table 16). Nonlinear regression analyses resulted in five site mean $r^{2}$ values ranging from 0.81 for a 15 minute time step to 1.00 at a seasonal time step.

Information regarding the effects of time scale on linear and nonlinear coefficients may also be important for improving our understanding of the relationship between $\mathrm{T}_{\mathrm{w}}$ and $\mathrm{T}_{\mathrm{a}}$. Linear coefficients $a$ and $b$ were affected by time scale. Coefficients $a$ decreased with time scale, while coefficients $b$ increased with time scale. Five site mean "coefficient $a$ " ranged from 1.96 at a seasonal time step to 4.67 at a 15 minute time step. Five site mean "coefficient $b$ " ranged from 0.72 at a 15 minute time step to 0.93 at a seasonal time step.

Nonlinear coefficients $\alpha$, and $\beta$ were not apparently affected by time scale (Table 17). But, coefficient $\gamma$ increased from sub-daily to monthly time scale. Five site mean “coefficient $\alpha$ " ranged from 29.99 at a 15 minute time step to 32.71 at a daily time step. Five site mean "coefficient $\beta$ " ranged from 14.39 at a seasonal time step to 16.10 at a 
daily time step. Five site mean "coefficient $\gamma$ " ranged from 0.12 at an hourly (with time lag) time step to 0.16 at a monthly time step.

The effects of time lag were investigated using cross correlation analyses and statistical software (Origin). The reader is directed to the Methods section page 35 for information on using cross-correlation analysis to quantify time lag. Time lag between $\mathrm{T}_{\mathrm{w}}$ and $\mathrm{T}_{\mathrm{a}}$ data was found at sub-daily time steps for linear and nonlinear regression results. Cross correlation analyses using the cross correlation function (CCF) (equations 11, 12, 13) showed time lag ranged from 1.5 hours at site \#2 $(\mathrm{CCF}=0.96)$ to 4.25 hours at site \#5 $(\mathrm{CCF}=0.95)$ when calculated using 15 minute data. When $\mathrm{CCF}$ were calculated using hourly data, time lag ranged from two hours at site \#2 $(\mathrm{CCF}=0.96)$ to four hours at site \#5 $(\mathrm{CCF}=0.95)$. Accounting for time lag increased levels of explained variance for sub-daily $\mathrm{T}_{\mathrm{w}}$ models (Tables 16 and 17). But, the level of explained variance was still poor compared to the daily and post daily $\mathrm{T}_{\mathrm{w}}$ models. This was especially true for the 15 minute linear $\mathrm{T}_{\mathrm{w}}$ models.

To improve the 15 minute linear $\mathrm{T}_{\mathrm{w}}$ model results, calibration parameters ( $\alpha$ and $\beta$ ) were added to the linear $\mathrm{T}_{\mathrm{w}}$ models (equations 14 and 15). 15 minute mean $\mathrm{T}_{\mathrm{w}}$ was more dependent on daily mean $T_{a}$ for the day interest, than 15 minute mean $T_{a}$ as calibration parameter $\beta$ was increased. Greater values for $\beta$ resulted in decreased diel (i.e. 24hr) range of 15 minute mean $T_{w}$. Please see Methods section page 36 for information on the "calibrated linear stream water temperature models". Results showing final calibration parameter values of the 15 minute linear $\mathrm{T}_{\mathrm{w}}$ models are in Table 21. Calibration parameter $\alpha$ ranged from 0.3 at site \#4 to 0.45 at site \#2. Calibration parameter $\beta$ ranged from 0.55 at site $\# 2$ to 0.7 at site $\# 4$. 
Table 18. Coefficients of determination $\left(\mathrm{r}^{2}\right)$ from linear and nonlinear regression analyses are shown for each time step considered (15 minute, hourly, daily, weekly, monthly, and seasonal) for each of five gauging sites in Hinkson Creek Watershed, U.S.A. The term "time lag" denotes analyses that accounted for the lagged response of $T_{a}$ relative to $T_{w}$. Lag was determined using cross-correlation analysis.

\begin{tabular}{lllllll}
\hline Time step & Model & Site \#1 & Site \#2 & Site \#3 & Site \#4 & Site \#5 \\
\hline 15 minute & Linear & 0.760 & 0.832 & 0.810 & 0.813 & 0.776 \\
& Nonlinear & 0.779 & 0.847 & 0.821 & 0.828 & 0.790 \\
\hline 15 minute & Linear & 0.797 & 0.843 & 0.832 & 0.839 & 0.799 \\
(time lag) & Nonlinear & 0.818 & 0.858 & 0.845 & 0.853 & 0.814 \\
\hline Hourly & Linear & 0.772 & 0.838 & 0.858 & 0.791 & 0.784 \\
& Nonlinear & 0.790 & 0.853 & 0.869 & 0.800 & 0.792 \\
\hline Hourly & Linear & 0.804 & 0.849 & 0.860 & 0.823 & 0.808 \\
(time lag) & Nonlinear & 0.821 & 0.865 & 0.872 & 0.831 & 0.816 \\
\hline Daily & Linear & 0.900 & 0.911 & 0.921 & 0.905 & 0.896 \\
& Nonlinear & 0.919 & 0.927 & 0.933 & 0.917 & 0.908 \\
\hline Weekly & Linear & 0.968 & 0.968 & 0.971 & 0.969 & 0.966 \\
& Nonlinear & 0.977 & 0.975 & 0.976 & 0.973 & 0.970 \\
\hline Monthly & Linear & 0.990 & 0.989 & 0.991 & 0.990 & 0.989 \\
& Nonlinear & 0.993 & 0.991 & 0.991 & 0.989 & 0.989 \\
\hline Seasonal & Linear & 0.994 & 0.993 & 0.994 & 0.992 & 0.993 \\
& Nonlinear & 0.995 & 0.995 & 0.996 & 0.994 & 0.995
\end{tabular}


Table 19. Coefficients $a$ (slope) and $b$ (y-intercept) from linear regression analyses are shown for each time step considered (15 minute, hourly, daily, weekly, monthly, and seasonal) for each of five study sites in Hinkson Creek Watershed, U.S.A. The term "time lag" denotes analyses that accounted for the lagged response of $T_{a}$ relative to $T_{w}$. Lag was determined using cross-correlation analysis.

\begin{tabular}{lllllll}
\hline Time step & Coefficient & Site \#1 & Site \#2 & Site \#3 & Site \#4 & Site \#5 \\
\hline 15 minute & $b$ & 5.621 & 4.101 & 3.869 & 4.840 & 4.902 \\
& $a$ & 0.654 & 0.774 & 0.732 & 0.747 & 0.705 \\
\hline 15 minute & $b$ & 5.432 & 4.038 & 3.743 & 4.680 & 4.763 \\
(time lag) & $a$ & 0.670 & 0.779 & 0.742 & 0.759 & 0.716 \\
\hline Hourly & $b$ & 5.550 & 4.443 & 3.876 & 4.864 & 4.878 \\
& $a$ & 0.664 & 0.766 & 0.770 & 0.727 & 0.703 \\
\hline Hourly & $b$ & 5.297 & 4.377 & 3.863 & 4.668 & 4.737 \\
(time lag) & $a$ & 0.676 & 0.771 & 0.771 & 0.742 & 0.713 \\
\hline Daily & $b$ & 4.067 & 3.276 & 2.838 & 3.325 & 3.360 \\
& $a$ & 0.781 & 0.854 & 0.844 & 0.841 & 0.815 \\
\hline Weekly & $b$ & 3.199 & 2.397 & 2.015 & 2.391 & 2.376 \\
& $a$ & 0.849 & 0.920 & 0.902 & 0.910 & 0.888 \\
\hline Monthly & $b$ & 2.893 & 2.036 & 1.689 & 2.045 & 2.009 \\
& $a$ & 0.873 & 0.946 & 0.926 & 0.936 & 0.915 \\
\hline Seasonal & $b$ & 2.715 & 1.746 & 1.503 & 1.929 & 1.897 \\
& $a$ & 0.887 & 0.968 & 0.939 & 0.944 & 0.924
\end{tabular}


Table 20. Coefficients $\alpha$ (estimated maximum $\mathrm{T}_{\mathrm{w}}$ ) and $\beta$ ( $\mathrm{T}_{\mathrm{a}}$ at the inflection point of the function) $\gamma$ (measure of the steepest slope) from nonlinear regression analyses are shown for each time step considered (15 minute, hourly, daily, weekly, monthly, and seasonal) for each of five study sites in Hinkson Creek Watershed, U.S.A. The term "time lag" denotes analyses that accounted for the lagged response of $T_{a}$ relative to $T_{w}$. Lag was determined using cross-correlation analysis.

\begin{tabular}{|c|c|c|c|c|c|c|}
\hline Time step & Coefficient & Site \#1 & Site \#2 & Site \#3 & Site \#4 & Site \#5 \\
\hline \multirow[t]{3}{*}{15 minute } & $\alpha$ & 28.187 & 31.878 & 30.489 & 30.418 & 28.980 \\
\hline & $\beta$ & 13.185 & 15.577 & 15.758 & 14.162 & 13.776 \\
\hline & $\gamma$ & 0.122 & 0.130 & 0.126 & 0.133 & 0.130 \\
\hline \multirow{3}{*}{$\begin{array}{l}15 \text { minute } \\
\text { (time lag) }\end{array}$} & $\alpha$ & 29.173 & 31.906 & 30.759 & 31.398 & 29.173 \\
\hline & $\beta$ & 13.931 & 15.576 & 15.891 & 14.848 & 13.921 \\
\hline & $\gamma$ & 0.121 & 0.132 & 0.128 & 0.130 & 0.132 \\
\hline \multirow[t]{3}{*}{ Hourly } & $\alpha$ & 27.957 & 32.503 & 32.429 & 30.426 & 30.805 \\
\hline & $\beta$ & 12.838 & 15.686 & 16.300 & 14.392 & 15.164 \\
\hline & $\gamma$ & 0.127 & 0.126 & 0.125 & 0.124 & 0.117 \\
\hline \multirow{3}{*}{$\begin{array}{l}\text { Hourly } \\
\text { (time lag) }\end{array}$} & $\alpha$ & 29.355 & 32.469 & 31.813 & 31.470 & 31.092 \\
\hline & $\beta$ & 14.072 & 15.651 & 15.877 & 15.128 & 15.360 \\
\hline & $\gamma$ & 0.121 & 0.127 & 0.129 & 0.122 & 0.119 \\
\hline \multirow[t]{3}{*}{ Daily } & $\alpha$ & 31.429 & 32.924 & 32.533 & 33.668 & 33.014 \\
\hline & $\beta$ & 15.342 & 15.869 & 16.307 & 16.460 & 16.524 \\
\hline & $\gamma$ & 0.130 & 0.138 & 0.137 & 0.129 & 0.128 \\
\hline \multirow[t]{3}{*}{ Weekly } & $\alpha$ & 29.886 & 31.474 & 31.024 & 31.917 & 31.156 \\
\hline & $\beta$ & 14.134 & 14.793 & 15.190 & 15.185 & 15.147 \\
\hline & $\gamma$ & 0.148 & 0.155 & 0.154 & 0.147 & 0.148 \\
\hline \multirow[t]{3}{*}{ Monthly } & $\alpha$ & 29.361 & 30.661 & 30.262 & 31.274 & 30.429 \\
\hline & $\beta$ & 13.774 & 14.294 & 14.698 & 14.768 & 14.664 \\
\hline & $\gamma$ & 0.154 & 0.164 & 0.161 & 0.155 & 0.157 \\
\hline \multirow[t]{3}{*}{ Seasonal } & $\alpha$ & 30.715 & 31.905 & 31.495 & 30.593 & 29.900 \\
\hline & $\beta$ & 14.256 & 14.623 & 15.088 & 14.002 & 13.977 \\
\hline & $\gamma$ & 0.130 & 0.139 & 0.136 & 0.142 & 0.142 \\
\hline
\end{tabular}


Table 21. Calibration parameters for the calibrated 15 minute linear $\mathrm{T}_{\mathrm{w}}$ model.

\begin{tabular}{lll}
\hline Gauging Site & $\alpha$ & $\beta$ \\
\hline Site \#1 & 0.38 & 0.62 \\
Site \#2 & 0.45 & 0.55 \\
Site \#3 & 0.41 & 0.59 \\
Site \#4 & 0.30 & 0.70 \\
Site \#5 & 0.32 & 0.68 \\
\hline
\end{tabular}

The effects of discharge on $T_{w}$ and $T_{a}$ relationships

Daily mean discharge, $\mathrm{T}_{\mathrm{a}}$, and $\mathrm{T}_{\mathrm{w}}$ data were sorted into 15 different flow classes to investigate the effects of stream discharge on the $T_{w}$ and $T_{a}$ relationship. Please see Methods section (page 41) for more information regarding the methods used (including statistical analyses). Linear regression analyses were performed using daily mean $\mathrm{T}_{\mathrm{w}}$ and $T_{a}$ data for each flow class to better elucidate the effects of discharge on the $T_{w}$ and $T_{a}$ relationship at a daily time step. Results from linear regression analyses for 15 different flow classes showed that the $\mathrm{r}^{2}$ values decreased significantly $(\mathrm{p}<0.01)$ as flow class increased (Table 22). This information may be important for water resource managers that are using $\mathrm{T}_{\mathrm{w}}$ models to estimate stream water temperature during stormflow periods. The $\mathrm{r}^{2}$ values in the $<50 \%$ flow class (below median discharge) ranged from 0.91 at site $\# 1$ to 0.94 at site \#3 with a five site mean of 0.92 . The $\mathrm{r}^{2}$ values in the $>50 \%$ flow class (above median discharge) ranged from 0.86 at site \#1 to 0.89 at site \#3 with a five site mean of 0.88 . The $r^{2}$ values in the $>90 \%$ flow class ranged from 0.68 at site \#4 to 0.72 at site \#2 with a five site mean of 0.70 . The $r^{2}$ values in the $>99 \%$ flow class ranged from 0.57 at site \#4 to 0.73 at site \#1 with a five site mean of 0.68 . 
Results from linear regression analyses for 15 different flow classes showed linear "coefficient $b$ " decreased, while linear "coefficient $a$ " increased as flow class increased (Table 23). When daily $\mathrm{T}_{\mathrm{w}} / \mathrm{T}_{\mathrm{a}}$ relationships were analyzed at 15 different flow classes, results showed five site mean "coefficient $a$ " ranged from 0.10 at the $>98 \%$ flow class to 3.86 at $>60 \%$ flow class. Five site mean "coefficient $b$ " ranged from 0.72 at $>93 \%$ flow class to 0.94 at the $>99 \%$ flow class. For a complete detailed description of linear regression results for each flow class considered see Tables 22 and 23.

Table 22. Coefficient of determination $\left(\mathrm{r}^{2}\right)$ values from linear regression results for fifteen different flow classes using daily average stream and air temperature data collected from five hydroclimatic stations located in Hinkson Creek Watershed, Missouri, USA.

\begin{tabular}{lllllll}
$\begin{array}{l}\text { Flow } \\
\text { Class }(\%)\end{array}$ & Site \#1 & Site \#2 & Site \#3 & Site \#4 & Site \#5 & $\begin{array}{l}\text { Five site } \\
\text { Mean }\end{array}$ \\
\hline$<50$ & 0.910 & 0.934 & 0.942 & 0.921 & 0.912 & 0.924 \\
$>50$ & 0.856 & 0.885 & 0.889 & 0.879 & 0.871 & 0.876 \\
\hline$>60$ & 0.836 & 0.880 & 0.873 & 0.866 & 0.856 & 0.862 \\
$>70$ & 0.841 & 0.872 & 0.850 & 0.827 & 0.820 & 0.842 \\
$>80$ & 0.822 & 0.832 & 0.799 & 0.800 & 0.788 & 0.808 \\
$>90$ & 0.714 & 0.719 & 0.701 & 0.680 & 0.682 & 0.699 \\
\hline$>91$ & 0.692 & 0.696 & 0.696 & 0.682 & 0.661 & 0.685 \\
$>92$ & 0.679 & 0.703 & 0.702 & 0.686 & 0.653 & 0.685 \\
$>93$ & 0.687 & 0.711 & 0.668 & 0.687 & 0.619 & 0.674 \\
$>94$ & 0.682 & 0.688 & 0.634 & 0.644 & 0.602 & 0.650 \\
$>95$ & 0.668 & 0.673 & 0.660 & 0.645 & 0.620 & 0.653 \\
$>96$ & 0.697 & 0.686 & 0.668 & 0.659 & 0.576 & 0.657 \\
$>97$ & 0.672 & 0.655 & 0.627 & 0.634 & 0.472 & 0.612 \\
$>98$ & 0.689 & 0.669 & 0.638 & 0.686 & 0.638 & 0.664 \\
$>99$ & 0.730 & 0.728 & 0.638 & 0.570 & 0.709 & 0.675 \\
\hline
\end{tabular}


Table 23. Flow empirical analysis $a$ and $b$ coefficients for fifteen different flow classes at a daily time step using data collected from five hydroclimate stations located in Hinkson Creek Watershed, Missouri, USA.

\begin{tabular}{|c|c|c|c|c|c|c|}
\hline $\begin{array}{l}\text { Flow } \\
\text { Class (\%) }\end{array}$ & Coefficient & Site \#1 & Site \#2 & Site \#3 & Site \#4 & Site \#5 \\
\hline \multirow[t]{2}{*}{$<50$} & $b$ & 4.421 & 2.267 & 1.897 & 2.855 & 2.557 \\
\hline & $a$ & 0.773 & 0.908 & 0.901 & 0.881 & 0.853 \\
\hline \multirow[t]{2}{*}{$>50$} & $b$ & 4.155 & 3.749 & 3.262 & 3.771 & 4.044 \\
\hline & $a$ & 0.761 & 0.821 & 0.802 & 0.801 & 0.790 \\
\hline \multirow[t]{2}{*}{$>60$} & $b$ & 4.125 & 3.784 & 3.549 & 3.844 & 3.978 \\
\hline & $a$ & 0.740 & 0.815 & 0.771 & 0.787 & 0.780 \\
\hline \multirow[t]{2}{*}{$>70$} & $b$ & 4.056 & 3.482 & 3.577 & 3.577 & 4.135 \\
\hline & $a$ & 0.757 & 0.824 & 0.752 & 0.790 & 0.744 \\
\hline \multirow[t]{2}{*}{$>80$} & $b$ & 3.970 & 2.962 & 3.403 & 3.396 & 3.657 \\
\hline & $a$ & 0.751 & 0.823 & 0.725 & 0.770 & 0.760 \\
\hline \multirow[t]{2}{*}{$>90$} & $b$ & 3.480 & 3.077 & 3.046 & 3.672 & 3.866 \\
\hline & $a$ & 0.740 & 0.738 & 0.727 & 0.712 & 0.708 \\
\hline \multirow[t]{2}{*}{$>91$} & $b$ & 3.343 & 3.271 & 2.908 & 3.521 & 3.887 \\
\hline & $a$ & 0.744 & 0.720 & 0.723 & 0.714 & 0.697 \\
\hline \multirow[t]{2}{*}{$>92$} & $b$ & 3.350 & 3.349 & 3.050 & 3.387 & 3.947 \\
\hline & $a$ & 0.739 & 0.708 & 0.725 & 0.722 & 0.680 \\
\hline \multirow[t]{2}{*}{$>93$} & $b$ & 3.131 & 3.152 & 3.045 & 3.004 & 3.964 \\
\hline & $a$ & 0.753 & 0.731 & 0.716 & 0.733 & 0.673 \\
\hline \multirow[t]{2}{*}{$>94$} & $b$ & 2.713 & 2.467 & 2.671 & 2.525 & 3.950 \\
\hline & $a$ & 0.770 & 0.773 & 0.738 & 0.775 & 0.670 \\
\hline \multirow[t]{2}{*}{$>95$} & $b$ & 2.455 & 1.576 & 1.556 & 2.345 & 3.470 \\
\hline & $a$ & 0.783 & 0.826 & 0.804 & 0.781 & 0.712 \\
\hline \multirow[t]{2}{*}{$>96$} & $b$ & 1.053 & 1.238 & 0.593 & 1.614 & 3.392 \\
\hline & $a$ & 0.860 & 0.837 & 0.859 & 0.822 & 0.724 \\
\hline \multirow[t]{2}{*}{$>97$} & $b$ & 0.201 & 0.101 & 0.929 & 0.676 & 5.080 \\
\hline & $a$ & 0.933 & 0.892 & 0.824 & 0.872 & 0.624 \\
\hline \multirow[t]{2}{*}{$>98$} & $b$ & 0.817 & 1.123 & 0.863 & 0.864 & 3.152 \\
\hline & $a$ & 0.995 & 0.997 & 0.933 & 0.979 & 0.761 \\
\hline \multirow[t]{2}{*}{$>99$} & $b$ & 1.217 & 5.748 & 1.656 & 2.006 & 5.629 \\
\hline & $a$ & 1.069 & 1.272 & 0.848 & 0.858 & 0.665 \\
\hline
\end{tabular}




\section{SWAT MODELING}

\section{SWAT calibration}

The SWAT model was successfully calibrated at a daily time step using observed stream discharge data from site \#5 and the four nested subbasins during the 2010 to 2012 water years (results are summarized in Table 24). Model evaluation results from site \#5 nearest the watershed outlet showed a Nash-Sutcliffe efficiency (NSE) value of 0.56, percent bias (PBIAS) value of $24.15 \%$, and a ratio of root mean square error to the standard deviation of observed data (RSR) value of 0.66. Simulated mean stream discharge was $2.6 \mathrm{~m}^{3} / \mathrm{s}$, which was $0.8 \mathrm{~m}^{3} / \mathrm{s}$ less than observed mean discharge during the calibration period. Simulated maximum stream discharge was $125.9 \mathrm{~m}^{3} / \mathrm{s}$, observed maximum stream discharge was $217.7 \mathrm{~m}^{3} / \mathrm{s}$.

Model evaluation results for the other four gauging sites showed NSE values ranging from 0.50 at site \#1 to 0.66 at site \#4. PBIAS values ranged from $-8.53 \%$ at site \#2 to $14.71 \%$ at site \#3. RSR values ranged from 0.58 at site \#4 to 0.71 at site \#1. MAE ranged from $0.76 \mathrm{~m}^{3} / \mathrm{s}$ at site $\# 1$ to $1.58 \mathrm{~m}^{3} / \mathrm{s}$ at site $\# 4$. MSE ranged from $7.12 \mathrm{~m}^{3} / \mathrm{s}$ at site \#1 to $23.84 \mathrm{~m}^{3} / \mathrm{s}$ at site \#4. RMSE ranged from $2.67 \mathrm{~m}^{3} / \mathrm{s}$ at site \#1 to $4.88 \mathrm{~m}^{3} / \mathrm{s}$ at site \#4. See Table 24 for more information on SWAT calibration results. 
Table 24. Simulated and observed stream discharge calibration results showing daily descriptive statistics and six model evaluation criterion for five gauging sites in Hinkson Creek, USA. Observed data are shown in parentheses for comparison with simulated data.

\begin{tabular}{llllll}
\hline Statistic & Site \#1 & Site \#2 & Site \#3 & Site \#4 & Site \#5 \\
\hline Mean $\left(\mathrm{m}^{3} / \mathrm{s}\right)$ & $0.9(0.8)$ & $1.2(1.1)$ & $1.4(1.59)$ & $2.3(2.3)$ & $2.6(3.4)$ \\
& & & & 115.7 & 125.9 \\
Max $\left(\mathrm{m}^{3} / \mathrm{s}\right)$ & $36.9(60.3)$ & $57.8(69.2)$ & $70.2(117.7)$ & $(145.0)$ & $(217.7)$ \\
Median $\left(\mathrm{m}^{3} / \mathrm{s}\right)$ & $0.2(0.0)$ & $0.3(0.1)$ & $0.3(0.2)$ & $0.5(0.3)$ & $0.5(0.5)$ \\
Min $\left(\mathrm{m}^{3} / \mathrm{s}\right)$ & $0.0(0.0)$ & $0.0(0.0)$ & $0.0(0.0)$ & $0.0(0.0)$ & $0.0(0.0)$ \\
\hline NSE & 0.50 & 0.51 & 0.60 & 0.66 & 0.56 \\
PBIAS $(\%)$ & -4.19 & -8.53 & 14.71 & 0.43 & 24.15 \\
RSR & 0.71 & 0.70 & 0.63 & 0.58 & 0.66 \\
\hline MAE $\left(\mathrm{m}^{3} / \mathrm{s}\right)$ & 0.76 & 1.06 & 1.21 & 1.58 & 2.40 \\
MSE $\left(\mathrm{m}^{3} / \mathrm{s}\right)$ & 7.12 & 10.80 & 18.69 & 23.84 & 60.47 \\
RMSE $\left(\mathrm{m}^{3} / \mathrm{s}\right)$ & 2.67 & 3.29 & 4.32 & 4.88 & 7.78 \\
\hline
\end{tabular}

NSE is Nash-Sutcliffe efficiency, PBIAS is percent bias, RSR is ratio of root mean square error to the standard deviation of observed data, MAE is mean absolute error, MSE is mean square error, RMSE is root mean square error.

\section{SWAT validation}

SWAT was successfully validated at a daily time step using observed stream discharge data from site \#5 and the four nested gauging sites during the 2013 water year (results are summarized in Table 25). Model evaluation results from site \#5 nearest the watershed outlet showed a NSE value of 0.48 , PBIAS value of $45.00 \%$, and a RSR value of 0.72 . Observed mean stream discharge during the calibration period was $4.3 \mathrm{~m}^{3} / \mathrm{s}$ while simulated stream discharge was $2.3 \mathrm{~m}^{3} / \mathrm{s}$. Observed maximum stream discharge was $137.9 \mathrm{~m}^{3} / \mathrm{s}$, simulated maximum stream discharge was $83.8 \mathrm{~m}^{3} / \mathrm{s}$.

Model evaluation results during the validation period for the other four gauging sites showed NSE values ranging from 0.49 at site \#1 to 0.67 at site \#4. PBIAS values ranged from $3.9 \%$ at site \#1 to $21.97 \%$ at site \#3. RSR values ranged from 0.71 at site \#1 to 0.57 at site \#4. MAE ranged from $0.96 \mathrm{~m}^{3} / \mathrm{s}$ at site \#1 to $1.66 \mathrm{~m}^{3} / \mathrm{s}$ at site \#4. MSE 
ranged from $12.73 \mathrm{~m}^{3} / \mathrm{s}$ at site \#1 to $33.62 \mathrm{~m}^{3} / \mathrm{s}$ at site \#3. RMSE ranged from $3.57 \mathrm{~m}^{3} / \mathrm{s}$ at site \#1 to $5.80 \mathrm{~m}^{3} / \mathrm{s}$ at site \#3. See Table 25 for more information on SWAT validation results.

Table 25. SWAT simulated and observed stream discharge validation results showing daily descriptive statistics and six model evaluation criterion for five gauging sites in Hinkson Creek, USA. Observed data are shown in parentheses.

\begin{tabular}{llllll}
\hline Statistic & Site \#1 & Site \#2 & Site \#3 & Site \#4 & Site \#5 \\
\hline Mean $\left(\mathrm{m}^{3} / \mathrm{s}\right)$ & $0.9(.9)$ & $1.2(1.2)$ & $1.3(1.7)$ & $2.1(2.2)$ & $2.3(4.3)$ \\
Max $\left(\mathrm{m}^{3} / \mathrm{s}\right)$ & $24.4(57.5)$ & $35.4(66.4)$ & $42.1(86.7)$ & $75.0(114.9)$ & $83.8(137.9)$ \\
Median $\left(\mathrm{m}^{3} / \mathrm{s}\right)$ & $0.1(0.0)$ & $0.1(0.1)$ & $0.1(0.1)$ & $0.2(0.1)$ & $0.2(0.4)$ \\
Min $\left(\mathrm{m}^{3} / \mathrm{s}\right)$ & $0.0(0.0)$ & $0.0(0.1)$ & $0.0(0.0)$ & $0.0(0.0)$ & $0.0(0.2)$ \\
\hline NSE & 0.49 & 0.49 & 0.52 & 0.67 & 0.48 \\
PBIAS & 3.9 & 5.79 & 21.97 & 4.54 & 45.00 \\
RSR & 0.71 & 0.71 & 0.69 & 0.57 & 0.72 \\
\hline MAE $\left(\mathrm{m}^{3} / \mathrm{s}\right)$ & 0.96 & 1.31 & 1.50 & 1.66 & 3.25 \\
MSE $\left(\mathrm{m}^{3} / \mathrm{s}\right)$ & 12.73 & 22.50 & 33.62 & 29.59 & 127.07 \\
RMSE $\left(\mathrm{m}^{3} / \mathrm{s}\right)$ & 3.57 & 4.74 & 5.80 & 5.44 & 11.27 \\
\hline
\end{tabular}

NSE is Nash-Sutcliffe efficiency, PBIAS is percent bias, RSR is ratio of root mean square error to the standard deviation of observed data, MAE is mean absolute error, MSE is mean square error, RMSE is root mean square error.

\section{STREAM TEMPERATURE MODEL COMPARISON}

Simulation results from the linear (equation 1), nonlinear (equation 2), and calibrated linear (equation 15), $\mathrm{T}_{\mathrm{w}}$ models were tested using six model evaluation criteria to compare the effectiveness of each of the $\mathrm{T}_{\mathrm{w}}$ models at daily and sub-daily (15 minute and hourly) time steps. The original SWAT $\mathrm{T}_{\mathrm{w}}$ model (equation 4), and Ficklin et al. (2012) $\mathrm{T}_{\mathrm{w}}$ model (equations 5, 6, 7, and 8) were also tested at a daily time step for $\mathrm{T}_{\mathrm{w}}$ model comparison. Evaluation results for the calibration period (WY 2011 and 2012) and validation period (WY 2013) are shown in Tables 26, 27, and 28. Five site mean $\mathrm{T}_{\mathrm{w}}$ model evaluation results are shown to summarize the data. More detailed tables showing 
$T_{w}$ model evaluation results for each of the five gauging sites are provided in Appendix B.

\section{5 minute stream temperature models}

Results showed model evaluation tests including NSE, RSR, MAE, MSE, and RMSE all significantly $(\mathrm{p}<0.01)$ favored the 15 minute calibrated linear $\mathrm{T}_{\mathrm{w}}$ model over the 15 minute linear and nonlinear $\mathrm{T}_{\mathrm{w}}$ models (with the exception of PBIAS values). Model evaluation results were not significantly $(p>0.05)$ different for the 15 minute nonlinear $\mathrm{T}_{\mathrm{w}}$ models and the 15 minute linear $\mathrm{T}_{\mathrm{w}}$ models (Table 26).

NSE values can range from $\infty$ to 1.0 (a value of 1.0 is a perfect simulation). Multiple evaluation results revealed five site mean NSE values ranging from 0.83 for the 15 minute linear $T_{w}$ model to 0.91 for the 15 minute calibrated linear $T_{w}$ model during the calibration period. Five site mean NSE values ranged from 0.83 for the 15 minute linear $\mathrm{T}_{\mathrm{w}}$ model to 0.89 for the 15 minute calibrated linear $\mathrm{T}_{\mathrm{w}}$ model during the validation period.

PBIAS results can range from $-100 \%$ to $100 \%$ (a value of 0.00 is a perfect simulation). Five site mean PBIAS values ranged from $0.02 \%$ for the 15 minute linear $\mathrm{T}_{\mathrm{w}}$ model to $2.37 \%$ for the 15 minute calibrated linear $\mathrm{T}_{\mathrm{w}}$ model during the calibration period. Five site mean PBIAS values ranged from $0.38 \%$ for the 15 minute nonlinear $\mathrm{T}_{\mathrm{w}}$ model to $4.50 \%$ for the 15 minute calibrated linear $\mathrm{T}_{\mathrm{w}}$ model during the validation period.

RSR values can range from 0.0 to 1.0 (a value of 0.0 is a perfect simulation). Five site mean RSR values ranged from 0.29 for the 15 minute calibrated linear $\mathrm{T}_{\mathrm{w}}$ model to 0.41 for the 15 minute linear $\mathrm{T}_{\mathrm{w}}$ model during the calibration period. Five site mean RSR 
values ranged from 0.33 for the 15 minute calibrated linear $T_{w}$ model to 0.42 for the 15 minute linear $\mathrm{T}_{\mathrm{w}}$ model during the validation period.

MAE, MSE, and RMSE values are a measure of model error that can range from 0.0 to $\infty{ }^{\circ} \mathrm{C}$ (a value of $0.0^{\circ} \mathrm{C}$ is a perfect simulation). Five site mean MAE, MSE, and RMSE values ranged from $1.66,6.18$, and $2.46{ }^{\circ} \mathrm{C}$, respectively, for the 15 minute calibrated linear $\mathrm{T}_{\mathrm{w}}$ model to $3.00,14.82$, and $3.85^{\circ} \mathrm{C}$, respectively, for the 15 minute linear $\mathrm{T}_{\mathrm{w}}$ model during the calibration period. Five site mean MAE, MSE, and RMSE values ranged from $2.26,8.88$, and $2.98^{\circ} \mathrm{C}$, respectively, for the 15 minute calibrated linear $\mathrm{T}_{\mathrm{w}}$ model to $2.97,14.69$, and $3.83{ }^{\circ} \mathrm{C}$, respectively, for the 15 minute linear $\mathrm{T}_{\mathrm{w}}$ model during the validation period. 
Table 26. Five site mean summary of 15 minute linear, nonlinear, and calibrated linear stream water temperature model evaluation results during calibration and validation periods for five gauging sites in Hinkson Creek Watershed, USA.

Five Site Mean 15 Minute Stream Water Temperature Model Evaluation Results

\begin{tabular}{|c|c|c|c|}
\hline Statistic & Linear & Nonlinear & Calibrated Linear \\
\hline \multicolumn{4}{|c|}{ Calibration } \\
\hline NSE & 0.83 & 0.84 & 0.91 \\
\hline PBIAS (\%) & 0.02 & 0.62 & 2.37 \\
\hline RSR & 0.41 & 0.4 & 0.29 \\
\hline $\operatorname{MAE}\left({ }^{\circ} \mathrm{C}\right)$ & 3 & 2.97 & 1.66 \\
\hline $\operatorname{MSE}\left({ }^{\circ} \mathrm{C}\right)$ & 14.82 & 14.44 & 6.18 \\
\hline $\operatorname{RMSE}\left({ }^{\circ} \mathrm{C}\right)$ & 3.85 & 3.8 & 2.46 \\
\hline \multicolumn{4}{|c|}{ Validation } \\
\hline NSE & 0.83 & 0.84 & 0.89 \\
\hline PBIAS (\%) & 0.69 & 0.38 & 4.5 \\
\hline RSR & 0.42 & 0.4 & 0.33 \\
\hline $\operatorname{MAE}\left({ }^{\circ} \mathrm{C}\right)$ & 2.97 & 2.81 & 2.26 \\
\hline $\operatorname{MSE}\left({ }^{\circ} \mathrm{C}\right)$ & 14.69 & 13.66 & 8.88 \\
\hline $\operatorname{RMSE}\left({ }^{\circ} \mathrm{C}\right)$ & 3.83 & 3.69 & 2.98 \\
\hline
\end{tabular}

NSE is Nash-Sutcliffe efficiency, PBIAS is percent bias, RSR is ratio of root mean square error to the standard deviation of observed data, MAE is mean absolute error, MSE is mean square error, RMSE is root mean square error.

\section{Hourly stream temperature models}

Results showed model evaluation tests including NSE, RSR, MAE, MSE, and RMSE all significantly $(\mathrm{p}<0.01)$ favored the hourly calibrated linear $\mathrm{T}_{\mathrm{w}}$ model over the hourly linear and hourly nonlinear $\mathrm{T}_{\mathrm{w}}$ models (with the exception of PBIAS values). Model evaluation results were not significantly $(\mathrm{p}>0.05)$ different for the hourly nonlinear $\mathrm{T}_{\mathrm{w}}$ models and the hourly linear $\mathrm{T}_{\mathrm{w}}$ models.

Results from hourly linear, hourly nonlinear, and hourly calibrated linear $\mathrm{T}_{\mathrm{w}}$ models are summarized in Table 27. Results showed five site mean NSE values ranged from 0.84 for the hourly linear $\mathrm{T}_{\mathrm{w}}$ model to 0.91 for the hourly calibrated linear $\mathrm{T}_{\mathrm{w}}$ model 
during the calibration period. Five site mean NSE values ranged from 0.83 for the hourly linear $\mathrm{T}_{\mathrm{w}}$ model to 0.90 for the hourly calibrated linear $\mathrm{T}_{\mathrm{w}}$ model during the validation period.

Five site mean PBIAS values ranged from $0.52 \%$ for the hourly linear $\mathrm{T}_{\mathrm{w}}$ model to $2.92 \%$ for the hourly calibrated linear $\mathrm{T}_{\mathrm{w}}$ model during the calibration period. Five site mean PBIAS values ranged from $1.27 \%$ for the hourly linear $\mathrm{T}_{\mathrm{w}}$ model to $4.28 \%$ for the hourly calibrated linear $\mathrm{T}_{\mathrm{w}}$ model during the validation period.

Five site mean RSR values ranged from 0.29 for the hourly calibrated linear $T_{w}$ model to 0.40 for the hourly linear $\mathrm{T}_{\mathrm{w}}$ model during the calibration period. Five site mean RSR values ranged from 0.32 for the hourly calibrated linear $T_{w}$ model to 0.41 for the hourly linear $\mathrm{T}_{\mathrm{w}}$ model during the validation period.

Five site mean MAE, MSE, and RMSE values ranged from 2.07, 7.73, and 2.78 ${ }^{\circ} \mathrm{C}$, respectively, for the hourly calibrated linear $\mathrm{T}_{\mathrm{w}}$ model to $2.97,14.64$, and $3.82{ }^{\circ} \mathrm{C}$, respectively, for the hourly linear $\mathrm{T}_{\mathrm{w}}$ model during the calibration period. Five site mean MAE, MSE, and RMSE values ranged from $2.21,8.42$, and $2.90^{\circ} \mathrm{C}$, respectively, for the hourly calibrated linear $\mathrm{T}_{\mathrm{w}}$ model to $2.93,14.48$, and $3.80{ }^{\circ} \mathrm{C}$, respectively, for the hourly linear $\mathrm{T}_{\mathrm{w}}$ model during the validation period. 
Table 27. Five site mean summary of hourly linear, nonlinear, and calibrated linear stream water temperature model evaluation results during calibration and validation periods for five gauging sites in Hinkson Creek Watershed, USA.

Five Site Mean Hourly Stream Water Temperature Model Evaluation Results

\begin{tabular}{llcl}
\hline Statistic & Linear & Nonlinear & Calibrated Linear \\
\hline & & Calibration \\
NSE & 0.84 & 0.84 & 0.91 \\
PBIAS $(\%)$ & 0.52 & 0.14 & 2.92 \\
RSR & 0.40 & 0.40 & 0.29 \\
MAE $\left({ }^{\circ} \mathrm{C}\right)$ & 2.97 & 2.97 & 2.07 \\
MSE $\left({ }^{\circ} \mathrm{C}\right)$ & 14.64 & 14.39 & 7.73 \\
RMSE $\left({ }^{\circ} \mathrm{C}\right)$ & 3.82 & 3.79 & 2.78 \\
\hline & & Validation & \\
NSE & 0.83 & 0.84 & 0.90 \\
PBIAS $(\%)$ & 1.27 & 1.18 & 4.28 \\
RSR & 0.41 & 0.40 & 0.32 \\
$\operatorname{MAE~}\left({ }^{\circ} \mathrm{C}\right)$ & 2.93 & 2.81 & 2.21 \\
$\operatorname{MSE}\left({ }^{\circ} \mathrm{C}\right)$ & 14.48 & 13.60 & 8.42 \\
RMSE $\left({ }^{\circ} \mathrm{C}\right)$ & 3.80 & 3.68 & 2.90
\end{tabular}

NSE is Nash-Sutcliffe efficiency, PBIAS is percent bias, RSR is ratio of root mean square error to the standard deviation of observed data, MAE is mean absolute error, MSE is mean square error, RMSE is root mean square error.

\section{Daily stream temperature models}

Results showed model evaluation tests including NSE, RSR, MAE, MSE, and RMSE favored the Ficklin et al. (2012) $\mathrm{T}_{\mathrm{w}}$ model over the original SWAT $\mathrm{T}_{\mathrm{w}}$ model, but the differences were not significant $(\mathrm{p}<0.05)$. Overall, every $\mathrm{T}_{\mathrm{w}}$ model tested performed well, with NSE values $>0.88$ and RMSE values $<3.17^{\circ} \mathrm{C}$. However, results from ANOVA analyses showed the daily nonlinear $\mathrm{T}_{\mathrm{w}}$ model performed significantly better than the original SWAT $\mathrm{T}_{\mathrm{w}}$ model for every model evaluation test considered including $\operatorname{NSE}(p=0.04), \operatorname{PBIAS}(\mathrm{p}<0.01), \operatorname{RSR}(\mathrm{p}<0.01), \operatorname{MAE}(\mathrm{p}<0.01), \operatorname{MSE}(\mathrm{p}<0.01)$, and RMSE ( $\mathrm{p}<0.01$ ) during the validation period (WY 2013). The calibrated linear $\mathrm{T}_{\mathrm{w}}$ model 
showed significantly $(\mathrm{p}<0.01)$ lower error (MAE, MSE, and RMSE) compared to the original SWAT $\mathrm{T}_{\mathrm{w}}$ during the validation period Results from daily linear, daily nonlinear, daily calibrated linear, the original SWAT model, and the Ficklin et al. (2012) $\mathrm{T}_{\mathrm{w}}$ models are summarized in Table 28 .

Results showed the mean NSE values for all five sites ranged from 0.90 for the original SWAT $\mathrm{T}_{\mathrm{w}}$ model to 0.94 for the daily nonlinear $\mathrm{T}_{\mathrm{w}}$ model during the calibration period. The mean NSE values for all five sites ranged from 0.88 for the original SWAT $\mathrm{T}_{\mathrm{w}}$ model to 0.91 for the daily nonlinear $\mathrm{T}_{\mathrm{w}}$ model during the validation period.

The mean PBIAS values for all five sites ranged from $-4.64 \%$ for the original SWAT $\mathrm{T}_{\mathrm{w}}$ model to $3.02 \%$ for the Ficklin et al. (2012) $\mathrm{T}_{\mathrm{w}}$ model during the calibration period. The mean PBIAS values for all five sites ranged from $-4.99 \%$ for original SWAT $\mathrm{T}_{\mathrm{w}}$ model to 5.6\% for the Ficklin et al. (2012) $\mathrm{T}_{\mathrm{w}}$ model during the validation period.

The mean RSR values for all five sites ranged from 0.24 for the daily calibrated linear $\mathrm{T}_{\mathrm{w}}$ model to 0.32 for the original SWAT $\mathrm{T}_{\mathrm{w}}$ model during the calibration period. The mean RSR values for all five sites ranged from 0.29 for the daily nonlinear $T_{w}$ model to 0.35 for the original SWAT $\mathrm{T}_{\mathrm{w}}$ model during the validation period.

The original SWAT $\mathrm{T}_{\mathrm{w}}$ model showed the greatest amount of error with the mean MAE, MSE, and RMSE values for all five sites of from $2.28,9.07$, and $3.01{ }^{\circ} \mathrm{C}$, respectively, during the calibration period, and, $2.45,10.10$, and 3.17 , respectively, during the validation period. The calibrated linear $T_{w}$ model showed the least amount of error during the calibration period with the mean MAE, MSE, and RMSE values for all five sites ranging from $1.94,6.76$, and $2.60{ }^{\circ} \mathrm{C}$, respectively. The nonlinear $\mathrm{T}_{\mathrm{w}}$ model 
showed the least amount of error during the validation period with the mean MAE, MSE, and RMSE values for all five sites ranging from $1.99,7.07$, and $2.65^{\circ} \mathrm{C}$, respectively.

Table 28. Summary of the mean model evaluation results from all five sites for the daily linear, nonlinear, calibrated linear, original SWAT, and Ficklin et al. (2012) stream water temperature model evaluation results during calibration and validation periods for five gauging sites in Hinkson Creek Watershed, U.S.A.

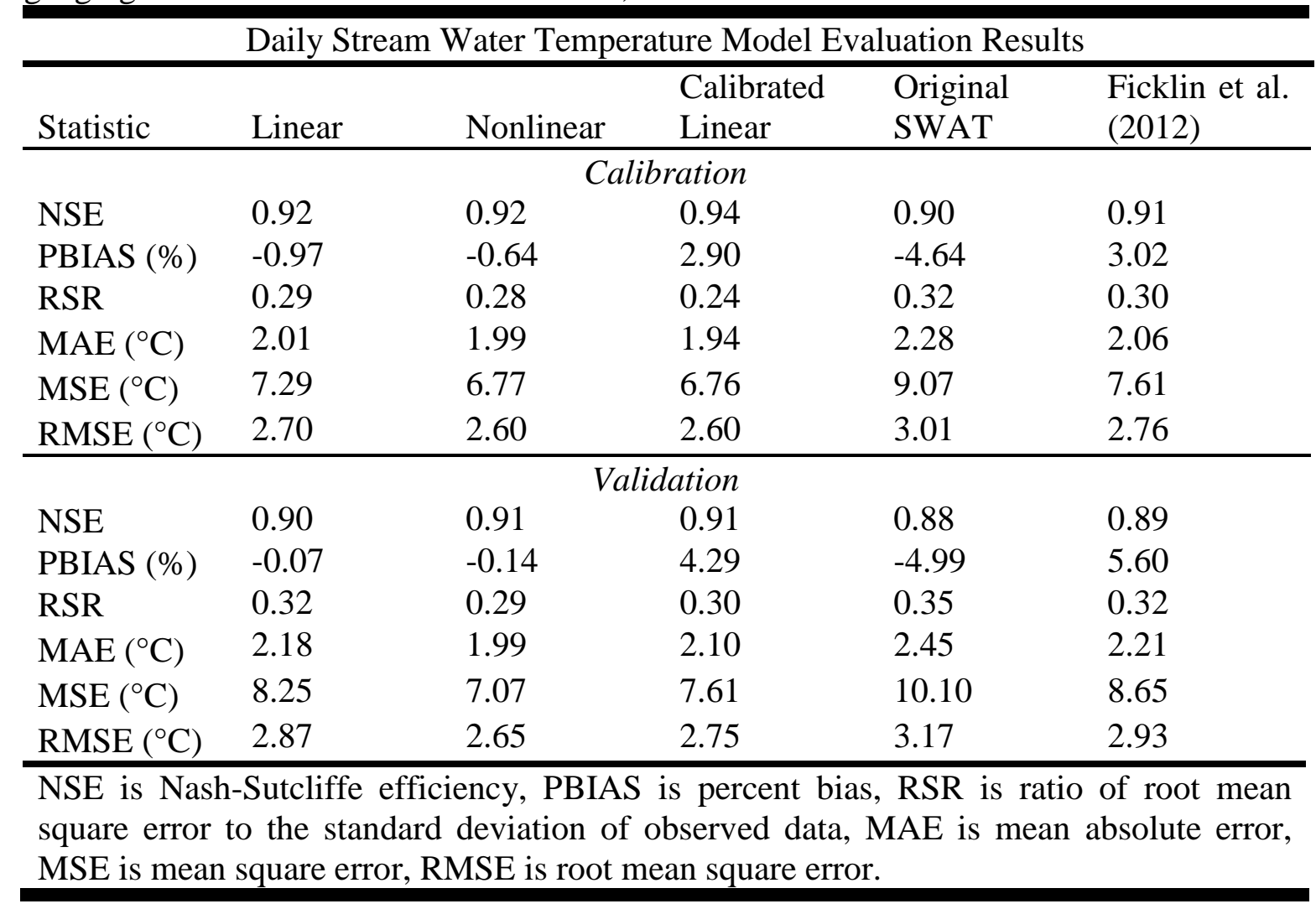




\section{CHAPTER IV}

\section{DISSCUSSION}

\section{HYDROCLIMATE}

\section{Climate}

Climate during the three year study period (WY 2011 - 2013) recorded at Sanborn Field climate station located on University of Missouri campus is shown in Appendix A. Climate during the study period was generally dryer than average. Drought conditions were observed during summer of WY 2012. Average annual total precipitation of $837.9 \mathrm{~mm}$ recorded during the three year study period was approximately $244 \mathrm{~mm}$ less than the aforementioned 30 year historic annual average precipitation of $1082 \mathrm{~mm}$. Average annual mean $\mathrm{T}_{\mathrm{a}}$ of $13.1^{\circ} \mathrm{C}$ was approximately $1.0^{\circ} \mathrm{C}$ lower than the historic annual average of $14{ }^{\circ} \mathrm{C}$. Average annual total daily solar radiation was of $13.8 \mathrm{MJ} / \mathrm{m}^{2}$ was $0.7 \mathrm{MJ} / \mathrm{m}^{2}$ lower than the 14 year record of $14.5 \mathrm{MJ} / \mathrm{m}^{2}$ measured at Sanborn Field climate station.

One-way ANOVA revealed significant $(\mathrm{p}=0.01)$ differences in daily mean $\mathrm{T}_{\mathrm{a}}$. Tukey-Kramer post hoc multiple comparison tests showed mean $\mathrm{T}_{\mathrm{a}}$ was significantly ( $\mathrm{p}=0.01) 1.2{ }^{\circ} \mathrm{C}$ higher at site \#3 compared to site \#1 (Figure 6). Considering site \#3 climate station is located in the urban area of HCW $(2.5 \mathrm{~km}$ east of the center of the City of Columbia) while site \#1 climate station is located in the rural area of HCW $(11.2 \mathrm{~km}$ northeast of the center of the City of Columbia), these results supply evidence of an urban heat island effect. Daily mean $\mathrm{T}_{\mathrm{a}}$ was greater at site \#3 compared to site \#1 by $1.6^{\circ} \mathrm{C}$. Studies by Akyuz et al. (2004) and Hubbart et al. (2014) also reported a "distinct urban 
influence" on $\mathrm{T}_{\mathrm{a}}$ in Columbia, Missouri. Akyuz et al. (2004) reported monthly maximum $\mathrm{T}_{\mathrm{a}}$ was $1.5^{\circ} \mathrm{C}$ to $3.5^{\circ} \mathrm{C}$ greater in urban sites compared to rural sites. Hubbart et al. (2014) showed an urban heat island effect on local climate during 1995 to 2013 where significant differences $(\mathrm{p}<0.01)$ in mean air temperature and relative humidity ranged from $13.47{ }^{\circ} \mathrm{C}$ and $12.89^{\circ} \mathrm{C}$, and $69.11 \%$ and $72.51 \%$ in urban and rural sites, respectively.

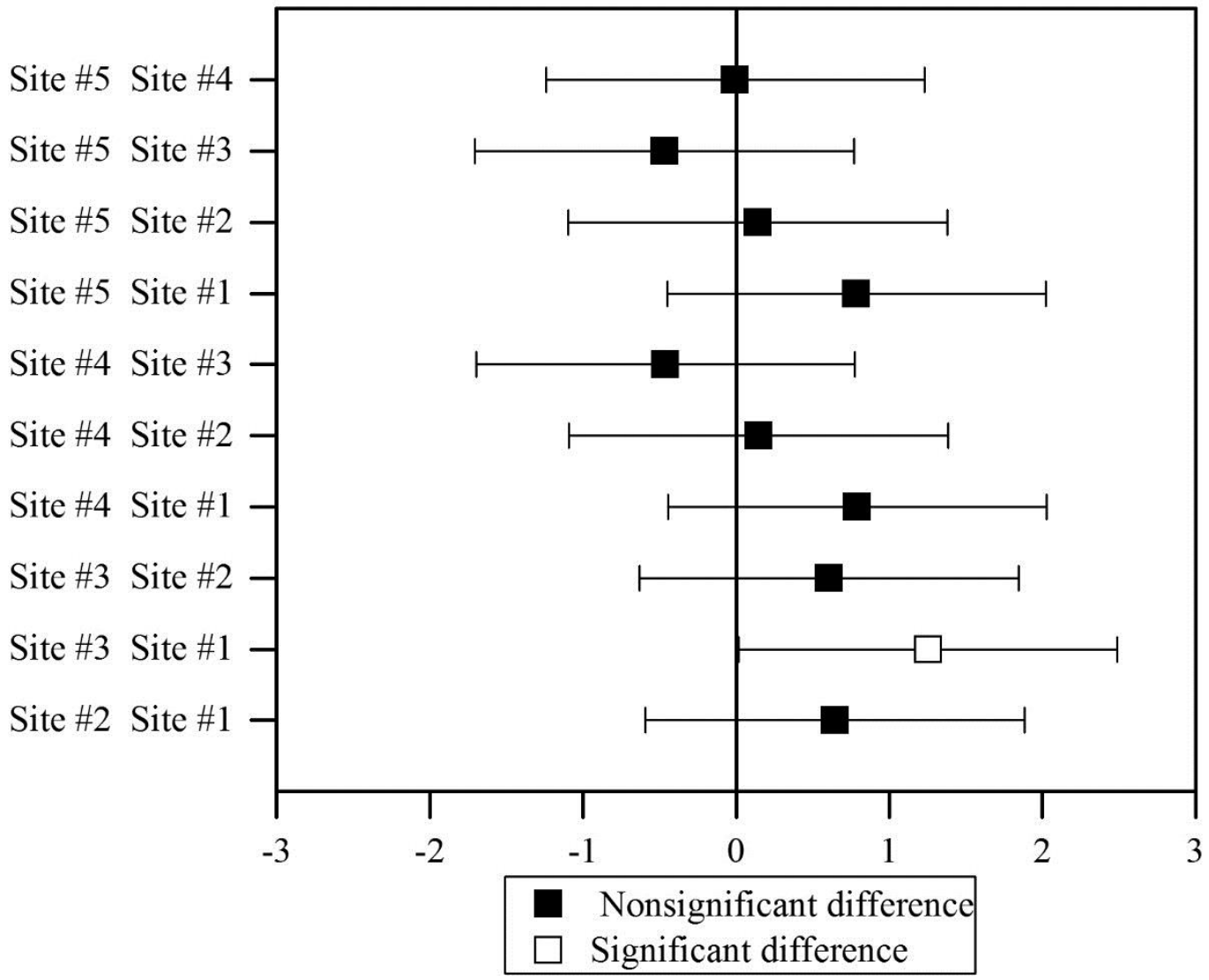

Figure 6. Tukey-Kramer multiple comparison results showing significant differences in daily mean air temperature in Hinkson Creek Watershed, Missouri, USA. The x-axis shows confidence interval values. The y-axis shows all possible pairs of sample means being compared. The bars show the confidence interval for each pair of sample means being compared. A significant difference is shown when a confidence interval does not contain the value of zero. 


\section{Discharge}

Dryer than average climate conditions during throughout the study period affected average discharge as well. Problems associated with decreased discharge during times of high temperature (summer months) are exacerbated with increased stream water evaporation rates and can impact aquatic ecosystem health (Bond et al. 2008). As water levels recede from riparian and littoral (shallow well lit portion of a stream) zones lateral connectivity between riparian zone and the stream is reduced leading to reduced habitat area (Boulton, 2003). Non motile fauna and flora in the littoral zone are left stranded to desiccate. Normally productive photosynthetic macrophytes in the littoral zone can no longer provide needed DO to microorganisms, macroinvertebrates, herptiles, and fish (Furey et al. 2006).

Precipitation and flow graphs in Figure 7 show precipitation and discharge data recorded at five gauging sites during the three year study period (WY 2011 - 2013). Mean discharge at site \#4 during the three year study period was $0.18 \mathrm{~m}^{3} / \mathrm{s}$ less than the aforementioned 23 year historic annual average discharge of $1.78 \mathrm{~m}^{3} / \mathrm{s}$ recorded at U.S. Geological Survey gauging station (\#06910230). Mean discharge was lowest at site \#1 and greatest at site \#5 as expected because site \#1 is in the headwaters and site \#5 is near the watershed outlet. Maximum discharge was greatest as site \#5 (137.9 $\left.\mathrm{m}^{3} / \mathrm{s}\right)$ as expected because drainage area was greatest at site \#5 nearest the watershed outlet.

Results of One way ANOVA indicated significant $(\mathrm{p}<0.01)$ differences in daily mean discharge between the five HC gauging stations. Tukey-Kramer multiple comparison test showed mean discharge was significantly higher at site \#5 compared to all other HC sites (Figure 8). Site \#4 daily mean discharge was significantly higher than 
gauging sites $\# 1$ and \#2. It's reasonable to expect that sites \#4 and \#5 would have significantly higher discharge considering drainage area increases from site \#1 to site \#5. In fact, sites \#4 and \#5 drain 78 and $89 \%$ of $\mathrm{HCW}$, respectively. There was a linear relationship found between observed mean discharge and drainage area upstream of the gauging site $\left(\mathrm{r}^{2}=0.842\right)$. There was also a linear relationship between discharge and percent urban land use upstream of the gauging site $\left(\mathrm{r}^{2}=0.946\right)$. Urban land use area (associated with impervious surfaces) increases exponentially from site \#1 to \#5 (Figure 9). At site \#5, Hinkson Creek drains approximately $60 \%$ of the City of Columbia which contains $27.74 \mathrm{~km}^{2}$ of impervious surface (Zhou et al. 2012). Impervious surfaces degrade the quality and increase the quantity of stormwater runoff (Brabec et al. 2002) by decreasing soil infiltration rates. Many stormwater drains in Columbia direct stormwater runoff into Hinkson Creek. Thus, area of the watershed drained and urban land use affected discharge in Hinkson Creek (Table 2). 


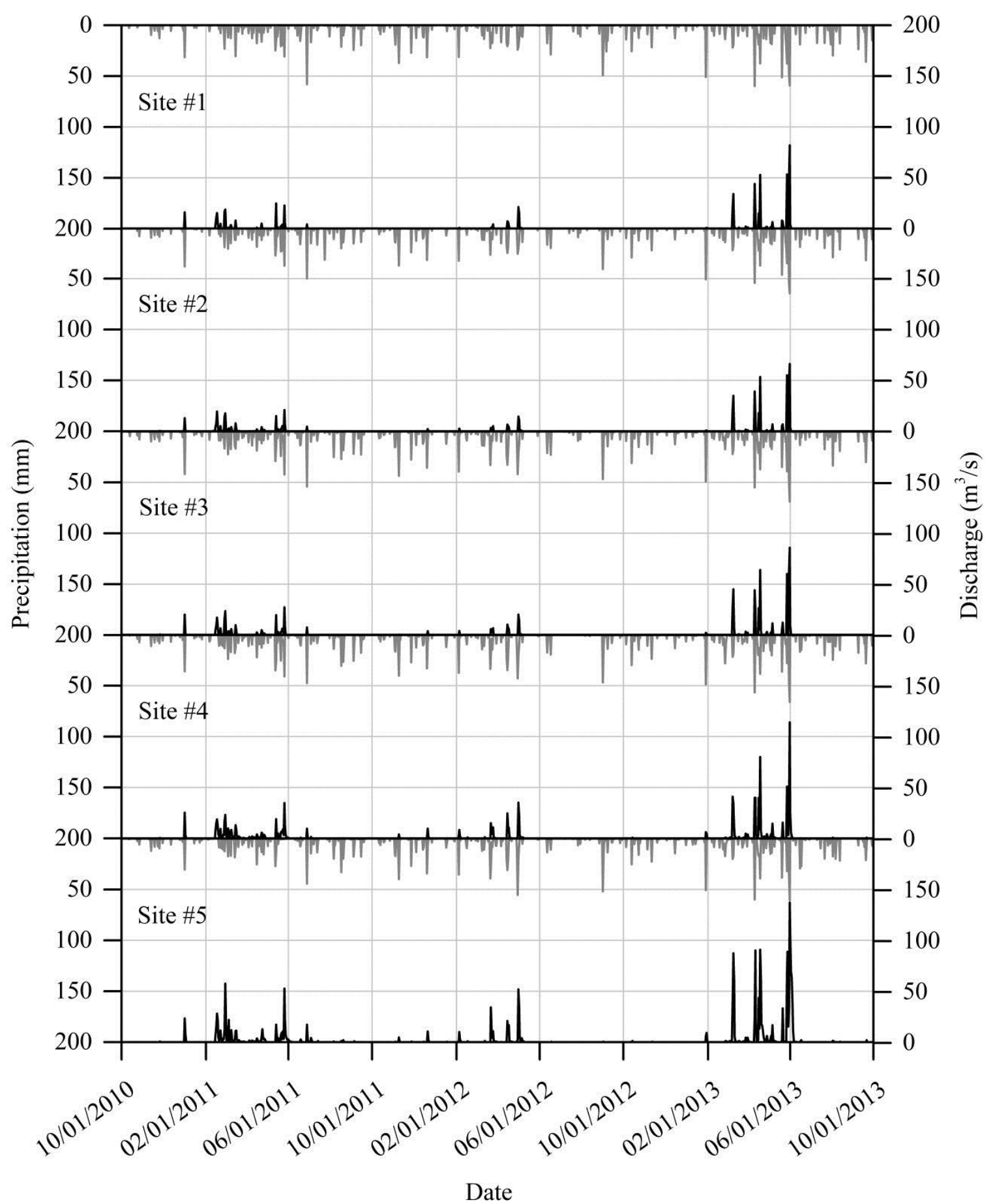

Figure 7. Time series precipitation and discharge are shown for the study period (WY 2010 - 2013) recorded at five climate stations (site \#1 on top - site \#5 on bottom) located in Hinkson Creek Watershed, Missouri, USA. 


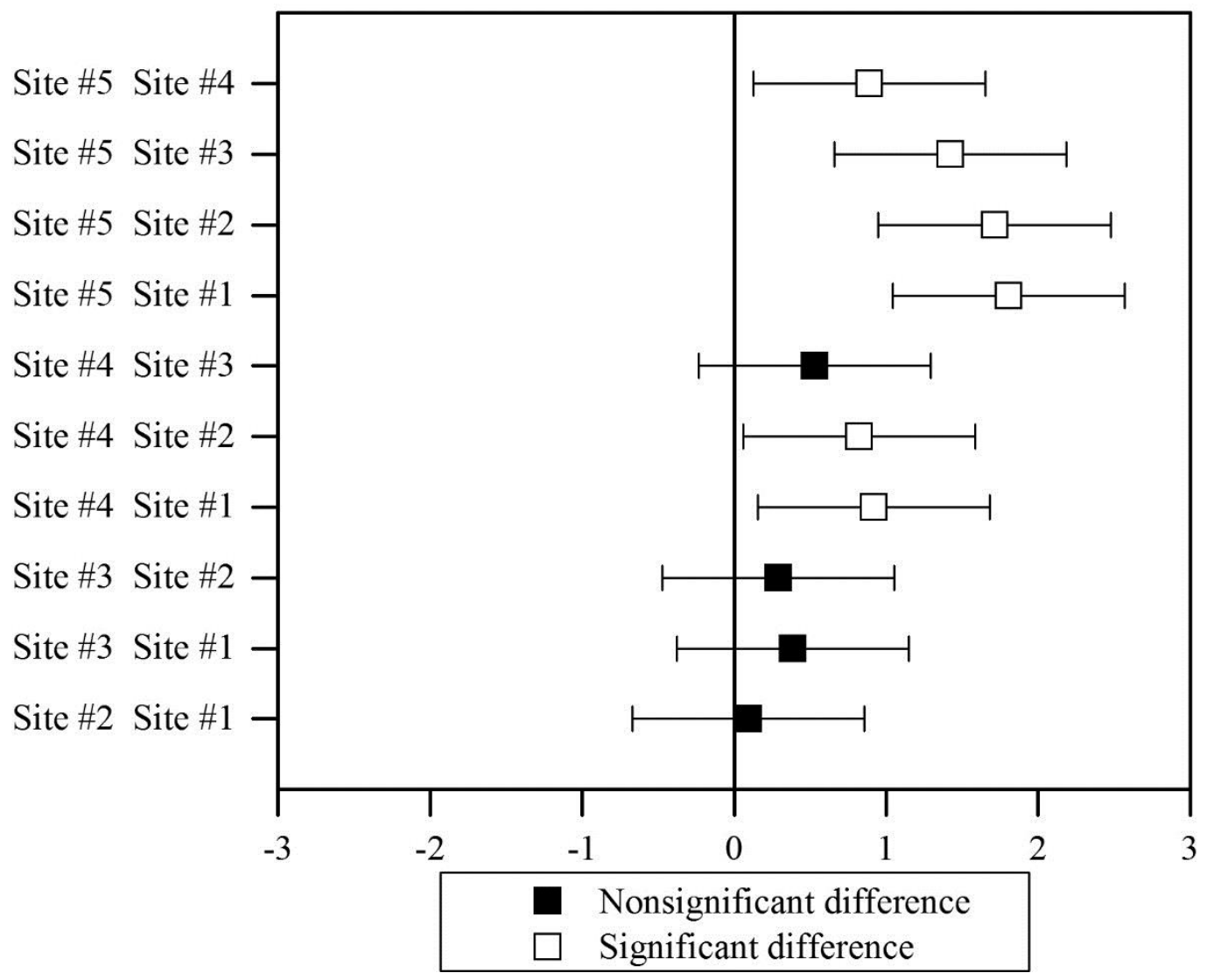

Figure 8. Tukey-Kramer multiple comparison results showing significant differences in daily mean discharge in Hinkson Creek Watershed, Missouri, USA. The x-axis shows confidence interval values. The $y$-axis shows all possible pairs of sample means being compared. The bars show the confidence interval for each pair of sample means being compared. A significant difference is shown when a confidence interval does not contain the value of zero. 


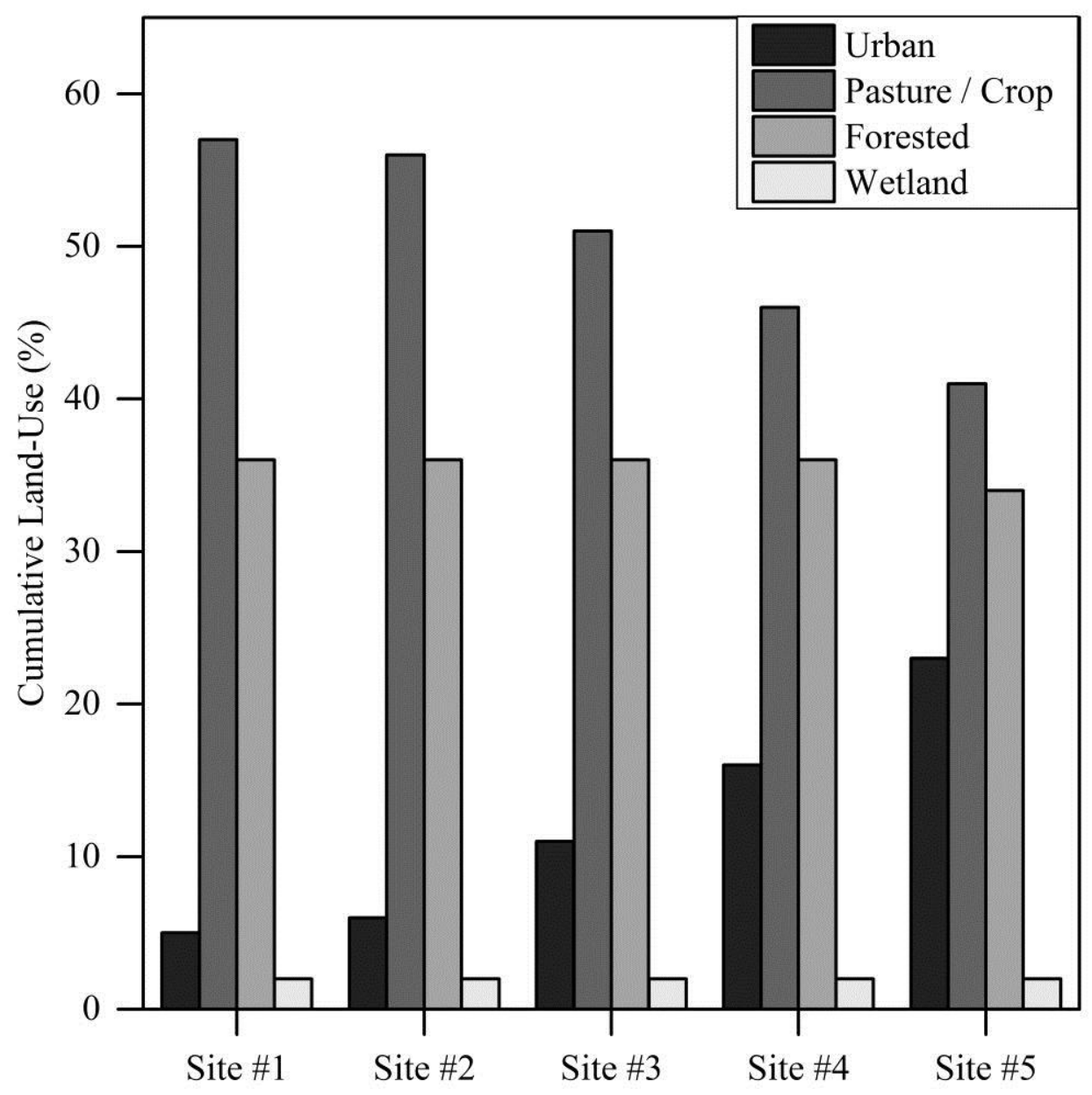

Figure 9. Cumulative land use percent showing percent urban, pasture / crop, forested, and wetland land uses for five subbasins located in Hinkson Creek Watershed, Boone County, Missouri. Site number increases with downstream distance from the headwaters. Site \#1 is located in the headwaters, and site \#5 is located near the watershed outlet.

\section{Stream water temperature}

While the differences between monitoring sites found in daily mean $T_{w}$ were not significant $(\mathrm{p}=0.51)($ Figure 10), there were significant $(\mathrm{p}<0.01)$ differences found in 15 minute mean $T_{w}$ between gauging sites during the study period, for each water year (WY 2011, 2012, 2013), and for each season (winter, spring, summer). 
The differences in $\mathrm{T}_{\mathrm{w}}$ were presumably attributable to differences in natural processes (e.g. meteorological conditions, and stream discharge, hydrogeomorphological variability) at each site and anthropogenic impacts from the drainage area upstream and upland of each gauging site. Maximum, mean, and minimum $\mathrm{T}_{\mathrm{a}}$ data were lower at site \#1 compared to all other sites. The differences in $\mathrm{T}_{\mathrm{a}}$ were, in part, due to an urban heat island effect. Site \#1 has 1 to $18 \%$ less urban land use than the other sites.

Topographic differences, including stream width and stream length, between monitoring sites could also explain the differences in daily mean $\mathrm{T}_{\mathrm{w}}$ since at the time of this study site \#1 had the narrowest stream width $(12.2 \mathrm{~m})$ while site \#4 had the widest channel (18.4 m). Narrow stream channels in headwater subbasins like site \#1 can have lower $\mathrm{T}_{\mathrm{w}}$ due to increased sheltering of stream heating from incoming solar radiation by overhanging riparian vegetation and stream banks (Webb, 2008). Wider stream channels are often less shaded and wind sheltered by riparian vegetation (Caissie, 2006). Consequently, more solar radiation and advected energy can reach the stream surface.

Stream water temperature has also been shown to increase with linear stream distance and with percent urban land use (Caissie, 2006). The stream is exposed to meteorological conditions (including solar radiation) as the stream flows from its source in the headwaters to the watershed outlet. When $T_{w}$ variability was investigated for each season during the study period results showed mean $\mathrm{T}_{\mathrm{w}}$ increased with downstream distance during the spring, but the same trend was not observed in the winter or summer seasons. Spring is the wet season in the central U.S. As a result, discharge is usually higher. As discharge increases, residence time decreases, and the stream is well mixed. There was a general trend for increased $\mathrm{T}_{\mathrm{w}}$ with stream distance during the spring. In this 
research the linear relationship between daily mean $T_{w}$ and stream distance was weak $\left(\mathrm{r}^{2}=0.30\right)$ and not significant $(\mathrm{p}=0.20)$ for the entire study period. Thus, stream distance did not account for $70 \%$ of the explained variance in mean $\mathrm{T}_{\mathrm{w}}$ for the study period Multiple regression analysis showed stream distance and urban land use combined increased the explained variance to 0.78 , but the relationship was not significant $(\mathrm{p}=0.11)$. When mean $\mathrm{T}_{\mathrm{w}}$ during the spring was regressed against stream distance, however, explained variance in mean $\mathrm{T}_{\mathrm{w}}$ significantly $(\mathrm{p}=0.04)$ increased by $42 \%$ $\left(\mathrm{r}^{2}=0.72\right)$. Multiple regression analysis showed stream distance and urban land use combined increased the explained variance in mean $\mathrm{T}_{\mathrm{w}}$ during the spring to $98 \%$ ! $\left(\mathrm{r}^{2}=0.98\right)$. This was also shown to be a significant relationship $(\mathrm{p}<0.01)$. 


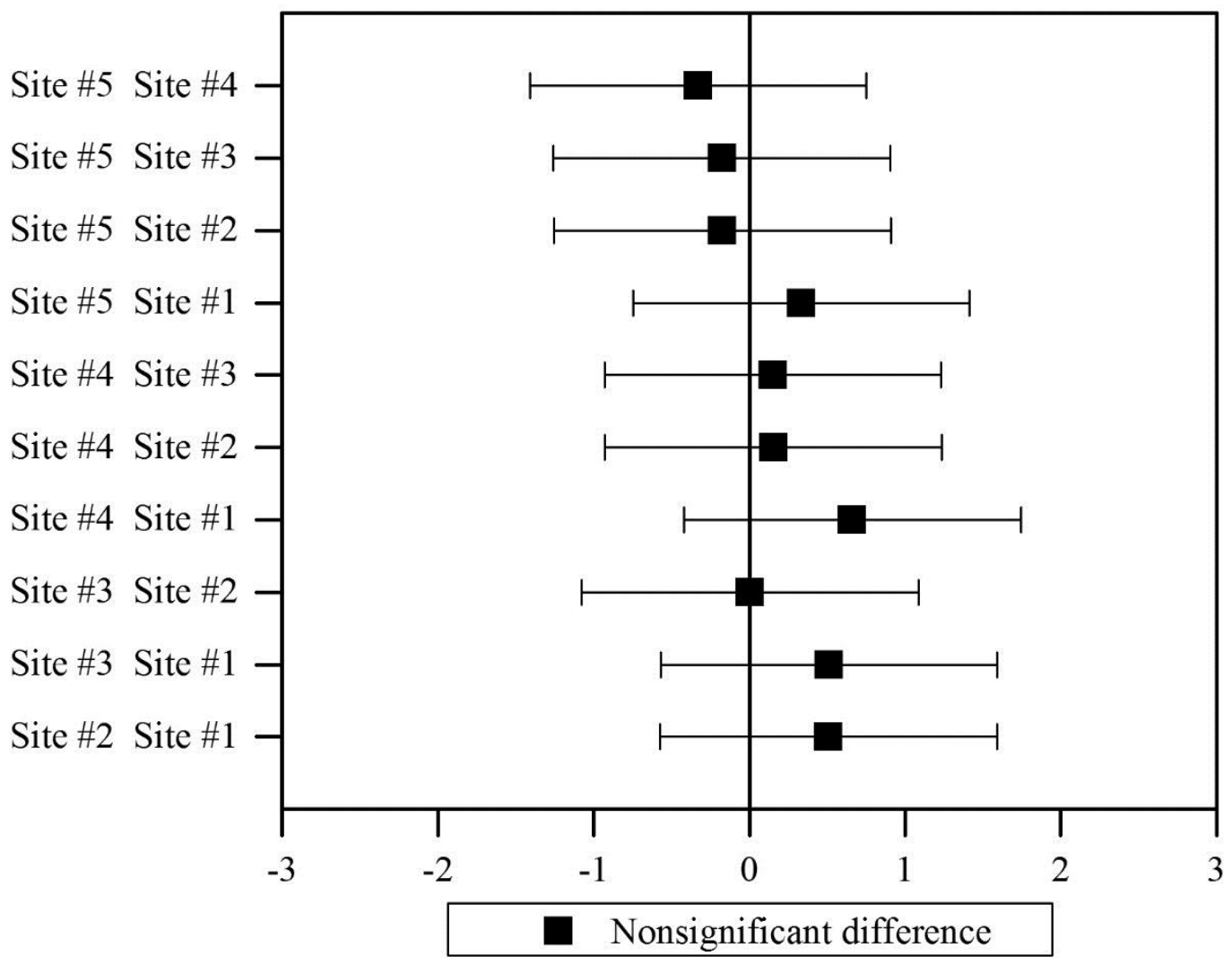

Figure 10. Tukey-Kramer multiple comparison results showing no significant differences in daily mean stream water temperature in Hinkson Creek, Missouri, USA. The x-axis shows confidence interval values. The y-axis shows all possible pairs of sample means being compared. The bars show the confidence interval for each pair of sample means being compared. A significant difference is shown when a confidence interval does not contain the value of zero.

\section{Thermal maximum}

The stacked plot in Figure 11 shows when $\mathrm{T}_{\mathrm{w}}$ exceeded the $32^{\circ} \mathrm{C}$ thermal maximum threshold and the $35^{\circ} \mathrm{C}$ critical thermal maximum threshold. The number of day's $\mathrm{T}_{\mathrm{w}}$ was above the $32{ }^{\circ} \mathrm{C}$ thermal maximum peaked at site \#3 for 55 days and decreased with stream distance. Maximum $\mathrm{T}_{\mathrm{w}}$ was above the $35^{\circ} \mathrm{C}$ critical thermal maximum at site \#3 for 5 days. In comparison to the study by Sinokrot and Gulliver (2000) in Platte River, Nebraska, the maximum number of day's $T_{w}$ was above $32{ }^{\circ} \mathrm{C}$, 
and $35^{\circ} \mathrm{C}$ was 46 days fewer, and 21 days fewer, respectively, in Hinkson Creek. The Platte River in Nebraska has a reputation for being "a mile wide and an inch deep". Increased stream width most likely contributed to the difference in the number of days $T_{w}$ was greater than $32{ }^{\circ} \mathrm{C}$, and $35^{\circ} \mathrm{C}$ during the study when discharge was low and solar radiation rates were high. 


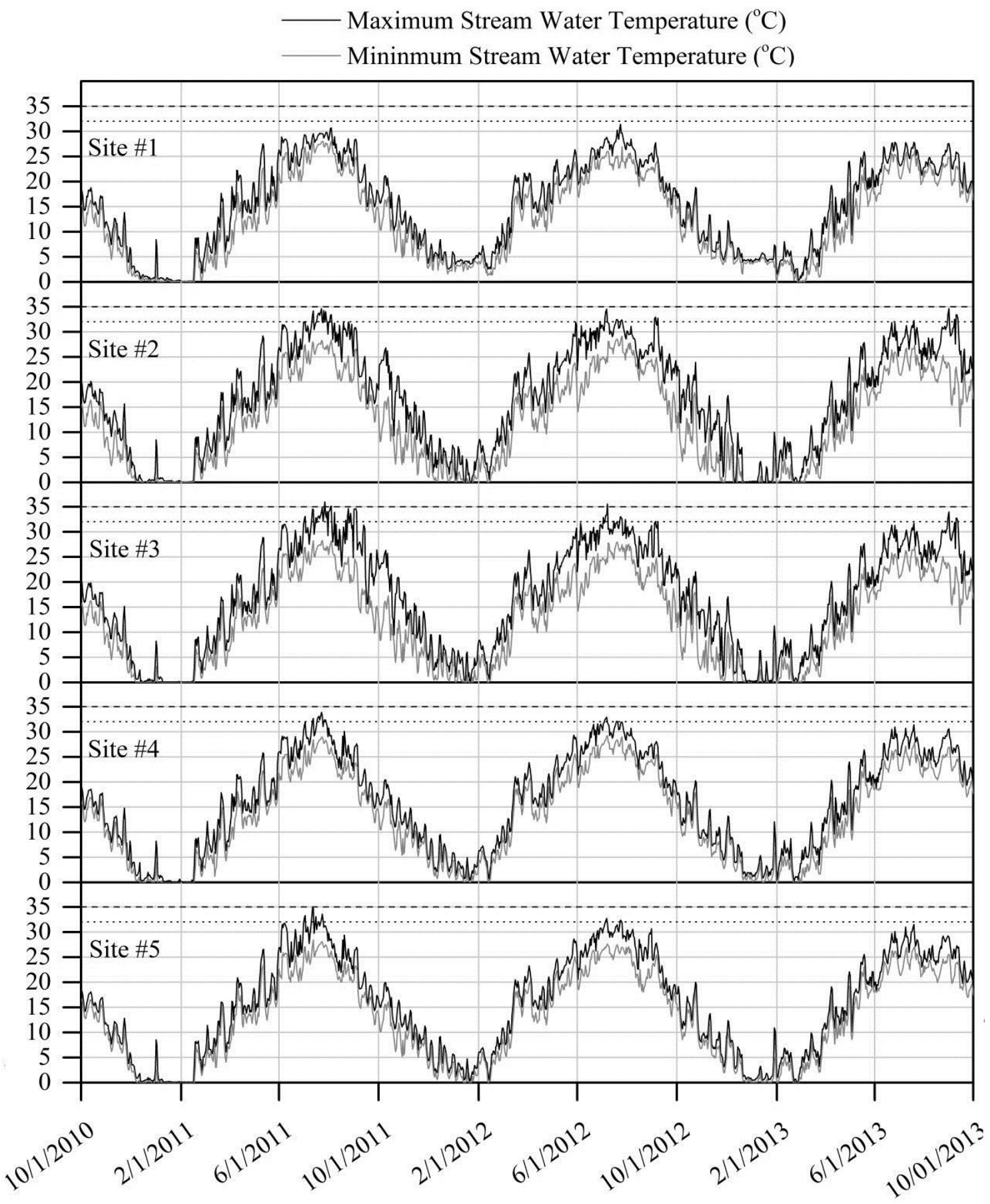

Figure 11. Time series daily maximum and minimum stream water temperatures are shown for the study period (WY 2010 - 2013) recorded at five climate stations (site \#1 on top - site \#5 on bottom) located in Hinkson Creek Watershed, Missouri, USA. The dotted line signifies the $32{ }^{\circ} \mathrm{C}$ thermal maximum threshold. The dashed line signifies the $35{ }^{\circ} \mathrm{C}$ critical thermal maximum threshold. 
During the summer of $2012, \mathrm{~T}_{\mathrm{w}}$ peaked at $36.1^{\circ} \mathrm{C}$ and exceeded the critical thermal maximum threshold of $35^{\circ} \mathrm{C}$ for 2.5 hours at site \#3, in part, due to reduced streamflow. Reduced cloud cover increased direct beam solar radiation at the stream surface. The stream reach at site \#3 is lined with limestone bedrock. When limestone bedrock is heated by incoming solar radiation, the bedrock reemits long wave radiation that can lead to stream water heating (Webb et al. 2008). Residence time increased as discharge decreased at site \#3. Stream water is exposed to local contributions to stream heating as residence time increases (Erickson and Stefan, 2000). Additionally, lower volumes of stream water associated with reduced rainfall respond faster to temperature changes considering heat capacity of water is dependent on the volume of water (Erickson and Stefan, 2000).

Considering anthropogenic impacts including deforestation, flow alteration, and increased impervious surfaces have been shown to affect $\mathrm{T}_{\mathrm{w}}$ regimes (Caissie, 2006; Webb et al. 2008), anthropogenic impacts may have contributed to the high $\mathrm{T}_{\mathrm{w}}$ recorded at site \#3. Percent urban land use in site \#3 was $11 \%$. Urban land use associated with impervious surfaces could have contributed to the observed urban heat island effect where maximum, mean and minimum $\mathrm{T}_{\mathrm{a}}$ were greatest at urban site $\# 3$ (Hubbart et al. 2014).

Sudden rises in stream water temperature

To investigate urban land use effects on stream heating, Thermochron iButtons (temperature sensors) were deployed during summer 2009 (June $1^{\text {st }}$ to August $31^{\text {st }}$ ). Twenty-three iButton temperature sensors detected $T_{w}$ surges during summer 2009 from 
the urbanized reaches of Hinkson Creek. The $\mathrm{T}_{\mathrm{w}}$ surges were observed following summertime precipitation events when heat from the impervious surfaces was transferred to stormwater runoff and transported into Hinkson Creek. It was assumed that impervious surfaces were hottest in the summer during the early afternoon when seasonal and diel solar radiation rates were highest for the year.

A recent study by Hester and Baumen (2012) also showed $\mathrm{T}_{\mathrm{w}}$ surges at a stormwater outfall at Stroubles Creek located in Blacksburg, Virginia USA during summer of 2009, corresponding to the time when the iButton sensors were deployed in Hinkson Creek. The $\mathrm{T}_{\mathrm{w}}$ surges recorded by iButton sensors in Hinkson Creek showed mean $\mathrm{T}_{\mathrm{w}}$ surge and mean $\mathrm{T}_{\mathrm{w}}$ surge duration $>1.2^{\circ} \mathrm{C}$ and $>9.4$ hours, respectively, compared to the study by Hester and Baumen (2012). Maximum $T_{w}$ surge and maximum $\mathrm{T}_{\mathrm{w}}$ surge duration $>5.6^{\circ} \mathrm{C}$ and $>24.75$ hours, respectively. The differences in magnitude and duration of $T_{w}$ surges were likely due to difference in location of the $T_{w}$ sensors, and the amount of water present (i.e. discharge) at the location of the sensor.

$T_{w}$ surges were also observed when data were analyzed from the in-stream $T_{w}$ sensors at each of the five gauging site in Hinkson Creek during summers of 2010, 2011, and 2012. Examples of $T_{\mathrm{w}}$ surges found in this study are provided in Figures 12, 13, and 14. Figure 12 shows how relatively small $\mathrm{T}_{\mathrm{w}}$ surges (approximately $1{ }^{\circ} \mathrm{C}$ increase in $\mathrm{T}_{\mathrm{w}}$ within 15 minutes) persisted from suburban site \#3 to downstream gauging sites \#4 and $\# 5$. The $\mathrm{T}_{\mathrm{w}}$ surge began at site \#3 as discharge increased following a precipitation event at 6:00 a.m. on July $20^{\text {th }}, 2010$ (Figure 12). Figure 13 shows how plumes of heated stormwater with a peak discharge of approximately $40 \mathrm{~m}^{3} / \mathrm{s}$ can increase $T_{w}$ by as much as $4{ }^{\circ} \mathrm{C}$ for up to 5 hours as the flood wave moves downstream from the City of 
Columbia. The $\mathrm{T}_{\mathrm{w}}$ surge at site \#5 at 18:00 p.m. on July $3^{\text {rd }}, 2011$ was not detected upstream at gauging site \#4. Therefore the $\mathrm{T}_{\mathrm{w}}$ surge must have come from stormwater runoff that entered the stream downstream of site \#4. Flat Branch Creek, a $1^{\text {st }}$ order tributary of Hinkson Creek, intersects with Hinkson Creek between sites \#4 and \#5 approximately 1.3 linear km downstream of site \#4. The headwaters of Flat Branch Creek originate in the downtown area of the City of Columbia and drain the majority of the high density urban land use from the City of Columbia. Rain transported heated stormwater runoff into Hinkson Creek between sites \#4 and \#5. This finding was important because it showed how the nested-scaled experimental watershed study design traced the source of a nonpoint source thermal pollutant.

Figure 14 shows how small summer precipitation events during summertime can transport heat into Hinkson Creek leading to $\mathrm{T}_{\mathrm{w}}$ surges, even in the middle of the night. For example, at 23:00 p.m. on July $29^{\text {th }}, 2012$ (during the summer of drought) discharge was low in Hinkson Creek at site \#3 $\left(<0.1 \mathrm{~m}^{3} / \mathrm{s}\right)$. A small precipitation event that occurred at approximately 00:15 a.m. transported heat from the urban subbasin \#3 into Hinkson Creek. At that time, there were two $\mathrm{T}_{\mathrm{w}}$ surges detected at site \#3 with a mean $\mathrm{T}_{\mathrm{w}}$ surge of approximately $1.5^{\circ} \mathrm{C}$. Had the precipitation event been larger and occurred when impervious surfaces were hottest for the day (e.g. around 18:00 hours) like the event observed in Figure 13, the magnitude and duration of the $T_{\mathrm{w}}$ surge observed in Figure 14 could have been larger. 


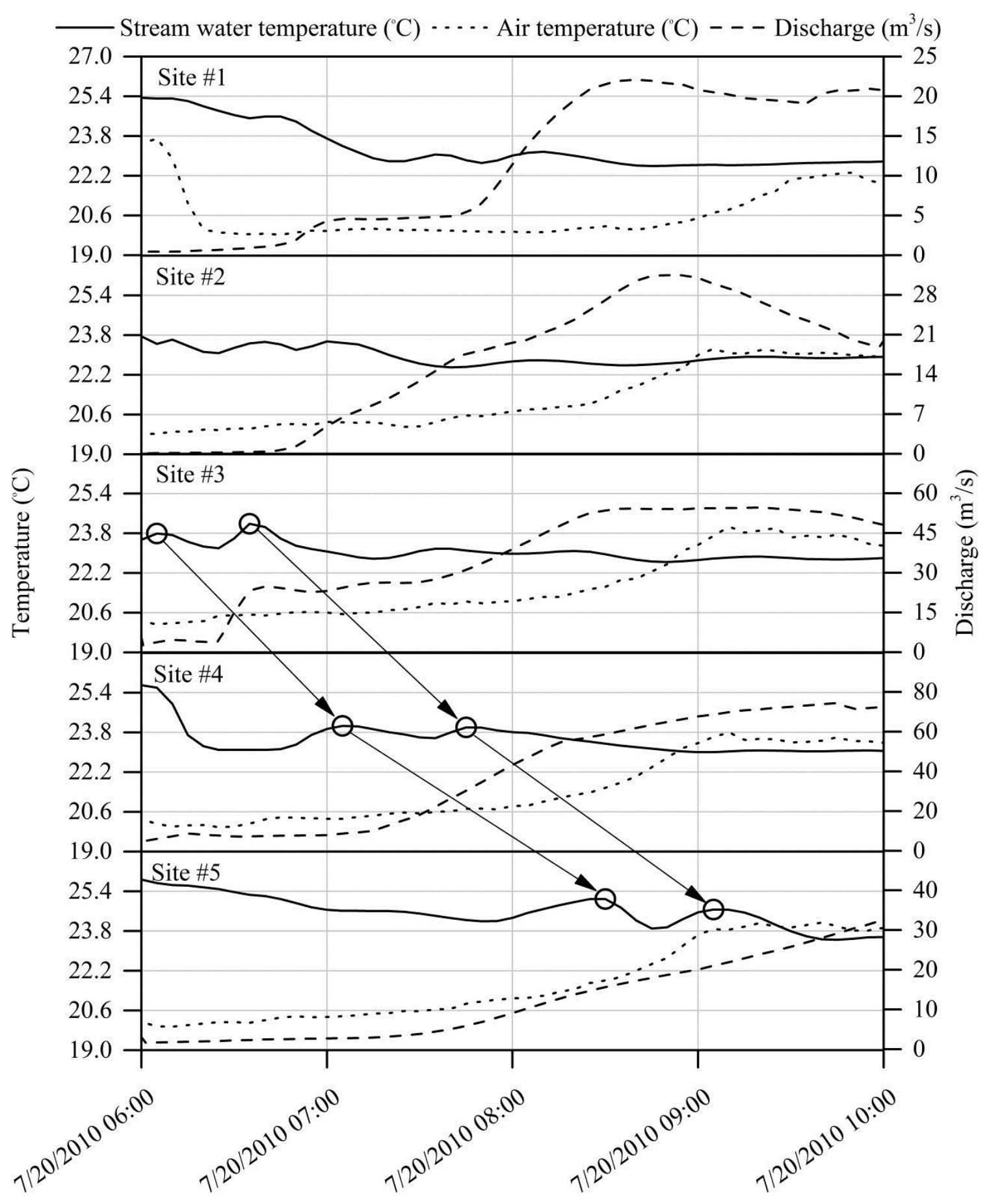

Figure 12. Stream water temperature surges following a summer thunderstorm sensed at gauging sites \#3, \#4, and \#5 in Hinkson Creek near sunset during summer 2010. The black circles mark the peak $T_{w}$ surges and the arrows track the $T_{w}$ surges downstream from site \#3 to sites \#4 and \#5. This figure shows how $\mathrm{T}_{\mathrm{w}}$ surges persisted at downstream gauging sites and how $\mathrm{T}_{\mathrm{w}}$ surge duration was longer at sites \#4 and \#5. 


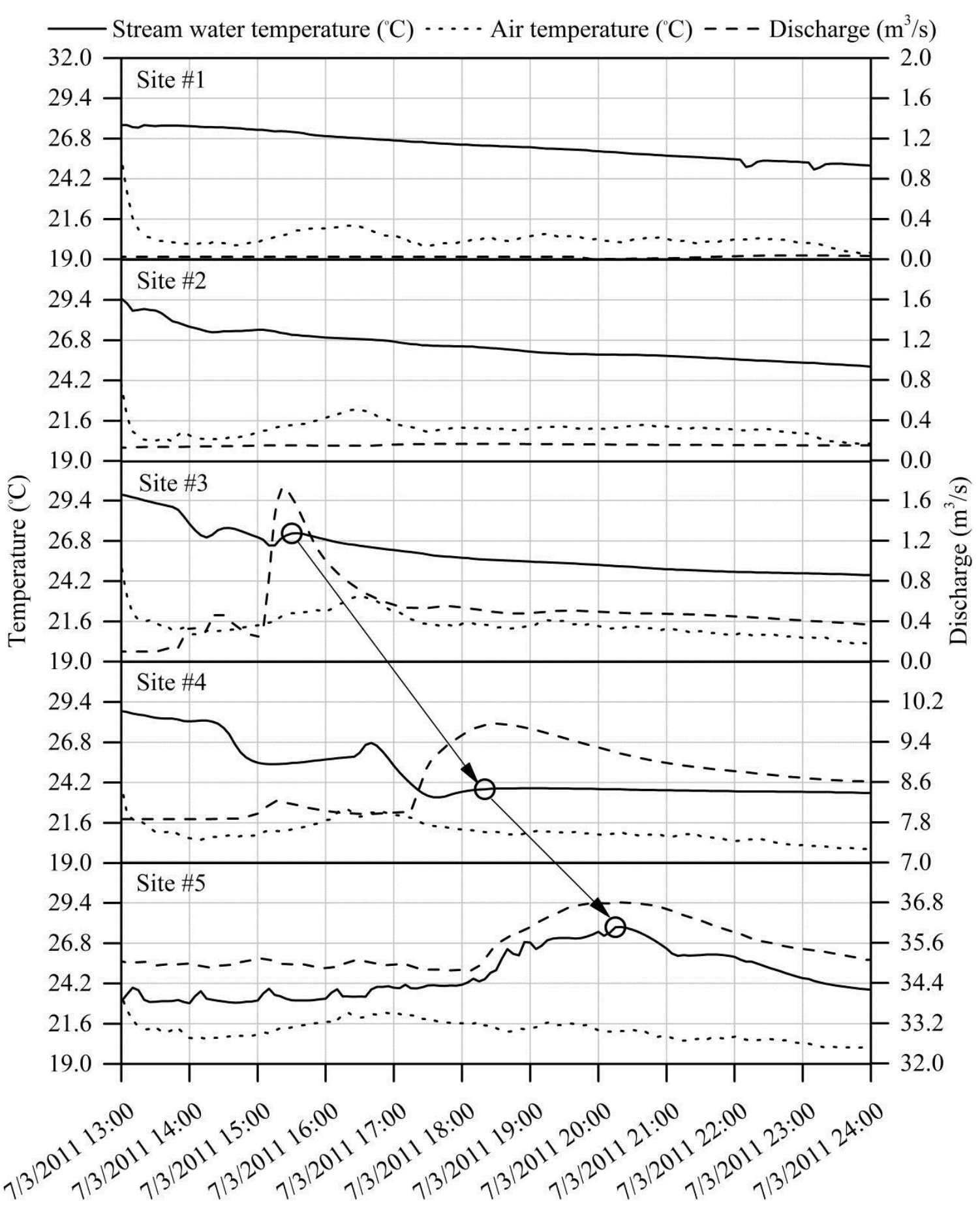

Figure 13. Plume of heated stormwater after a summer thunderstorm sensed at site \#5 in Hinkson Creek during summer 2011. The black circles mark the peak $\mathrm{T}_{\mathrm{w}}$ after the increase in discharge and the arrows track the event downstream from site \#3 to sites \#4 and \#5. The plume of heated stormwater was observed at site \#5, but not upstream at site $\# 4$. Thus, the origin of the heated stormwater was downstream of site \#4 and upstream of site \#5. 


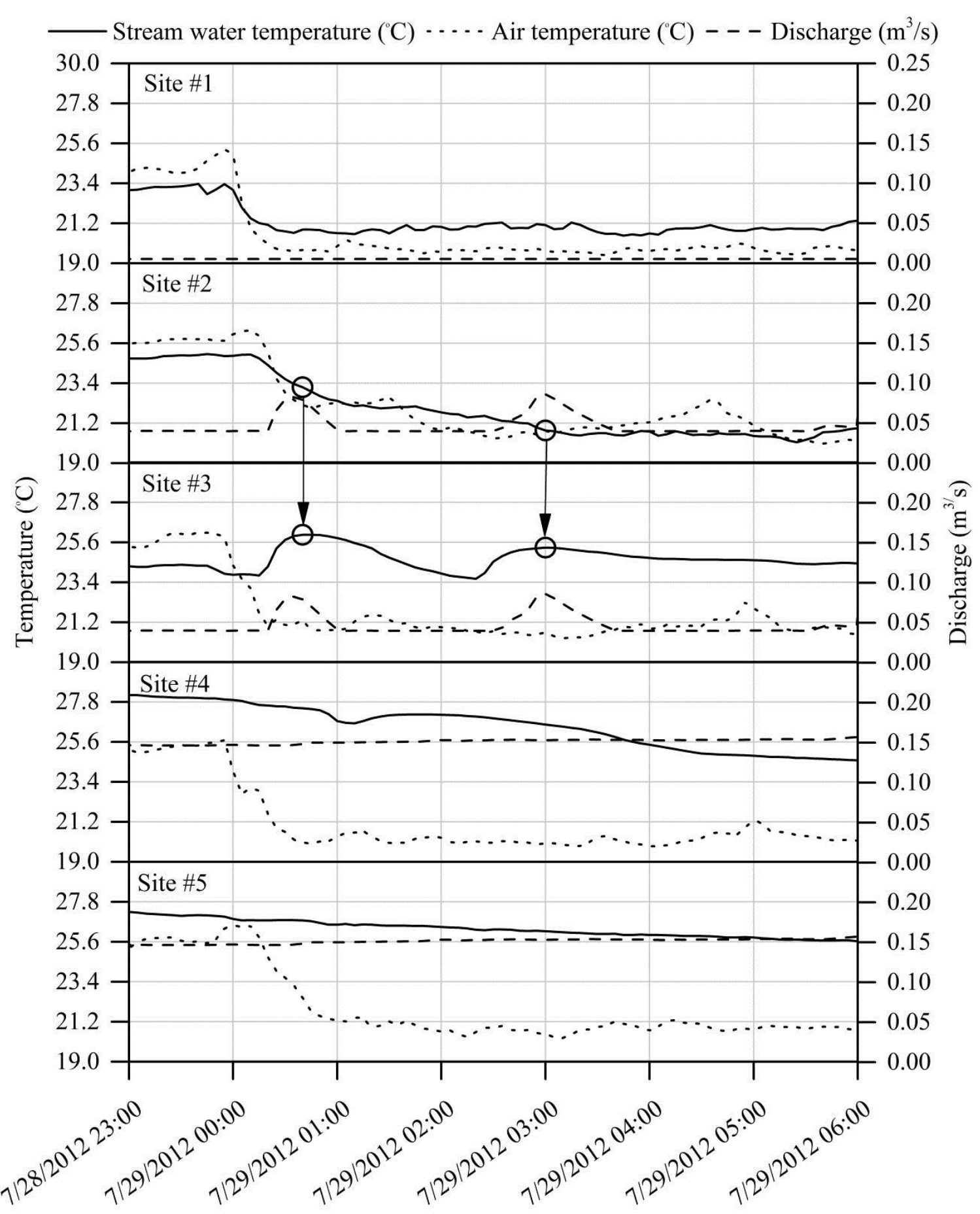

Figure 14. Two stream water temperature surges following a summer thunderstorm sensed at site \#3 in Hinkson Creek during summer 2012. The black circles mark the peak $\mathrm{T}_{\mathrm{w}}$ following the increase in discharge at site \#3 and the arrows track the event downstream from site \#2 to site \#3. This figure shows how the $T_{w}$ surges were observed at site \#3, but not observed upstream showing the origin of the heated stormwater was downstream of site \#2 and upstream of site \#3. 
Nelson and Palmer (2007), Rice et al. (2011), and Anderson et al. (2011) also reported evidence concerning the effects of urban land use and land cover on increased $\mathrm{T}_{\mathrm{w}}$. Nelson and Palmer (2007) showed minimum and maximum $\mathrm{T}_{\mathrm{w}}$ surges of $>1.0{ }^{\circ} \mathrm{C}$ and $>4.8^{\circ} \mathrm{C}$, respectively, in comparison to the in-stream temperature surges observed during the summers of 2010, 2011, and 2012 in this study. Rice et al. (2011) showed minimum and maximum $\mathrm{T}_{\mathrm{w}}$ surges of $>0.3{ }^{\circ} \mathrm{C}$ and $>1.1{ }^{\circ} \mathrm{C}$, respectively, when compared to this study. The relationship between amount of impervious surface coverage (ISC) and magnitude of mean $\mathrm{T}_{\mathrm{w}}$ surges would explain why Nelson and Palmer and Rice et al. (2011) found $T_{w}$ surges of greater magnitude and duration. Rice et al. (2011) found that ISC within smaller spatial scales (i.e. 25 meter buffer of the urban stream) correlated with $\mathrm{T}_{\mathrm{w}}$ surge events when buffers of $1 \%$ ISC showed mean $\mathrm{T}_{\mathrm{w}}$ surge amplitude of $1.9^{\circ} \mathrm{C}$ and buffers of $75 \%$ ISC showed mean $\mathrm{T}_{\mathrm{w}}$ surge amplitude of $3.27{ }^{\circ} \mathrm{C}$. The comparison of this work to other work was important because results showed that any additional ISC within a 25 meter buffer of Hinkson Creek could increase the magnitude and duration of $\mathrm{T}_{\mathrm{w}}$ surges.

\section{The effects of discharge on stream water temperature}

Separating mean $\mathrm{T}_{\mathrm{w}}$ into different flow classes (similar to the methods used by Webb et al. 2003) supplied relationships of $\mathrm{T}_{\mathrm{w}}$ at each gauging site in Hinkson Creek to increasing flow. Flow classes $<50 \%$ best predicted $\mathrm{T}_{\mathrm{w}}$ during periods of low flow, or base flow. While, the $>50 \%$ flow class best represented stormflows. To investigate $\mathrm{T}_{\mathrm{w}}$ during stormflow periods the $>50 \%$ flow class was separated into an additional four flow classes. The $>90 \%$ flow class was assumed to best represent peakflow times when the 
stream was turbid and presumably well mixed, so it's assumed there was less variability of $\mathrm{T}_{\mathrm{w}}$ with depth and lateral distance. The $90 \%$ flow class was also separated into an additional nine flow classes. The $>99 \%$ flow class was assumed to best represent $\mathrm{T}_{\mathrm{w}}$ when Hinkson Creek was close to or overbank full. It was important to analyze $\mathrm{T}_{\mathrm{w}}$ at different flow classes to examine the effects of urban stormwater on $\mathrm{T}_{\mathrm{w}}$ in Hinkson Creek. Results showing mean stream discharge, mean $\mathrm{T}_{\mathrm{a}}$, and mean $\mathrm{T}_{\mathrm{w}}$ for 15 different flow classes are shown in Figures 15 to 17. The increase in stream discharge was nonlinear for every flow class considered from site \# 1 to site \#5 (Figure 15). When $\mathrm{T}_{\mathrm{a}}$ was investigated at each flow class, urban site \# 3 was always the highest for $\mathrm{T}_{\mathrm{a}}$, and site \#1 was always the lowest for $\mathrm{T}_{\mathrm{a}}$. Figure 16 shows how $\mathrm{T}_{\mathrm{a}}$ at rural sites \#1 and \#2 was always lower than urban sites \#3, \#4, and \#5. Conversely, $\mathrm{T}_{\mathrm{w}}$ at urban sites \#4 and \#5 increased with each flow class relative to the other Hinkson Creek gauging sites as shown in Figure 17. The change in $\mathrm{T}_{\mathrm{w}}$ between gauging sites as flow class increased was less correlated to a change in $\mathrm{T}_{\mathrm{a}}$ between sites as flow class increased. Conversely, correlations between discharge and mean $\mathrm{T}_{\mathrm{w}}$ increased as flow class increased, but ANOVA analyses did not show a significant relationship at the $95 \%$ confidence level $(\mathrm{p}=0.07)$. This information shows that the difference in $\mathrm{T}_{\mathrm{w}}$ between sites was not caused by a change in $T_{a}$, and not solely caused by increased. The increase in $T_{w}$ at sites $\# 4$ and \#5 was likely caused by urban land use.

Mean $\mathrm{T}_{\mathrm{w}}$ at sites \#2, \#3, and \#4 was significantly ( $\left.\mathrm{p}>0.5\right)$ higher than sites \#1 and \#5 when discharge was lower for the $<50 \%$ flow class. When discharge is low $\mathrm{T}_{\mathrm{w}}$ can be more variable with depth, laterally (from bank to bank), and longitudinally (with stream distance) compared to when discharge is high and the stream is well mixed (Webb et al. 
2008). As discharge increased, results from the $>50 \%$ flow class showed mean $T_{w}$ at sites \#4 and \#5 were significantly ( $p>0.5$ ) higher than sites \#1, \#2, \#3 (see Figure 21). Stream water temperature at sites \#4 and \#5 continued to increase relative to sites \#1, \#2, and \#3 as flow class increased from the $>50 \%$ flow class to the $>90 \%$ flow class (Figure 17). This information was important because it provided evidence that urban land use effected $\mathrm{T}_{\mathrm{w}}$.

There was a significant $(\mathrm{p}=0.01)$ longitudinal increase in $\mathrm{T}_{\mathrm{w}}$ in Hinkson Creek with stream distance as the stream flowed from the headwaters at site \#1 to site \#5. Increased travel time coupled with increased exposure to meteorological conditions and friction between the streambed and the banks were assumed to have contributed to higher $\mathrm{T}_{\mathrm{w}}$ at sites $\# 4$ and $\# 5$ relative to the other sites. Stream travel time from the headwaters was calculated as approximately 4.8 hours at site \#4 and 6.2 hours at site \#5. A study by Webb and Zhang $(1997,1999)$ that reported heat fluxes measured at 17 different sites in the United Kingdom showed friction between the stream bed and banks contributed $15.8 \%$ of stream heating. While the increase in $\mathrm{T}_{\mathrm{w}}$ at sites \#4 and \#5 was presumably, at least in part, due to natural impacts of exposure to meteorological conditions and friction, the primary cause was believed to be due to urban stormwater runoff considering the sudden increases in $\mathrm{T}_{\mathrm{w}}$ at urban gauging sites and the relative significant $(\mathrm{p}<0.01)$ differences in mean $\mathrm{T}_{\mathrm{w}}$ at urban sites relative rural sites. As previously stated, multiple regression analyses showed significant $(\mathrm{p}=0.05)$ correlations between stream distance and urban land use as flow class increased accounting for $90 \%$ of the explained variance in mean $\mathrm{T}_{\mathrm{w}}$. 
Urban site \#5 showed the greatest increase in $\mathrm{T}_{\mathrm{w}}$ with increased flow relative to all the other Hinkson Creek sites. For the $<50 \%$ flow class, $\mathrm{T}_{\mathrm{w}}$ was $0.6 \mathrm{C}$ lower at site \#5 compared to site \#4, and from the $>90 \%$ flow class and beyond $\mathrm{T}_{\mathrm{w}}$ between sites $\# 4$ and \#5 were nearly equal with differences in $\mathrm{T}_{\mathrm{w}}<0.1{ }^{\circ} \mathrm{C}$. These data provided additional significant $(\mathrm{p}=0.02)$ evidence that heated stormwater runoff flowed into Hinkson Creek between sites \#4 and \#5 during the study period. A review by Webb et al. (2008) also indicated that increased impervious surfaces can increase $T_{w}$ when stormwater runoff transports heat energy from impervious surfaces to a stream.

The difference in $\mathrm{T}_{\mathrm{w}}$ between sites \#2 and \#3 was negligible $\left(0.1^{\circ} \mathrm{C}\right)$, but urban site \#4 showed an increase in $\mathrm{T}_{\mathrm{w}}$ with increased flow relative to the upstream suburban / rural Hinkson Creek sites. The difference in mean $\mathrm{T}_{\mathrm{w}}$ between sites \#4 and \#3 was $0.5^{\circ} \mathrm{C}$ at the $>99 \%$ flow class $(\mathrm{n}=265)$ as shown in Figure 17. Site $\# 4$ drained $15.7 \mathrm{~km}^{2}$ more urban land cover, associated with impervious surfaces, compared to site \#3. 


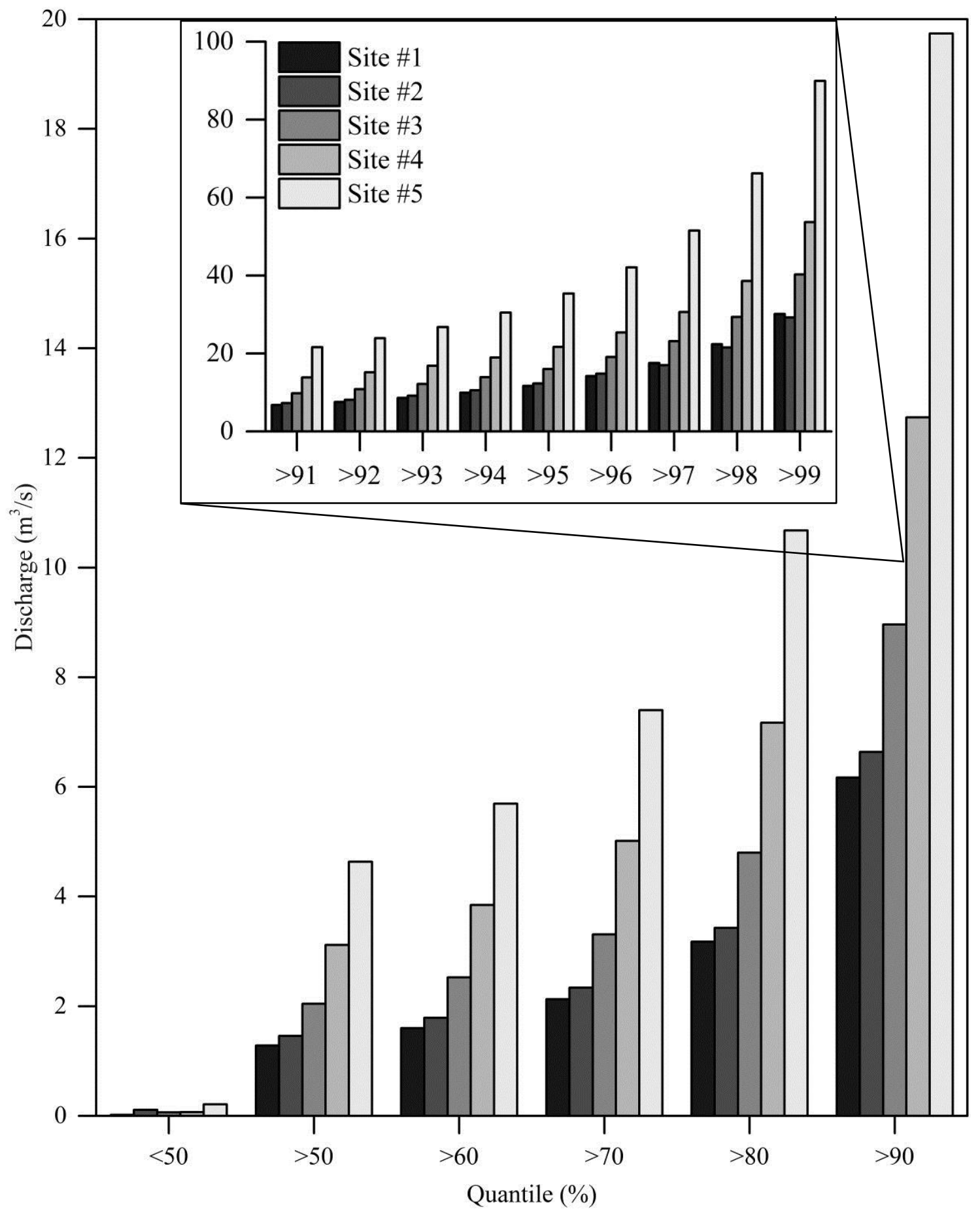

Figure 15. Mean discharge above and below median values are shown for each study site examined during the study period in Hinkson Creek Watershed, U.S.A. Additionally, four other flow classes are shown. A nested plot expands the >90\% quantile for a total of 15 flow classes. 


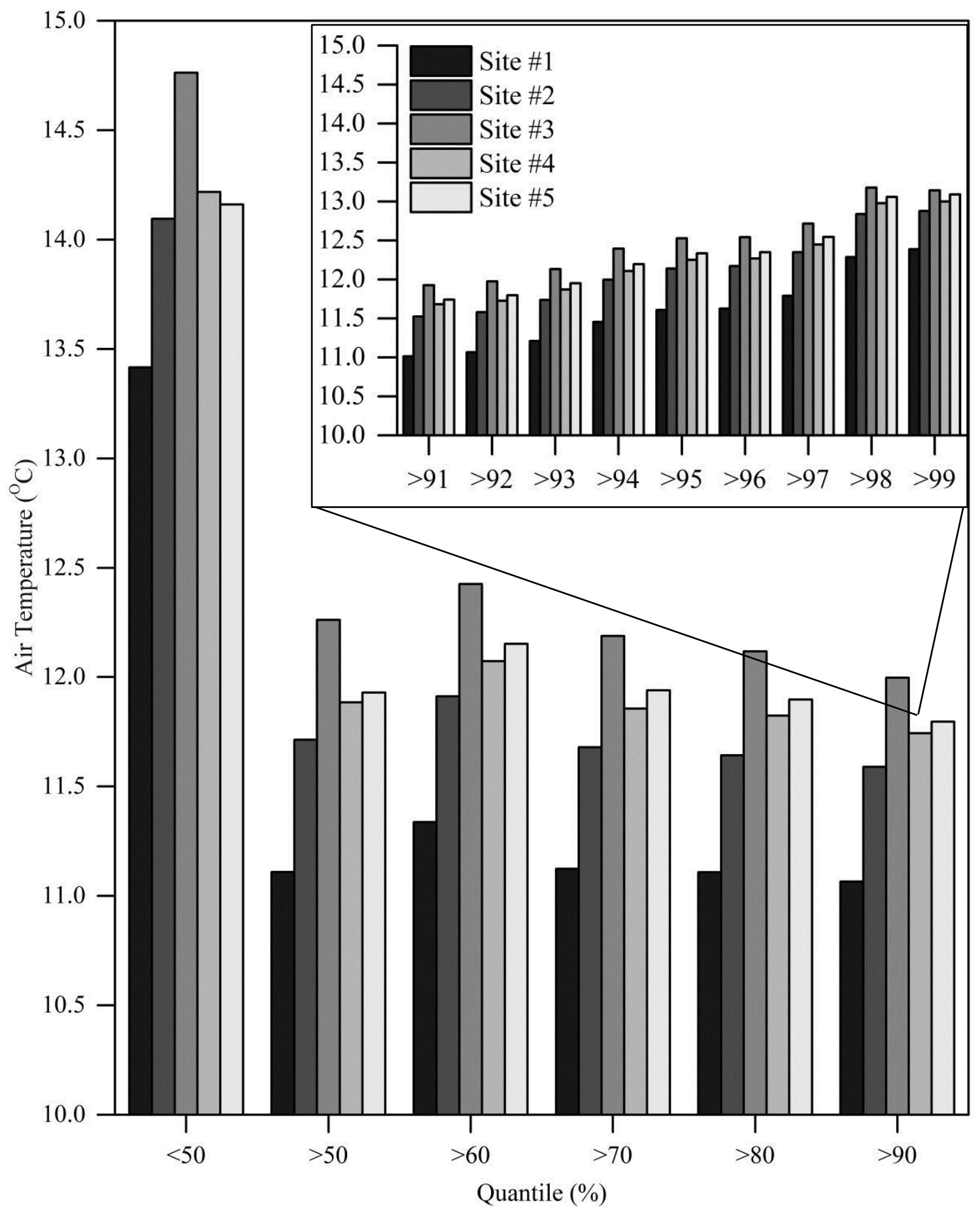

Figure 16. Mean air temperatures above and below median values are shown for each study site examined during the study period in Hinkson Creek Watershed, U.S.A. Additionally, four other flow classes are shown. A nested plot expands the $>90 \%$ quantile for a total of 15 flow classes. 


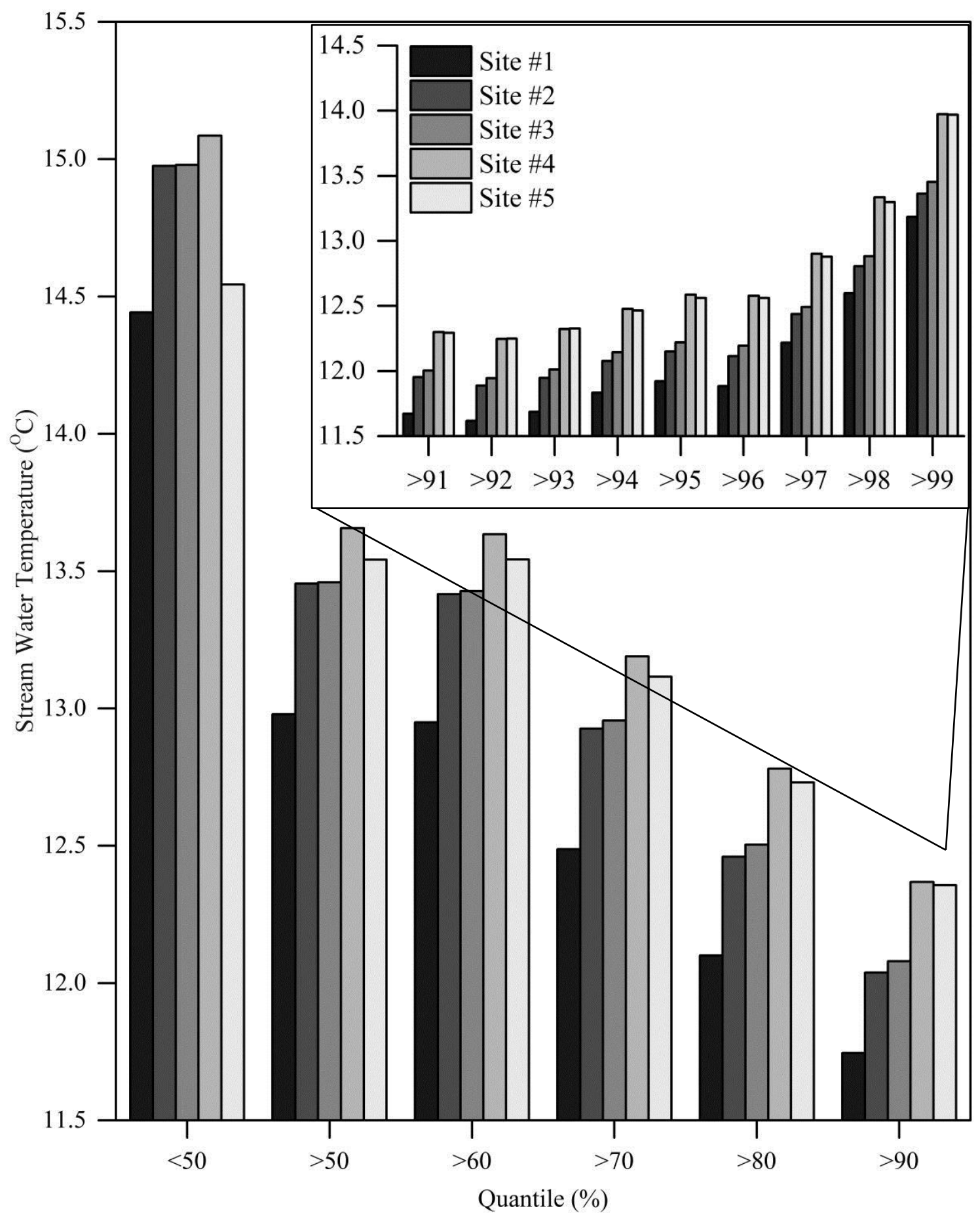

Figure 17. Mean stream water temperatures above and below median values are shown for each study site examined during the study period in Hinkson Creek Watershed, U.S.A. Additionally, four other flow classes are shown. A nested plot expands the $>90 \%$ quantile for a total of 15 flow classes. 


\section{STREAM AND AIR TEMPERATURE RELATIONSHIPS}

Linear and nonlinear $T_{w}$ models (see Methods) were created to simulate mean $T_{w}$ using observed mean $T_{a}$ data. $T_{w}$ models are useful tools for water resource managers because the models provide a cost effective way to predict $T_{w}$ changes due to land use or other anthropogenic impacts (e.g. global warming due to human induced climate change). The equations can be forced in computer programs (e.g. Excel) using readily available $T_{a}$ data from nearby weather stations and the appropriate corresponding coefficients. For example, if the model user needed to know daily mean $T_{w}$ at site \#1, then they could run the daily linear $\mathrm{T}_{\mathrm{w}}$ model in Excel. To force the $\mathrm{T}_{\mathrm{w}}$ model in Excel, the model user would have to first, create a new workbook. Then, manually input daily mean $T_{a}$ for the day of interest into a column, and corresponding row (e.g. cell "A1"). Next, the linear $\mathrm{T}_{\mathrm{w}}$ model for site \#1 would need to be manually input into an adjacent column, and corresponding row (e.g. cell "B1") using linear coefficients $a$ and $b$ derived from linear regression analyses that correspond to the appropriate $\mathrm{T}_{\mathrm{w}}$ model. Table 19 shows linear coefficients $a$, and $b$ were 0.781 , and 4.067 , respectively, for the daily linear $\mathrm{T}_{\mathrm{w}}$ model. So, the format of the function typed into the adjacent cell (e.g. cell "B1") would be “ $=\left(0.781^{*} \mathrm{~A} 1\right)+4.067^{\prime}$. If daily mean $\mathrm{T}_{\mathrm{a}}$ was $21.0^{\circ} \mathrm{C}$ at site $\# 1$, then simulated daily mean $\mathrm{T}_{\mathrm{w}}$ would be $20.5^{\circ} \mathrm{C}$.

Results from linear and nonlinear regression analyses are shown in Figures 18 to 21. Accounting for time lag at sub-daily time steps increased $r^{2}$ values for linear and nonlinear models by 0.2 to $3.7 \%$, and 0.3 to $3.9 \%$, respectively (Figure 18). Results showed site \#1 had a weaker $\mathrm{T}_{\mathrm{w}}$ and $\mathrm{T}_{\mathrm{a}}$ relationship compared to the other gauging sites (Figure 19). Differences in $r^{2}$ values between site \#1 and the other four gauging sites 
ranged from 8.6 to $1.1 \%$. Site \#1 also showed a lag of 4.25 hours. Figure 11 shows how $\mathrm{T}_{\mathrm{w}}$ at site \#1 was often higher in the winter (above freezing) and lower in the summer (below $32^{\circ} \mathrm{C}$ ) unlike the other sites during WY's 2012 and 2013. Reviews by Caissie (2006) and Webb et al. (2008) indicated that groundwater influence can lead to increases in $T_{w}$ in the winter and decreases in $T_{w}$ in the summer. The weak $T_{w} / T_{a}$ relationship at site \#1 could also be explained by pooling and decreased stream width. Similar results were presented by Erickson and Stefan (2000) when groundwater inflows, stream shading and wind sheltering affected $\mathrm{T}_{\mathrm{w}} / \mathrm{T}_{\mathrm{a}}$ relationship. Groundwater inflows were shown to increase the $y$-intercept and decreased the slope of linear $\mathrm{T}_{\mathrm{w}} / \mathrm{T}_{\mathrm{a}}$ relationships and stream shading affected the $T_{w} / T_{a}$ relationship assuming $T_{w}$ and $T_{a}$ are dependent on solar radiation input at the stream surface (Erickson and Stefan, 2000). In addition, wind sheltering was found to decrease advective heat transfer at the stream-atmosphere interface thereby buffering $\mathrm{T}_{\mathrm{w}}$ from meteorological conditions (Erickson and Stefan, 2000). Therefore, linear and nonlinear $T_{w}$ regression models dependent on $T_{a}$ may not simulate $T_{\mathrm{w}}$ well in headwater sub basins where groundwater inflows, stream shading and wind sheltering can affect $\mathrm{T}_{\mathrm{w}}$. 


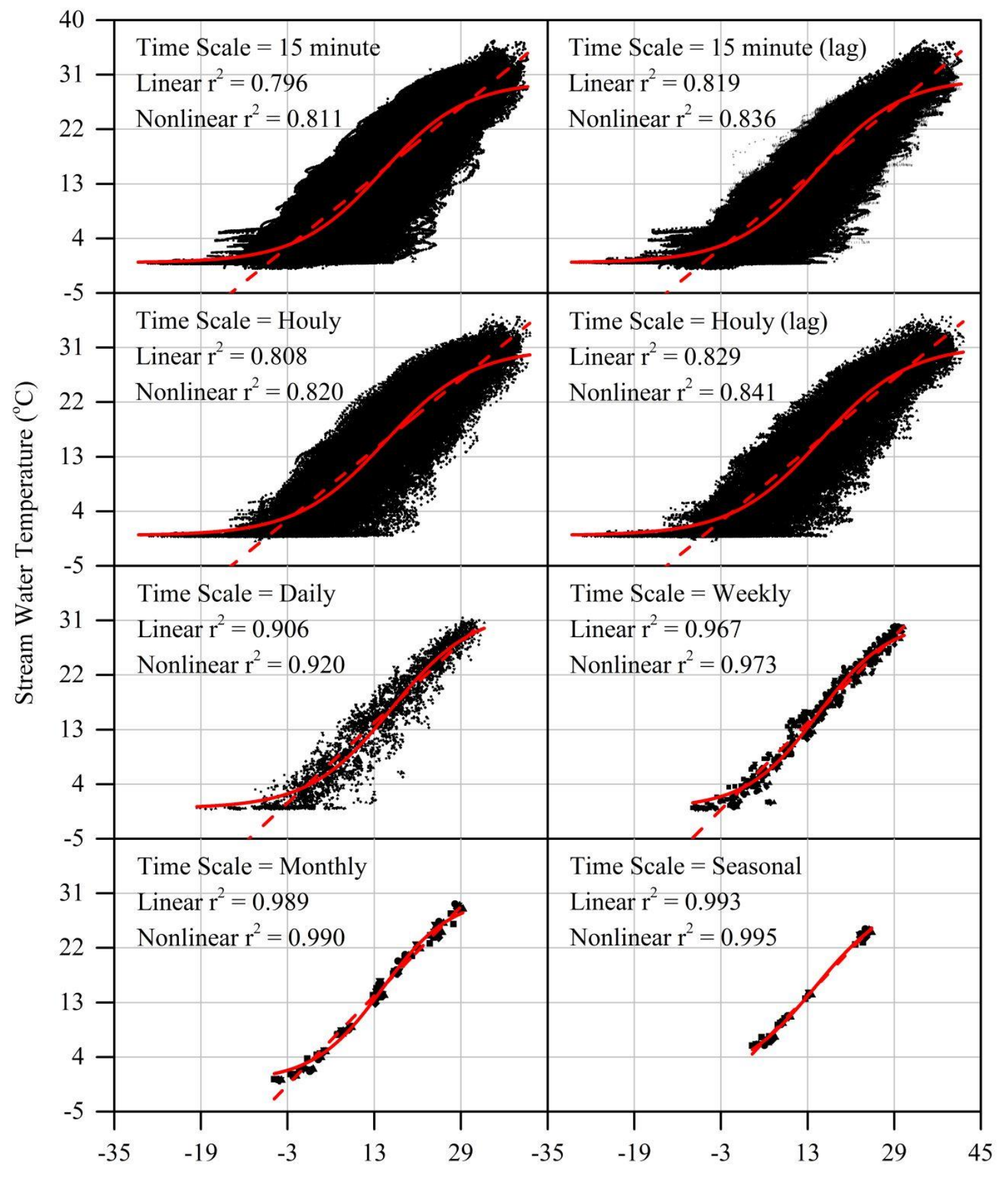

Air Temperature $\left({ }^{\circ} \mathrm{C}\right)$

Figure 18. Five site mean coefficients of determination $\left(\mathrm{r}^{2}\right)$ from linear (dashed line) and nonlinear (solid curve) regression analyses are shown for each time step considered (15 minute, hourly, daily, weekly, monthly, and seasonal) and for five gauging sites examined during the study period located in Hinkson Creek Watershed, U.S.A. 


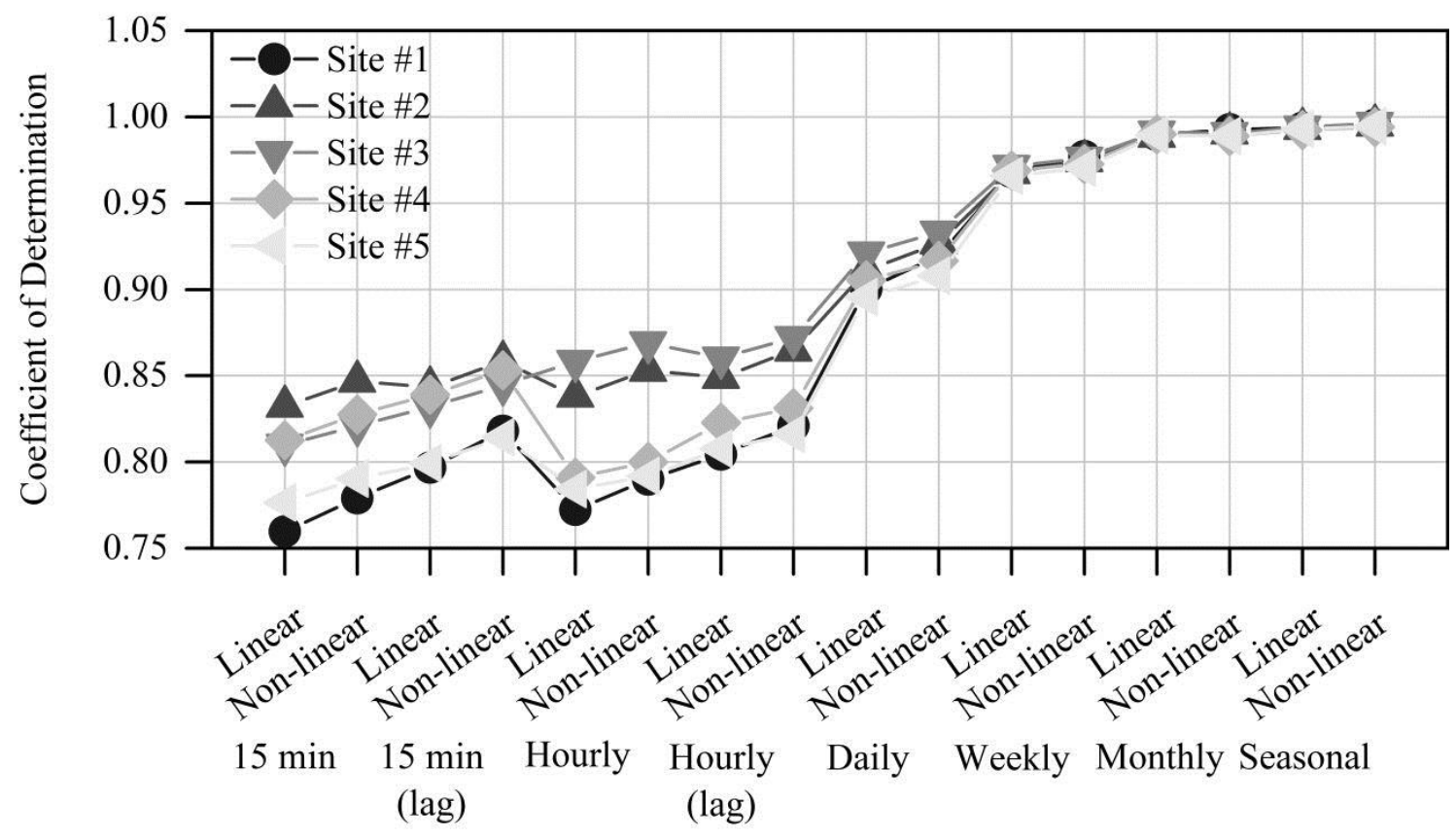

Figure 19. Coefficients of determination from linear and nonlinear regression analyses are shown for each time step considered (15 minute, hourly, daily, weekly, monthly, and seasonal) and for each study site examined during the study period located in Hinkson Creek Watershed U.S.A.

Studies showed $T_{w} / T_{a}$ relationships are often affected by increased discharge (Webb et al. 2003) and urban land use (Rice et al. 2011). In this study there was a trend for $T_{w} / T_{a}$ relationships to decrease (i.e. time lag increased and $r^{2}$ values decreased) from site \#2 to site \#5 as discharge and urban land use increased. Webb et al. (2003) showed that $r^{2}$ values were higher when flow was above median flow values. Increased discharge decreases stream interaction with the atmosphere because surface area to volume ratios decrease as discharge increases below bank-full. Large volumes of water can buffer the relationship between $T_{w}$ and $T_{a}$ considering the high specific heat capacity of water (Webb et al. 2003; Stefan and Preud'homme, 1993). Rice et al. (2011) showed that $\mathrm{r}^{2}$ values decreased as impervious surface land coverage increased by 0.28 for daily linear $\mathrm{T}_{\mathrm{w}}$ models and 0.37 for weekly and monthly linear $\mathrm{T}_{\mathrm{w}}$ models. The decreases in $\mathrm{r}^{2}$ values 
were attributed to the long term increase in mean $\mathrm{T}_{\mathrm{w}}$ and short term temperature surge events where stream water temperature increased by $1{ }^{\circ} \mathrm{C}$ within 15 minutes and ground water interaction in a gaining urban stream (Boone Creek) in North Carolina.

Results from the current study showed linear and nonlinear regression $r^{2}$ values were significantly $(\mathrm{p}=0.01)$ affected by the time scale considered. As time step increased from 15 minute to seasonal averages, $\mathrm{r}^{2}$ values increased from 0.760 to 0.995 . As time series $\mathrm{T}_{\mathrm{a}}$ and $\mathrm{T}_{\mathrm{w}}$ data were reduced, the variation or "noise" in the data was attenuated by the averaging. The $r^{2}$ values quantify the total variation in $y$ values attributed to the model relationship (Moriasi et al. 2007). Obviously, any data reduction by averaging increases $r^{2}$ values. Similar results were found in a study by Erickson and Stefan (2000) who showed that stream water temperature was more accurately estimated at timescales greater than one day (e.g. weekly, monthly, and seasonal), in part because there was more "noise" or detail in high resolution $\mathrm{T}_{\mathrm{w}}$ data. Therefore, there was an important cost (decrease in detail) and benefit (increase in model accuracy) observed as time scale increased. This information is may be important to land managers that need to predict $\mathrm{T}_{\mathrm{w}}$ at less than weekly time steps.

Time scale also significantly affected $(\mathrm{p}<0.01)$ linear regression coefficients, but not nonlinear coefficients. The range of the data sets decreased when averaged; meaning, the maximums decrease and the minimums increase. Air temperature had a greater diel and seasonal range than $\mathrm{T}_{\mathrm{w}}$ mainly because of the specific heat capacity of water. Thus, $\mathrm{T}_{\mathrm{a}}$ was affected more by averaging causing a slight counterclockwise rotation of the best fit line (Erickson and Stefan, 2000). This explains why, for linear regression analyses, the slope of the best fit lines (linear coefficient $a$ ) increased and the y-intercept (linear 
coefficient $b$ ) decreased as the data were reduced from 15 minute to seasonal averages (Figure 20). While nonlinear regression coefficients were not affected by data reduction, results showed a positive relationship between alpha / beta coefficients, and an inverse relationship between gamma coefficients and alpha / beta coefficients (Figure 21). Erickson and Stefan (2000) showed similar results for the effect of time scale on linear regression analyses between $T_{w}$ and $T_{a}$. This information helped improve our understanding of the effects of time scale on $\mathrm{T}_{\mathrm{w}}$ regression models. 


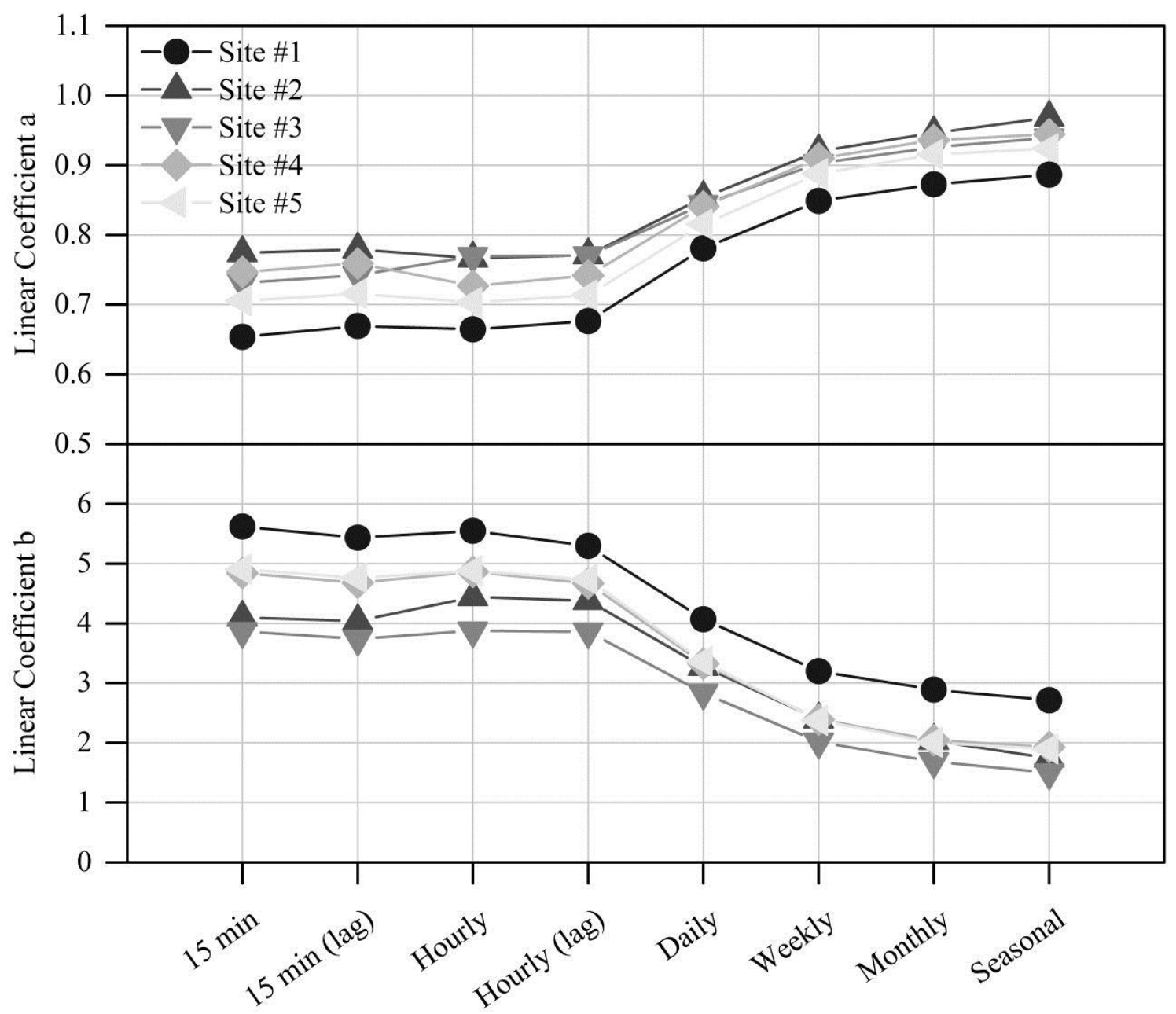

Figure 20. Results from linear regression analyses are shown for comparison of each time step considered (15 minute, hourly, daily, weekly, monthly, and seasonal). Linear coefficients $b$ (top) and $a$ (bottom) are displayed for each study site during the study period located in Hinkson Creek Watershed, U.S.A. 


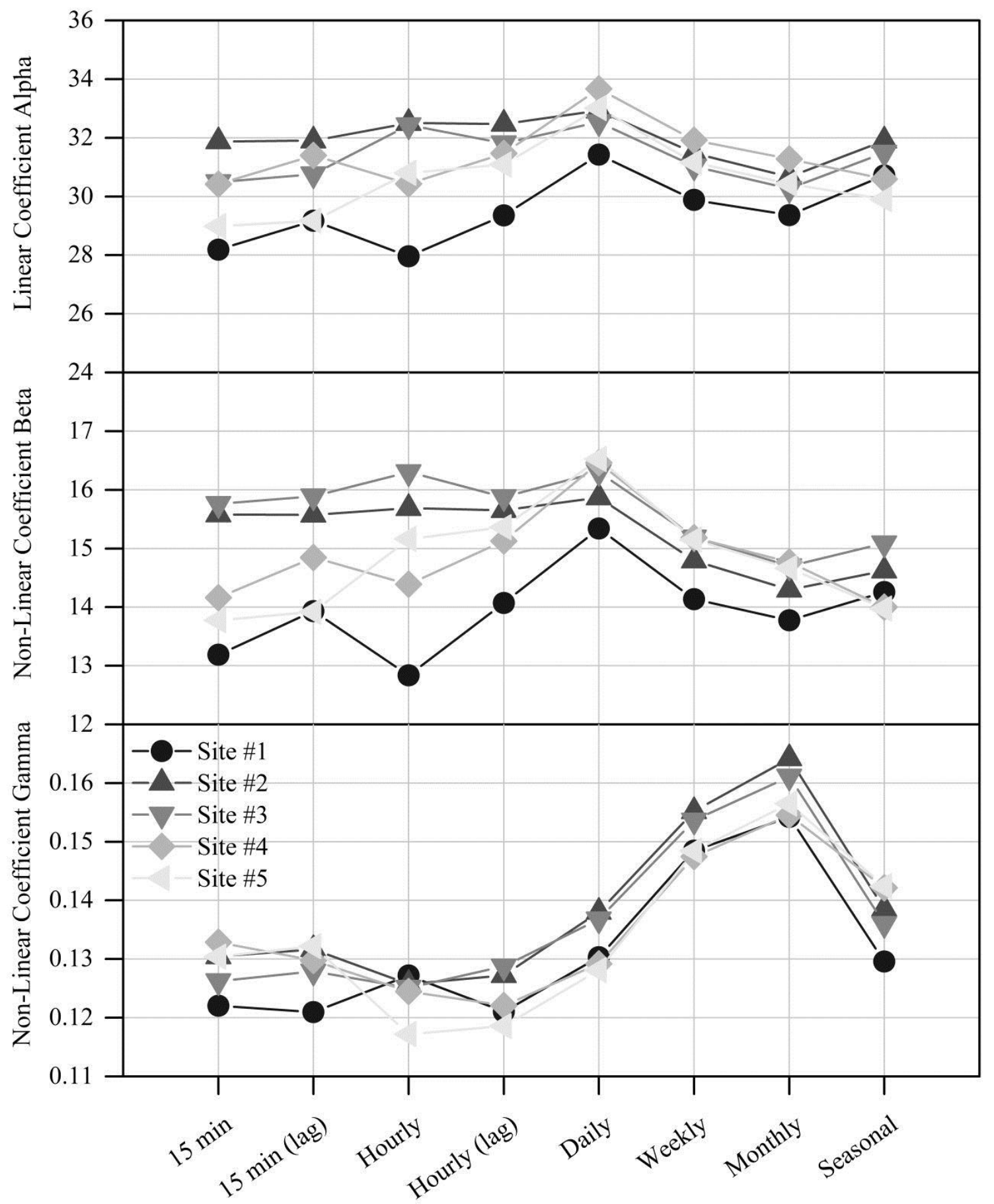

Figure 21. Results from nonlinear regression analyses are shown for each time step considered (15 minute, hourly, daily, weekly, monthly, and seasonal). Nonlinear coefficients alpha (top), beta (middle), and gamma (bottom) are displayed for each study site during the study period located in Hinkson Creek Watershed, U.S.A. 


\section{The effects of discharge on $T_{w}$ and $T_{a}$ relationships}

Results from $T_{w}$ and $T_{a}$ linear regression analyses at a daily time step for 15 different flow classes are shown in Figure 22. Results for this study showed as flow class increased $r^{2}$ values significantly $(p<0.01)$ decreased. The differences in $r^{2}$ values between the $<50 \%$ flow class and the $>50 \%$ flow class ranged from 4.9 to $5.4 \%$. The most dramatic change in $\mathrm{r}^{2}$ values between flow classes was found between the $>80 \%$ flow class and the $>90 \%$ flow class. Then, the difference in $\mathrm{r}^{2}$ values ranged from 9.8 to $11.98 \%$. The decrease in $\mathrm{r}^{2}$ values slightly decreased the slope of the best fit line. As the slope of the best fit line decreased, y-intercepts increased. Webb et al. (2003) found similar results. Webb et al. (2003) showed for four study catchments in England the r ${ }^{2}$ values were significantly higher between the $<50 \%$ flow class and the $>50 \%$ flow class ranged from 1.7 to 9.8\%. An earlier study by Smith and Lavis (1975) showed daily maximum and minimum air temperature relationships with $\mathrm{T}_{\mathrm{w}}$ were affected by discharge in two small upland catchments (approximately $1 \mathrm{~km}^{2}$ drainage area with elevations ranging from 610 to $470 \mathrm{~m}$ ) in Upper Waredale, England.

When discharge was below median values, $r^{2}$ values were greatest at site \#3 $\left(r^{2}=0.942\right)$, and there was no general trend in the change in $r^{2}$ values with downstream distance from the headwaters. But, $\mathrm{r}^{2}$ values generally decreased with stream distance for every flow class above $70 \%$. The observed decreases in $r^{2}$ values were explained by accompanied increases in stream discharge $(\mathrm{p}<0.01)$, and by urban land use percent in the sub-basin $(p=0.03)$. There were not only significant decreases in $T_{w} / T_{a}$ relationships with each increase in flow class, but also with downstream distance from the headwaters when flow rates were above median discharge $(\mathrm{p}<0.01)$. Urban land use also increased 
with distance from the headwaters. Figure 22 shows the largest difference in $r^{2}$ values in the $>96 \%$ and $>97 \%$ flow classes when $\mathrm{r}^{2}$ values were up to 0.20 less at urban site \#5 compared to the other gauging sites. The decreased $r^{2}$ values found at site \#5 was not correlated with increased discharge ( $p>0.5)$, but cumulative urban land use percent $(\mathrm{p}=0.02)$.

Stream water temperature regimes are controlled by meteorological conditions (e.g. solar radiation, and $\mathrm{T}_{\mathrm{a}}$ ), particularly during low flow periods. This fact is apparent in this study given $\mathrm{T}_{\mathrm{w}}$ and $\mathrm{T}_{\mathrm{w}} / \mathrm{T}_{\mathrm{a}}$ relationships were higher for the $<50 \%$ flow class. But, hydrologic factors (e.g. volume of water, source of water) dominate during high flow periods as shown in this study when $\mathrm{T}_{\mathrm{w}} / \mathrm{T}_{\mathrm{a}}$ relationships were in the $>50 \%$ flow class. As discharge increases, streams are more thermally stable and less responsive to changes in meteorological conditions, in part, because of the high specific heat capacity of water buffers the streams response to changes in the surrounding environment as discharge increases (Stefan and Preud'homme, 1993). Additionally, residence times decrease as flow rates increase. Decreased residence times decrease stream interaction with the atmosphere (Erickson and Stefan, 2000). Thus, $T_{w}$ is more dependent on the temperature of inflows as discharge increases (Ward, 1985). Empirical $\mathrm{T}_{\mathrm{w}}$ models incapable of accounting for the temperature of inflows will lack the capability to accurately model $T_{w}$ during high flow periods as shown in this study when daily $\mathrm{T}_{\mathrm{w}} / \mathrm{T}_{\mathrm{a}}$ relationships $\mathrm{r}^{2}$ values fell below 0.80 for flow classes $>80 \%$. 


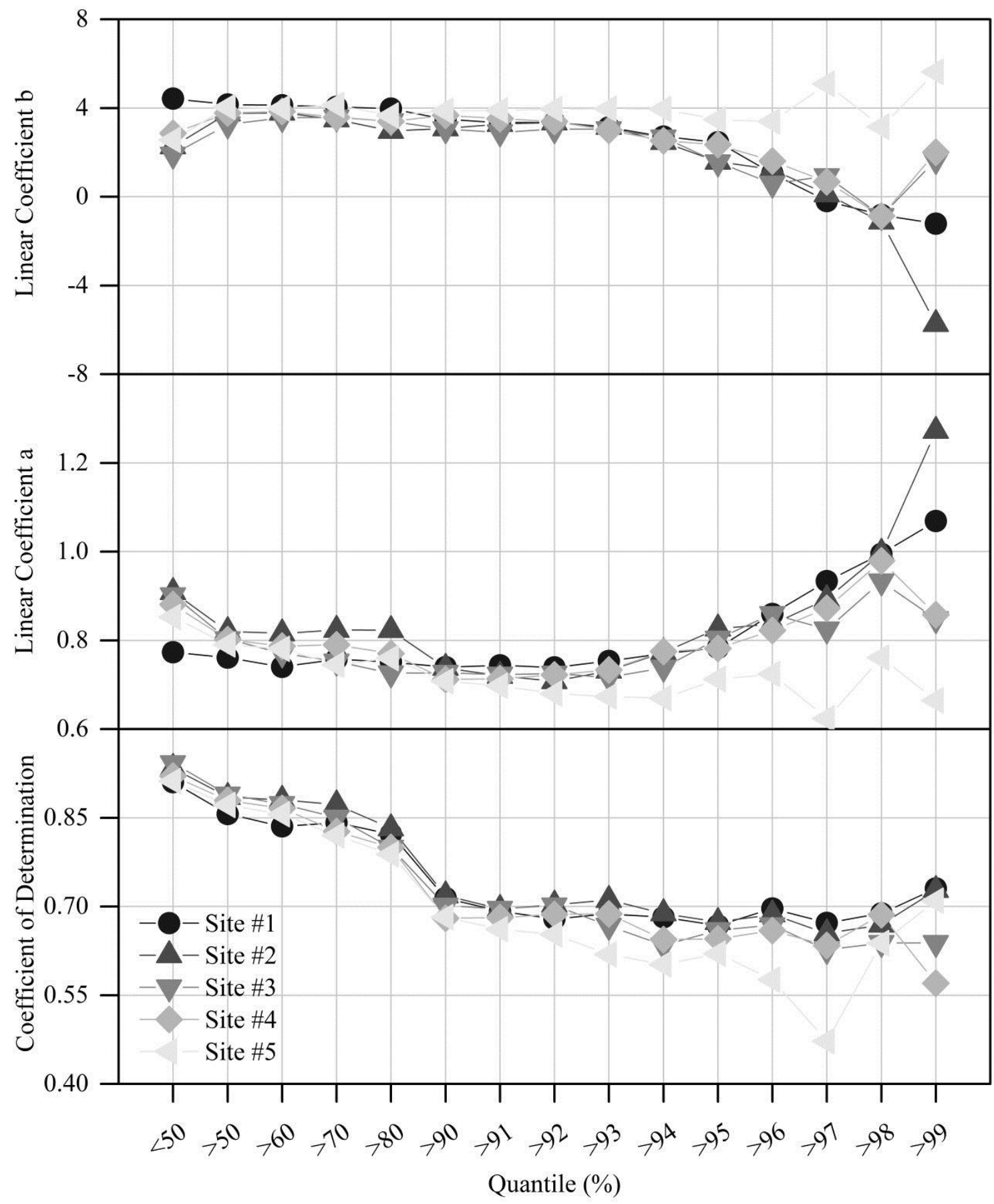

Figure 22. Coefficients of determination from linear regression analyses are shown for 15 different flow classes (quantiles) and for each study site examined during the study period. 


\section{SWAT MODELING}

\section{SWAT calibration}

Arnold et al. (2012) noted that SWAT model calibration should include 1) wet, average, and dry years of observed data, 2) numerous model evaluation criteria, 3) calibrating all variables estimated, and 4) verification that other key model outputs are realistic. To satisfy the four objectives for model calibration proposed by Arnold et al. (2012) this research used three WY's (2010 to 2012) for calibration ranging from wet (WY 2010) to dry (WY 2012), six model evaluation criteria (including NSE, PBIAS, and RSR), and "SWAT check" were used to test if manual calibration yielded realistic results. Observed streamflow data collected during the 2010, 2011, and 2012 water years from all five gauging sites were used for calibration concurrently to improve stream flow simulations at each gauging site as per the work of Qi and Grunwald (2005). SWAT check is a tool embedded in SWAT that tests model output for potential problems (White et al. 2010).

Results from SWAT model calibration are shown in Figure 23. Peak flows were underestimated during the calibration period. For example, maximum simulated discharge was $72.7 \mathrm{~m}^{3} / \mathrm{s}$ less than observed discharge at site \#5. But, the NSE, PBIAS and RSR values were all above the guidelines published by Moriasi et al. (2007) for satisfactory model evaluation at a monthly time step. Usually, model simulations are less accurate for shorter time scales, therefore, daily model evaluation criteria should be less strict compared to monthly model evaluation criteria (Moriasi et al. (2007). NSE, PBIAS, and RSR values were all in the "Satisfactory" range. Considering standards for model 
evaluation at a monthly time step should be stricter than a daily time step the model was deemed well calibrated to site \#5 near the watershed outlet.

Results showed NSE and RSR values were just above and below the threshold of "Satisfactory" for sites \#1 and \#2. But, the model was still deemed sufficiently calibrated for this research using the guidelines proposed by Moriasi et al. (2007) considering the effects of time scale on SWAT model output for streamflow. Model evaluation results showed NSE, PBIAS, and RSR values were all well within the "Satisfactory" range for site \#3, and ranged from "Good" to "Very Good" at site \#4.

\section{SWAT validation}

The SWAT model was validated using observed streamflow data collected during the 2013 water year from all five gauging sites in Hinkson Creek Watershed. Model evaluation results for streamflow during the validation period were not significantly different $(\mathrm{p}>0.05)$ from the calibration period. Model performance should be better during calibration compared validation because parameters are optimized by making adjustments during calibration, but not during validation, therefore, the validation results were better than expected. Validation results ranged from slightly "Unsatisfactory" (e.g. NSE $=0.49$ ) to "Very Good" (e.g. PBIAS=3.9\%). While many of the model evaluation results were just below "Satisfactory" according the criteria published by Moriasi et al. (2007) at a monthly time step, there were at least one model evaluation criterion close enough to the "Satisfactory" threshold for a monthly time step to deem the model capable of simulating acceptable results during WY 2013 at a daily time step. Additionally, considering the model evaluation guidelines used were designed for monthly streamflow 
estimations, the model was deemed well validated for the intended use of this work (i.e. to provide the model forcing's required to work the Ficklin et al. (2012) $T_{w}$ model). 


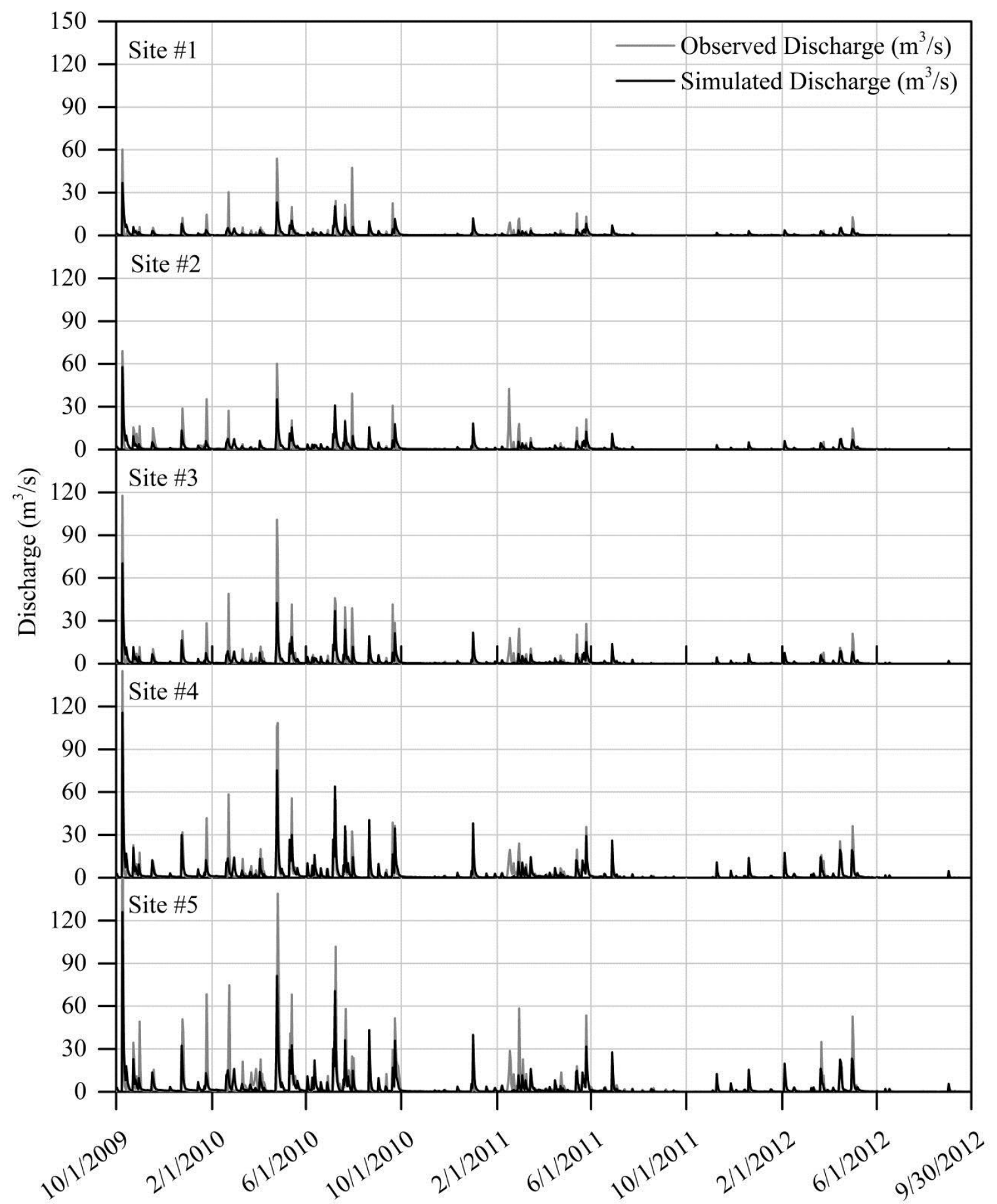

Figure 23. Time series SWAT simulated and observed discharge data collected during the calibration period (water years 2010 - 2012) recorded at five gauging sites located in Hinkson Creek Watershed, U.S.A. 


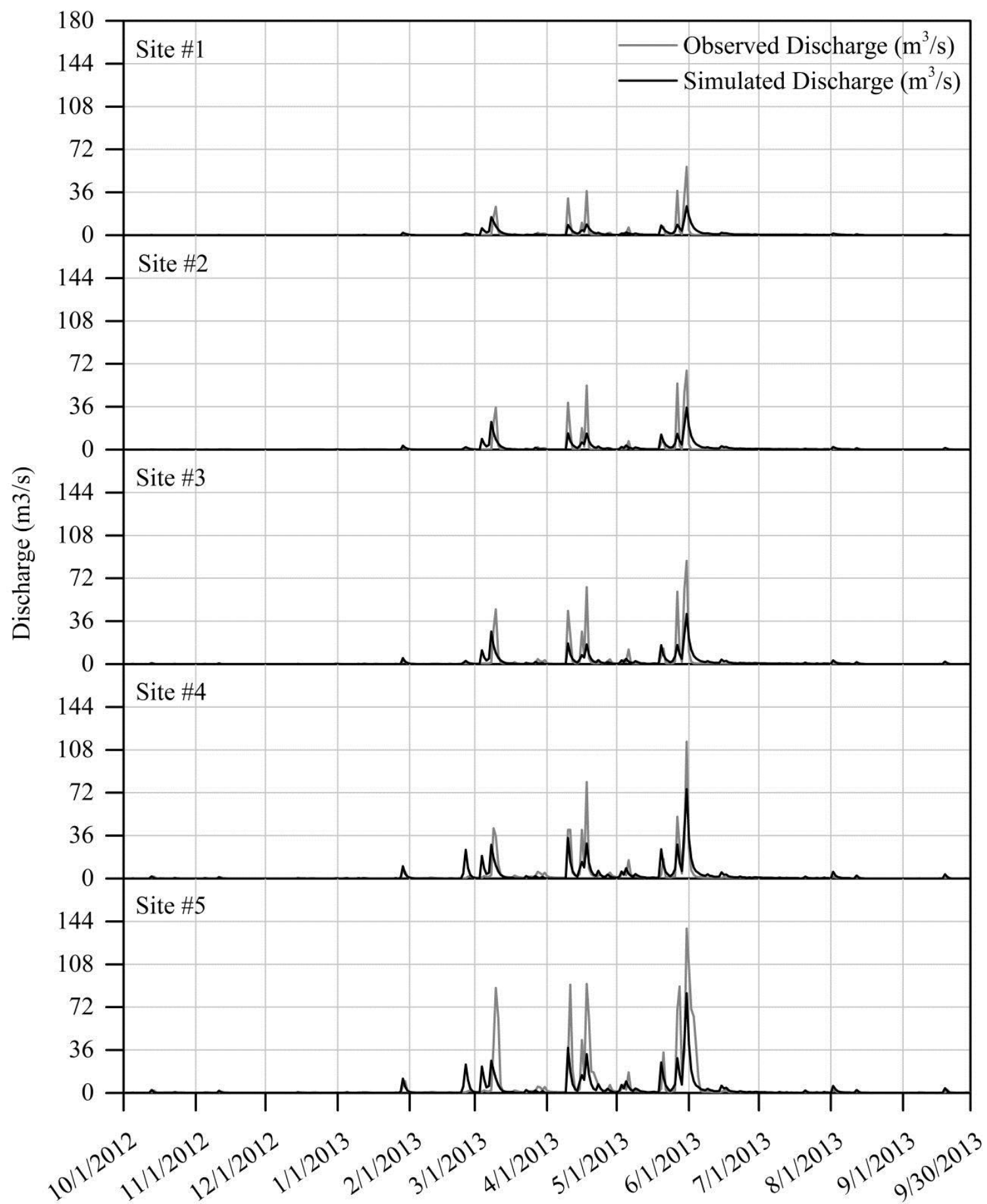

Figure 24. Time series SWAT simulated and observed discharge data collected during the validation period (water year 2013) recorded at five gauging sites located in Hinkson Creek Watershed, U.S.A. 

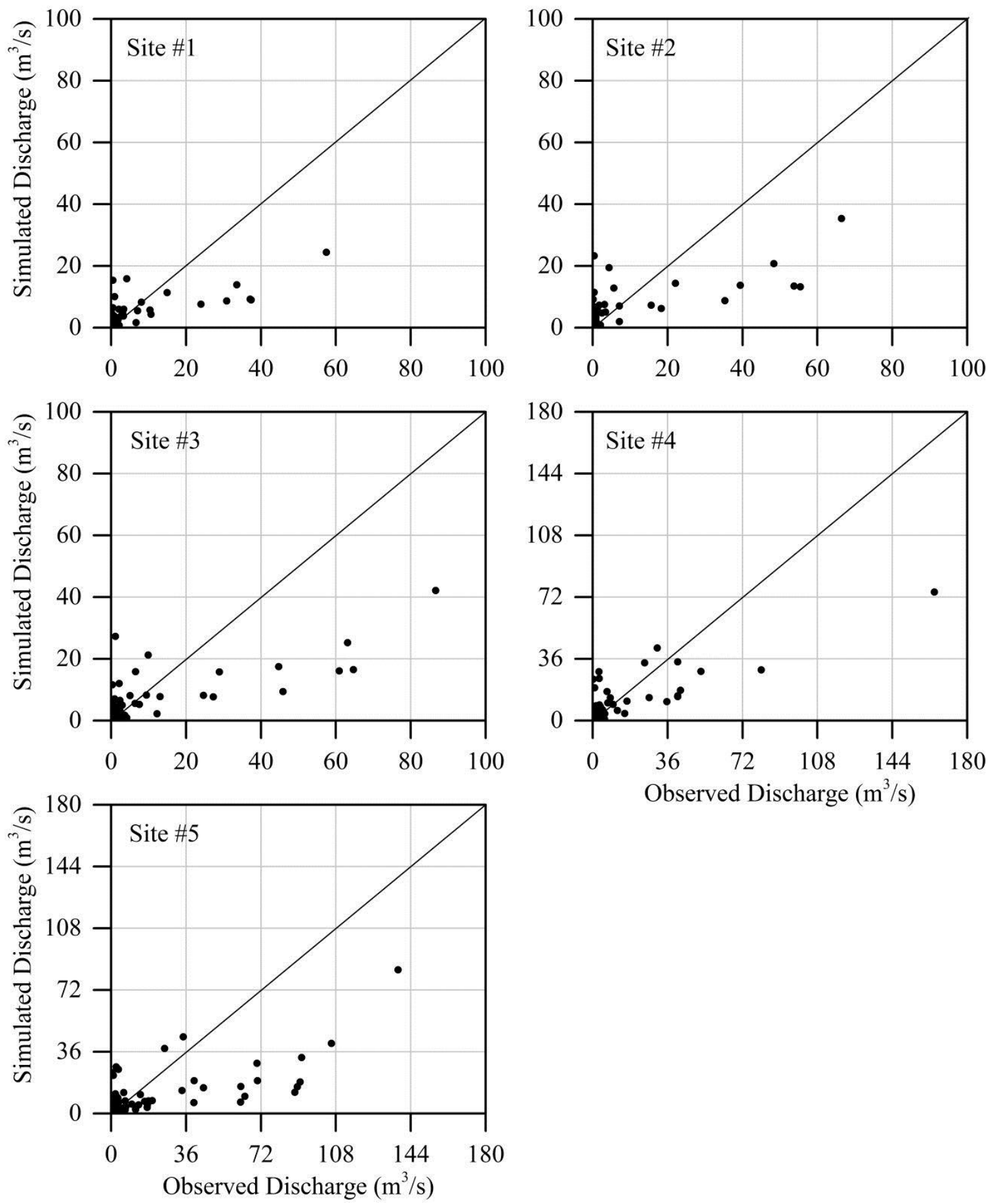

Figure 25. Validation results showing observed discharge versus SWAT simulated discharge data collected during the validation period (water year 2013) recorded at five gauging sites located in Hinkson Creek Watershed, U.S.A. 


\section{STREAM TEMPERATURE MODEL COMPARISON}

\section{5 minute stream temperature models}

The effectiveness of 15 minute regression $\mathrm{T}_{\mathrm{w}}$ models were tested using model evaluation criteria. Studies that validated the $\mathrm{T}_{\mathrm{w}}$ regression models efficacy at 15 minute time steps were not found in four different literature reviews on $T_{w}$ written by Smith (1972), Ward (1985), Caissie (2006), and Webb et al. (2008), or after searching online databases of peer-reviewed primary literature. Therefore, model evaluation results could not be compared to other research at the same time scale. Regardless, this work showed that 15 minute linear regression models improved by calibration coefficients $\alpha$ and $\beta$ performed as well and, at times, better than the hourly and even daily $\mathrm{T}_{\mathrm{w}}$ linear and nonlinear regression models tested with RMSE values approximately $\leq 2{ }^{\circ} \mathrm{C}$. Results from this research show that linear and nonlinear models do not produce accurate simulations of $\mathrm{T}_{\mathrm{w}}$ at sub-daily time scales, but adding the calibration coefficients $\alpha$ and $\beta$ to the linear $\mathrm{T}_{\mathrm{w}}$ models increased model accuracy significantly $(\mathrm{p}<0.01)$ thereby making the model useful at sub-daily time steps.

Results from the three types of $\mathrm{T}_{\mathrm{w}}$ regression models tested including 15 minute linear, nonlinear, and calibrated linear $\mathrm{T}_{\mathrm{w}}$ models are shown in Appendix $\mathrm{C}$ (Figures $\mathrm{C} 1$ to $\mathrm{C} 4)$. Results showed all site mean NSE values from the 15 minute calibrated linear $\mathrm{T}_{\mathrm{w}}$ model were 8.0 to $9.2 \%$ lower compared to the nonlinear and linear $\mathrm{T}_{\mathrm{w}}$ models during the calibration period and 5.8 to $7.0 \%$ lower during the validation period. Additionally, all site mean PBIAS values from the 15 minute calibrated linear $\mathrm{T}_{\mathrm{w}}$ model were 1.17 to $2.39 \%$ higher compared to the linear and nonlinear $\mathrm{T}_{\mathrm{w}}$ models during the calibration period and 4.88 to $5.19 \%$ higher during the validation period. Finally, all site mean RSR 
values from the 15 minute calibrated linear $\mathrm{T}_{\mathrm{w}}$ model were 31.9 to $34.29 \%$ lower relative to the linear and nonlinear $\mathrm{T}_{\mathrm{w}}$ models during the calibration period and 19.18 to $24.00 \%$ lower during the validation period. Thus, NSE and RSR values showed that the calibrated linear stream water temperature models tested performed better than the linear and nonlinear models tested, but PBIAS values were stronger for linear and nonlinear models. Therefore, simply adding calibration coefficients $\alpha$ and $\beta$ to the linear $\mathrm{T}_{\mathrm{w}}$ models improved $\mathrm{T}_{\mathrm{w}}$ model performance ratings significantly $(\mathrm{p}<0.01)$.

Linear and nonlinear $\mathrm{T}_{\mathrm{w}}$ model output tracked $\mathrm{T}_{\mathrm{a}}$ well, which improved $\mathrm{T}_{\mathrm{w}}$ estimates at daily and greater time scales, but not at sub-daily time scales. Observed $\mathrm{T}_{\mathrm{w}}$ did not track $T_{a}$ as well at sub-daily time steps as shown in Figure 26 . The $\mathrm{T}_{\mathrm{a}}$ time series were visibly more "noisy" compared to the $\mathrm{T}_{\mathrm{w}}$ data. The difference in noise was, in part, due to the higher heat capacity of water compared to air (Erickson and Stefan, 2000). The linear and nonlinear $\mathrm{T}_{\mathrm{w}}$ models simulated $\mathrm{T}_{\mathrm{w}}$ nearly equal to the noisy $\mathrm{T}_{\mathrm{a}}$ between $5^{\circ} \mathrm{C}$ and $20{ }^{\circ} \mathrm{C}$. Conversely, calibrated linear $\mathrm{T}_{\mathrm{w}}$ model outputs were visibly less noisy and thus closer to observed $T_{w}$ (Figure 26). The calibrated linear $T_{w}$ models decreased the noise associated with the $T_{w}$ time series by weighting diel $T_{w}$ periods to daily mean $T_{a}$ for the day of interest effectively dampening the $T_{w}$ time series. This explains why the calibrated linear $\mathrm{T}_{\mathrm{w}}$ models predicted $\mathrm{T}_{\mathrm{w}}$ more accurately than linear and nonlinear models. Adding calibration made 15 minute $\mathrm{T}_{\mathrm{w}}$ regression models more robust. 


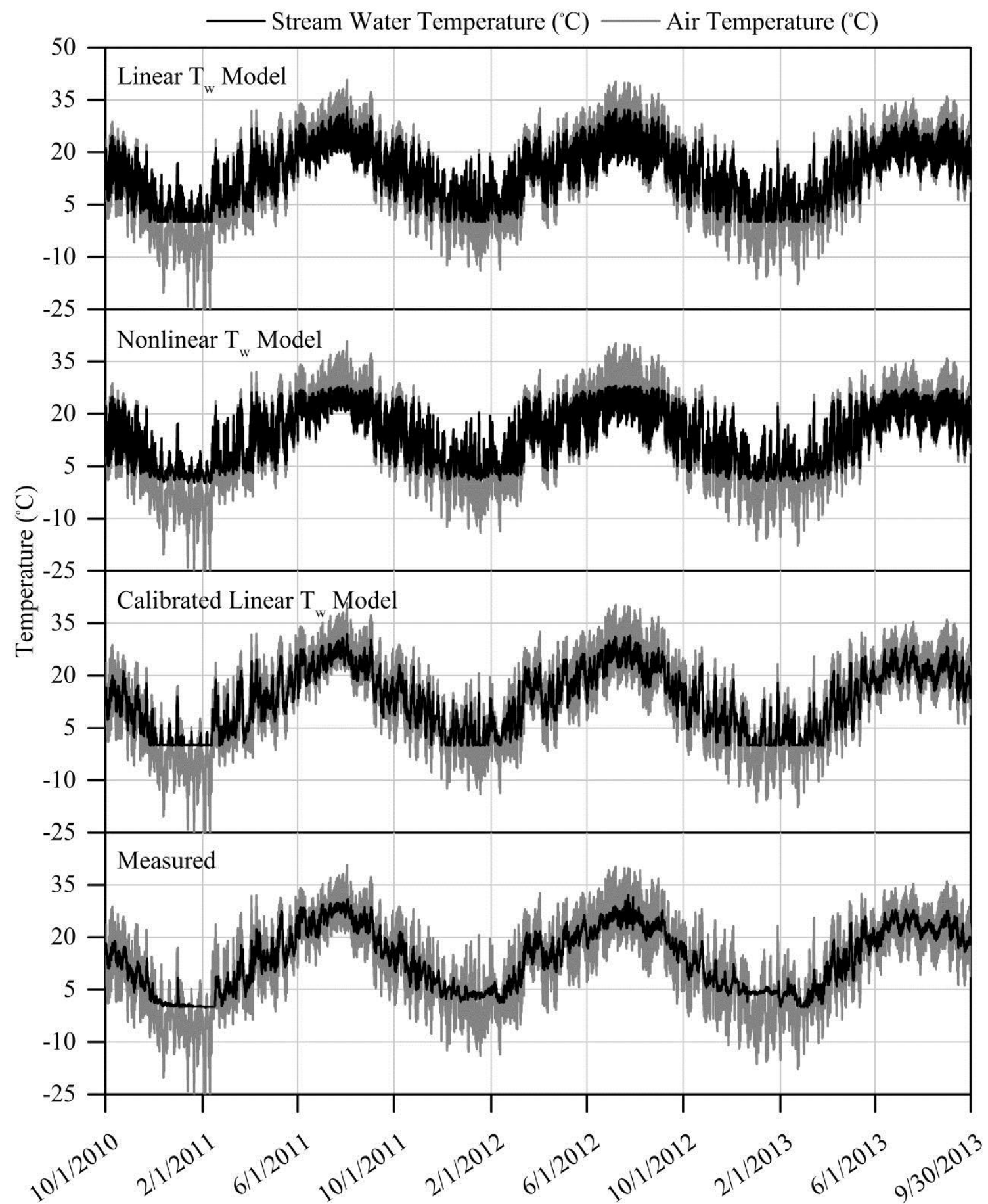

Figure 26. Results from calibrated linear regression model simulations showing 15 minute time series stream water temperature from five gauging sites in Hinkson Creek for the three year study period. Measured air temperature data are shown as a reference. 


\section{Hourly stream temperature models}

Previous studies successfully predicted $\mathrm{T}_{\mathrm{w}}$ at hourly time steps using statistical models (e.g. dispersion, linear and nonlinear regression models) (Caissie, 2006). Hourly $\mathrm{T}_{\mathrm{w}}$ regression models are less often found in the literature relative to daily and post daily $\mathrm{T}_{\mathrm{w}}$ regression models. Linear and nonlinear regression $\mathrm{T}_{\mathrm{w}}$ models work better at daily and greater time scales because reducing the data by averaging attenuates diel variability thereby simplifying the time series. Even less often have the studies tested the accuracy of their regression models with multiple model evaluation criteria. For example, Webb et al. (2003) used linear and nonlinear regression models to predict $T_{w}$ using $T_{a}$ data and showed that $\mathrm{r}^{2}$ values ranged from 0.80 to 0.89 between $\mathrm{T}_{\mathrm{w}}$ and $\mathrm{T}_{\mathrm{a}}$, but did not validate the regression models with observed $\mathrm{T}_{\mathrm{w}}$ data. Validation results that quantify the accuracy of sub-daily $\mathrm{T}_{\mathrm{w}}$ models are important information for end users that need to know the error associated with a specific $\mathrm{T}_{\mathrm{w}}$ model. For example, $>3{ }^{\circ} \mathrm{C}$ RMSE may not be acceptable for fisheries management decisions that rely on accurate $T_{w}$ estimations.

Rivers-Moore and Lorentz (2004) predicted hourly $\mathrm{T}_{\mathrm{w}}$ using a statistical model dependent on $\mathrm{T}_{\mathrm{a}}$. Results showed $\mathrm{r}^{2}$ values between observed and simulated $\mathrm{T}_{\mathrm{w}}$ ranged from 0.73 to 0.88 which was similar to the results from linear and nonlinear $T_{w}$ models tested in the current work, but the calibrated linear $\mathrm{T}_{\mathrm{w}}$ models tested in this work showed higher $\mathrm{r}^{2}$ values ranging from $3.0 \%$ to $19.0 \%$ compared to the study by Rivers-Moore and Lorentz (2004). In the current research, $\mathrm{r}^{2}$ values ranged from 0.81 to 0.87 for the linear $\mathrm{T}_{\mathrm{w}}$ models, 0.81 to 0.87 for the nonlinear $\mathrm{T}_{\mathrm{w}}$ models, and 0.91 to 0.92 for the calibrated linear $\mathrm{T}_{\mathrm{w}}$ models. Calibration coefficients added to the linear $\mathrm{T}_{\mathrm{w}}$ models improved $\mathrm{r}^{2}$ values by 5.4 to $9.6 \%$ and decreased model error (RMSE) by approximately $1{ }^{\circ} \mathrm{C}$. 
Results from hourly stream water temperature models from this research are shown in Appendix C (Figures C5 to C8). Results showed all site mean NSE values from the hourly calibrated linear $\mathrm{T}_{\mathrm{w}}$ model compared to the nonlinear and linear $\mathrm{T}_{\mathrm{w}}$ models were significantly $(\mathrm{p}<0.01) 8.0 \%$ higher during the calibration period and 6.9 to $8.1 \%$ higher during the validation period. Additionally, all site mean PBIAS values from the hourly calibrated linear $\mathrm{T}_{\mathrm{w}}$ model were significantly $(\mathrm{p}=0.01) 3.06$ to $3.44 \%$ higher during the calibration period and 5.46 to $5.55 \%$ higher compared to the linear and nonlinear $\mathrm{T}_{\mathrm{w}}$ models during the validation period. All site mean RSR values from the 15 minute calibrated linear $\mathrm{T}_{\mathrm{w}}$ model were significantly $(\mathrm{p}<0.01) 31.8 \%$ lower during the calibration period and 22.2 to $24.7 \%$ lower compared to the linear and nonlinear $\mathrm{T}_{\mathrm{w}}$ models during the validation period. Similar to the results from 15 minute $\mathrm{T}_{\mathrm{w}}$ model evaluation, NSE and RSR values showed that the calibrated linear stream water temperature model performed better than the linear and nonlinear models, but PBIAS values were stronger for linear and nonlinear models.

Figure $\mathrm{C} 5$ shows measured time series $\mathrm{T}_{\mathrm{w}}$ and $\mathrm{T}_{\mathrm{a}}$ at an hourly time step. Hourly mean $T_{w}$ and $T_{a}$ data showed diel fluctuations in time series temperature. Similar to the 15 minute data, the amplitudes of the diel periods of $T_{a}$ data were visibly greater than $T_{w}$, and thus, the $\mathrm{T}_{\mathrm{a}}$ time series appeared more "noisy" (Figures $\mathrm{C} 1$ and $\mathrm{C5}$ ). And, the linear and nonlinear $\mathrm{T}_{\mathrm{w}}$ models simulated noisy $\mathrm{T}_{\mathrm{w}}$ (Figures C6 and C7). Calibrated linear $\mathrm{T}_{\mathrm{w}}$ model outputs were less noisy and predicted $\mathrm{T}_{\mathrm{w}}$ more accurately the linear and nonlinear models (Figure C8). Thus, adding calibration coefficients $\alpha$ and $\beta$ to the linear $\mathrm{T}_{\mathrm{w}}$ models improved $\mathrm{T}_{\mathrm{w}}$ model performance ratings significantly $(\mathrm{p}<0.01)$. This information may be important to land managers that require hourly estimates of $T_{w}$. 


\section{Daily stream temperature models}

Results from daily stream water temperature models are provided in Appendix C (Figures C9 to C13). Results showed nonlinear $\mathrm{T}_{\mathrm{w}}$ models performed significantly $(\mathrm{p}<0.1)$ better than the original SWAT $\mathrm{T}_{\mathrm{w}}$ model. There were not significant differences ( $>>0.05$ ) between the original SWAT $T_{w}$ model and the Ficklin et al. (2012) $T_{w}$ model. Thus, the nonlinear $T_{w}$ models are a better choice for land managers that need to estimate or predict $\mathrm{T}_{\mathrm{w}}$ at a daily time step in the region for various applications (e.g. fisheries management, ecological modeling, etc.). Additionally, the SWAT model may benefit from considering using a nonlinear $\mathrm{T}_{\mathrm{w}}$ model instead of the linear $\mathrm{T}_{\mathrm{w}}$ model.

Graphical representations of observed versus simulated $T_{w}$ are shown in Figure 26. Stream water temperature below $0{ }^{\circ} \mathrm{C}$ was not observed because ice that covers a stream limits surface heat exchange between the stream and the atmosphere (Mohseni and Stefan, 1999). The linear, nonlinear, and original SWAT model tended to overestimate $\mathrm{T}_{\mathrm{w}}$ in the lower ranges $\left(0\right.$ to $\left.5{ }^{\circ} \mathrm{C}\right)$. Conversely, the calibrated linear and Ficklin et al. (2012) $\mathrm{T}_{\mathrm{w}}$ model tended to underestimate $\mathrm{T}_{\mathrm{w}}$ in the lower ranges $\left(0\right.$ to $\left.5{ }^{\circ} \mathrm{C}\right)$. Accurate predictions of $\mathrm{T}_{\mathrm{w}}$ in the 0 to $5{ }^{\circ} \mathrm{C}$ temperature range are important considering ice covers for extended periods of time can cause fish kills.

All models showed high amounts of variance below $20^{\circ} \mathrm{C}$ (Figure 27). High flow rates affect $T_{w}$ when $T_{a}$ is between 0 to $20{ }^{\circ} \mathrm{C}$ (Mohseni and Stefan, 1999). Thus, one limitation to the linear and nonlinear $\mathrm{T}_{\mathrm{w}}$ models is that the models do not account for hydrology and therefore may not estimate $\mathrm{T}_{\mathrm{w}}$ accurately when Ta is between 0 to $20{ }^{\circ} \mathrm{C}$ (e.g. during the spring season). The Ficklin et al. (2012) $\mathrm{T}_{\mathrm{w}}$ model accounts for hydrology, but the variance was not significantly ( $p>0.05)$ lower compared to the linear 
and nonlinear $\mathrm{T}_{\mathrm{w}}$ models. There was less variability in $\mathrm{T}_{\mathrm{w}}$ results in the higher temperature range $\left(>20^{\circ} \mathrm{C}\right)$. Higher temperature ranges are associated with low flow periods (Mohseni and Stefan, 1999). During low flow periods, $\mathrm{T}_{\mathrm{w}}$ is usually more dependent on $\mathrm{T}_{\mathrm{a}}$ than hydrology.

The Ficklin et al. (2012) $\mathrm{T}_{\mathrm{w}}$ model performed slightly better than the existing SWAT $\mathrm{T}_{\mathrm{w}}$ model, but the differences were not significant $(\mathrm{p}>0.05)$. Percent differences for all site mean NSE, PBIAS, RSR, MAE, MSE, and RMSE values were 1.10, -42.30, $6.45,-10.14,-17.51,-8.67 \%$ during the calibration period and $1.13,11.52,-8.96,-10.30$, $15.47,-7.87 \%$ during the validation period, respectively. Like the original SWAT $\mathrm{T}_{\mathrm{w}}$ model, the Ficklin et al. (2012) $\mathrm{T}_{\mathrm{w}}$ model accounts for $\mathrm{T}_{\mathrm{a}}$. Additionally, the Ficklin et al. (2012) $\mathrm{T}_{\mathrm{w}}$ model can be calibrated and accounts for hydrology, including the volume of and temperature of inflows from snowmelt, groundwater, surface water runoff, and soil water lateral flow making the model a more robust option for land management. Thus, the Ficklin et al. (2012) $\mathrm{T}_{\mathrm{w}}$ model performed equally as well as the original SWAT $\mathrm{T}_{\mathrm{w}}$ model in the central U.S. in the current research, however, the original SWAT $\mathrm{T}_{\mathrm{w}}$ model did not perform well in the study by Ficklin et al. (2012).

Ficklin et al. (2012) showed that the original SWAT $\mathrm{T}_{\mathrm{w}}$ model did not perform well in the mountainous and coastal regions of the western U.S. with a seven site mean NSE, PBIAS, and mean error (ME) of $-0.27,-42.14 \%$, and $3.21^{\circ} \mathrm{C}$, respectively, during the calibration period and $-0.26,-41.16 \%$, and $3.02^{\circ} \mathrm{C}$, respectively during the validation period. Conversely, the process based $\mathrm{T}_{\mathrm{w}}$ model published by Ficklin et al. (2012) performed well with seven site mean NSE, PBIAS, and mean error (ME) of 0.81, $-8.91 \%$, and $-0.70{ }^{\circ} \mathrm{C}$, respectively, during the calibration period and $0.82,7.74 \%$, and $-.058{ }^{\circ} \mathrm{C}$, 
respectively during the validation period. The results of the Ficklin et al. (2012) publication and this research combined show the original SWAT $\mathrm{T}_{\mathrm{w}}$ model does not perform satisfactory in all regions, but the Ficklin et al. (2012) $\mathrm{T}_{\mathrm{w}}$ model has performed well (NSE values >0.70) in the mountainous and coastal regions of the western U.S. and in the central United States. The Ficklin et al. (2012) $\mathrm{T}_{\mathrm{w}}$ model performed better in different regions because it accounts for watershed hydrology (snowmelt, soil water lateral flow, overland flow, and groundwater flow) and meteorological conditions $\left(\mathrm{T}_{\mathrm{a}}\right)$, whereas the original SWAT $\mathrm{T}_{\mathrm{w}}$ model is not process based and only accounts for $\mathrm{T}_{\mathrm{a}}$ (Ficklin et al. 2012). Both $\mathrm{T}_{\mathrm{w}}$ models; however, showed greater error than the accuracy of modern $\mathrm{T}_{\mathrm{w}}$ sensors $\left( \pm 0.1^{\circ} \mathrm{C}\right)$, and thus, it would be best if directly measured $\mathrm{T}_{\mathrm{w}}$ data could be input into SWAT weather input files. This information may be important to the SWAT model development team.

The Ficklin et al. (2012) $\mathrm{T}_{\mathrm{w}}$ model was the only model that did not generally underestimate $T_{w}$ in the higher temperature range in the current research (Figure 27). For example, the original SWAT model and the nonlinear $\mathrm{T}_{\mathrm{w}}$ model did not simulate $\mathrm{T}_{\mathrm{w}}>30$ ${ }^{\circ} \mathrm{C}$ during the study period. Accurate predictions of $\mathrm{T}_{\mathrm{w}}$ during summer months are important because of the risks associated with elevated $\mathrm{T}_{\mathrm{w}}$ and aquatic ecosystem health. 

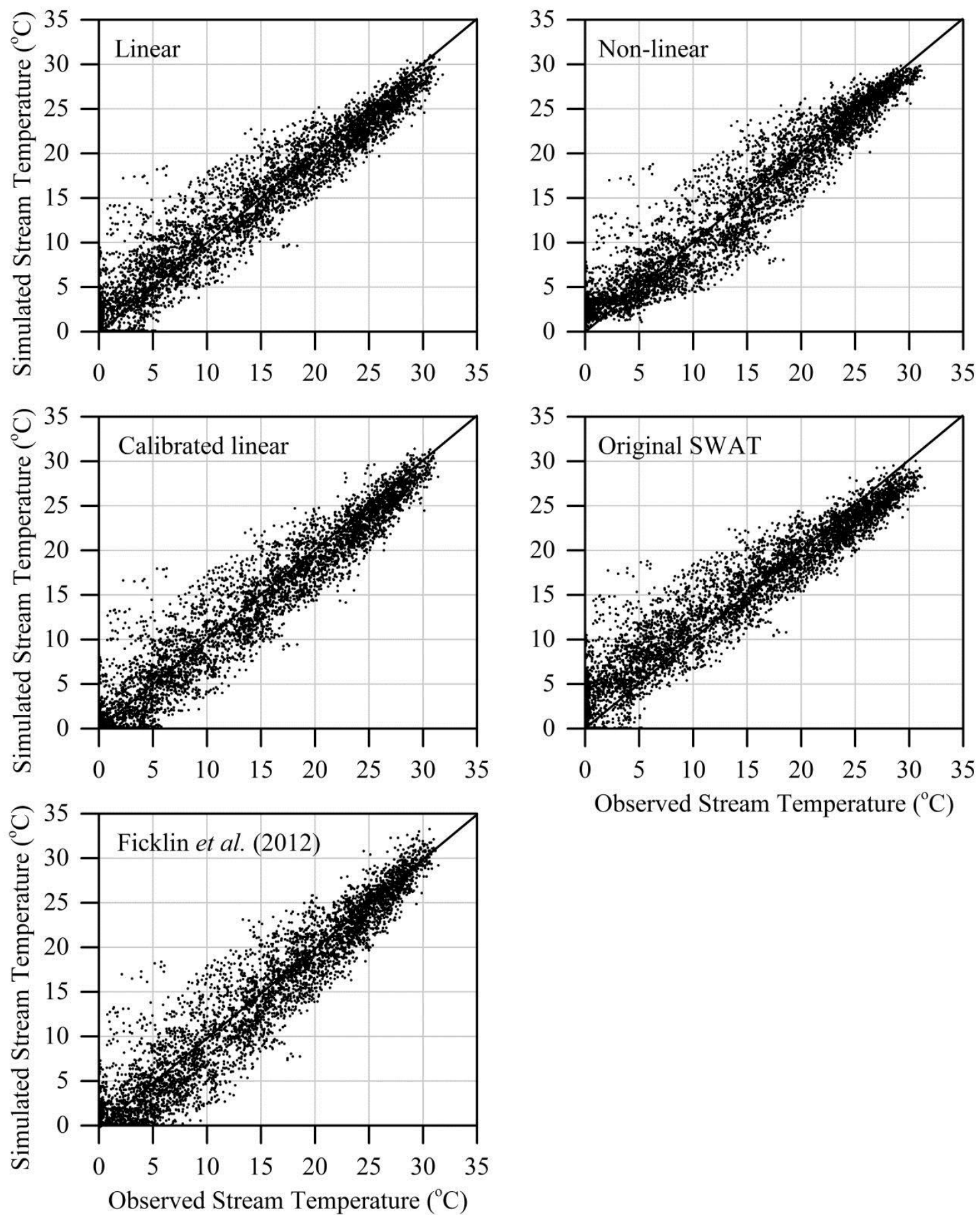

Figure 27. Results showing observed stream water temperature versus simulated stream water temperature data for each of the models tested at a daily time step collected during the study period (water years 2011, 2012, 2013) located in Hinkson Creek Watershed, U.S.A. 


\section{STREAM WATER TEMPERATURE MEASURING AND MODELING RECOMMENDATIONS}

Choosing the appropriate $\mathrm{T}_{\mathrm{w}}$ model is dependent on the objectives of the research and time scale of the required $\mathrm{T}_{\mathrm{w}}$ estimations or predictions (Rivers-Moore and Lorentz, 2004). Deterministic $T_{w}$ models generally result in the most accurate estimates of $T_{w}$.

But, it's more cost effective to measure $\mathrm{T}_{\mathrm{w}}$ directly, than to measure all the meteorological and hydrologic variables needed to calculate the energy balance (Caissie, 2006). Measuring $\mathrm{T}_{\mathrm{w}}$ directly whenever possible is best because of the error associated with modeling. But, this may not always be possible due to of costs associated with instruments (sensors, data loggers, etc.) and labor (installation, maintenance, etc.). A best estimate of $\mathrm{T}_{\mathrm{w}}$ using regression models dependent on $\mathrm{T}_{\mathrm{a}}$ from nearby weather stations may be a more viable option. There is also a cost and benefit to consider involving time scale when deciding on what $\mathrm{T}_{\mathrm{w}}$ model to use. Daily and post daily models did not show any detail of diel fluctuations in $\mathrm{T}_{\mathrm{w}}$, but $\mathrm{T}_{\mathrm{w}}$ regression model accuracy increased with time scale. This study showed that $\mathrm{T}_{\mathrm{w}}$ regression models can be calibrated to accurately predict $\mathrm{T}_{\mathrm{w}}$ at sub-daily time scales. Linear and nonlinear regression $\mathrm{T}_{\mathrm{w}}$ models without the calibration parameters did not perform as well. If sub-daily $\mathrm{T}_{\mathrm{w}}$ data are needed in a situation where $T_{\mathrm{w}}$ cannot be directly measured, then the linear $\mathrm{T}_{\mathrm{w}}$ model cannot be calibrated to observed data. Simulating $\mathrm{T}_{\mathrm{w}}$ using regression models at sub-daily time scales may not be practical because of the error associated with modeling $\mathrm{T}_{\mathrm{w}} \mathrm{using}$ regression models at sub-daily time scales.

The SWAT model would benefit from implementing the Ficklin et al. (2012) $\mathrm{T}_{\mathrm{w}}$ model because the Ficklin et al. (2012) $\mathrm{T}_{\mathrm{w}}$ model has shown to work well in different regions while the linear $T_{w}$ model in SWAT 2012 has not. The Ficklin et al. (2012) $T_{w}$ 
model performed better than the original $\mathrm{SWAT} \mathrm{T}_{\mathrm{w}}$ model in the mountainous and coastal regions of the western U.S. (Ficklin et al. 2012), and equally as well as the SWAT $\mathrm{T}_{\mathrm{w}}$ model in this study. Another option would be to implement the nonlinear $\mathrm{T}_{\mathrm{w}}$ model because results from this research showed that the nonlinear $\mathrm{T}_{\mathrm{w}}$ model performed significantly better than the linear $\mathrm{T}_{\mathrm{w}}$ model used in the current version of SWAT. It would be best, however, if the end user could input measured $\mathrm{T}_{\mathrm{w}}$ data into SWAT. Allowing the end user to input measured $\mathrm{T}_{\mathrm{w}}$ data into SWAT could improve estimates of in-stream water quality and biological processes simulated by SWAT. Additionally, changes should be made to SWAT that would simplify SWAT model auto-calibration to make the model a more practical choice for land managers.

Further research is needed to improve mechanistic understanding of the relationships between natural and anthropogenic processes that control $\mathrm{T}_{\mathrm{w}}$ (Webb et al. 2008), and ultimately the relationship between $\mathrm{T}_{\mathrm{w}}$ and $\mathrm{T}_{\mathrm{a}}$ (Caissie, 2006). Ongoing interdisciplinary research is needed to investigate the natural and anthropogenic impacts on interacting physical, chemical, and biological processes, particularly in urbanizing watersheds. Considering most of the increase in human population in the next 35 years will occur in urban areas of the developing world, the effects of urbanization on all aspects of environmental water quality is of great concern (Myer et al. 2005). Nonpoint source thermal pollution is of particular concern due to the central role of $\mathrm{T}_{\mathrm{w}}$ in overall aquatic ecosystem health (Rice et al. 2011). Tracing the casual source of thermal pollution is complicated, in part, due to the numerous independent and interacting natural and anthropogenic impacts involved. Long term monitoring is needed to study the effects of urbanization on water quality and the effectiveness of watershed restoration efforts. 
The long term in-stream measurement of $\mathrm{T}_{\mathrm{w}}$ in urban stream systems is also complicated, in part, because in-stream $\mathrm{T}_{\mathrm{w}}$ sensors can be displaced, entrained in sediment, damaged, or lost after large runoff events. Additionally, fluctuations in stage complicate measuring $\mathrm{T}_{\mathrm{w}}$ because sensors can come out of water as water levels recede during dry seasons, or be deep below the surface as stage increases during wet seasons. Monitoring of $\mathrm{T}_{\mathrm{w}}$ is expensive because of costs associated with purchasing and maintaining instruments (sensors, data loggers, etc.) and labor (installation, maintenance, etc.) (Caissie, 2006; Benyahya et al. 2007), and funding may be limited depending on the state of the economy.

Because of the problems associated with in-stream measurement of $\mathrm{T}_{\mathrm{w}}$, the advent of remotely sensing $\mathrm{T}_{\mathrm{w}}$ variability using thermal infrared imagery (TIR) is promising (Webb et al. 2008). TIR data could be collected at multiple spatial scales via satellite, aircraft and ground-based platforms. Comparison of the TIR images overtime could assist in monitoring the effects of anthropogenic impacts on $\mathrm{T}_{\mathrm{w}}$ as well as the effectiveness of restoration efforts. For example, satellite TIR images overtime could help monitor the effects of human induced global warming on $\mathrm{T}_{\mathrm{w}}$ regimes in high order rivers (e.g. The Amazon River, The Mississippi River, The Congo River). Smaller scale projects targeted at the effects of urbanization on $\mathrm{T}_{\mathrm{w}}$ variability in low-order streams like Hinkson Creek could be performed by mounting a camera capable of collecting TIR images to a bridge wing wall over an urban stream to monitor the frequency, magnitude, and duration of $\mathrm{T}_{\mathrm{w}}$ surges following summer precipitation events as well as the effectiveness of restoration efforts. 


\section{CHAPTER V \\ CONCLUSION AND SYNTHESIS}

Hinkson Creek is a 3rd order stream that drains a multiuse urbanizing watershed in the central United States. The creek was instrumented in fall 2008 with a nested-scale experimental watershed study design ( $\mathrm{n}=5$ gauging stations). The current work took advantage of three water years of 15 minute $T_{w}, T_{a}$, and discharge data collected from 2009 to 2012 water years to investigate $T_{w}$ variability and test and develop $T_{w} / T_{a}$ models. Investigation of long term high resolution data in low order urban streams was needed mainly because of the paucity of observed data in "flashy" multi-land use urbanizing catchments (Anderson et al. 2011; Nelson and Palmer, 2007). Investigation of $\mathrm{T}_{\mathrm{w}}$ in urban streams was deemed important because increasing urban land use will continue to affect $T_{w}$, which is an important water quality variable because of its effects on nearly all aspects of physical and chemical properties of water, and biological processes in aquatic ecosystems (Anderson et al. 2011).

To investigate $T_{w}$ variability, hydroclimate data including $T_{w}, T_{a}$, and stream discharge from the 2011, 2012, and 2013 water years were reduced to 15 minute, hourly, daily, weekly, monthly, seasonal, and water year time steps for further analysis. The number of days and maximum duration $\mathrm{T}_{\mathrm{w}}$ was above $32{ }^{\circ} \mathrm{C}$ and $35^{\circ} \mathrm{C}$ during the study period were recorded. ANOVA and Tukey-Kramer multiple comparison test were used to test for significant differences $(\mathrm{p}<0.05)$ in hydroclimate measurements between multiple gauging stations. Observed $\mathrm{T}_{\mathrm{w}}$ data were analyzed for $\mathrm{T}_{\mathrm{w}}$ surges. $\mathrm{T}_{\mathrm{w}}$ data were separated into 15 different flow classes to test for the effects of discharge on $T_{w}$ and the $T_{w} / T_{a}$ 
relationship. Linear and nonlinear regression analyses were performed using mean $T_{w} v s$. mean $T_{a}$ data for each site at 15 minute, hourly, daily, weekly, monthly, and seasonal time steps. Calibration confidents $\alpha$ and $\beta$ were added to the 15 minute and hourly linear regression $T_{w}$ models to improve $T_{w}$ model performance at sub-daily time steps. Additionally, the original SWAT linear $\mathrm{T}_{\mathrm{w}}$ model and the process based $\mathrm{T}_{\mathrm{w}}$ model created by Ficklin et al. (2012) were tested against observed $\mathrm{T}_{\mathrm{w}}$ data from five gauging sites.

Significant differences in $T_{a}, T_{w}$, and discharge were found between five stream study sites. Fifteen sudden increases in $T_{w}$ following summer thunderstorms $\left(T_{w}\right.$ surges $)$ with a maximum peak $\mathrm{T}_{\mathrm{w}}, \mathrm{T}_{\mathrm{w}}$ surge, and surge duration of $34.2{ }^{\circ} \mathrm{C}, 2.6^{\circ} \mathrm{C}$, and 6.3 hours, respectively, were observed during summers of 2010, 2011, and 2012. The $T_{w} / T_{a}$ relationships were compared between five study stream sites. The effects of discharge and land use in the $T_{w} / T_{a}$ relationship were quantitatively characterized. The $T_{w}$ model utilized in the SWAT 2012, and the new $\mathrm{T}_{\mathrm{w}}$ model developed by Ficklin et al. (2012) were tested with observed hydroclimate data from multiple sites of the study stream. The Ficklin et al. $\mathrm{T}_{\mathrm{w}}$ model produced better predictions than the original SWAT $\mathrm{T}_{\mathrm{w}}$ model in seven coastal and mountainous regions of the western United States, however, the models were not tested in the central United States where hydrogeological and land use interactions are different.

\section{FINDINGS ON HYDROCLIMATE IN HINKSON CREEK WATERSHED}

Climate during the study period included two wetter than average years (2009 and 2010), and two years of drought (2011 and 2012). Site \# 1, located at the intersection of 
Rogers's road and Hinkson Creek in Columbia, Missouri, was ephemeral during the summer of 2012 due to reduced rainfall. But, Hinkson Creek was perennial from site \#2, located at the intersection of Mexico Gravel Road and Hinkson Creek in Columbia, Missouri, to the watershed outlet. Drought conditions during the summer of 2012 provided a worst case scenario for the effects of low discharge on $\mathrm{T}_{\mathrm{w}}$ in a low-order urban stream of the central U.S.

The first objective of this study was to test for significant differences in $T_{w}$ in the study stream sites. ANOVA analyses showed significant differences in $T_{w}$ in the stream study sites, therefore the null hypothesis (i.e. no difference in $T_{w}$ between study sites) was rejected.

\section{FINDINGS ON HIGH STREAM WATER TEMPERATURE IN HINKSON CREEK}

It was assumed when impervious surfaces heated up in the summertime, heat energy from impervious surfaces is transferred to stormwater runoff by conduction following precipitation events (Herb et al. 2008). Then, the heated stormwater is transported to streams causing sudden increases in $\mathrm{T}_{\mathrm{w}}$ that exceeded $5{ }^{\circ} \mathrm{C}$. Stream water temperature did not return to pre-surge temperature for $>6$ hours following the surges in $\mathrm{T}_{\mathrm{w}}$. Anthropogenic impacts were suspect when results showed significant evidence of an "urban heat island effect" on $\mathrm{T}_{\mathrm{a}}$ at urban site \#3 in Hinkson Creek Watershed in the current work. Buffered stream water temperature regime observed at site \#1 was due to effects of pooling considering the high specific heat capacity of water $\left(4.184 \mathrm{~J} / \mathrm{g}{ }^{\circ} \mathrm{C}\right)$. The observed urban heat island effect may have contributed to elevated $\mathrm{T}_{\mathrm{w}}$ observed at 
gauging site \#3 and downstream at site \#4. Stream water temperature exceeded "Critical Thermal Maximum" for 5 days for a maximum duration of 2.5 hours at urban site \#3.

The effects of discharge on $T_{w}$ were investigated to explain the significant differences $T_{w}$ between gauging sites. Mean discharge, $T_{a}$ and $T_{w}$ data were separated into 15 different flow classes. Results showed mean discharge increased exponentially from the headwaters to the watershed outlet, and the differences between sites grew exponentially with every increase in flow class. Discharge did not significantly affect $T_{\mathrm{w}}$ at any flow class $(p>0.5)$. Stream water temperature was, however, was significantly affected by cumulative urban land use percent in all flow classes $>90 \%$ ( $\mathrm{p}=0.03)$. Stream water temperature at urban sites \#4 and \#5 increased relative to other Hinkson Creek gauging with every increase in flow class, but the differences in $T_{w}$ were not statistically significant ( $>0.05$ ) until the $>90 \%$ flow class. These results provided additional evidence that $\mathrm{T}_{\mathrm{w}}$ in Hinkson Creek was increased by heated urban stormwater runoff.

\section{FINDINGS ON STREAM AND AIR TEMPERATURE RELATIONSHIPS}

Time lag affected $\mathrm{T}_{\mathrm{w}} / \mathrm{T}_{\mathrm{a}}$ relationships at every monitoring site in this study. Accounting for lag improved $\mathrm{r}^{2}$ values at sub-daily time steps. Lag was greatest at site \#1 and at site \#5. Pooling buffered stream response to changes in air temperature at site \#1. In general, time lag increased with stream distance from sites \#2 to \#5 because discharge increased with stream distance. Discharge buffered $\mathrm{T}_{\mathrm{w}}$ response to meteorological conditions thereby increasing the lagged response of $T_{w}$ to changes in $T_{a}$.

The second objective in this research was to compare $T_{w} / T_{a}$ relationships between study stream sites. ANOVA analyses showed differences in $T_{w} / T_{a}$ relationships 
between study stream sites for flow classes $>90 \%$; thus, the null hypothesis was rejected $(\mathrm{p}=0.03)$. Independent and interacting natural processes and human impacts affected the strength of the $T_{w} / T_{a}$ relationship. There was a general trend for $T_{w} / T_{a}$ relationships to decrease with increasing stream distance and urban land use. Increased discharge buffered stream interaction with meteorological conditions decreasing $\mathrm{r}^{2}$ values.

The effect of time scale on $T_{w} / T_{a}$ relationships was also investigated because the third objective of this research was to compare $T_{w} / T_{a}$ relationships at 15 minute, hourly, daily, weekly, monthly, and seasonal time scales. Results showed $\mathrm{r}^{2}$ values significantly increased for linear and nonlinear models as time step increased $(\mathrm{p}<0.01)$. The null hypothesis was rejected. Linear coefficients were affected as time step increased from 15 minute to seasonal averages, but nonlinear coefficients were not affected. But, results showed a positive relationship in nonlinear relationships between alpha / beta coefficients, and an inverse relationship between gamma coefficients and alpha / beta coefficients.

The effects of discharge on the $T_{w} / T_{a}$ relationship were investigated to complete the fourth objective, quantitatively characterize the significance of the effects of discharge in the $T_{w} / T_{a}$ relationship. Mean discharge, $T_{a}$ and $T_{w}$ data were separated into 15 different flow classes. Linear regression analyses were performed for each flow class. The relationship between $T_{w}$ and $T_{a}$ was affected by discharge. As flow class increased, $T_{a}$ explained significantly less variance in $T_{w}(p<0.01)$. Stream water temperature regimes were controlled by meteorological conditions (e.g. solar radiation, and $\mathrm{T}_{\mathrm{a}}$ ), particularly during low flow periods. But, hydrologic factors (e.g. volume of water, source of water) dominate during high flow periods, in part, because of high heat capacity 
of water and decreased residence time. Residence time decreased as discharge increased. As residence time decreased, stream interaction with the atmosphere decreased. These results reject the null hypothesis and show empirical $\mathrm{T}_{\mathrm{w}}$ models that do not account for hydrology are not as accurate during stormflow periods.

\section{FINDINGS ON STREAM WATER TEMPERATUIRE MODEL COMPARRISON}

To test sub-daily linear and nonlinear regression $\mathrm{T}_{\mathrm{w}}$ models with observed hydroclimatic data from five sites of the study stream for the fifth objective, results from sub-daily models were evaluated. The null hypothesis was rejected $(\mathrm{p}<0.01)$. The calibrated linear $T_{w}$ model was the only model to produce realistic results at 15 minute and hourly time steps. Air temperature and stream water temperature data showed a sinusoidal period over a diel period. The crests and troughs over a diel period were greater in $\mathrm{T}_{\mathrm{a}}$ compared to $\mathrm{T}_{\mathrm{w}}$. Thus, the $\mathrm{T}_{\mathrm{a}}$ data appeared more "noisy". The difference in noise was, in part, due to the high heat capacity of water compared to air. The linear and nonlinear $\mathrm{T}_{\mathrm{w}}$ models simulated $\mathrm{T}_{\mathrm{w}}$ nearly equal to the noisy $\mathrm{T}_{\mathrm{a}}$ between $5{ }^{\circ} \mathrm{C}$ and $20{ }^{\circ} \mathrm{C}$. Conversely, calibrated linear $\mathrm{T}_{\mathrm{w}}$ model outputs were visibly less noisy and thus closer to observed $\mathrm{T}_{\mathrm{w}}$ at sub-daily time steps. Linear and nonlinear $\mathrm{T}_{\mathrm{w}}$ models that require only $\mathrm{T}_{\mathrm{a}}$ data to predict $\mathrm{T}_{\mathrm{w}}$ should not be used at sub-daily time steps because they do not accurately simulate diel temperature fluctuations. But, the calibrated linear $\mathrm{T}_{\mathrm{w}}$ models produce satisfactory results by adding two simple calibration parameters capable of decreasing the amplitude of the sinusoidal period observed in diel $\mathrm{T}_{\mathrm{w}}$.

The noise associated with diel variability in $\mathrm{T}_{\mathrm{w}}$ and $\mathrm{T}_{\mathrm{a}}$ data was lost in the averaging process when $T_{w}$ and $T_{a}$ data were reduced by averaging sub-daily data to a 
daily time step. At a daily time step, $\mathrm{T}_{\mathrm{w}}$ and $\mathrm{T}_{\mathrm{a}}$ data are generally nearly equal between 5 ${ }^{\circ} \mathrm{C}$ and $20{ }^{\circ} \mathrm{C}$. Thus, linear and nonlinear $\mathrm{T}_{\mathrm{w}}$ models produce realistic results. Overall, the nonlinear $\mathrm{T}_{\mathrm{w}}$ models performed better than all other $\mathrm{T}_{\mathrm{w}}$ models evaluated at a daily time step. Nonlinear daily time step models account for cooling due to latent heat of vaporization observed in daily mean $\mathrm{T}_{\mathrm{w}}$ data.

Results from the original SWAT $T_{w}$ model, and the Ficklin et al. (2012) $T_{w}$ model were compared to complete the sixth objective, test the daily $\mathrm{T}_{\mathrm{w}}$ model utilized in the SWAT 2012, and the new $\mathrm{T}_{\mathrm{w}}$ model developed by Ficklin et al. (2012) with observed hydroclimate data from five sites of the study stream.. Results failed to reject the null hypothesis. The Ficklin et al. (2012) $\mathrm{T}_{\mathrm{w}}$ model yielded model evaluation numbers that were not significantly different than the original SWAT $\mathrm{T}_{\mathrm{w}}$ model $(\mathrm{p}>0.05)$. Both $\mathrm{T}_{\mathrm{w}}$ models yielded "Very good" results (i.e. $0.75<\mathrm{NSE} \leq 0.90 ; \pm 5 \leq$ PBIAS $< \pm 10 ; 0.30<$ RSR $\leq 0.50)$. The Ficklin et al. (2012) $\mathrm{T}_{\mathrm{w}}$ model can be calibrated and accounts for hydrology, but the model was computationally demanding. The Ficklin et al. (2012) $\mathrm{T}_{\mathrm{w}}$ model simulated accurate predictions when $\mathrm{T}_{\mathrm{w}}>30^{\circ} \mathrm{C}$ during the summer. The original SWAT $T_{w}$ model usually underestimated $T_{w}$ during the summer. The original SWAT $T_{w}$ model did not work well in the mountainous and coastal regions of the western United States because the process based Ficklin et al. (2012) $T_{w}$ model is more transferrable to other regions than the original SWAT $\mathrm{T}_{\mathrm{w}}$ model.

Results in this study showed equipping the SWAT model with the Ficklin et al. (2012) $T_{w}$ model could produce $T_{w}$ simulations as accurate as the original SWAT T model in the central U.S. Additionally, the SWAT model would better simulate in-stream water quality and biological processes dependent on $T_{w}$ if the SWAT model was capable 
of uploading observed $\mathrm{T}_{\mathrm{w}}$ weather input data. Estimates involving in-stream water quality and biological processes that share a positive relationship with $\mathrm{T}_{\mathrm{w}}$ are likely underestimated when $\mathrm{T}_{\mathrm{a}}$ is above $20^{\circ} \mathrm{C}$ using the original SWAT $\mathrm{T}_{\mathrm{w}}$ model.

\section{MANAGEMENT IMPLICATIONS}

Results from this research provide baseline $\mathrm{T}_{\mathrm{w}}$ information on the thermal regime in an EPA 303(d) listed urban stream located in an urbanizing watershed of the Lower Missouri Moreau River Basin (LMMRB). The study site for this research was important because Hinkson Creek watershed is representative of the LMMRB in regard to hydrologic processes, water quality, climate, and land use making the study site a useful tool for watershed restoration efforts focused on controlling nonpoint source pollution in the region (Hubbart et al. 2010). The nested scale experimental watershed study design was used to trace a diffuse pollutant (i.e. $\mathrm{T}_{\mathrm{w}}$ surges). This information is useful to land managers faced with the task of remediating nonpoint source pollutants in the region.

Land managers concerned with the protection of aquatic ecosystem health should consider implementing management practices that attempt to cool heated stormwater in urban subbasins \#3, \#4, and \#5 because of the relationship between increased $\mathrm{T}_{\mathrm{w}}$ and urban land use associated with impervious surfaces observed in this research. Site \#3 showed 5 days $\mathrm{T}_{\mathrm{w}}$ was above "Critical Thermal Maximum" $\left(>35^{\circ} \mathrm{C}\right)$. Stream temperature surges $>1{ }^{\circ} \mathrm{C}$ in a time span of 15 minutes were observed at site \#3. The $\mathrm{T}_{\mathrm{w}}$ surges observed in this research were fewer and of lesser magnitude and duration compared to other studies by Nelson and Palmer (2007) and Rice et al. (2011) considering the relationship observed by Nelson and Palmer (2007) between $\mathrm{T}_{\mathrm{w}}$ surge frequency and 
\%impervious surface in the watershed draining to the sampling point, and the relationship observed by Rice et al. (2001) between amount of impervious surface coverage within a 25 meter buffer and magnitude of and duration of $T_{w}$ surges. Thus, terrestrial development that involves increased impervious surfaces in the watershed is expected to lead to more frequent $T_{\mathrm{w}}$ surges. Further, increases in impervious surface coverage within a 25 meter buffer of Hinkson Creek or its tributaries should be avoided or $\mathrm{T}_{\mathrm{w}}$ surges could increase in magnitude and duration. Reviews by Webb et al. (2008) and Caissie (2007) showed forested riparian zones help keep streams cool by providing shade that reduces solar radiation at the stream surface. The $\mathrm{T}_{\mathrm{w}}$ increase of approximately $4{ }^{\circ} \mathrm{C}$ at site \#5 that was not detected upstream at site \#4 provided evidence that heated stormwater entered Hinkson Creek in subbasin \#5. The $\mathrm{T}_{\mathrm{w}}$ of Flatbranch Creek should be investigated because it enters Hinkson Creek approximately 1.3 linear km downstream of site \#4 in sub-basin \#5 and drains the majority of high density urban land use in the City of Columbia associated with increased imperious surfaces. Sudden increases in $\mathrm{T}_{\mathrm{w}}$ like the $\mathrm{T}_{\mathrm{w}}$ surges observed during this work have been shown to impair aquatic ecosystem health (Nelson and Palmer, 2007).

The 15 minute calibrated linear $\mathrm{T}_{\mathrm{w}}$ regression models are useful for ecological and water quality studies that need to estimate diel variability in $T_{w}$ in Hinkson Creek. The models are also good tools for land management that require estimates of $\mathrm{T}_{\mathrm{w}}$. The validated $T_{w}$ models from this research are useful to aid in the protection of water quality, thereby providing local land managers with the knowledge to make informed management decisions in the central United States. If RMSE of $3{ }^{\circ} \mathrm{C}$ for 15 minute $\mathrm{T}_{\mathrm{w}}$ model simulations is deemed an unacceptable amount of error, then $\mathrm{T}_{\mathrm{w}}$ should be directly 
measured. Practical $\mathrm{T}_{\mathrm{w}}$ regression models dependent on $\mathrm{T}_{\mathrm{a}}$ are an attractive choice, however, because of the costs associated with installing and maintaining instruments capable of measuring in-stream $\mathrm{T}_{\mathrm{w}}$.

\section{ADVANCES TO SCIENCE}

Information from this research advanced scientific understanding of $T_{w}$ variability in a multi-land use watershed of the central United States by analyzing three water years of high resolution (15 minute) $\mathrm{T}_{\mathrm{w}}$ data using a nested scale experimental watershed study design approach to elucidate the effects of discharge and land use on $T_{w}$ variability. This research evaluated the efficacy of using linear and nonlinear $T_{w}$ regression models at 15 minute, hourly, and daily time scales using six model evaluation criteria. The calibrated linear $T_{w}$ models created and tested showed simple linear $T_{w}$ regression models are capable of accurately estimating $T_{w}$ with readily available $T_{a}$ data at 15 minute and hourly time steps. While the linear $\mathrm{T}_{\mathrm{w}}$ model used in the current version of SWAT (SWAT 2012) produced satisfactory estimates of $\mathrm{T}_{\mathrm{w}}$ at a daily time step, however, the nonlinear $\mathrm{T}_{\mathrm{w}}$ models tested at a daily time step performed significantly $(\mathrm{p}<0.01)$ better the linear $\mathrm{T}_{\mathrm{w}}$ model currently used in SWAT. A newly proposed SWAT $\mathrm{T}_{\mathrm{w}}$ model that was designed to work better than the original SWAT $\mathrm{T}_{\mathrm{w}}$ model had not yet been tested in the central U.S. was evaluated and results showed the $T_{w}$ model proposed by Ficklin et al. (2012) worked equally as well compared to the linear $T_{w}$ model currently used in SWAT. Finding the Ficklin et al. $T_{w}$ model worked well in this study is significant because the study site was cited to be representative of hydrologic processes, water quality, climate, and land use in the LMMRB making the Ficklin et al. $\mathrm{T}_{\mathrm{w}}$ model useful tool for watershed 
restoration efforts focused on controlling nonpoint source pollution in the region. Results from the daily $T_{w}$ model analyses advance our ability to accurately predict $T_{w}$ with SWAT, a highly used and robust hydrologic model.

\section{CLOSING STATEMENT}

Empirical techniques, such as the regression models created in this work, are often less computationally complex compared to analytical techniques (e.g. deterministic models). There will always be, however, a place for empirical theory in modeling (Rigler, 1982). The inclusions of more complex statistical analysis methods (e.g. time series analysis) in union with recent technological advances (statistical software, and process based simulation modeling) could help improve predictive modeling by reducing scaledependencies and the explained variation in predictions (Pace, 2001). Scientific advances alone, however, will not improve prediction modeling. The future of prediction modeling in aquatic sciences also depends on the cooperation of multiple disciplines. 


\section{LITERATURE CITED}

Akyuz FA, Market PS, Guinan PE, Lam JE, Oehl AM, Maune WC. 2004. The Columbia, Missouri, Heat Island Experiment (COHIX) and the Influence of a Small City on the Local Climatology. Transactions of the Missouri Academy of Science 38: 5671.

Anderson WP, Storniolo RE, Rice JS. 2011. Bank thermal storage as a sink of temperature surges in urbanized streams. Journal of Hydrology 409: 525-537.

Anka-Lufford L, Bets JD, Cooper AM, Daly AL, Soundariarajan S, Stingel AM, Winschel GA. 2007. A chemical and anthropogenic impact study of Lake Lonely. Skidmore College, Saratoga Springs, NY 12866.

Arnold JG, Moriasi DN, Gassman PW, Abbaspour KC, White MJ, Srinivasan R, Santhi C, Harmel RD, van Griensven A, Van Liew MW, Kannan N, Jha MK. 2012. SWAT: Model use, calibration, and validation, American Society of Agricultural and Biological Engineers 55 (4): 1491-1508.

Beitinger TL, Bennett WA, McCauley RW. 1998. Temperature tolerances of North American freshwater fishes exposed to dynamic changes in temperature, Environmental Biology of Fishes 58: 237-275.

Bennett KD. 1990. Milankovitch Cycles and Their Effects of Species in Ecological and Evolutionary Time, Paleobiology 16(1): $11-21$.

Benyahya L, Caissie D, StHiaire A, Ouarda TBMJ, Bobee B. 2007. A review of statistical water temperature models. Canadian Water Resources Association 32 (3): 179192.

Bogan T, Stefan HG, Mohseni O. 2004. Imprints of secondary heat sources on the stream temperature/equilibrium temperature relationship, Water Resources Research 40: $1-16$.

Bond NR, Lake PS, Arthington AH. 2008. The impacts of drought on freshwater ecosystems: an Austrailian perspective. Hydrobiologia 600: 3 - 16.

Bonett DG. 2002. Sample site requirements for estimating intraclass correlations with desired precision. Statistics in Medicine 21: 1331 - 1335.

Boulton AJ. 2003. Parallels and contrasts in the effects of drought on stream macroinvertebrate assemblages. Freshwater Biology 48 (7): 1173 - 1185. 
Brabec E, Schulte S, Richards PL. 2002. Impervious surfaces and water quality: a review of current literature and its implications for watershed planning. Journal of Planning Litterature 16 (4): 500 - 514.

Brown LE, Hannah DM, Milner AM. 2005. Spatial and temporal water column and streambed temperature dynamics within an alpine catchment: implications for benthic communities. Hydrological Processes 19: 15851610.

Bulliner, 2011. Quantifying riparian canopy energy attenuation and stream temperature using An energy balance approach. Master's Thesis, The University of Missouri, Columbia, MO 65211.

Caissie D. 2006. The thermal regime of rivers: a review. Freshwater Biology 51: 13891406.

Caissie D. Satish MG, ElJabi N. 2007. Predicting water temperatures using a deterministic model: Application on Miramichi River catchments (New Brunswick, Canada). Journal of Hydrology 336: 303315.

Chapman SS, Omernik JM, Griffith GE, Schroeder WA, Nigh TA, Wilton TF. 2002. Ecoregions of Iowa and Missouri (color poster with map, descriptive text, summary tables, and photographs): Reston, Virginia, U.S. Geological Survey.

Dinan KF. 1992. Application of the stream network temperature model (SNTEMP) to the central Platte River, Nebraska. Professional Paper, Department of Fishery and Wildlife Biology, Colorado State University, Fort Collins, CO. 89 pp.

Dong J, Chen J, Brosofske KD, Naiman RJ. 1998. Modeling air temperature gradients across managed small streams in western Washington. Journal of Environmental Management 53: 309321.

Dottori F, Martina MLV, Todini E. 2009. A dynamic rating curve approach to indirect discharge measurement. Hydrology Earth System Sciences 13: 847863.

Doyle MW, Shields FD. 2012. Compensatory mitigation for streams under the clean water act: reassessing science and redirection policy. Journal of the American Water Resources Association (JAWRA) 48: 494509.

Environmental Protection Agency (EPA) 2011. Region 7,Total Maximum Daily Load, Hinkson Creek (MO_1007 and_1008) Boone County, Missouri.

Erickson TR, Stefan HG. 2000. Linear air/water temperature correlations for streams during open water periods. Journal of Hydrologic Engineering 317-321. 
Ficklin DL, Lou Y, Stewart IT, Maurer EP. 2012. Development and application of a hydroclimatological stream temperature model within the Soil and Water Assessment Tool, Water Resources Research 48: 116.

Freeman, 2011. Quantifying suspended sediment loading in a Mid-Missouri urban watershed using laser particle diffraction. Master's Thesis, The University of Missouri, Columbia, MO 65211.

Furey PC, Nordin RN, Mazumder A, 2006. Littoral benthic macroinvertebrates under contrasting drawdown in a reservoir and a natural lake. Journal of the North American Benthological Society 25: 19-31.

Gomi T, Moore RD, Dhakal AS. 2006. Stream water temperature response to clearcut harvesting with different riparian treatments, coastal British Columbia, Canada. Water Resources Research 42: 111.

Herb WR, Janke B, Mohseni O, Stefan HG. 2008. Thermal pollution of streams by runoff from paved surfaces. Hydrological Processes 22: 987999.

Herschy RW. 1985. Accuracy in streamflow measurements. Elsevier. Amsterdam.

Hester ET, Bauman KS. 2012. Stream and Retention pond thermal response to heated summer runoff from urban impervious surfaces, Journal of the American Water Resources Association 49(2): 328-342.

Hubbart JA. 2011. Urban floodplain management: understanding consumptive wateruse potential in urban forested floodplains. Stormwater 12(6): $56-63$.

Hubbart JA, Freeman GW. 2010. Sediment laser diffraction: a new approach to an old problem in the central U.S. Stormwater Journal 11(7): 3644.

Hubbart JA, and Zell C. 2013. Considering streamflow trend analyses uncertainty in urbanizing watersheds: a baseflow case study in the central United States. Earth Interactions 17(5): $1-28$.

Hubbart JA, Link TE, Gravelle JA, William EJ. 2007. Timber harvest impacts of water yield in the continental/maritime hydroclimatic region of the United States. Forest Science 53(2): 169180.

Hubbart JA, Holmes J, Bowman G. 2010. Integrating science based decision making and TMDL allocations in urbanizing watersheds. The Watershed Science Bulletin 01: 1924.

Hubbart JA, Muzika RM, Huang D, Robinson A. 2011. Bottomland hardwood forest influence on soil water consumption in an urban floodplain: potential to improve 
flood storage capacity and reduce stormwater runoff. The Watershed Science Bulletin Fall: 3443.

Hubbart JA, Kellner E, Freeman G. 2013. A case study considering the comparability of mass and volumetric suspended sediment data. Environmental Earth Science 71: 40514060.

Hubbart JA, Kellner E, Hooper L, Lupo AR, Market PS, Guinan PE, Stephan K, Fox NI, Svoma BM. 2014. Localized climate and surface energy flux alterations across an urban gradient in the central U.S. Energies 7: 17701791.

Hutchinson VH, 1961. Critical thermal maxima in salamanders. Physiological Zoology 34:97-125.

Krashnikikov SA. 1987. About Optimal Approximation for Stage Discharge Relationship. Proceedings of the State Hydrological Institute 328: 5869.

Kaushal SS, Likens GE, Jaworski NA, Pace ML, Sides AM, Seekell D, Belt KT, Secor DH, Wingate RL. 2010. Rising Stream and River Temperatures in the United States. Research Communications 8(9): 46166.

Lin C, Chen F, Huang JC, Chen WC, Liou YA, Chen WN, SC Liu. 2008. Urban heat island effect and its impact on boundary layer development and land- sea circulation over northern Taiwan. Atmospheric Environment 42: 56355649.

McClain ME, Bilby RE, Triska FJ. 1998. Nutrient cycles and response to disturbance. p. 347367. In: River ecology and management R. J. Naiman and R. E. Bilby (eds.). Springer Verlag, New York.

MDNR. 2006. Stream Survey Sampling Report. Phase III Hinkson Creek Stream Study, Columbia, Missouri, Boone County. Prepared by the Missouri Department of Natural Resources, Field Services Division, Environmental Services Program, Water Quality Monitoring Section.

MDNR, 2011. Total Maximum Daily Load for Hinkson Creek Boone County, Missouri. Prepared by the Missouri Department of Natural Resources Water Protection Program.

Missouri Resource Assessment Program (MRAP). 2005. Land use/Land Cover Data.

Mohseni O, Stefan HG, Erickson TR. 1998. A nonlinear regression model for weekly stream temperatures. Water Resources Research 34(10): 2685692.

Mohseni O, Erickson TR, Stefan HG. 1999. Sensitivity of stream temperatures in the United States to air temperatures projected under a global warming scenario. Water Resources Research. 35(12): 3723733. 
Moore R, Spittlehouse D, Story A. 2005. Riparian microclimate and stream temperature response to forest harvesting: a review. Journal of the American Water Resources Association 41: 813834.

Monk WA, Wood PJ, Hannah DM, Wilson DA. 2008. Macroinvertebrate community response to interannual and regional river flow regime dynamics. River Research and Applications 24: 9981001.

Moriasi DN, Arnold JG, Van Liew, Bingner RL, Harmel, Veith TL. 2007. Model evaluation guidelines for systematic quantification of accuracy in watershed simulations. American Society of Agricultural and Biological Engineers 50(3): 885900.

Nelson KC, Palmer MA. 2007. Stream water temperature surges under urbanization and climate change: data, models, and responses. Journal of the American Water Resources Association 43(2): 44052.

Neitsch, SL, Arnold JG, Kiniry JR, Williams JR, and King KW. 2005. Soil and Water Assessment Tool Theoretical Documentation: Version2005, Texas Water Resources Institute, College Station, TX.

Nigh TA, Schroeder WA. 2002. Atlas of Missouri ecological sections. Missouri Department of Conservation.

Pace ML. 2001. Prediction and the aquatic sciences. Canadian Journal of Fisheries and Aquatic Sciences 58: 63-72.

Peck R, Devore JL. 2012. Statistics: The Exploration and Analysis of Data, Boston: Brooks/Cole, Cengage Learning, 2012. Print.

Perkins B. 1995. Temporal variability in a Midwestern stream during spring. Master's Thesis, The University of Missouri, Columbia, MO 65211.

Poole GC, Berman CH. 2001. An Ecological Perspective on In-Stream Temperature: Natural Heat Dynamics and Mechanisms of Human Caused Thermal Degradation. Environmental Management 27(6): 787802.

Qi C, Grunwald S. 2005. GIS-based hydrologic modeling in the Sandusky watershed using SWAT, American Society of Agricultural Engineers 48(1): 169-180.

Rice JS, Anderson WP, Thaxton CS. 2011. Urbanization influences on stream temperature behavior within low-discharge headwater streams. Hydrological Research Letters 5: 27-31. 
Rigler, FH. 1982. Recognition of the possible: an advantage of empiricism in ecology. Canadian Journal of Fisheries and Aquatic Sciences 39: 1323-1331.

Rivers-Moore NA, Lorentz S, 2004. A simple, physically-based statistical model to simulate hourly water temperatures in a river. South African Journal of Science. 100: 331-333.

Scollan DP. 2011. A multiconfiguration evaluation of the Soil and Water Assessment Tool (SWAT) in a mixed land use watershed in the central U.S.A. Master's Thesis, The University of Missouri, Columbia, MO 65211.

Shiklomanov AI, Yakovleva TI, Lammers RB, Karasev IP, Vorosmarty CJ, Linders E. 2005. Cold region river discharge uncertainty estimates from a large Russian river. Journal of Hydrology 326: 231256.

Sinokrot BA, Gulliver JS. 2000. Instream flow impact on river water temperatures. Journal of hydrologic research 38: 339349.

Silva L, Williams D. 2001. Buffer zone versus whole catchment approaches to studying land use impact on river water quality. Water Resources 35(14): 34623472.

Smith K. 1972. River water temperature - an environmental review. Scottish Geographical Magazine 88: 211 - 220.

Smith K, Lavis ME. 1975. Environmental influences on the temperature of a small upland stream. Oikos 26(2): 228 - 236.

Stefan HG, Preud'homme EB. 1993. Stream water temperature estimation from air temperature. Water Resources Bulletin 29(1): 27 - 45.

Stoline MR. 1981. The status of multiple comparisons: Simultaneous estimation of all pairwise comparisons in oneway ANOVA designs. The American Statistician, 35(3): 134141.

Subehi L, Fukushima T, Onada Y, Mizugaki S, Gomi K, Kosugi K, Hiramatsu S, Kitahara H, Kuraji K, Terajima T. 2010. Analysis of stream water temperature changes during rainfall events in forested watersheds. Limnology 11: 11524.

Sutron Corporation. Accubar Constant Flow Bubble Gauge/Recorder 560133. 8 Feb. 2008. Operations and Maintenance Manual. 21300 Ridgetop Circle, Sterling, Virginia.

United States Census Bureau (USCB). 2011. U.S. Census Bureau Delivers Missouri's 2010 Census Population Totals, including First Look at Race and Hispanic Origin Data for Legislative Redistricting, Accessed March 22, 2011. Available on line at: http://2010.census.gov/news/releases/operations/cb11cn49.html. 
United States Core of Engineers (USCE), 1962. Statistical Methods in Hydrology. U.S. Corps of Engineers Institute for Water Resources Hydrologic Engineering Center, Davis, California.

Wahr JM. 1998. The Earth's rotation, Annual of Review of Earth and Planetary Sciences 16: $231-249$.

Ward JV. 1985. Thermal characteristics of running waters. Hydrobiologia 125: 31 - 46.

Webb BW, Walling DE. 1993. Longer-term water temperature behavior in an upland stream. Hydrological Processes 7: 1932.

Webb BW, Nobilis F. 1997. A long-term perspective on the nature of the air - water temperature relationship: a case study. Hydrological Processes 11: $137-147$.

Webb BW, Zhang Y. 1997. Spatial and seasonal variability in the components of the river heat budget. Hydrological Processes 11: 79 - 101.

Webb BW, Zhang Y. 1999. Water temperatures and heat budgets in Dorset chalk water courses, Hydrological Processes 13: 309 - 321.

Webb BW, Zhang Y. 2004. Intra-annual variability in the non advective heat energy budget of Devon streams and rivers. Hydrological Processes 18: 21172146.

Webb BW, Zhang Y, Nobilis F. 1995. Scale related water temperature behavior, Effects of Scale on Interpretation and Management of Sediment and Water Quality, (Proceedings of a Boulder Symposium). International Association of Hydrological Sciences Publication No. 226; 231 - 239.

Webb BW, Clack PD, Walling DE. 2003. Water - air temperature relationships in a Devon River system and the role of flow. Hydrological Processes 17: 30693084.

Webb B, Hannah D, Moore R, Brown L, Nobilis F. 2008. Recent advances in stream and river temperature research. Hydrological Processes 22: 902918.

White ED, Easton ZM, Fuka DR, Collick AS, Adgo E, McCarney M, Awulachew SB, Selassie YG, Steenhuis TS. 2010. Development and application of a physically based landscape water balance in the SWAT model, Hydrological Processes 25(6): 915-925.

Yu B. 2000. A systematic over estimation of flows. Journal of Hydrology 233: 258262.

Zachos J, Pagani M, Sloan L, Thomas E, Billups K. 2001. Trends, Rhythms, and aberrations in global climate 65 Ma to present, Science 292: 686-693. 
Zhou B, He HS, Nigh TA, Schulz JH. 2012. Mapping and analyzing change of impervious surface for two decades using multitemporal Landsat imagery in Missouri, International Journal of Applied Earth Observation and Geoinformation, 18: 195206. 
APPENDIX A

CLIMATE DURING THE STUDY PERIOD 


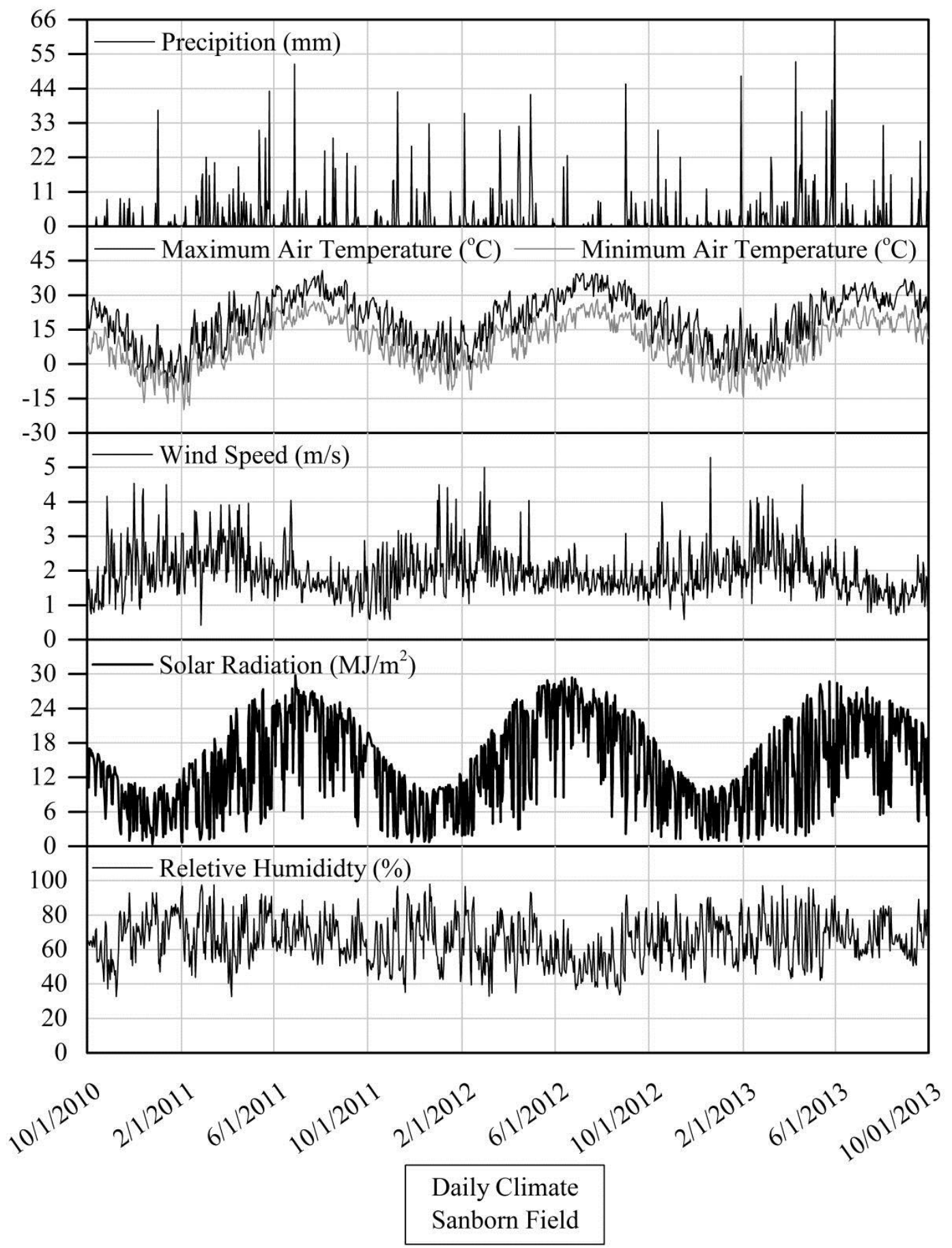

A1. Climate during the study period (WY 2010 - 2013) recorded at Sanborn Field climate station located in Hinkson Creek Watershed, Missouri, USA. 


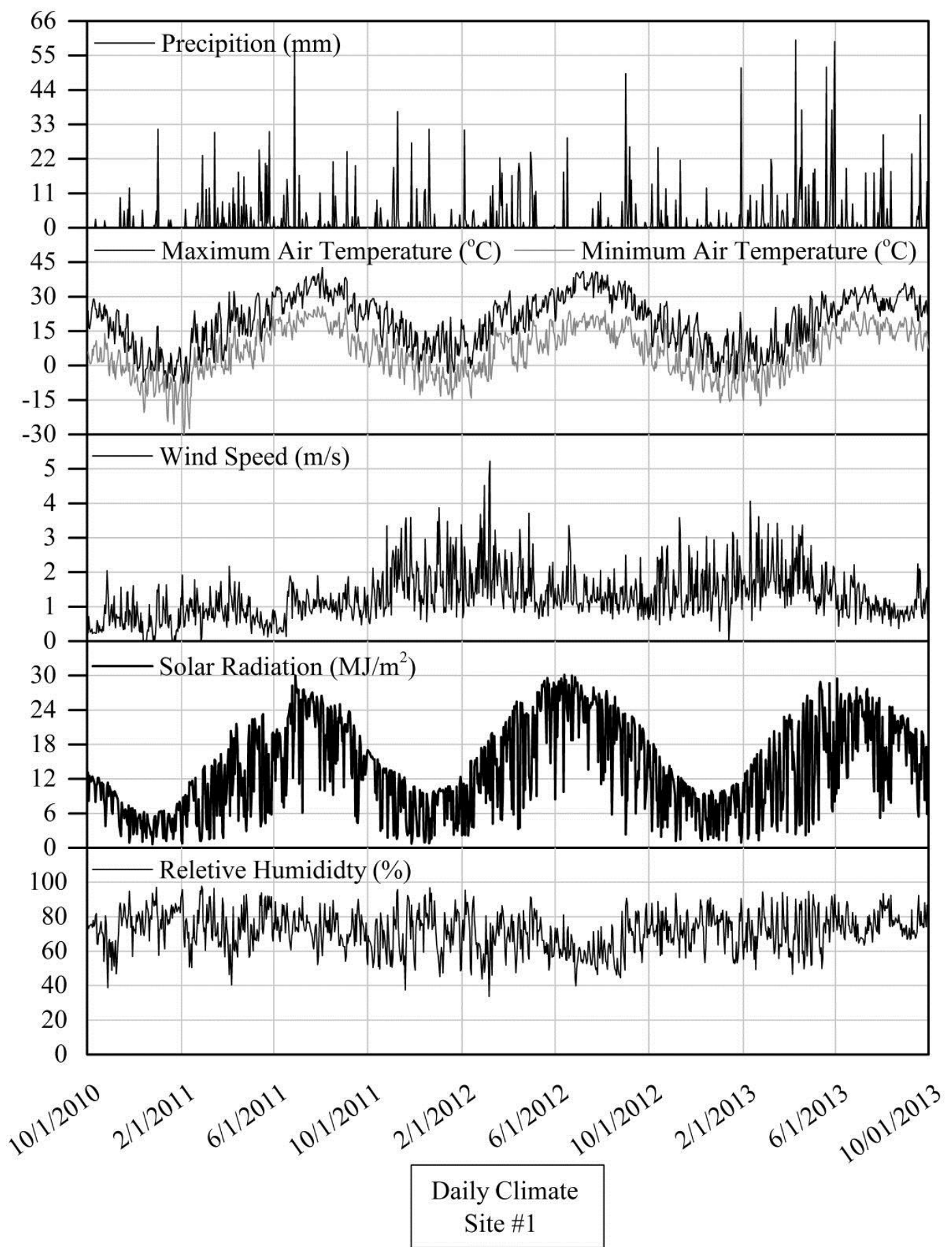

A2. Climate during the study period (WY 2010 - 2013) recorded at the site \#1 climate station located in Hinkson Creek Watershed, Missouri, USA. 


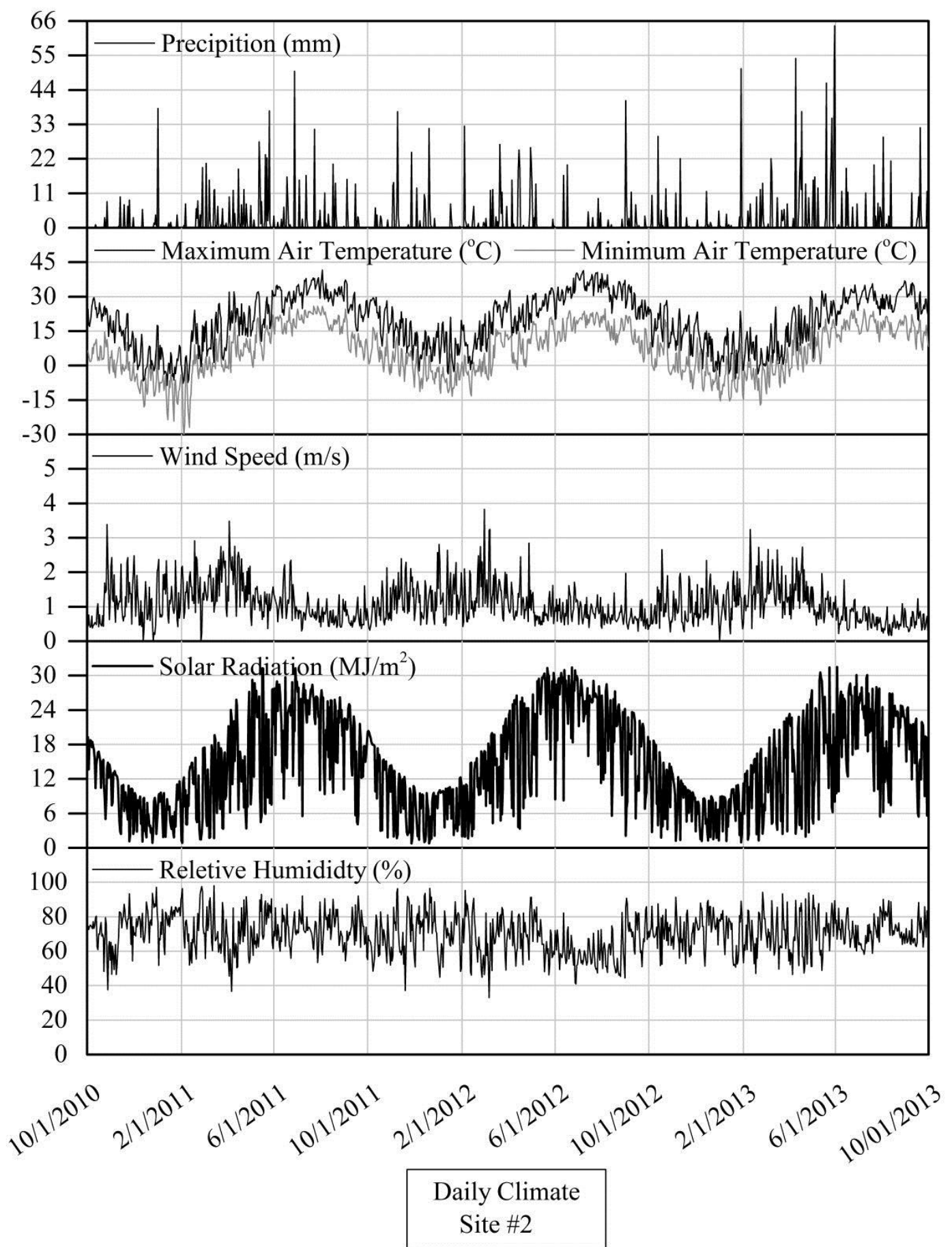

A3. Climate during the study period (WY 2010 - 2013) recorded at the site \#2 climate station located in Hinkson Creek Watershed, Missouri, USA. 


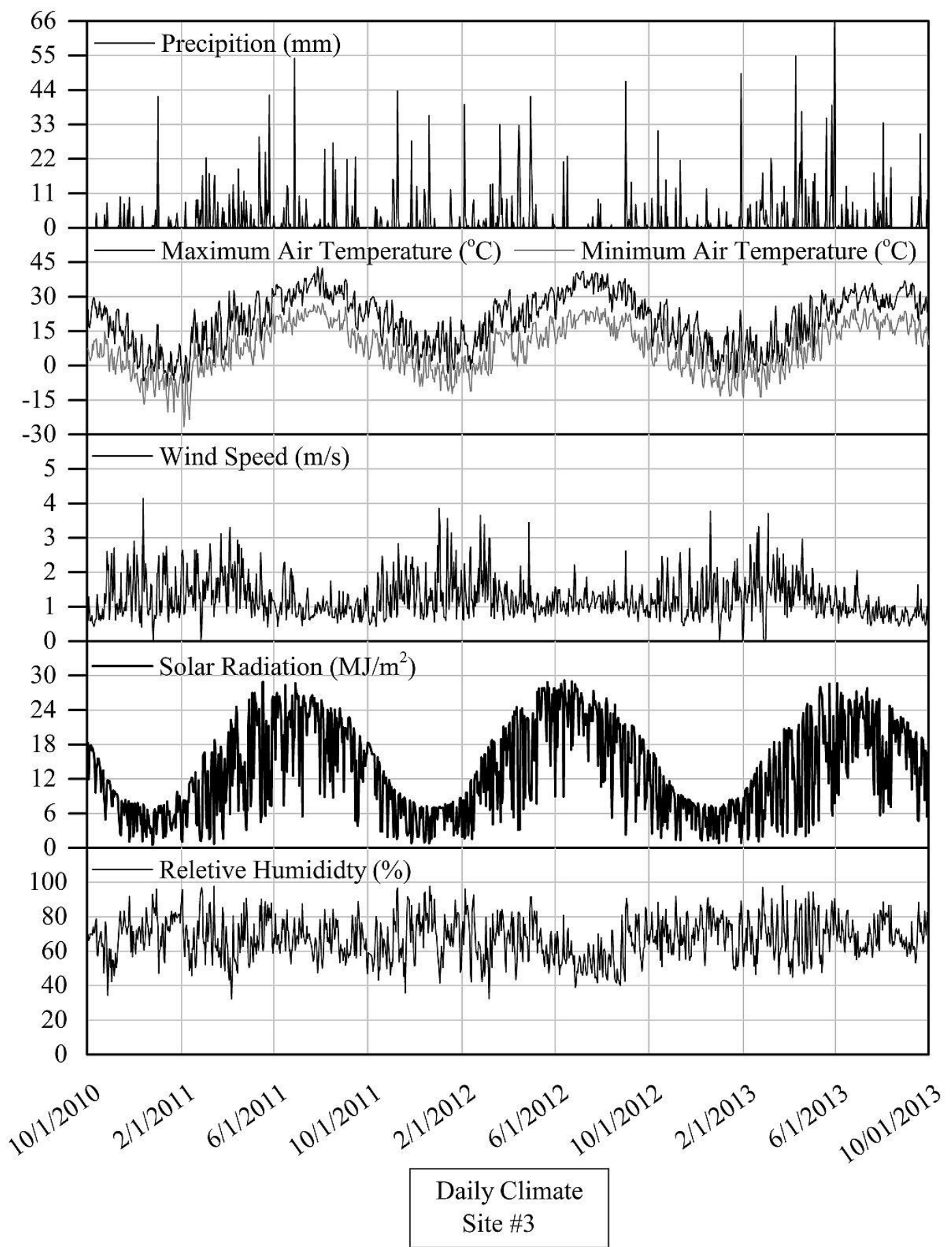

A4. Climate during the study period (WY 2010 - 2013) recorded at the site \#3 climate station located in Hinkson Creek Watershed, Missouri, USA. 


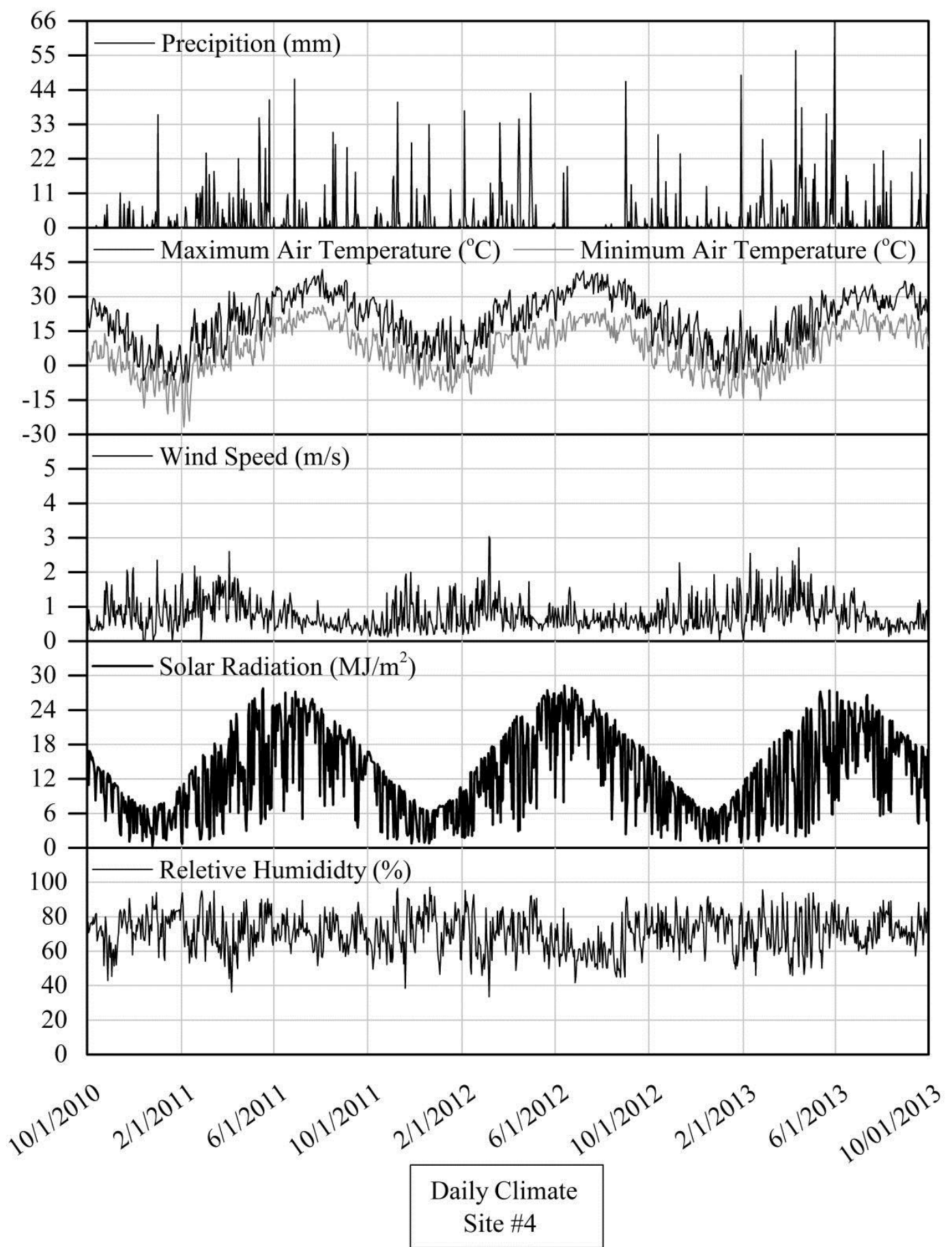

A5. Climate during the study period (WY 2010 - 2013) recorded at the site \#4 climate station located in Hinkson Creek Watershed, Missouri, USA. 


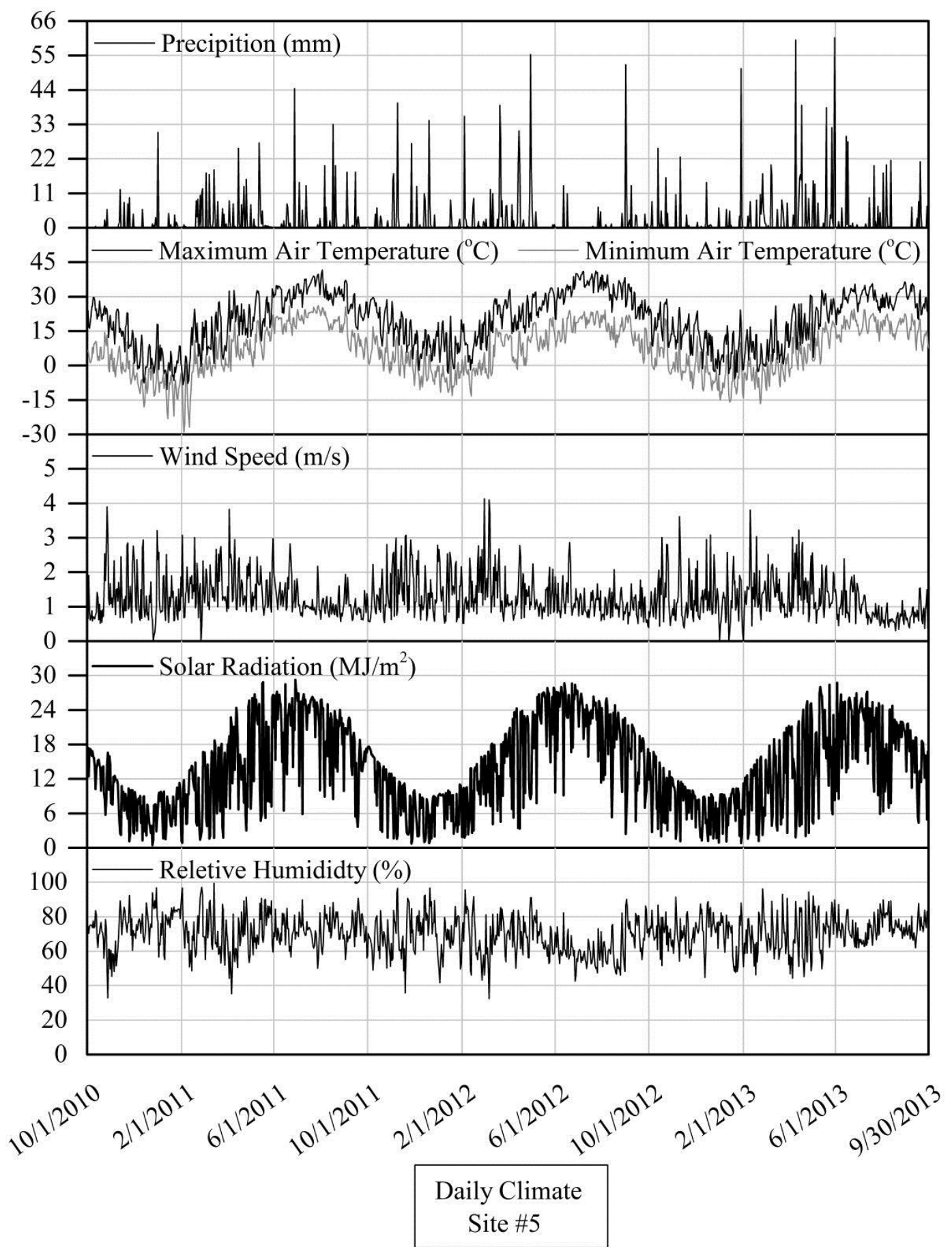

A6. Climate during the study period (WY 2010 - 2013) recorded at the site \#5 climate station located in Hinkson Creek Watershed, Missouri, USA. 


\section{APPENDIX B}

\section{STREAM WATER TEMPERATURE MODEL EVALUATION RESULTS}

B1. Summary of 15 minute linear stream water temperature model evaluation results during calibration and validation periods for five gauging sites in Hinkson Creek Watershed, USA.

15 Minute Linear Stream Water Temperature Model

\begin{tabular}{lllllll}
\hline Statistic & Site \#1 & Site \#2 & Site \#3 & Site \#4 & Site \#5 & All sites \\
\hline & & \multicolumn{5}{c}{ Calibration } \\
NSE & 0.82 & 0.86 & 0.86 & 0.83 & 0.80 & 0.83 \\
PBIAS $(\%)$ & 0.33 & 0.45 & 2.75 & 2.02 & 0.94 & 0.02 \\
RSR & 0.43 & 0.38 & 0.37 & 0.41 & 0.44 & 0.41 \\
MAE $\left({ }^{\circ} \mathrm{C}\right)$ & 2.99 & 2.88 & 2.80 & 3.11 & 3.21 & 3.00 \\
MSE $\left({ }^{\circ} \mathrm{C}\right)$ & 14.37 & 13.98 & 12.88 & 16.02 & 16.85 & 14.82 \\
RMSE $\left({ }^{\circ} \mathrm{C}\right)$ & 3.79 & 3.74 & 3.59 & 4.00 & 4.11 & 3.85 \\
\hline & & & Validation & & \\
NSE & 0.79 & 0.85 & 0.86 & 0.82 & 0.80 & 0.83 \\
PBIAS $(\%)$ & 0.23 & 1.94 & 1.52 & 2.14 & 1.11 & 0.69 \\
RSR & 0.46 & 0.38 & 0.37 & 0.42 & 0.45 & 0.42 \\
MAE $\left({ }^{\circ} \mathrm{C}\right)$ & 3.02 & 2.82 & 2.78 & 2.98 & 3.23 & 2.97 \\
$\operatorname{MSE}\left({ }^{\circ} \mathrm{C}\right)$ & 14.28 & 14.06 & 13.02 & 14.92 & 17.17 & 14.69 \\
RMSE $\left({ }^{\circ} \mathrm{C}\right)$ & 3.78 & 3.75 & 3.61 & 3.86 & 4.14 & 3.83 \\
\hline
\end{tabular}

NSE is Nash-Sutcliffe efficiency, PBIAS is percent bias, RSR is ratio of root mean square error to the standard deviation of observed data, MAE is mean absolute error, MSE is mean square error, RMSE is root mean square error. 
B2. Summary of 15 minute nonlinear stream water temperature model evaluation results during calibration and validation periods for five gauging sites in Hinkson Creek Watershed, USA.

15 Minute Nonlinear Stream Water Temperature Model

\begin{tabular}{lllllll}
\hline Statistic & Site \#1 & Site \#2 & Site \#3 & Site \#4 & Site \#5 & All sites \\
\hline & & \multicolumn{5}{c}{ Calibration } \\
NSE & 0.83 & 0.86 & 0.87 & 0.83 & 0.81 & 0.84 \\
PBIAS $(\%)$ & 0.35 & 1.07 & 2.98 & 1.01 & 0.27 & 0.62 \\
RSR & 0.42 & 0.38 & 0.36 & 0.41 & 0.44 & 0.40 \\
MAE $\left({ }^{\circ} \mathrm{C}\right)$ & 2.90 & 2.89 & 2.81 & 3.09 & 3.18 & 2.97 \\
MSE $\left({ }^{\circ} \mathrm{C}\right)$ & 13.65 & 13.76 & 12.51 & 15.75 & 16.55 & 14.44 \\
RMSE $\left({ }^{\circ} \mathrm{C}\right)$ & 3.69 & 3.71 & 3.54 & 3.97 & 4.07 & 3.80 \\
\hline & & \multicolumn{5}{c}{ Validation } \\
NSE & 0.81 & 0.87 & 0.87 & 0.83 & 0.81 & 0.84 \\
PBIAS $(\%)$ & 0.71 & 1.61 & 1.34 & 1.44 & 0.91 & 0.38 \\
RSR & 0.43 & 0.37 & 0.36 & 0.41 & 0.44 & 0.40 \\
$\operatorname{MAE~}\left({ }^{\circ} \mathrm{C}\right)$ & 2.74 & 2.72 & 2.69 & 2.84 & 3.09 & 2.81 \\
$\operatorname{MSE}\left({ }^{\circ} \mathrm{C}\right)$ & 12.88 & 12.94 & 11.94 & 14.20 & 16.35 & 13.66 \\
RMSE $\left({ }^{\circ} \mathrm{C}\right)$ & 3.59 & 3.60 & 3.46 & 3.77 & 4.04 & 3.69 \\
\hline
\end{tabular}

NSE is Nash-Sutcliffe efficiency, PBIAS is percent bias, RSR is ratio of root mean square error to the standard deviation of observed data, MAE is mean absolute error, MSE is mean square error, RMSE is root mean square error. 
B3. Summary of 15 minute calibrated linear stream water temperature model evaluation results during calibration and validation periods for five gauging sites in Hinkson Creek Watershed, USA.

\begin{tabular}{|c|c|c|c|c|c|c|}
\hline Statistic & Site \#1 & Site \#2 & Site \#3 & Site \#4 & Site \#5 & All sites \\
\hline \multicolumn{7}{|c|}{ Calibration } \\
\hline NSE & 0.91 & 0.91 & 0.91 & 0.94 & 0.90 & 0.91 \\
\hline PBIAS (\%) & 3.37 & 2.94 & 0.62 & 3.01 & 1.93 & 2.37 \\
\hline RSR & 0.30 & 0.30 & 0.31 & 0.25 & 0.31 & 0.29 \\
\hline $\operatorname{MAE}\left({ }^{\circ} \mathrm{C}\right)$ & 1.88 & 1.96 & 1.34 & 1.07 & 2.05 & 1.66 \\
\hline $\operatorname{MSE}\left({ }^{\circ} \mathrm{C}\right)$ & 6.56 & 7.48 & 4.96 & 3.80 & 8.11 & 6.18 \\
\hline $\operatorname{RMSE}\left({ }^{\circ} \mathrm{C}\right)$ & 2.56 & 2.74 & 2.23 & 1.95 & 2.85 & 2.46 \\
\hline \multicolumn{7}{|c|}{ Validation } \\
\hline NSE & 0.89 & 0.88 & 0.91 & 0.90 & 0.89 & 0.89 \\
\hline PBIAS (\%) & 4.08 & 6.57 & 2.41 & 5.38 & 4.08 & 4.50 \\
\hline RSR & 0.34 & 0.35 & 0.30 & 0.31 & 0.34 & 0.33 \\
\hline $\operatorname{MAE}\left({ }^{\circ} \mathrm{C}\right)$ & 2.29 & 2.28 & 2.24 & 2.24 & 2.29 & 2.26 \\
\hline $\operatorname{MSE}\left({ }^{\circ} \mathrm{C}\right)$ & 9.45 & 8.49 & 8.73 & 8.28 & 9.45 & 8.88 \\
\hline $\operatorname{RMSE}\left({ }^{\circ} \mathrm{C}\right)$ & 3.07 & 2.91 & 2.95 & 2.88 & 3.07 & 2.98 \\
\hline
\end{tabular}


B4. Summary of hourly linear stream water temperature model evaluation results during calibration and validation periods for five gauging sites in Hinkson Creek Watershed, USA.

Hourly Linear Stream Water Temperature Model

\begin{tabular}{lllllll}
\hline Statistic & Site \#1 & Site \#2 & Site \#3 & Site \#4 & Site \#5 & All sites \\
\hline & & \multicolumn{5}{c}{ Calibration } \\
NSE & 0.82 & 0.86 & 0.87 & 0.83 & 0.81 & 0.84 \\
PBIAS (\%) & 0.02 & 0.95 & 0.82 & 0.29 & 0.51 & 0.52 \\
RSR & 0.43 & 0.38 & 0.36 & 0.41 & 0.44 & 0.40 \\
MAE $\left({ }^{\circ} \mathrm{C}\right)$ & 2.97 & 2.87 & 2.67 & 3.13 & 3.20 & 2.97 \\
MSE $\left({ }^{\circ} \mathrm{C}\right)$ & 14.28 & 13.99 & 12.13 & 16.01 & 16.79 & 14.64 \\
RMSE $\left({ }^{\circ} \mathrm{C}\right)$ & 3.78 & 3.74 & 3.48 & 4.00 & 4.10 & 3.82 \\
\hline & & \multicolumn{5}{c}{ Validation } \\
NSE & 0.79 & 0.85 & 0.87 & 0.82 & 0.80 & 0.83 \\
PBIAS $(\%)$ & 0.62 & 3.66 & 2.13 & 0.49 & 0.69 & 1.27 \\
RSR & 0.45 & 0.38 & 0.36 & 0.42 & 0.45 & 0.41 \\
$\operatorname{MAE~}\left({ }^{\circ} \mathrm{C}\right)$ & 3.01 & 2.85 & 2.61 & 2.99 & 3.22 & 2.93 \\
$\operatorname{MSE}\left({ }^{\circ} \mathrm{C}\right)$ & 14.20 & 14.24 & 12.13 & 14.77 & 17.08 & 14.48 \\
RMSE $\left({ }^{\circ} \mathrm{C}\right)$ & 3.77 & 3.77 & 3.48 & 3.84 & 4.13 & 3.80 \\
\hline
\end{tabular}

NSE is Nash-Sutcliffe efficiency, PBIAS is percent bias, RSR is ratio of root mean square error to the standard deviation of observed data, MAE is mean absolute error, MSE is mean square error, RMSE is root mean square error. 
B5. Summary of hourly nonlinear stream water temperature model evaluation results during calibration and validation periods for five gauging sites in Hinkson Creek Watershed, USA.

\section{Hourly Nonlinear Stream Water Temperature Model}

\begin{tabular}{lllllll}
\hline Statistic & Site \#1 & Site \#2 & Site \#3 & Site \#4 & Site \#5 & All sites \\
\hline & & \multicolumn{5}{c}{ Calibration } \\
NSE & 0.83 & 0.86 & 0.87 & 0.83 & 0.81 & 0.84 \\
PBIAS $(\%)$ & 0.36 & 0.40 & 0.39 & 0.03 & 0.23 & 0.14 \\
RSR & 0.42 & 0.37 & 0.36 & 0.41 & 0.44 & 0.40 \\
MAE $\left({ }^{\circ} \mathrm{C}\right)$ & 2.90 & 2.87 & 2.72 & 3.13 & 3.22 & 2.97 \\
MSE $\left({ }^{\circ} \mathrm{C}\right)$ & 13.64 & 13.61 & 12.23 & 15.69 & 16.79 & 14.39 \\
RMSE $\left({ }^{\circ} \mathrm{C}\right)$ & 3.69 & 3.69 & 3.50 & 3.96 & 4.10 & 3.79 \\
\hline & & \multicolumn{7}{c}{ Validation } \\
NSE & 0.81 & 0.86 & 0.87 & 0.83 & 0.80 & 0.84 \\
PBIAS $(\%)$ & 0.81 & 3.28 & 2.07 & 0.59 & 0.76 & 1.18 \\
RSR & 0.43 & 0.37 & 0.36 & 0.41 & 0.44 & 0.40 \\
MAE $\left({ }^{\circ} \mathrm{C}\right)$ & 2.74 & 2.73 & 2.60 & 2.86 & 3.13 & 2.81 \\
MSE $\left({ }^{\circ} \mathrm{C}\right)$ & 12.83 & 13.07 & 11.78 & 13.94 & 16.36 & 13.60 \\
RMSE $\left({ }^{\circ} \mathrm{C}\right)$ & 3.58 & 3.61 & 3.43 & 3.73 & 4.04 & 3.68 \\
\hline NSE &
\end{tabular}

NSE is Nash-Sutcliffe efficiency, PBIAS is percent bias, RSR is ratio of root mean square error to the standard deviation of observed data, MAE is mean absolute error, MSE is mean square error, RMSE is root mean square error. 
B6. Summary of hourly calibrated linear stream water temperature model evaluation results during calibration and validation periods for five gauging sites in Hinkson Creek Watershed, USA.

\begin{tabular}{|c|c|c|c|c|c|c|}
\hline Statistic & Site \#1 & Site \#2 & Site \#3 & Site \#4 & Site \#5 & All sites \\
\hline \multicolumn{7}{|c|}{ Calibration } \\
\hline NSE & 0.91 & 0.92 & 0.92 & 0.92 & 0.90 & 0.91 \\
\hline PBIAS (\%) & 3.49 & 3.57 & 2.26 & 3.41 & 1.86 & 2.92 \\
\hline RSR & 0.30 & 0.29 & 0.28 & 0.29 & 0.31 & 0.29 \\
\hline $\operatorname{MAE}\left({ }^{\circ} \mathrm{C}\right)$ & 1.98 & 2.15 & 1.97 & 2.09 & 2.16 & 2.07 \\
\hline $\operatorname{MSE}\left({ }^{\circ} \mathrm{C}\right)$ & 6.93 & 8.25 & 7.17 & 7.82 & 8.47 & 7.73 \\
\hline RMSE $\left({ }^{\circ} \mathrm{C}\right)$ & 2.63 & 2.87 & 2.68 & 2.80 & 2.91 & 2.78 \\
\hline \multicolumn{7}{|c|}{ Validation } \\
\hline NSE & 0.88 & 0.91 & 0.92 & 0.90 & 0.89 & 0.90 \\
\hline PBIAS (\%) & 6.57 & 2.72 & 2.64 & 5.38 & 4.07 & 4.28 \\
\hline RSR & 0.35 & 0.30 & 0.29 & 0.31 & 0.33 & 0.32 \\
\hline $\operatorname{MAE}\left({ }^{\circ} \mathrm{C}\right)$ & 2.27 & 2.19 & 2.08 & 2.23 & 2.27 & 2.21 \\
\hline $\operatorname{MSE}\left({ }^{\circ} \mathrm{C}\right)$ & 8.44 & 8.56 & 7.60 & 8.22 & 9.29 & 8.42 \\
\hline $\operatorname{RMSE}\left({ }^{\circ} \mathrm{C}\right)$ & 2.90 & 2.93 & 2.76 & 2.87 & 3.05 & 2.90 \\
\hline
\end{tabular}


B7. Summary of daily linear stream water temperature model evaluation results during calibration and validation periods for five gauging sites in Hinkson Creek Watershed, USA.

Daily Linear Stream Water Temperature Model

\begin{tabular}{lllllll}
\hline Statistic & Site \#1 & Site \#2 & Site \#3 & Site \#4 & Site \#5 & All sites \\
\hline & & \multicolumn{5}{c}{ Calibration } \\
NSE & 0.91 & 0.92 & 0.93 & 0.91 & 0.90 & 0.92 \\
PBIAS (\%) & -1.15 & 0.21 & -1.37 & -1.24 & -1.29 & -0.97 \\
RSR & 0.30 & 0.28 & 0.26 & 0.29 & 0.31 & 0.29 \\
MAE $\left({ }^{\circ} \mathrm{C}\right)$ & 1.96 & 2.05 & 1.83 & 2.07 & 2.13 & 2.01 \\
$\operatorname{MSE}\left({ }^{\circ} \mathrm{C}\right)$ & 6.92 & 7.39 & 6.29 & 7.66 & 8.19 & 7.29 \\
RMSE $\left({ }^{\circ} \mathrm{C}\right)$ & 2.63 & 2.72 & 2.51 & 2.77 & 2.86 & 2.70 \\
\hline & & \multicolumn{5}{c}{ Validation } \\
NSE & 0.88 & 0.91 & 0.92 & 0.90 & 0.88 & 0.90 \\
$\operatorname{PBIAS}(\%)$ & 0.97 & -1.12 & -1.35 & 0.85 & 0.30 & -0.07 \\
RSR & 0.35 & 0.30 & 0.28 & 0.31 & 0.34 & 0.32 \\
$\operatorname{MAE}\left({ }^{\circ} \mathrm{C}\right)$ & 2.20 & 2.22 & 1.96 & 2.19 & 2.34 & 2.18 \\
$\operatorname{MSE}\left({ }^{\circ} \mathrm{C}\right)$ & 8.15 & 8.45 & 6.99 & 8.04 & 9.62 & 8.25 \\
RMSE $\left({ }^{\circ} \mathrm{C}\right)$ & 2.85 & 2.91 & 2.64 & 2.83 & 3.10 & 2.87 \\
\hline
\end{tabular}

NSE is Nash-Sutcliffe efficiency, PBIAS is percent bias, RSR is ratio of root mean square error to the standard deviation of observed data, MAE is mean absolute error, MSE is mean square error, RMSE is root mean square error. 
B8. Summary of daily nonlinear stream water temperature model evaluation results during calibration and validation periods for five gauging sites in Hinkson Creek Watershed, USA.

Daily Nonlinear Stream Water Temperature Model

\begin{tabular}{lllllll}
\hline Statistic & Site \#1 & Site \#2 & Site \#3 & Site \#4 & Site \#5 & All sites \\
\hline & & \multicolumn{5}{c}{ Calibration } \\
NSE & 0.92 & 0.92 & 0.93 & 0.93 & 0.90 & 0.92 \\
PBIAS (\%) & -0.38 & -0.73 & -0.74 & -0.67 & -0.66 & -0.64 \\
RSR & 0.29 & 0.28 & 0.26 & 0.26 & 0.31 & 0.28 \\
MAE $\left({ }^{\circ} \mathrm{C}\right)$ & 1.92 & 2.03 & 1.90 & 1.89 & 2.19 & 1.99 \\
$\operatorname{MSE}\left({ }^{\circ} \mathrm{C}\right)$ & 6.47 & 7.11 & 6.29 & 5.78 & 8.18 & 6.77 \\
RMSE $\left({ }^{\circ} \mathrm{C}\right)$ & 2.54 & 2.67 & 2.51 & 2.40 & 2.86 & 2.60 \\
\hline & & \multicolumn{5}{c}{ Validation } \\
NSE & 0.90 & 0.92 & 0.93 & 0.93 & 0.89 & 0.91 \\
$\operatorname{PBIAS}(\%)$ & 1.48 & -2.46 & -1.20 & 1.01 & 0.46 & -0.14 \\
RSR & 0.32 & 0.28 & 0.27 & 0.26 & 0.33 & 0.29 \\
$\operatorname{MAE}\left({ }^{\circ} \mathrm{C}\right)$ & 1.94 & 2.04 & 1.87 & 1.85 & 2.26 & 1.99 \\
$\operatorname{MSE}\left({ }^{\circ} \mathrm{C}\right)$ & 6.88 & 7.46 & 6.42 & 5.55 & 9.06 & 7.07 \\
RMSE $\left({ }^{\circ} \mathrm{C}\right)$ & 2.62 & 2.73 & 2.53 & 2.36 & 3.01 & 2.65 \\
\hline
\end{tabular}

NSE is Nash-Sutcliffe efficiency, PBIAS is percent bias, RSR is ratio of root mean square error to the standard deviation of observed data, MAE is mean absolute error, MSE is mean square error, RMSE is root mean square error. 
B9. Summary of daily calibrated linear stream water temperature model evaluation results during calibration and validation periods for five gauging sites in Hinkson Creek Watershed, USA.

\begin{tabular}{lllllll}
\hline \multicolumn{7}{c}{ Daily Calibrated Linear Stream Water Temperature Model } \\
\hline Statistic & Site \#1 & Site \#2 & Site \#3 & Site \#4 & Site \#5 & All sites \\
\hline & & \multicolumn{5}{c}{ Calibration } \\
NSE & 0.92 & 0.95 & 0.96 & 0.95 & 0.94 & 0.94 \\
PBIAS $(\%)$ & 3.46 & 3.56 & 2.25 & 3.40 & 1.84 & 2.90 \\
RSR & 0.28 & 0.22 & 0.21 & 0.23 & 0.25 & 0.24 \\
MAE $\left({ }^{\circ} \mathrm{C}\right)$ & 1.89 & 1.99 & 1.78 & 1.99 & 2.07 & 1.94 \\
MSE $\left({ }^{\circ} \mathrm{C}\right)$ & 6.22 & 6.94 & 5.73 & 7.10 & 7.83 & 6.76 \\
RMSE $\left({ }^{\circ} \mathrm{C}\right)$ & 2.49 & 2.63 & 2.39 & 2.66 & 2.80 & 2.60 \\
\hline & & \multicolumn{5}{c}{ Validation } \\
NSE & 0.88 & 0.92 & 0.93 & 0.91 & 0.89 & 0.91 \\
PBIAS $(\%)$ & 6.57 & 2.74 & 2.66 & 5.38 & 4.08 & 4.29 \\
RSR & 0.34 & 0.28 & 0.26 & 0.31 & 0.33 & 0.30 \\
MAE $\left({ }^{\circ} \mathrm{C}\right)$ & 2.19 & 2.06 & 1.85 & 2.18 & 2.21 & 2.10 \\
MSE $\left({ }^{\circ} \mathrm{C}\right)$ & 7.86 & 7.37 & 6.13 & 7.83 & 8.88 & 7.61 \\
RMSE $\left({ }^{\circ} \mathrm{C}\right)$ & 2.80 & 2.72 & 2.48 & 2.80 & 2.98 & 2.75 \\
\hline
\end{tabular}

NSE is Nash-Sutcliffe efficiency, PBIAS is percent bias, RSR is ratio of root mean square error to the standard deviation of observed data, MAE is mean absolute error, MSE is mean square error, RMSE is root mean square error. 
B10. Summary of original SWAT stream water temperature model evaluation results during calibration and validation periods for five gauging sites in Hinkson Creek Watershed, USA.

\section{Original SWAT Stream Water Temperature Model}

\begin{tabular}{lllllll}
\hline Statistic & Site \#1 & Site \#2 & Site \#3 & Site \#4 & Site \#5 & All sites \\
\hline & & \multicolumn{5}{c}{ Calibration } \\
NSE & 0.90 & 0.90 & 0.90 & 0.89 & 0.89 & 0.90 \\
PBIAS $(\%)$ & -4.60 & -2.92 & -6.28 & -3.55 & -5.87 & -4.64 \\
RSR & 0.32 & 0.32 & 0.31 & 0.33 & 0.34 & 0.32 \\
MAE $\left({ }^{\circ} \mathrm{C}\right)$ & 2.05 & 2.39 & 2.21 & 2.38 & 2.35 & 2.28 \\
MSE $\left({ }^{\circ} \mathrm{C}\right)$ & 7.73 & 9.47 & 8.82 & 9.45 & 9.88 & 9.07 \\
RMSE $\left({ }^{\circ} \mathrm{C}\right)$ & 2.78 & 3.08 & 2.97 & 3.07 & 3.14 & 3.01 \\
\hline & & & Validation & & & \\
NSE & 0.87 & 0.88 & 0.89 & 0.88 & 0.87 & 0.88 \\
PBIAS $(\%)$ & -3.18 & -5.65 & -7.92 & -2.74 & -5.48 & -4.99 \\
RSR & 0.36 & 0.34 & 0.34 & 0.34 & 0.37 & 0.35 \\
$\operatorname{MAE}\left({ }^{\circ} \mathrm{C}\right)$ & 2.21 & 2.64 & 2.42 & 2.46 & 2.52 & 2.45 \\
$\operatorname{MSE}\left({ }^{\circ} \mathrm{C}\right)$ & 8.62 & 11.10 & 10.01 & 9.65 & 11.13 & 10.10 \\
RMSE $\left({ }^{\circ} \mathrm{C}\right)$ & 2.94 & 3.33 & 3.16 & 3.11 & 3.34 & 3.17 \\
\hline
\end{tabular}

NSE is Nash-Sutcliffe efficiency, PBIAS is percent bias, RSR is ratio of root mean square error to the standard deviation of observed data, MAE is mean absolute error, MSE is mean square error, RMSE is root mean square error. 
B11. Summary of Ficklin et al. (2012) stream water temperature model evaluation results during calibration and validation periods for five gauging sites in Hinkson Creek Watershed, USA.

Ficklin et al. (2012) Stream Water Temperature Model

\begin{tabular}{lllllll}
\hline Statistic & Site \#1 & Site \#2 & Site \#3 & Site \#4 & Site \#5 & All sites \\
\hline & & \multicolumn{5}{c}{ Calibration } \\
NSE & 0.91 & 0.92 & 0.93 & 0.91 & 0.90 & 0.91 \\
PBIAS $(\%)$ & 4.20 & 4.76 & 0.88 & 3.80 & 1.46 & 3.02 \\
RSR & 0.31 & 0.28 & 0.27 & 0.30 & 0.32 & 0.30 \\
MAE $\left({ }^{\circ} \mathrm{C}\right)$ & 2.08 & 2.05 & 1.86 & 2.11 & 2.18 & 2.06 \\
MSE $\left({ }^{\circ} \mathrm{C}\right)$ & 7.33 & 7.45 & 6.44 & 8.13 & 8.72 & 7.61 \\
RMSE $\left({ }^{\circ} \mathrm{C}\right)$ & 2.71 & 2.73 & 2.54 & 2.85 & 2.95 & 2.76 \\
\hline & & \multicolumn{5}{c}{ Validation } \\
NSE & 0.86 & 0.91 & 0.92 & 0.89 & 0.88 & 0.89 \\
PBIAS $(\%)$ & 8.23 & 5.27 & 2.53 & 7.41 & 4.58 & 5.60 \\
RSR & 0.37 & 0.29 & 0.28 & 0.33 & 0.35 & 0.32 \\
$\operatorname{MAE}\left({ }^{\circ} \mathrm{C}\right)$ & 2.37 & 2.12 & 1.87 & 2.32 & 2.36 & 2.21 \\
$\operatorname{MSE}\left({ }^{\circ} \mathrm{C}\right)$ & 9.16 & 7.97 & 6.79 & 9.10 & 10.21 & 8.65 \\
RMSE $\left({ }^{\circ} \mathrm{C}\right)$ & 3.03 & 2.82 & 2.61 & 3.02 & 3.20 & 2.93 \\
\hline
\end{tabular}

NSE is Nash-Sutcliffe efficiency, PBIAS is percent bias, RSR is ratio of root mean square error to the standard deviation of observed data, MAE is mean absolute error, MSE is mean square error, RMSE is root mean square error.

B12. Coefficients of determination $\left(\mathrm{r}^{2}\right)$ from stream water temperature model evaluation results during the study period (WY 2011 to 2013) for five gauging sites in Hinkson Creek Watershed, USA.

\begin{tabular}{lllllll}
\hline Time Scale & $\mathrm{T}_{\mathrm{w}}$ Model & Site \#1 & Site \#2 & Site \#3 & Site \#4 & Site \#5 \\
\hline 15 minute & Linear & 0.811 & 0.859 & 0.870 & 0.832 & 0.810 \\
& Nonlinear & 0.823 & 0.863 & 0.874 & 0.837 & 0.813 \\
& Calibrated & 0.908 & 0.918 & 0.924 & 0.918 & 0.906 \\
\hline Hourly & Linear & 0.812 & 0.860 & 0.874 & 0.834 & 0.812 \\
& Nonlinear & 0.823 & 0.864 & 0.872 & 0.834 & 0.806 \\
& Calibrated & 0.909 & 0.918 & 0.924 & 0.916 & 0.901 \\
\hline Daily & Linear & 0.904 & 0.923 & 0.931 & 0.918 & 0.904 \\
& Nonlinear & 0.914 & 0.924 & 0.931 & 0.919 & 0.900 \\
& Calibrated & 0.916 & 0.927 & 0.936 & 0.922 & 0.907 \\
& Original SWAT & 0.899 & 0.918 & 0.925 & 0.908 & 0.896 \\
& Ficklin et al. (2012) & 0.904 & 0.925 & 0.931 & 0.913 & 0.901 \\
\hline
\end{tabular}




\section{APPENDIX C}

STREAM WATER TEMPERATURE MODEL EVALUATION RESULTS 


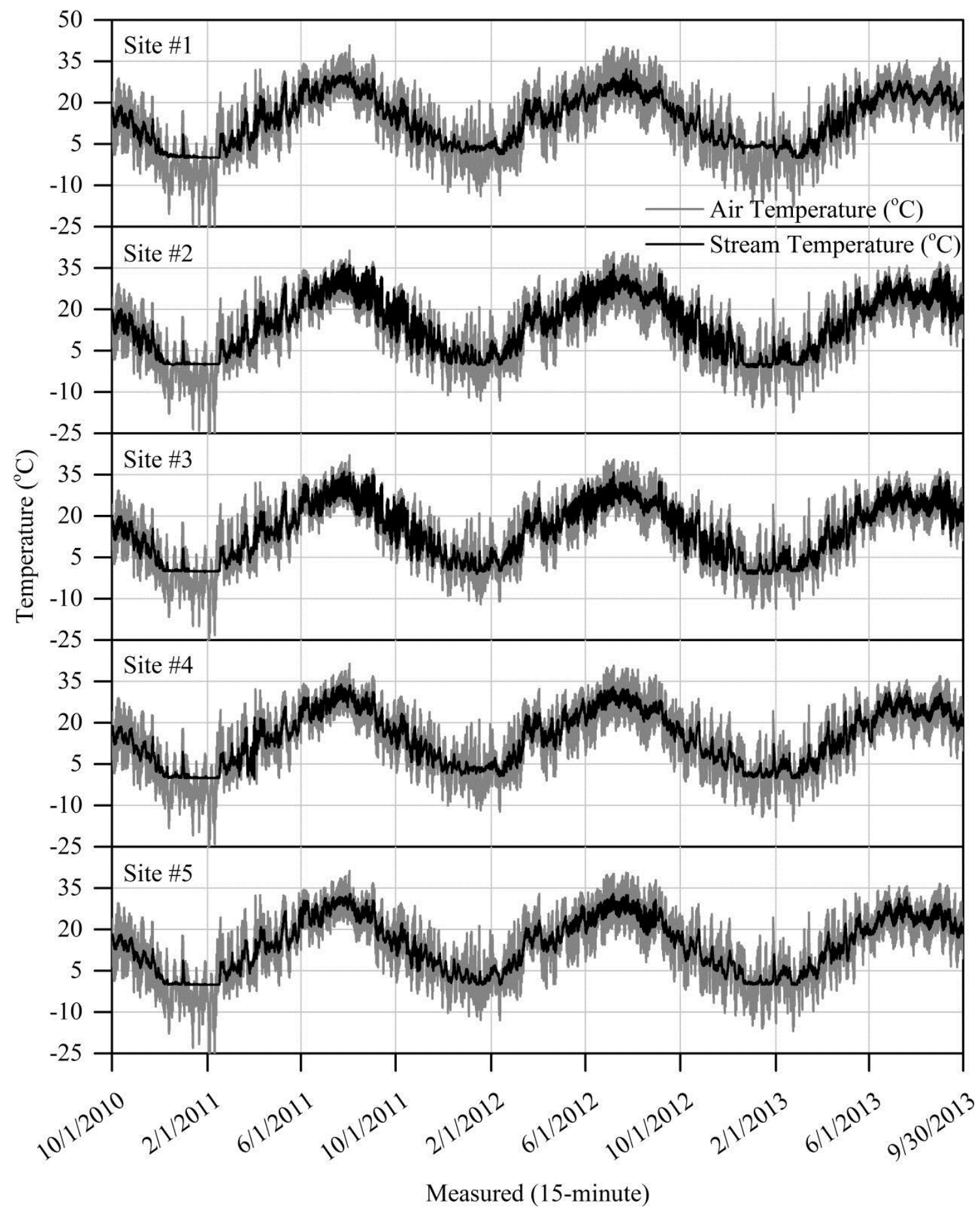

C1. Measured 15 minute time series air and stream water temperature from five gauging sites in Hinkson Creek for the three year study period. 


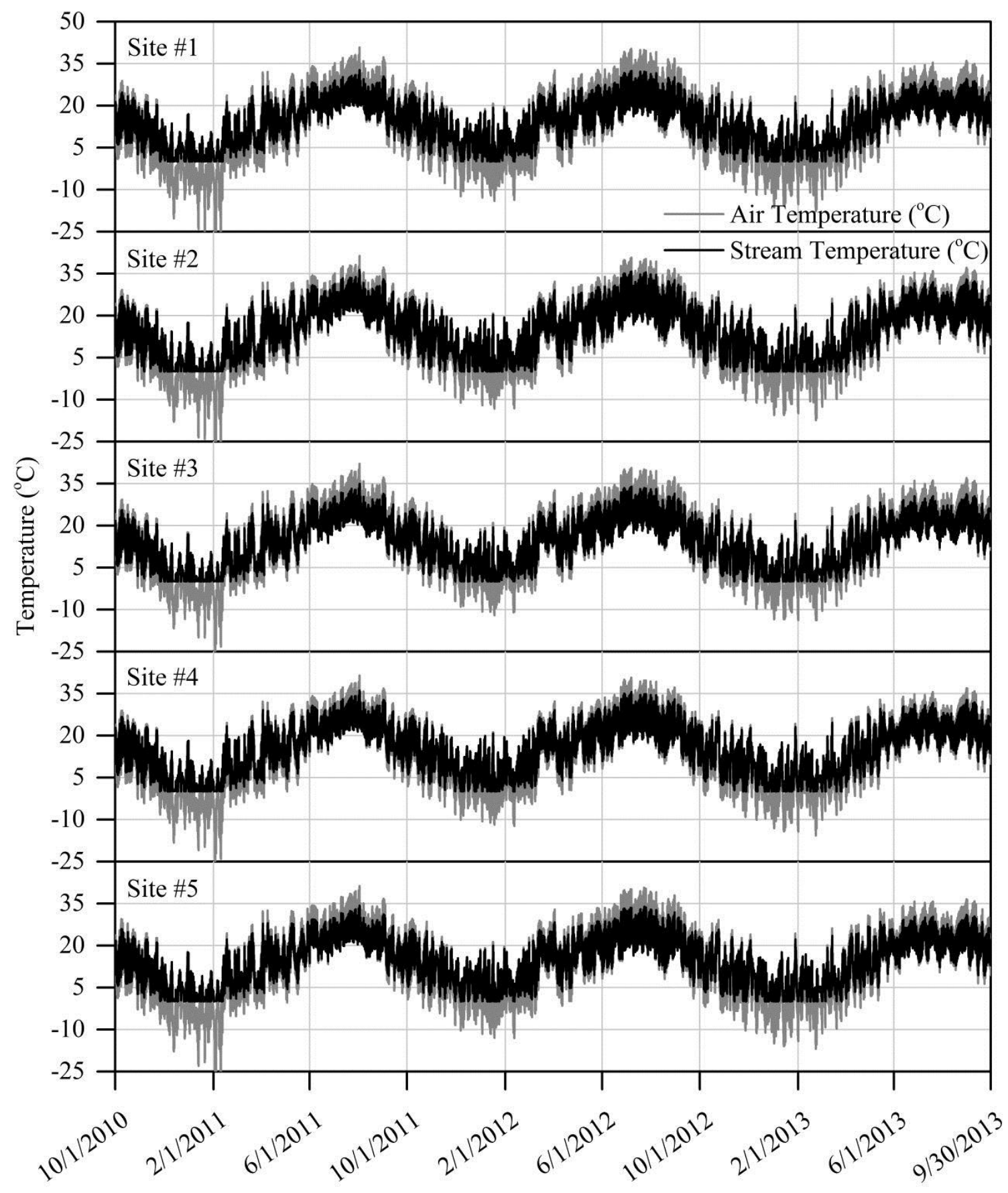

Linear (15-minute)

C2. Results from linear regression model simulations showing 15 minute time series stream water temperature from five gauging sites in Hinkson Creek for the three year study period. Measured air temperature data are shown as a refrence. 


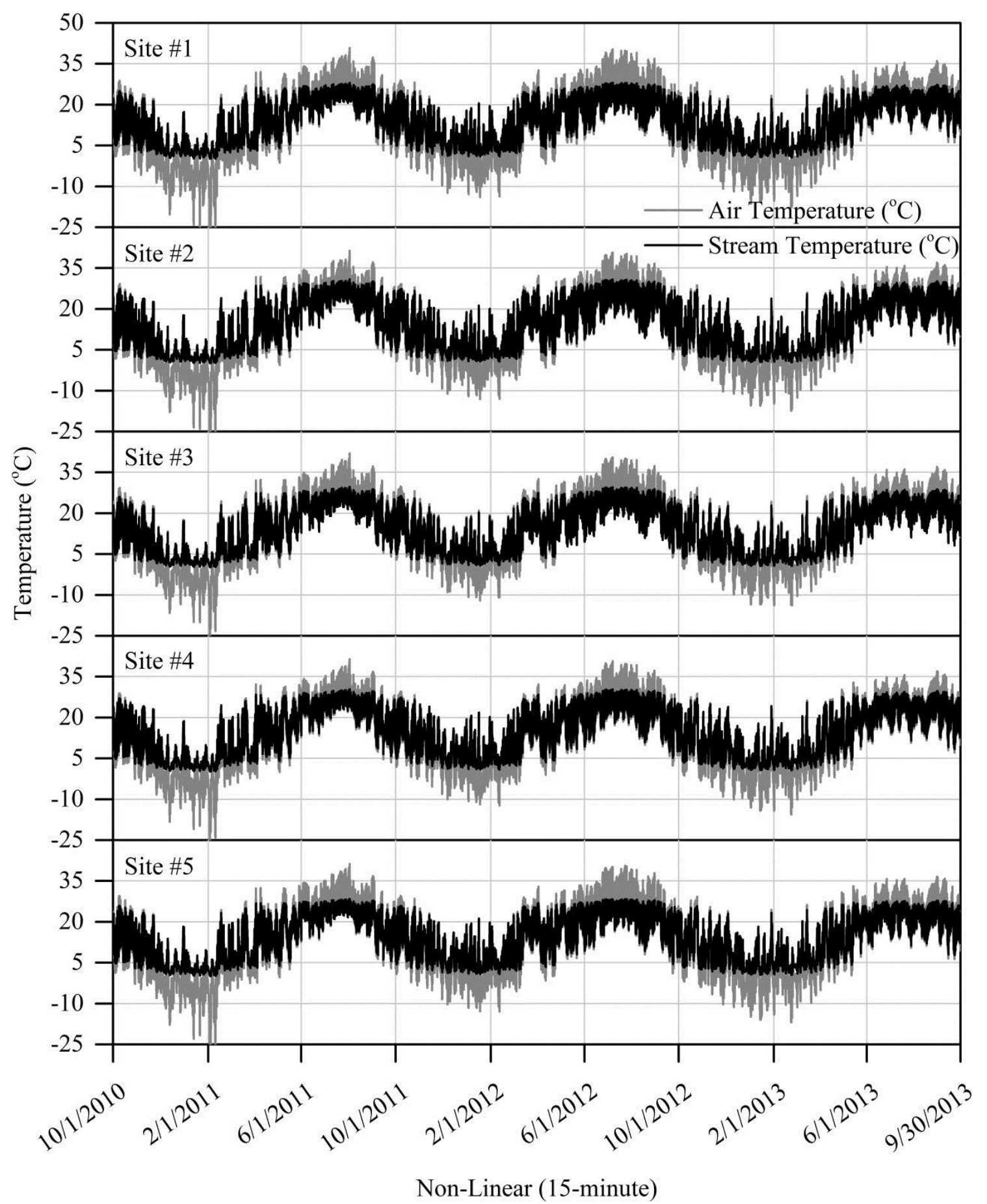

C3. Results from nonlinear regression model simulations showing 15 minute time series stream water temperature from five gauging sites in Hinkson Creek for the three year study period. Measured air temperature data are shown as a refrence. 


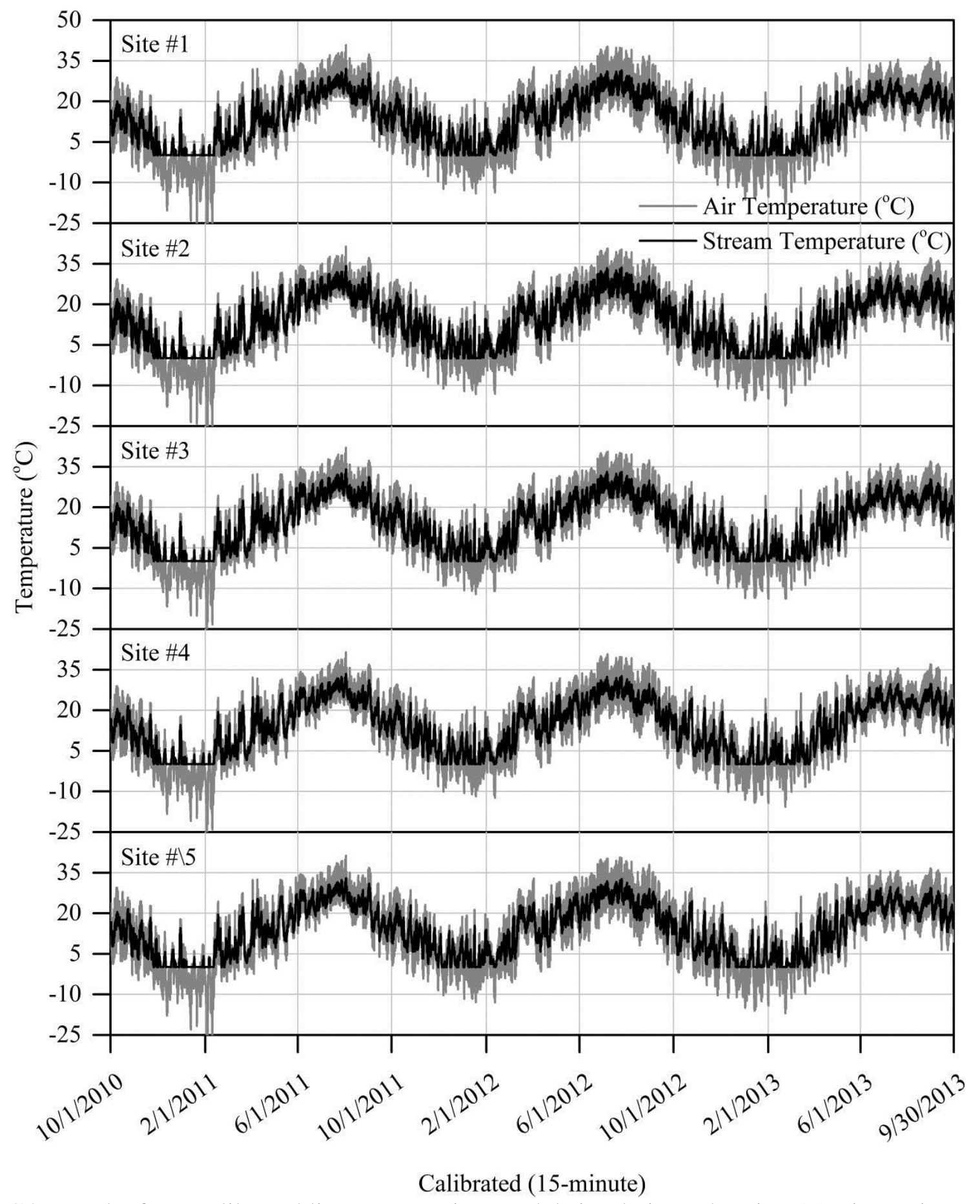

C4. Results from calibrated linear regression model simulations showing 15 minute time series stream water temperature from five gauging sites in Hinkson Creek for the three year study period. Measured air temperature data are shown as a refrence. 


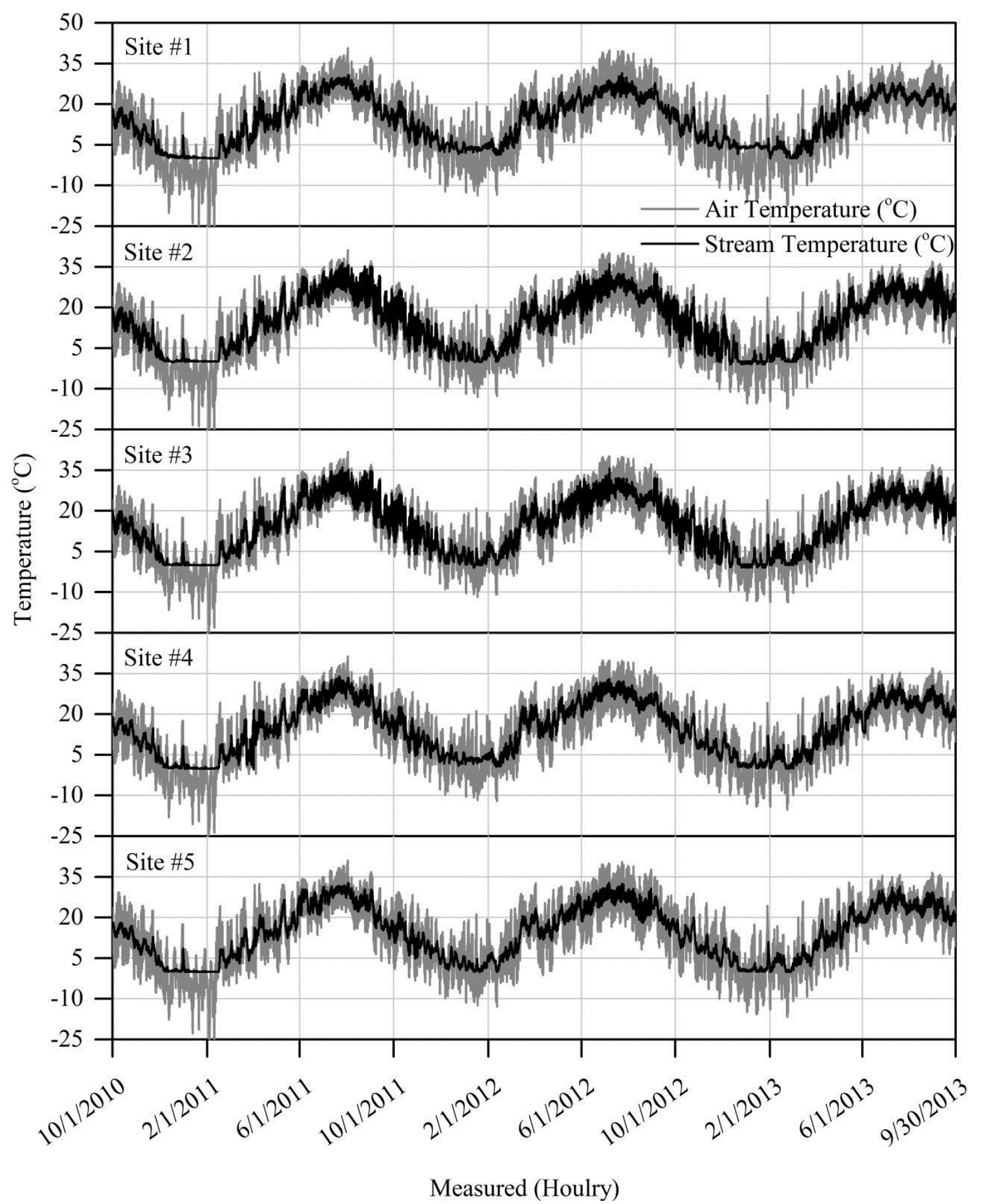

C5. Measured hourly time series air and stream water temperature from five gauging sites in Hinkson Creek for the three year study period. 


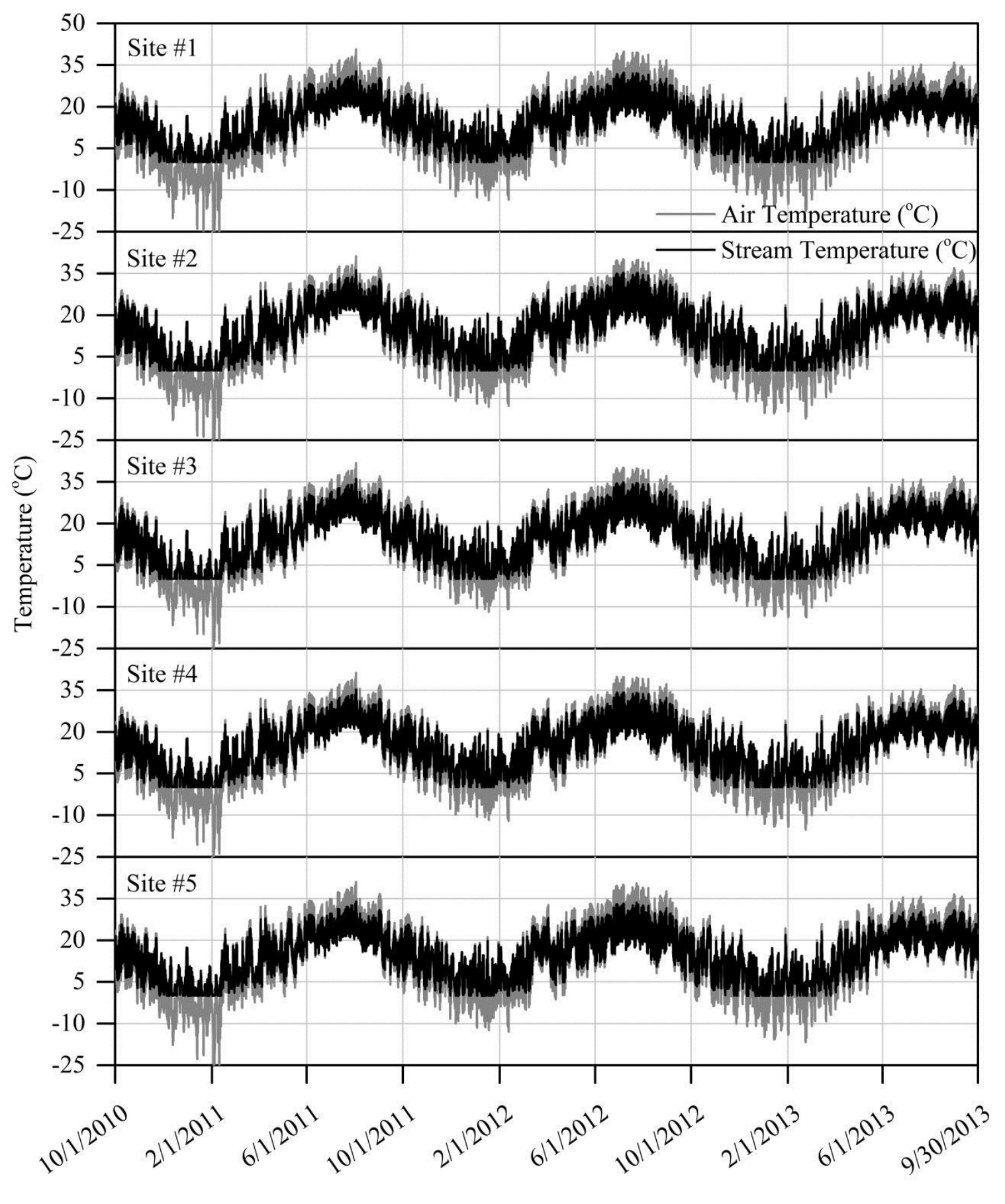

Linear (Houlry)

C5. Results from linear regression model simulations showing hourly time series stream water temperature from five gauging sites in Hinkson Creek for the three year study period. Measured air temperature data are shown as a refrence. 


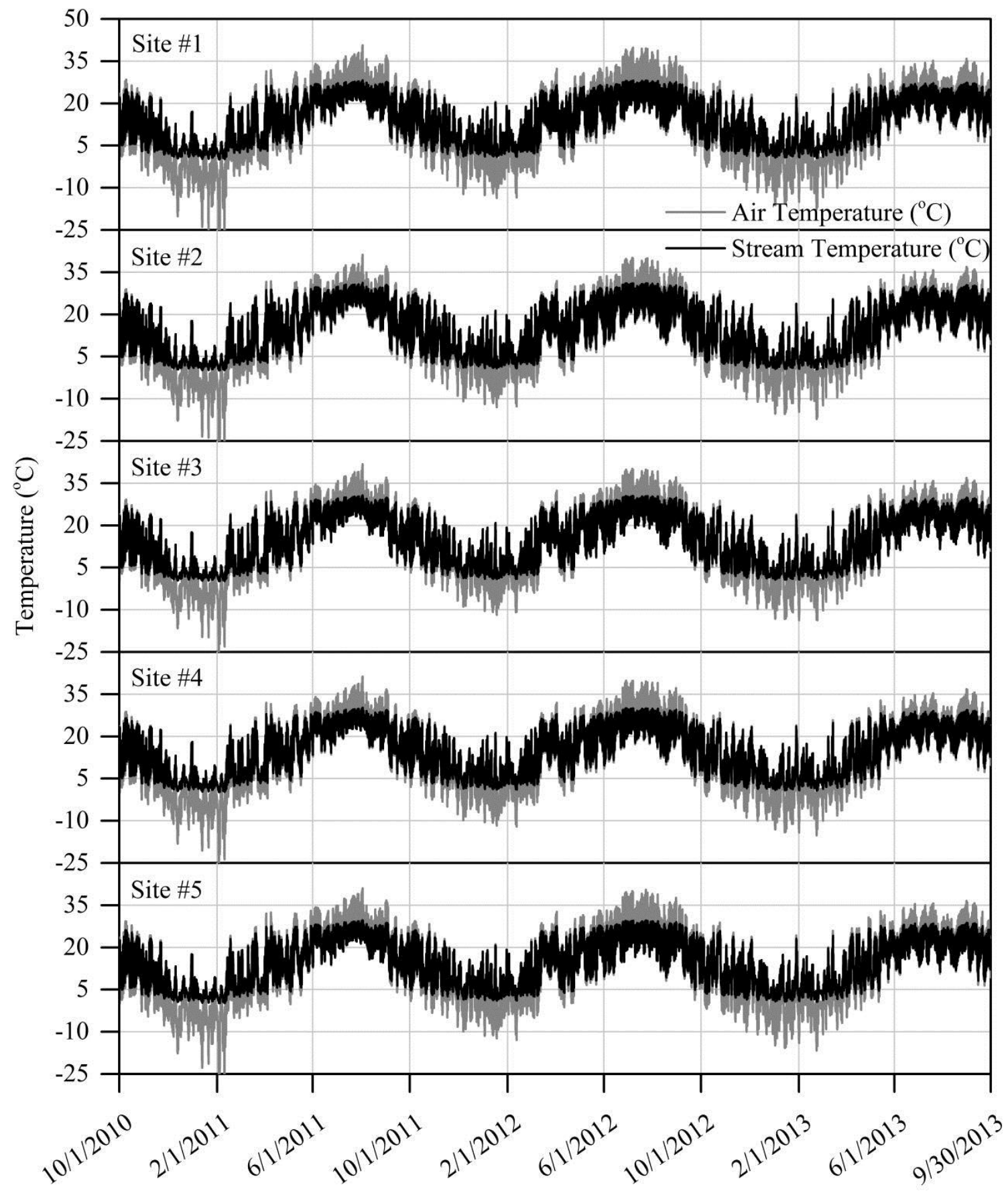

Non-Linear (Houlry)

C6. Results from nonlinear regression model simulations showing hourly time series stream water temperature from five gauging sites in Hinkson Creek for the three year study period. Measured air temperature data are shown as a refrence. 


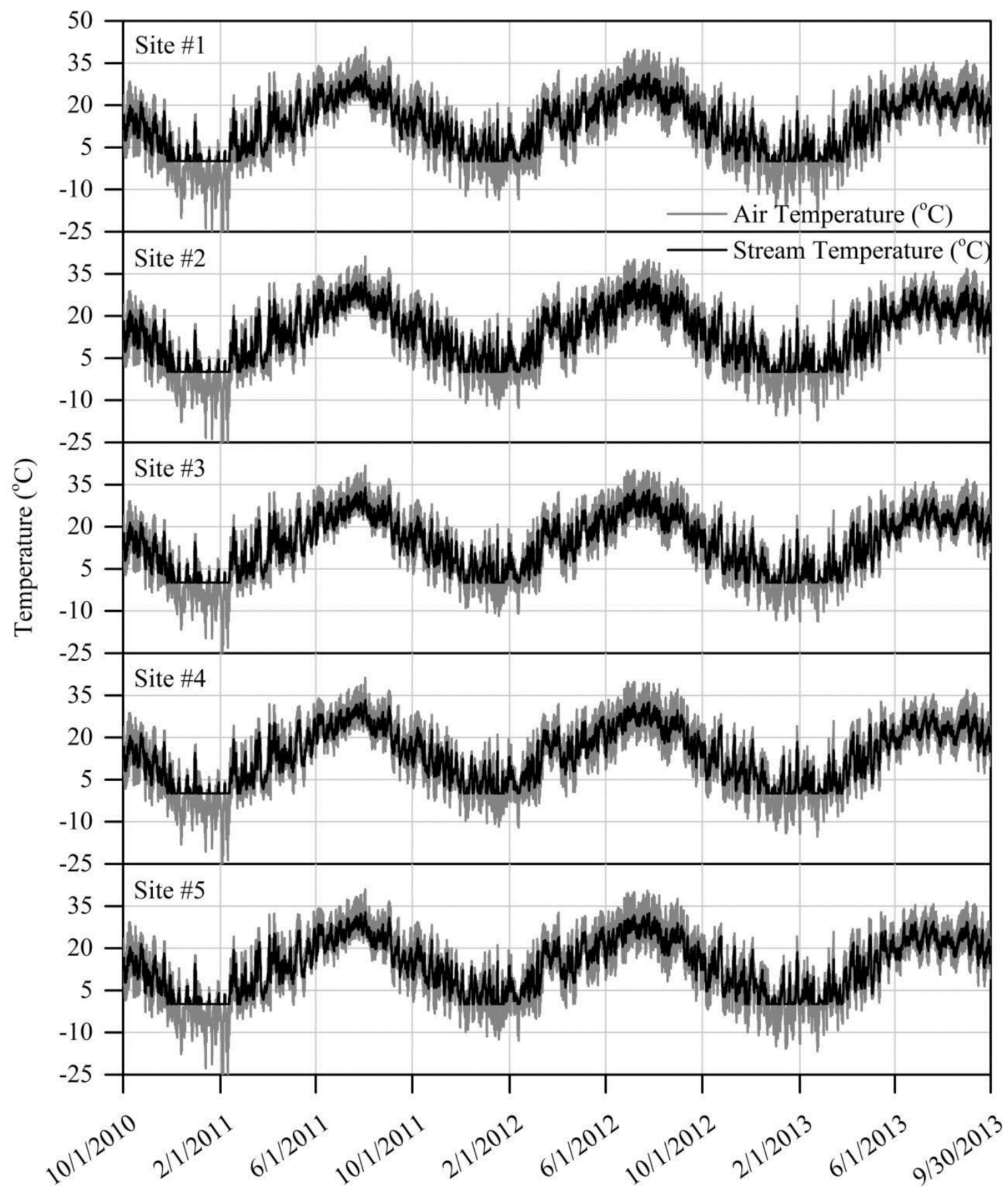

Calibrated Linear (Houlry)

C7. Results from calibrated linear regression model simulations showing hourly time series stream water temperature from five gauging sites in Hinkson Creek for the three year study period. Measured air temperature data are shown as a refrence. 


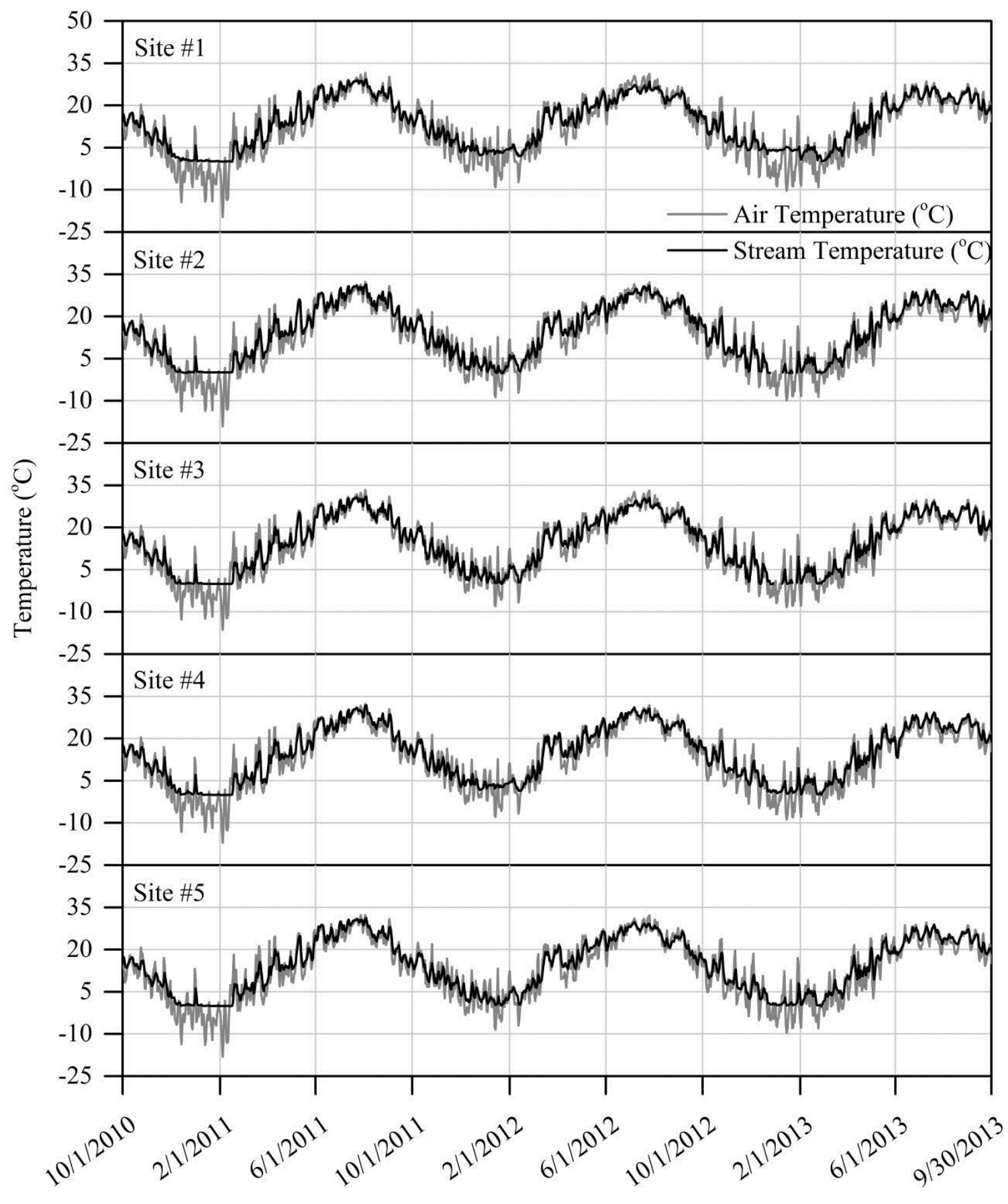

Measured (Daily)

C8. Measured daily time series air temperature and stream water temperature from five gauging sites in Hinkson Creek for the three year study period. 


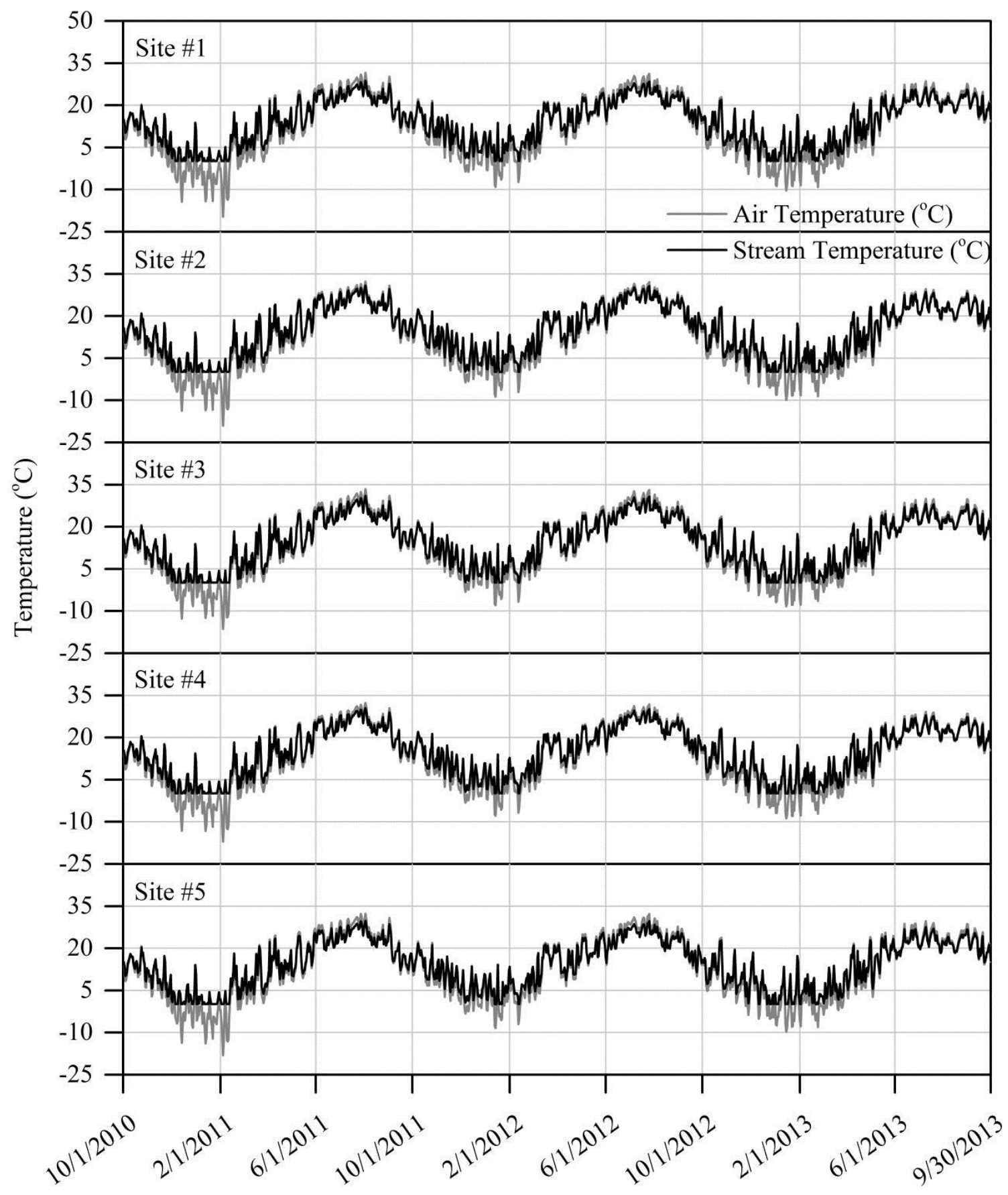

Linear (Daily)

C9. Results from linear regression model simulations showing daily time series stream water temperature from five gauging sites in Hinkson Creek for the three year study period. Measured air temperature data are shown as a refrence. 


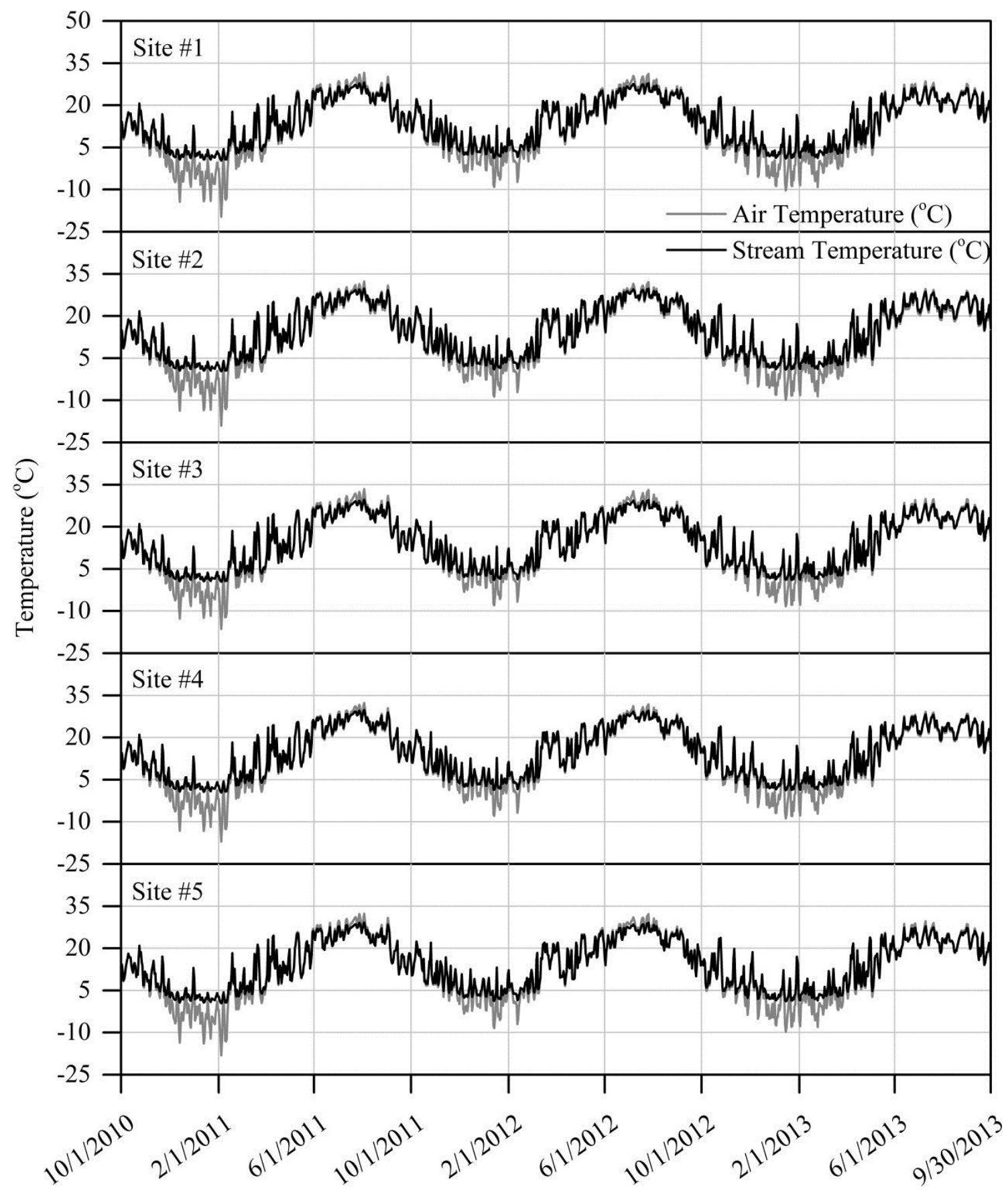

Non-Linear (Daily)

C10. Results from nonlinear regression model simulations showing daily time series stream water temperature from five gauging sites in Hinkson Creek for the three year study period. Measured air temperature data are shown as a refrence. 


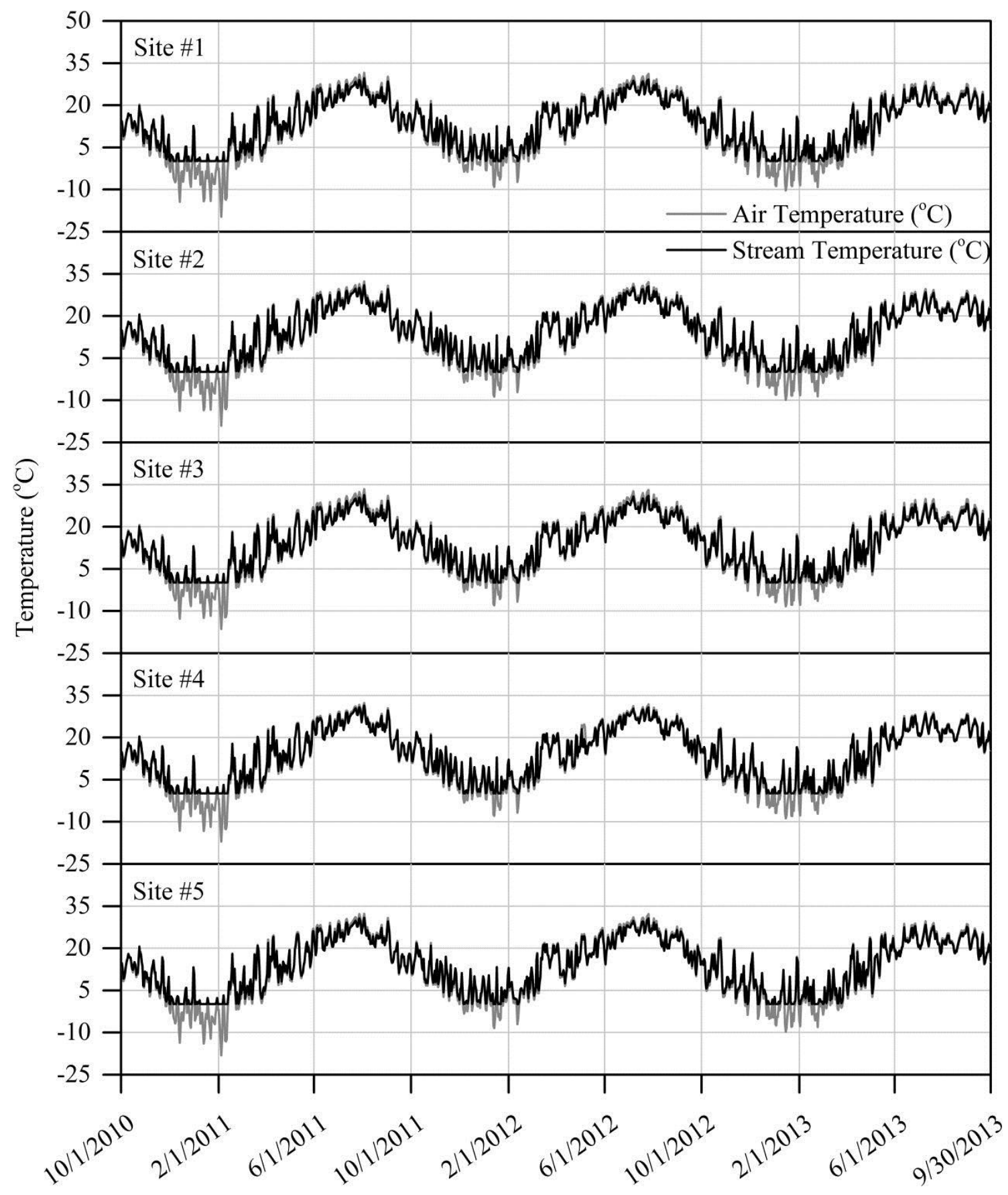

Calibrated (Daily)

C11. Results from calibrated linear regression model simulations showing daily time series stream water temperature from five gauging sites in Hinkson Creek for the three year study period. Measured air temperature data are shown as a refrence. 


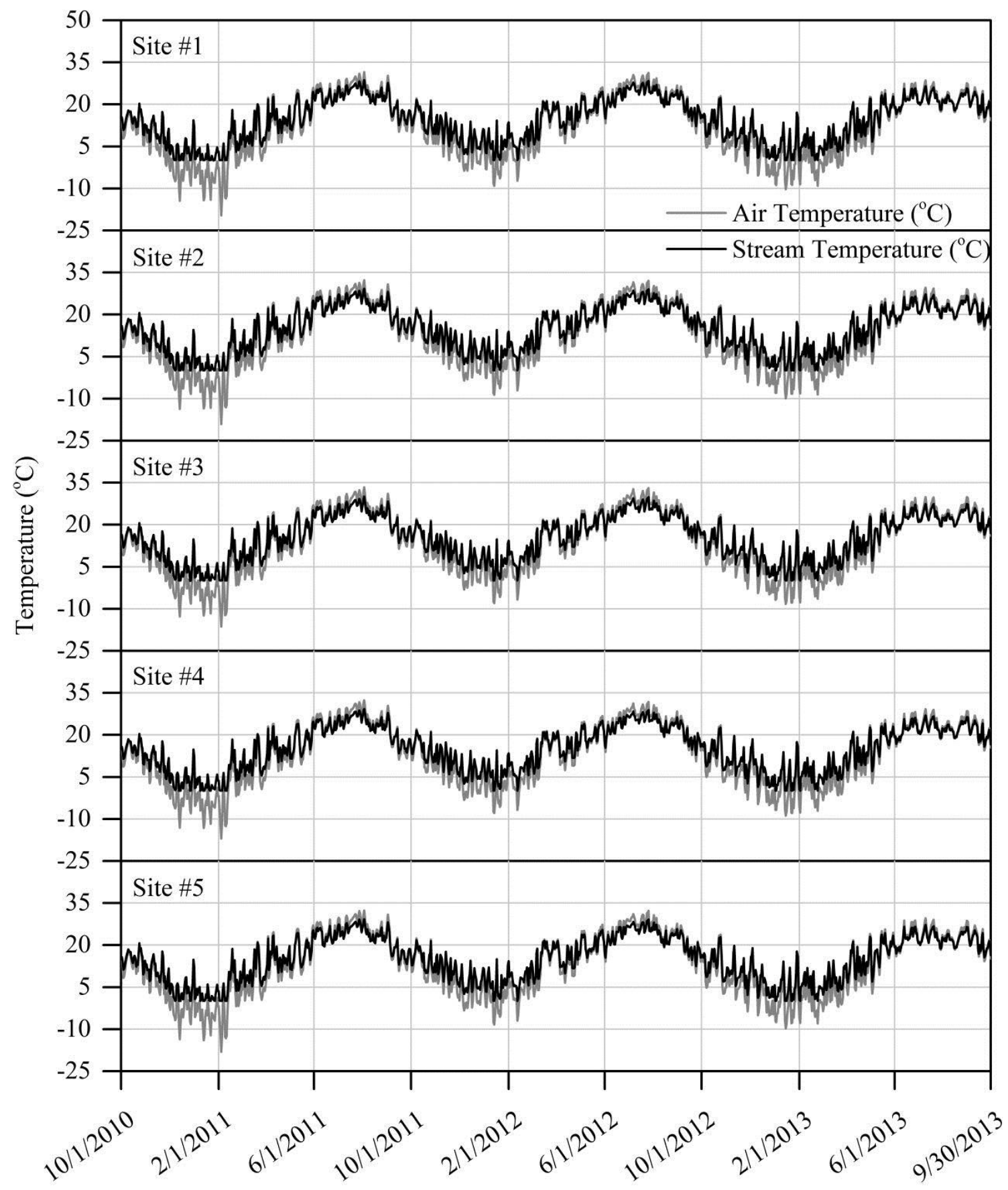

Original SWAT Model (Daily)

C12. Results from the original SWAT stream water tempeature model simulations showing daily time series stream water temperature from five gauging sites in Hinkson Creek for the three year study period. Measured air temperature data are shown as a refrence. 


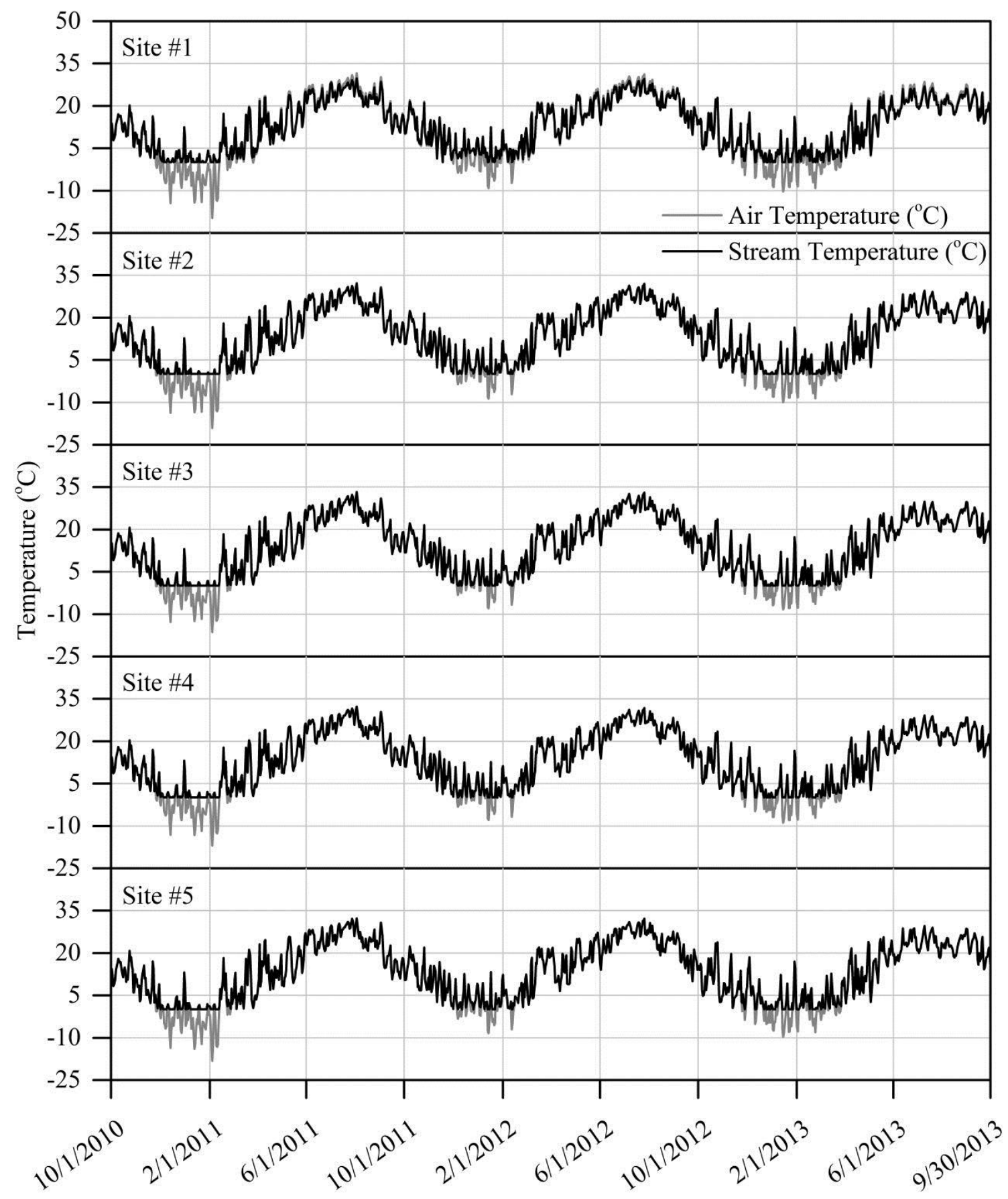

Ficklin et al. (2012) Model (Daily)

C13. Results from Ficklin et al. (2012) stream water temperature model simulations showing daily time series stream water temperature from five gauging sites in Hinkson Creek for the three year study period. Measured air temperature data are shown as a refrence. 